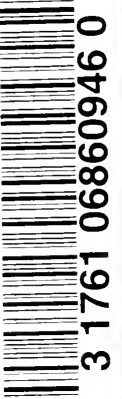




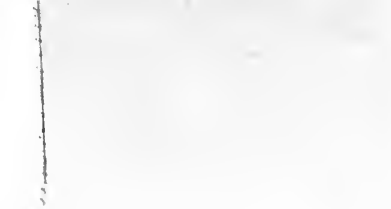



- 




\title{
INDIVIDUALITY AND DESTINY
}

\author{
THE GIFFORD LECTURES FOR 1911-12
}




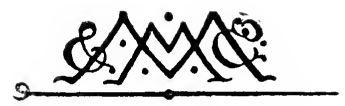

MACMILLAN AND CO., LIMITED

LONDON - BOMBAY - CALCUTTA MELBOURNE

THE MACMILLAN COMPANY

NEW YORK - BOSTON - CHICAGO

DALLAS - SAN FRANCISCO

THE MACMILLAN CO. OF CANADA, Ltd. TORONTO 


\section{THE PRINCIPLE}

OF

\section{N D I V I D U A L I T Y}

\section{AND VALUE}

THE GIFFORD I,ECTURES FOR 1911 DELIVERED IN EDINBURGH UNIVERSITY

B. BOSANQUET

$$
\text { LL.D., D.C.L. }
$$

FELLOW OF THE BRITISH ACADEMY

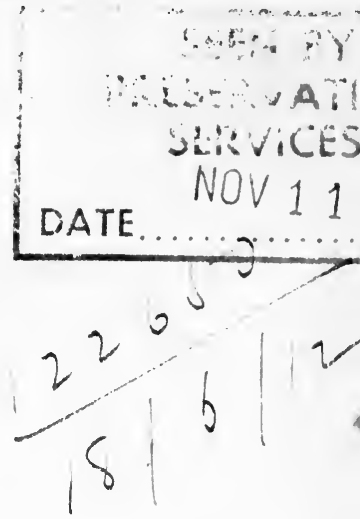

MACMILLAN AND CO., LIMITED ST. MARTIN'S STREET, LONDON 
COPYRIght. 


\section{PREFACE}

These lectures, however defective, at least contain the record of a very strong conviction. I feel assured that a great deal is offered us, especially in modern philosophy, which we do not really care about and cannot seriously expect to prove. On the other hand, I am persuaded that if we critically consider what we really want and need, we shall find that it can be rationally established by a straightforward argument.

In thus maintaining that philosophy gives us the quintessence of life, I am not suggesting that the best thing in life is the pursuit of philosophy". What I mean is that the things which are most important in man's experience are also the things which are most certain to his thought. And further, I should urge, this is not an accident but inevitable, because importance and reality are sides of the same characteristic.

And if, as is quite likely, I have almost entirely failed to maintain this connection in its detail, I am confident that others will be found to take up the work with better success. Indeed, I do not conceal my belief that in the main the work has been done, and that what is now needed is to recall and con- 
centrate the modern mind out of its distraction rather than to invent wholly new theoretical conceptions.

But, it will be asked, is there to be no progress in philosophy? How, one might retort, can there be progress if no definite ground is ever to be recognised as gained? There is no progress in a Penelope's web. Problems of thought are deepening and ramifying, no doubt, from generation to generation; but this is just because an advance has been made. We do not even know, it may be said, what we mean by matter, nor how it is related to mind. But we do know, I think, the limits within which the explanation must fall, and we can exclude certain ways of approaching the problem as certainly unfertile.

I chose Individuality as the clue to my subject, because it seemed to be the principle which must ultimately determine the nature of the real and its constituents, of what is complete and self-contained, and of what approximates or belongs to such a reality. I wished to investigate its positive nature, to show what it intrinsically demands, and what are mere incidents annexed to it by a mistaken tradition. I hoped that it might be possible to disengage the positive nexus of philosophical thought from the details of critical controversy which have been necessary to secure its line of advance, and which have erroneously been held to indicate a mainly destructive attitude. My inmost aspiration, I admit, would be expressed if I could say to the critics of Absolutism, "Mark now, how a plain tale shall put 
you down." But I am well aware that my performance does not justify such language.

I have retained in this book the formal title of lectures. But, of course, it was not possible to deliver the whole of what is here printed in ten addresses each occupying less than an hour. I have, therefore, some hope that the book may appear more coherent than the lectures may perhaps have seemed to those who heard them.

It may be noted that I have not sharply distinguished between God and the Absolute. If I am able to complete a second course I shall hope to go back upon this distinction in dealing specifically with the religious experience.

The fourth lecture is based on a paper which appeared in the Proceedings of the British Academy; the second Appendix to the tenth lecture is part of a paper which was published in the International Journal of Ethics. I have to thank the editors in both cases for permission to make use of this material. For the ideas expressed in the latter as much credit is due to Professor Burnet's edition of Aristotle's Ethics as its author is willing to accept.

I have reprinted, after the Table of Contents, the abstracts of the Lectures prepared by me for the daily press, which, as free and popular versions, may be of service to some readers.

BERNARD BOSANQUET.

EdINBURGH, November I 9 I I. 



\section{CONTENTS}

\section{- LECTURE I \\ INTRODUCTION-THE CENTRAL EXPERIENCES}

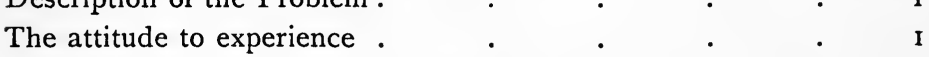

I. The truly obvious $\quad$ r $\quad$. $\quad$. $\quad$. $\quad$. 3

2. The Pilgrim's Progress of Philosophy . $\quad$. 7

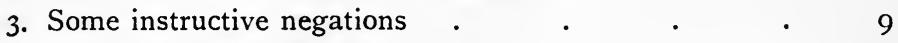

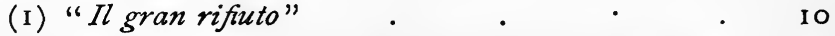

(2) "Fact," "Life," and "Self" dangerous immediates I 3

(3) Immediacy involves individualism, . . $\quad$ I 5

(4) and rules out tension from perfection, . $\quad$ I 7

(5) and thrusts the Absolute out of Life . . $\quad$ I9

4. Some central points . . . . . 20

(I) What counts is mind as such . . . 20

(2) Logic the spirit of value . . . . 23

(3) The "good" of a world . . . $\quad 24$

(4) The greatness of souls . . . . $\quad$. 26

(5) We have the Absolute throughout . . 27

5. Intended course of the lectures a . . 29

\section{LECTURE II}

THE CONCRETE UNIVERSAL

Universal as a general rule

I. Defects of general rule

2. "World" a better type of the universal . . 37

3. and is one with the Individual. Why trust the nisus towards a cosmos? . $\quad . \quad$. $\quad . \quad$. 40

(I) The whole is truth $\quad . \quad$. $\quad . \quad 4$ I

(2) Non-contradiction involves a world or whole . 44 
4. Truth or the whole as non-contradiction or satisfaction. What whole?

5. The concrete universal embodies the nisus of thought to individuality

6. The negligent Dualism must and can be overcome in principle

i. Sensation can become transparent to thought

ii. Thought is the life of feeling

iii. Thought the essence of free activity

7. The goal of the universal $\quad . \quad$. $\quad . \quad .68$

i. Individuality = a world self-complete . $\quad 68$

ii. Individual is positively unique, i.e. has his own quality

iii. Individuality prior to purpose .

iv. The individual is infinite but not a series

70

8. Is the spiritual inward ? $\quad . \quad . \quad . \quad 42$

i. The "inward" not spatial nor mechanical . 72

ii. True inwardness is outwardness absorbed . 74

9. Revolting from Mechanism we should go not to History but to Art and Religion

\section{LECTURE III}

\section{UNIFORMITY AND GENERAL LAW NOT ANTAGONISTIC} TO INDIVIDUALITY

1. Alleged Mentality in Nature at issue with Uniformity $\quad 82$

2. Uniformity as similar repetition dist. relevancy . $\quad 83$

3. Physical measurements compared to social averages . 85

i. "Average" and "Constant" distinguished . 86

ii. In comparing group-averages the analogy breaks down . $\quad . \quad$. $\quad . \quad$. $\quad . \quad 87$

4. Physical statistics would be second-class. Social are firstclass

5. Misconception of Uniformity due to theories of similarity and repetition

6. Individuality implies precisely determinate response

i. False ideas of what Law involves

ii. Every Individual system is a complex of Laws .

iii. True, a shallower world does not give law to a deeper

7. To change a response the system must be inwardly changed 


\section{LECTURE IV}

THE TELEOLOGY OF FINITE CONSCIOUSNESSA SUB-FORM OF INDIVIDUALITY

I. Individuality is the universal as spirit of a world of which

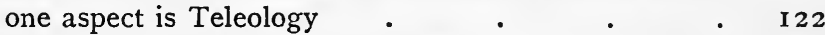

2. End and means run into one another . . . . 123

3. The End as Satiety is not Satisfaction . . . I 28

4. Teleology supported by Miracle on Monadism . . 132

5. Teleology and Objective Selection . . . $\quad$ I 35

6. Convergence of spiritual value and mechanical intelligibility 138

7. Organic mechanism due to the world-wisdom, not to finite consciousness

8. The "plan" is the working of the whole

9. Two points

i. Teleology below consciousness . $\quad . \quad$. $\quad$ I 53

ii. Teleology above consciousness . $\quad . \quad$. $\quad$ I 54

Io. What applies to Finite Consciousness applies to the god

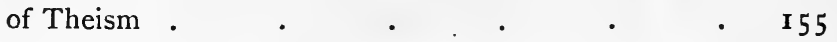

\section{¿ECTURE V}

\section{BODILY BASIS OF MIND AS A WHOLE OF CONTENT -}

I. Alleged subordination of Mechanism . . . I6 I

2. Dangers of "Interaction" . . . . . I66

3. Suggestion is based on idea of qualitative systems quantitatively conditioned $\quad . \quad$. $\quad . \quad$ I 74

(a) Mechanical series in mind . . . $\quad$. 176

(b) Finite Mind based on a complex of determinate adjustments . $\quad . \quad$. $\quad$. 177

4. Vice of admitting discontinuity in the logical nexus . 179

5. Ends are physically embodied in such reactions as that of Drosera . $\quad . \quad$. $\quad . \quad$. $\quad$ I85

6. The sciences of body and mind do reinforce each other

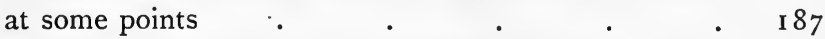

7. The world of finite consciousness is also its pre-condition $\quad 189$

8. The point . $\quad . \quad . \quad . \quad . \quad . \quad 193$

i. Mind is a self-shaping world, the centre of an externality 
ii. Life is very much wider than finite mind, and relatively "natural" . . . . . .

iii. Conscious Process is meaning, not effect, of physical process $\quad . \quad 2 . \quad . \quad 196$

APPENDIX I.-The “Guidance" TheORIES . . 204

APPENDIX II.-Neural AND Conscious Process - 208

i. A Logical system can act through a Causal system adapted to it. $\quad . \quad 2 \quad . \quad 209$

ii. Mind the mainly non-spatial unity of body in action

a. On this view, what acts is not the man?

Yes, it is; his system responds, through

his machine . . . .

$\beta$. Mind is unity of self-direction, but absolute condition of sense of value . . 216

iii. "Soul" does not help. The unity of finite mind is an ideal, not a fact .

\section{LECTURE VI .}

\section{SELF-CONSCIOUSNESS AS THE CLUE TO THE TYPICAL STRUCTURE OF REALITY}

Finite Consciousness not ultimate. Is it a defect in the Universe?

I. The resistant and the responsive not-self .

2. Contradiction. What is a solved contradiction ? $\quad 223$

3. The spirit of otherness is Negativity . • . 228

4. Hostility (Contradiction) confused with Responsiveness

(Negativity). Vraisemblance of the confusion . 234

5. Conclusions opposed to current opinions . . 240

(a) Finiteness and evil not illusions . . . 240

$(\beta)$ The perfect stability must not exclude activity . 243

$(\gamma)$ "Surplus of pleasure over pain" not the true point at issue $\quad . \quad 2 . \quad . \quad 244$

( $\delta$ ) All-important whence we adopt suggestions of satisfaction . $\quad . \quad 2 \quad . \quad 246$

6. The two aspects of the not-self. Is discord essential to self hood?

7. Has finite selfhood a value? The higher mysticism;

Continuity with Absolute 


\section{LECTURE VII}

\section{OURSELVES AND THE ABSOLUTE}

I. "Man itself" beyond "man." That it is so is the bedrock fact of life . $\quad . \quad 2 \quad . \quad 257$

2. The spirit of Logic must carry us to the whole . 262

3. The higher experiences are the clue to true individuality and to the mode of inclusion of the lower . $\quad 269$

i. Three vicious analogies for Individual: Thing, Legal Person, Self in reflective self-consciousness $\quad 283$ ii. Mind is sui generis best described as "a world". 286

\section{LECTURE VIII}

\section{INDIVIDUALITY AS THE LOGICAL CRITERION OF VALUE}

I. Doctrine that you cannot argue on ultimate values $\quad 29$ I Possible subordinate meanings of it . . . . 292

i. Judgment infallible pro tempore . . . 292

ii. Value relative to Feeling : but criticised Feeling . 294

2. An identical criterion in all forms of satisfaction . $\quad 297$

3. Explanation of contingency of de facto Valuations. Impotence, pre-occupation, means, and ends . . 299

4. "All values relative to Persons" compared with "nothing has value but conscious states of conscious beings." The two propositions may be sharply opposed

i. States of consciousness, if abstracted from the objective world, are meaningless and valueless.

ii. You cannot value states of consciousness apart from individuals or the Individual . .

iii. You cannot value finite individuals apart from universe . . . . . .

iv. True in a sense that universe is not "good" or "bad"; but the whole is always the unit of value v. Instance the State. Is its value unitary? The Greek theory, making it one mind in a number of bodies

5. Conclusion. Things can only be valued in their full nature, and a state of consciousness has not this within it 


\section{LECTURE IX}

FREEDOM AND INITIATIVE

I. Our view inclusive-Individuality means being a world in oneself and implies a special kind of self-determination

PAGE 318

2. Objection that we make circumstance the only differentiating influence. We hold the self to be the inwardness of circumstance

3. Objection from pre-determination. Answered by exhibition of creative nature of Logic, carrying its past in its present, as in Art . $\quad . \quad$.

4. Difficulties in the emptiness and timelessness of self-consciousness

$a$. Its emptiness is its omnipotentiality

$\beta$. Its timelessness is its "durée"

5. Logic is perfect determination. Fatalism is determinist, i.e. imperfect determination : . $\cdot$.

6. Apparent exceptions to "Determinateness $=$ perfection of a self".

(i.) The animal self comparable to data without a theory-an abstraction . . .

(ii.) The naive good self compared to grasp of a fundamental principle alone . . .

(iii.) The evil self compared to a theory persistent against completer knowledge .

7. The ideal of Contingency rests on a confusion between the original and the arbitrary . . . .

\section{LECTURE $X$}

NATURE, THE SELF, AND THE ABSOLUTE

I. "Nature" the environment of selves, considered as selfexistent. The line between it and mind not fixed. E.g. Has it Beauty?

2. Nature inseparable from mind

i. Starting from kinship we arrive at Monadism or

Pan-psychism. Starting from "otherness" we arrive at "source of content" 
3. Finite minds the living copula of Nature and the Absolute -an everyday experience. . . . .

4. The real point is in the transmuting or expanding power of common finite mind $\quad$. $\quad$. $\quad$. $\quad .376$

5. The Absolute the high-water mark of a familiar fluctuation. An audacious illustration $\quad . \quad 6 \quad . \quad . \quad 378$

APPENDIX I.-Doctrines of the AbSolute • 387

I. An all-inclusive span of consciousness either transforms the events or is no gain. $\quad$. 387

2. Perfection must contain imperfection, though in finite experience we seldom find that it does

3. Absolute cannot be will or purpose because these must always be parts within wholes . . $39 \mathrm{I}$

4. Numerical Infinity a hybrid doctrine • • 393

APPENDIX II.-The Perfecting of the Soul in

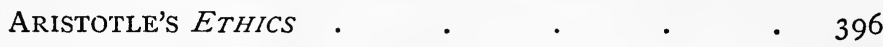

I. The minimum act of duty $\quad$. $\quad$. $\quad$. 396

2. The expansion which it involves. The "mean" the precise adjustment essential to excellence or vitality

3. The standard involved in moral duty. Practical wisdom

4. Theoretical wisdom or religion ultimately standard, viz. as the ultimate value or quintessence of life

5. "Friendship," i.e. communion in the highest experience, the link between group-welfare and religion 



\title{
ABSTRACTS OF LECTURES
}

\author{
LECTURE I \\ THE CENTRAL EXPERIENCES
}

LORD GIFFORD especially desired that the knowledge conveyed by these lectures should be "true "- not merely nominal, and "felt"- not a mere theory. They were to communicate, or try to communicate, a grave experience. This demand introduces us to the double task of philosophy. It needs the best of logic, but also the best of life, and neither can be had in philosophy without the other. The present lecture will be devoted to explaining by anticipation and without technical proof on what sort of experiences the lectures will lay stress as a clue to the best of life. It will be clearest to begin by a general statement, and some negations.

To begin with, what philosophy needs as its material is the sort of thing that is in a sense obvious, and yet is hard to make plain and distinct. The very greatest things are of this kind-simple examples are, what the painter perceives when he represents a wood, and not merely a number of trees, or the sociologist, when he understands a crowd and not merely a number of persons-both late in being learnt, though the things are so obvious. The central facts should be in the centre. This needs a continual arduous effort, as opposed to resting upon fixed points here and there. Only the great men attain a survey of this kind, and thus, comparatively speaking, are right, a far more arduous thing than to be clever.

Following such a clue, we should begin by rejecting $\mathrm{xvii}$ 
the presumption that we are secure in resting where we are. A Pilgrim's Progress is inevitable, both in life and in thought. Stability, if found at all, must be in the end and not in the beginning; this again is obvious, but neglected. Other over-hasty ideas might be found in the false denial that great philosophy offers the quintessence of life; in uncriticised reliance on "the solid fact," the "sense of living," the "unsharable self." All these mark just such timid or indolent withdrawals from the great world of reality.

So with other naîve ideas-compensating justice, ethics which treat the individual as isolated, teleology as guidance by finite minds, and their satisfaction; a heaven modelled on the naĩve experience of pleasure, a philosophical "hope without guidance," which seems to thrust the absolute reality outside the world we deal with-all these have certain claims to truth; but there are more "central" experiences than these.

Such, if we turn to the gist of our positive argument, would be the conviction that what really matters is not the preservation of separate minds as such, but the quality and achievement which as trustees for the universe they elicit from the resources assigned them; in other words, it is logic, the spirit of totality or effort to self-completion, which, being the principle of individuality, is the key to reality, value, and freedom. Thus the "good" of the universe would be emphatically such as must belong to a world, not to a mere member of one. It must be such as makes possible the finite being and his task, but cannot be the same as what he develops in his task. The universe could not truly be thought of as a place of pleasure, nor even of probation and justice ; it would be nearer the truth to think of it as a place of "soul-making." And it would be recognised that, so far from our feeling absolute reality to be foreign and remote, it is what we feel most fully and intimately, for we feel it in everything.

The present course will deal with the principle of individuality - of self-completeness - as the clue to reality 
and value, and consider its relation to general law, teleology, freedom, and the connection of nature and the self in absolute reality. The result will be nothing new or startling, but will perhaps express and define the reasonable faith of open-minded men. It will suggest that a sane and central theory is not full of oddities and caprices, but is a rendering, in coherent thought, of what lies at the heart of actual life and love.

\section{LECTURE II}

\section{THE “CONCRETE UNIVERSAL"}

AN experience which throws light on something beyond itself is called " universal." Our first impulse is to think of this in the form of a general rule-something which is true of a number of similar things beyond that in which we first noticed it. So we say, e.g., "Same causes, same effects," and we take a rule of this kind to express the nature of thought. But from the first, though useful in its way, this is untrue. The truth which it disguises is that thought has always the nature of a system of connected members, and is an effort to take that form, which we may call a "world." This is the only sort of thing which can satisfy the logical law that contradiction is a mark of unreality, or-the same law-that the truth or the real is "the whole."

What is really universal, then-i.e., what' expresses the work of thought in throwing light on experience-is always of the nature of "a world." In the structure of a world every detail gains incalculably in intensity and in meaning. "A second of time may be apprehended as a part of a minute, or of a musical phrase, or of an act of forbearance"; and its meaning varies accordingly. The moral of this is that logical completeness or universality is not a deadening but a vitalising quality, and thought is not a principle of reproducing reality with omissions, but of organising worlds and investing their detail with fresh 
significance. We should compare it with a painter's touch or poet's phrase, which embodies vast stores of meaning in its vital precision. The essence of thought is this nisus towards a whole-to adjustment, to seeing things as harmonious. It is, therefore, the principle of freedom-of removing barriers, transforming the alien into the kindred. And it is in all finite experience.

There is, of course, a dualism, or rather a multiplicity, in our experience at first sight; but it is naïve and hasty for philosophy to accept that appearance without an attempt to overcome it. In sensation, for example, we can see the principle of thought. Of course, sensation speaks to us and has its laws-e.g., of colour and sound. They are not the less logical that we cannot translate them into words. A colour-harmony is a necessity of thought as much as a syllogism. "Colour is a spirit upon things by which they become expressive to the spirit." Suppose all sensation were to us like the touch or voice of a friend. Then it would have meaning enough. So with emotion. The structure, as of a "world," does not check it, but expresses, and in expressing creates it; in a great work of music, for example. So with action. To be "active" as an originative being is active is to be a world which reshapes itself by its own principle, to be a "free cause."

Thus we arrive at the idea of the logical universal as a living world, complete and acting out of itself. This, so far as complete, is the "individual," and ultimately must be one only, and perfect. It is not, therefore, an atom, which is its extreme opposite. It is rather indivisible as a life is indivisible, not as something too small or too unreal to be divided, like a mere point. Individuality, then; is positive. It means that what is individual, so far as it is so, is itself; not merely that it is not somebody else. In finite life individuals repeat each other a good deal; this does not make them less individual if what they have is really made their own; compare the borrowings of a great poet. Individuality rather defines purpose than is defined by it. Purpose is 
determined by the world in which it arises; it is the need to remove some contradiction.

Is an individual infinite? It is self-complete, and so without limit in so far as perfect, but only seems an endless series in so far as imperfectly understood. Thus to know God as a series in time would be an endless task, because misconceived from the beginning. The individual is the true spiritual ; but not "inward" as conventionally opposed to "outward." It is a mistake to confuse determination or definiteness with externality and mechanism, and the emptiness of most revelations of the higher experiences is due to this. True spirituality is not the annihilation of the "outward," but its transfiguration in the total life. We want to realise what is individual as a positive self-moulding cosmos, a definite striving of the universe.

\section{LECTURE III}

INDIVIDUALITY AND UNIFORMITY OR “GENERAL LAW"

THE object of this lecture is to remove the idea of inconsistency between individuality and the "Uniformity of Nature," or the reign of "General Law." There is a suggestion that the observations of physical science may conceal a high variability in the minute elements of matter, just as social averages disguise the differences of human beings. But it must be noted that high variability, unless in principle inexplicable, is in no way opposed to the conception of uniformity (relevancy), and that social statistics are marked by an extraordinary sensitiveness and progressiveness to which nothing in the material world shows any parallel. To discount the contrast between matter and mind is a mistake.

So with the reign of law. In attempting to defend spontaneity against general law, there is grave danger of abandoning the relevancy of response to occasion. The error lies in a conception of "general law," which treats 
it as a predicate of a class of similar objects. But a plurality of similar things is not the proper example of the application of law, but is a sub-form, and is never strictly found. As explained in previous lectures, a true universal connection is that which holds between the differing parts of an individual system, such that the parts, and their variations, though not similar, determine each other, as in any machine, or more completely in an organism or mind. The law of falling bodies would be very poorly described as a common predicate of falling bodies. It is essentially a quantitative connection between distinct factors. And, in principle, each case of the connection is unique, being a distinct and separate variation of the principle. They might or might not be apparently (never exactly) repeated. That has nothing to do with the universality of the law, which lies in the nexus between the different constituents which enter into each case under it.

Thus, the more perfect the individual the more complete would be its universality, and the smaller the element of repetition. When a need or function has once been provided for, to provide for it again means that the first attempt was unsuccessful. But every feature of the whole is in a nexus of variation with every other. We might think of a man's actions. The " universal" is the man's nature. The interest of his actions depends on their expressing this connectedly, but differently in different situations. Every individual is a universal law expressed in a set of connected functions, precise in quantity and adjustment. A moral failure, for instance, betrays itself in some maladjustment of the thousand details of action. (See Appendix II. to Lecture X.)

What is meant when individuality is contrasted with general law is that the laws, e.g., of space and time, do not explain the conduct of a person. This is not because they are too universal, but because they are not universal enough. They have too little in them. So Laplace's "calculator" could not predict everything, unless he knew much more than the position of all physical elements. 
He would not be a true type of intelligence. What is repugnant to man is not prediction of his conduct, but reduction of himself to a different kind of existence. We could only predict action in as far as we are the same with the agent. But this is not a prohibitive condition. The spiritual world depends wholly on our being continuous with one another- " entering into " one another, and, in fact, the main outline of men's life and work constantly is anticipated by others. "General law," it is said, "would require a man to do the same in the same situation; but his will might be changed, so that he behaved differently." But a will could not be changed without changing the world which is the man; it is re-shaped, and the whole situation is different. The intention of the views here combated is to show intelligence as inadequate to spiritual reality. But, in fact, the spiritual world depends on the unity of intelligence, and "man is a shop of rules," and even prediction, which is a form of mutual understanding, is not wholly to be rejected.

\section{LECTURE IV}

\section{THE TELEOLOGY OF FINITE CONSCIOUSNESS}

THE question for this lecture is what help we get from the notion of a mind which purposes or desires things, in appreciating the worth of factors in the universe. The idea called "Teleology" is that you find something valuable when you find what has been the purpose or intention of some mind, human or divine; just as in daily life there are some things we want ("ends") and other things ("means") we only choose to help us in getting the former, and only the "ends" are valuable for their own sake. But to be desired by a human mind is almost no proof of value, for their desires are constantly wrong; while it is impossible seriously to treat a mind which is the universe as a workman of limited resources, aiming at some things 
and obliged to accept others as means to these. Thus the distinction of what is purposed for its own sake and what is not so could not be applied to the universe ; and teleology, if the word was kept, could only be a name for some principle which would help to tell us what has value, quite independent of being or not being the purpose of some mind. It would mean not purposiveness but worthiness to be purposive. And this would be much more important, because the actual purpose of human or animal minds seems constantly to be wrong, i.e., to defeat itself. If such a point of view were pressed home, the distinction between mental purpose and natural mechanism, on which commonplace teleology rests, would be superseded so far as this, that we should look for the value of the universe in its entire and continuous working; and while its order or unity would be recognised as expressing itself in part through human consciousness, we should not treat this as super-adding a new principle of plan and direction upon the ordinary laws of Nature considered as directionless. We should consider the whole, nature and mind, as the revelation of the value of the universe. The bearing and result of these considerations would be to lay greater stress on a factor which might be called in a very wide sense "natural selection"; that is to say, on the moulding of the organic world, and even the world of mind, in relation to the environment which we know as physical Nature, by and through which the possibilities of life and mind are elicited and determined; while they, in turn, elicit and determine those of Nature. There would be no priority in "mind," as if it possessed a "plan" apart from Nature.

It would become apparent that there is a teleology (if the word is to be retained) deeply rooted in the universe, wholly above and beyond any plan or contrivance of a consciousness guiding or directing the universe, but expressing itself, for example, in conjunctions and results of the co-operation of human minds, quite beyond the knowledge and intentions of any of them; and, again, in the character and formations of inorganic nature altogether 
below the region of intelligent action, but plainly the foundation of the development to which that action belongs, e.g., as geological to biological evolution. It should be noted that of the lower forms of consciousness at least it is impossible to suggest that they guide organic evolution. It is plain that the guidance comes from the environment, and even if subjective selection assists adaptation, it stands or falls finally by the verdict of natural selection. The conclusion would be that the value of the universe, or its capacity to constitute an experience without defect, lies much deeper than in what is commonly called teleology; which is understood to imply direction by a supreme mind outside or above the universe, and by finite minds within it. The suggestion would be that the universe is, as a whole, self-directing and self-experiencing; that minds (such as ours) are members of it, which play their part, taught and moulded through Nature, in the work of direction, and a very essential part in the work of appreciation. But the supreme principle of value and reality would be wholeness, completeness, individuality, and not teleology.

\section{LECTURE V}

\section{BODILY BASIS OF MIND AS A WHOLE OF CONTENT}

THE relation of mind to body is a leading instance of the true nature of individuality. The view of this relation which we should favour would be more akin to "parallelism" than to "interaction," because we should wish to think of mind rather as a perfection and co-operation of the adaptations and acquisitions stored in the body than as a separate thing, independent of these, and acting upon the body from the outside without being regulated by them.

To abandon the idea that the mind expresses itself in action through energy, whose quantity and distribution depend on the nourishment and organisation of the nervous system (and "interaction" in principle abandons this idea), 
withdraws all limit from the supply, and rationality from the distribution, of the energy which that theory must suppose to be gratuitously furnished by the mind without participation of the body. Views of this type only escape manifest conflict with common sense by restricting the amount of energy so furnished to an amount below the possibility of measurement, operating analogously to the release of a trigger or to the spark which explodes the gas in a gas-engine. But this restriction to an inappreciable quantity seems to be really an appeal to ignorance. In principle it sacrifices the constancy of energy, but attempts to do so in a degree which can never be experimentally detected. It may be that the constancy of energy ought to be set aside; but, if so, there seems no reason for not setting it aside much more boldly, in a degree which would at once conflict with common sense. It is not its own certainty that makes its maintenance in this application desirable, but the necessity for some order and limit in the operation of the whole "body and mind"; which has to be furnished by bare imagination if this simple equivalence, which we accept unhesitatingly on the large scale (in the dependence of life on food, etc.), is to be thrown aside.

Answers to the objection that a physical system (the brain) cannot possibly represent a "meaning" or an "end" are to be found in any complex reaction in which the nature of a physical whole responds to a simple stimulus, as in the reaction of a carnivorous plant or of a penny-in-the-slot machine, and in the action of the brain as a whole in support of a particular system realising itself.

Thus there is nothing in mind which the physical counterpart cannot represent, and the whole life of mind being continuous, and new purposes interwoven at every point with old purposes and experiences, it cannot be said that portions of mind are such as to be represented in the physical counterpart and portions are not. This would make mind discontinuous with itself.

Thus, admitting that we cannot think of "explaining" 
"consciousness," we should obtain a more genuine notion of the finite soul. It would seem to be a perfection, following upon certain physical conditions, and constituting a conscious'world, capable of diverse degrees of unity and perfection, and essentially an organ of the universe for focussing and appreciating that special range of the external world with which it is connected.

This point of view would suggest the importance of the support of abstract ideas (say, ethical ideas) by active habits, in opposition to the view for which the merit of ideas has nothing to do with their effectiveness. The conditions of completeness of an idea are highly analogous to the conditions of prevalence of a nervous impulse. An idea which has no range of application to reality is imperfect by that fact. Body, then, would be a highly organised and adapted causal system; a mind, a logical one. The difference between them could not be explained away ; but we understand them best if we take mind as the significance and interpretation (not the effect) of body; and body as the stored "acquisitions" and "adaptations which are the foundation and machinery of the single but complex world which is a mind.

\section{LECTURE VI}

SELF-CONSCIOUSNESS AS THE CLUE TO THE STRUCTURE OF REALITY

IT has been made clear by the argument up to this point that minds like ours, planning and guiding matter to ends, even though immensely greater than ours, could not be the main directors of the universe. They rest on arrangements below them; they indicate in every feature fuller forms of completeness above them. Still their main character, the consciousness of self, might indicate to us something of the structure of reality. What would it suggest? The approximation of self-consciousness to an absolute experience must be determined by two well-known 
phases of experience-contradiction, and the negativity or 'sense of tension' which survives in the solution of a contradiction, which latter may be described in general as satisfaction. Logical contradiction consists in different natures claiming the same place in the same system, so that they conflict, and cause logical or even general dissatisfaction and unrest, which constitute an impulse to the "solution" of the conflict. This would consist in such a readjustment of terms, by a new distinction or the introduction of a fresh point of view, that the conflicting terms can find place together within the system in question, both of them, and the system, being somewhat modified. Any advance in theory or reconciliation in practical life, is an example. Such a contradiction is not a mere mistake of ours which ought not to exist. It is a character of the finite world, and, because it is intolerable to the mind, is the mainspring of movement and effort in that world.

Now it is natural to think that when a "contradiction" is "solved" nothing like it survives in the solution. But this cannot really be so. If it were we should not feel it to be a solution or satisfaction. There is always the sense that something has been overcome, and that the one term is expanded by coalescence with the other. The satisfaction of desire is an example. This we may call the Negativity which survives in satisfaction.

Now-to return to the self-it is obvious that the consciousness of self (cp. "self-consciousness" in the bad sense) often depends on a sense of hostility to the not-self, in which it appears to conflict with or contradict the self. Sometimes this is treated in theory as the only basis of the assurance of self. In that case it would be analogous to contradiction, and the sense of self would disappear as experience was harmonised, just as contradiction disappears in a "solution." But this would neglect another obvious fact, that the self is at its best and fullest, and the sense of it, in a way, strongest, when the not-self is most expanded and also most harmonious with it (cp. e.g. a savage with Newton or Darwin). And the suggestion of 
this fact is confirmed by the above logical account of negativity in satisfaction. The sense of distinctness is not lost in a "solution"; on the contrary, the sense of having found yourself in another is an essential of satisfaction. Thus the suggestion is that though contradiction disap-1 pears in perfection, negativity does not; and though hostility to the not-self may help in awakening selfconsciousness, yet a harmony in distinction with the not-self is a deeper element in self-assurance, and one that increases with the perfection of the self. This points to the conclusion that a perfect experience maintains the positive sense of the self as something which continually passes out of and regains itself (dies to live). It is indicated by this conclusion that pain and evil are not illusions, but essential to the structure of reality, being of the same general type as satisfaction and good, but rendered contradictory by their imperfection. The general form of reality, self-sacrifice and satisfaction, being ultimately of the same type throughout, would be in a perfect life completed in a way in which both would be experienced.

\section{LECTURE VII}

\section{OURSELVES AND THE ABSOLUTE}

THIS lecture is meant to summarise the reasons for . believing in the Absolute, and to explain what indications we possess of the way in which we could be included in something greater than ourselves; and how, in consequence, we ought to think of our own being and of our connection with others. Beginning with a current criticism, first made by Aristotle, "If we know what man is, what is the sense of talking of 'real man' as if it were something more?" the answer is, "We do not know man as he is; his nature is only in process of being communicated to him." This is to be seen in everyday life. When some great experience-art, love, war-carries a man "out of himself," you say, "I shouldn't have known 
him," and he feels the same. So in the perfect experience, only more so. Of course, what we see of him is "in the Absolute," because everything is ; only there is much more of him than we see.

The argument that expresses these facts is technically known as the argument a contingentia mundi-i.e., the fundamental process of logic, which works by the creative method of meeting and removing contradictions through the development of the world of thought. This is the law of non-contradiction in its positive operation, finding the solution of difficulties in "the whole." It gives rise to the sort of unity by which, e.g., we now think of the Antipodes in one and the same idea with the earth's surface as we see it, or of the mere parental instinct in one idea with the civilised family. An argument of this kind carries us to the Absolute without a break, merely insisting on what our given nature implies. What it does for us is not to assure us of a new and disconnected experience, such as "Heaven," but to show us what is more trustworthy and stable, and what is more incoherent and defective, in the range of our life. It gives us " hope," but also "guidance." "Higher, truer, more beautiful, better, and more real, these, on the whole, count in the Universe as they count for us."

$\checkmark$ To do such an argument justice, we should take into account man at his best. The minimum meaning of a word or thing is often treated as the one genuine meaning, because it is current. But this is a groundless prejudice. It is careless to say that a man "really is" separate and self-centred because he feels so at his worst. Why not found our theories on men as they are when they fight on the same side, or give their life for a friend? To think in this way would help us with perhaps the greatest difficulty in conceiving the Absolute-viz., how one mind or mood can be included in another. Take Dante's religion. It includes religious absorption, moral struggle, the æsthetic sense, and intellectual satisfaction. We weaker minds can only get hold of these moods in succession, though each really implies all the others. What we grasp 
of them at any moment is like a bit of a mountain seen through a mist. It looks quite different from what it would if we saw more. But it is part of that "more," only dissociated from it by our weakness, which is necessary, perhaps, for its perfect realisation.

The conclusion would be that we should not think of ourselves merely after the pattern of separate things, or personalities in the legal sense, or even as selves in the sense of isolation and exclusion of others. We are minds, i.e., living microcosms, not with hard and fast limits, but determined by our range and powers, which fluctuate very greatly. There would be no gain in wiping out the distinction between one self and another in finite life; our limitations themselves no doubt have a value. Still, in principle, our limitations are merely de facto: there is no hard barrier set that can make our being discontinuous with others or with the perfect experience.

\section{LECTURE VIII}

\section{INDIVIDUALITY AS THE ULTIMATE CRITERION OF VALUE}

THE subject to be considered is "Individuality" as the ultimate criterion of value. The meaning of this might be approached through two well-known sayings, "It is no good arguing about tastes," and "Excellence in art depends on fundamental brainwork." The former we should deny, the latter we should maintain. "Individuality" we saw to mean logical self-completeness, freedom from incoherence. And we saw that this comes only by a strong and consistent positive nature. So the idea we are to maintain is that things, acts, feelings, have "value" in as far as they are completely organised, do not break down, have parts or members which confirm and sustain one another. Art is only one case ; the principle extends to everything within experience. In short, the power of giving satisfaction, "satisfactoriness," is a thing that can 
profitably be argued about. We are not satisfied, i.e. we do not value things, without some positive reason in their nature. The denial that values can be profitably argued upon may mean either of two things which are true as far as they go. It may mean that our judgments hold good till they are reversed by subsequent judgments; and in practice this is a hard thing to get done. This is true, but equally true of all judgment, and, of course, we do modify our judgments through argument. Or it may mean that "value" is a matter of feeling, which is a simple fact, and judgment may state it, but cannot produce it. This is true so far that, apart from feeling, there can be no value. But, having feeling, we can both test it and modify it by critical reasoning. Good literary criticism shows how this can be done. In truth, the education of feeling is the most important of all education-teaching people to like and dislike rightly - as the Greeks knew ; and this means that there is a standard.

The question of "value" then is the question of complete and durable satisfaction, and it depends on what Plato would call "amount of reality and of trueness." Plato's doctrine is reproduced with higher intensity, but without its logical basis, in the passage, "He that drinketh of this water shall thirst again," etc.

It is easy to explain why our de facto valuations are so conflicting. It is just like our conduct and our opinions. Our minds are very limited, and are preoccupied by this or that interest, which prevents us really attending to others.

Two views, which sound much alike, of the relation of value to conscious minds, must be sharply distinguished - "all values concern persons," and "all values attach to conscious states." Certainly there must be consciousness and feeling in order to appreciate values. But the second statement may be taken to mean that the value resides in the separate successive conscious states (as e.g. in moments of pleasure), each by itself, without reference to their place in the personality, or in any higher unity such as the social whole to which they may belong. So 
interpreted, the second statement not only does not repeat the first, but flatly contradicts it.

But the first seems true. Things can only be valued right when valued in their whole nature, and that they only have in the complete being to which they belong. So the Greek theory of the State expressly says you cannot value the individuals separately, and then find the value of the social whole by adding up those of the individuals, because each individual only has his full and real nature and value in the whole life of the community. Thus not only the servant has his value largely in his master's work, which he makes possible; but the rulers have their value in the qualities which they share with and learn from the subject classes. This is true of every community, and a fortiori, of the conscious moments within the life of an individual compared with the person himself. The conclusion is that the judgment of value can be logically supported, because the objects of our likings and dislikings possess as much of satisfactoriness, which is the same thing with) value, as they possess of "reality and trueness." This is value for us, because our whole being is implicated in the world about us, while our vitality-our feeling-is raised and lowered by the nutrition, so to speak, which at any point that world affords to our mind and body.

\section{LECTURE IX}

\section{FREEDOM AND INITIATIVE}

OUR view leads us to regard freedom and initiativethe subject of the lecture-as the inherent effort of mind, considered as a "world," in the direction of unity and self-completeness, i.e. individuality. If it is objected that according to such a doctrine the difference between one mind and another springs, not from the nature of its self-consciousness, but from the range of circumstances which fill up its world, the answer is, in the main, that 
that is what our minds are for-to elicit, to represent in themselves, the "true inwardness" of that special field of experience in which they are embodied; and they find their freedom and individual initiative in the working, the "logic" of this special contribution to the eternal deed. Of course it would be untrue to suppose that circumstances are, in such a mind or active focus, what they seem as seen from the outside, or as in any other mind or focus.

This may be tested by the further objection that our doctrine involves determination of the mind by previous events, which are fixed and past, and cannot be remodelled, so that the action of the "individual" has been compared to the "rattling off of a chain " previously forged - "Tout est donné" is Bergson's reiterated criticism.

The usual and sufficient answer to this criticism lies in the distinction between a motive, which is the mind reading itself as a whole into a situation as a whole (so that, of course, any factor in the situation may take on quite a new aspect), and a cause, in which there is no such total presence of a self, but only a succession such as an outside observer may note.

Instead of restating this familiar point, we might raise the same question more sharply by asking what sort of novelty or origination there is which would satisfy us, if the inherent logic of the self will not? What, e.g. do we really expect and demand of what we call "creative" art in its best and most original products? There is much misconception in the popular mind on this point, and it is aggravated by recent theories which break up the inventive process of transformation into sheer imitation plus inexplicable invention in a quite fallacious manner. Art is "creative" by the concreteness of its content and the depth of its penetration, and it cannot be predicted, for the same reason that whole lives cannot-that you cannot do a thing beforehand except by being its author beforehand; and this is more possible in abstractions (e.g. calculation) than in very concrete life. But all the same, its creativeness lies in its fulness and penetration, not in arbitrariness and 
discontinuity with reality, and in ultimate principle its initiative and originality is of the same nature with selftransformation of the self in moral action. Any freedom or initiative which were not of this nature would be wholly devoid of the continuity which is necessary to a human interest. "Life," which we are offered as the type of active duration or freedom, is, compared with the freedom we speak of, like a bird's song to the Iliad. A freedom freer than the latter type has never produced anything worth having, and never could. The "timelessness" of this self, i.e. its presence to itself, is the same thing in principle with the durée of which so much is said to-day. This determinateness, which must be fullest in the most perfect being, is opposite in principle to determinism, which is the partial determinateness of unawakened beings whose responses are relative to exceedingly limited totalities, and form what we call physical causation. It is interesting to consider why imperfect determinateness in a conscious being is not always a sign of grave moral evil, as it certainly is of some kind of imperfection. The answer is that it only means moral evil: where there is a deep-seated contradiction within a determinate self. Otherwise, as in naîve morality, though it indicates a defect, that defect is not an explicit contradiction. Our view has attempted, by distinguishing determinateness and determinism, to rescue our moral freedom from the two vicious ideals of contingency and predetermination, and to exhibit it in connection with the type of activity for which, by common consent, the terms "original" and "creative" are most appropriately reserved.

\section{LECTURE X}

NATURE, THE SELF, AND THE ABSOLUTE

THE object of this lecture-" Nature, the Self, and the Absolute"-is to summarise the suggestions which had been made in the lectures as to the connection between 
the main factors of experience as we know it, "Nature" and "the Self," when we try to think of them as belonging to a complete and single system, which may be called the Absolute. It is very difficult to draw the line between Nature and the Self. Nature as regarded by mathematical physics is not a reality, but merely a way of representing certain characters of the world which are convenient for calculation. Nature, as we really experience it, with primary, secondary, and tertiary (æsthetic) qualities, can only be distinguished from ourselves as fragmentary experiences from conscious centres of experience. It is actually real; but that cannot mean that it is real by itself, i.e., apart from minds which experience it. Its being physical cannot exclude its being continuous with what is psychical. Now Nature, so understood, is closely bound up with Mind or Self; but the question is, How?

It is sometimes taken as made up of elements having minds, though showing to us as bodies. This is the doctrine of Pan-psychism, treating Nature as like Mind. The difficulty is that what we want of it is its body rather than its mind. Its mind (e.g., that of a lake or mountain) does nothing, and is not what we want from it. Our minds represent its nature better than its own mind could.

Therefore, it seems better to accept it frankly as complementary to mind, i.e., as an external system, continuous with our minds, through which the content and purposes of the universe are communicated. Note, this is not saying that our minds lay down purposes which Nature is bound to carry out; but that they are able to learn from Nature what the universe suggests and demands. Nature is not the slave of man. Nature, then, lives and is complete in the life of our minds, each of which draws its content from some particular range of Nature, so that all the detail of the universe is elicited into mental foci, and "external" conditions are held together in such foci, and pass, through them, into the complete experience which we call the whole or the Absolute. 
From such a point of view the Absolute is the highwater mark of an effort in which our minds actually consist and have their being, fluctuating in the successfulness of the effort within everyday experience. Each self is more like a rising and falling tide, which covers a wider area as it is deeper at the deepest point, than like an isolated pillar with a fixed circumference, which is the idea suggested by popular Pluralism. Thus the important point of view is what we might call Multiplicism, to mark the distinction from Pluralism-viz., the variety of levels, not the number of centres, in experience ; and the problem of Monism would be how far we could conceive a highest level including and representing all the others. Dualism has no prerogative of importance; Plato deals in triplicism, quadruplicism, and multiplicism quite as much as in dualism. The transmutation of experience, according to the level of a mind's energy and self-completeness, is a fact of daily life, and is sufficient in principle to establish the reality of the Absolute.

We should note that, as is natural in finite beings, the qualities of the same mind do not keep step. Plato, for instance, leaves plenty of room for "the Treasure of the Humble."

Just to bring our suggestions together by a very imperfect simile, we might compare the Absolute to, say, Dante's mind as uttered in the Divine Comedy. The point would be that in it external nature, say, Italy, becomes an emotion and a value, not less but more than spatial; each self, say Paolo or Francesca, while still its real self, is also a factor in the poet's mind, which is uttered in all these selves taken together; and the whole poetic experience is single, and yet includes a world of space and persons, which to any common mind fall apart and become "a geographical expression" plus certain commonplace historical figures. This inclusion we compare to the Absolute, as it holds together what for us is finite experience. Next year I hope to apply these ideas to human (i.e. finite) value and destiny. 



\section{LECTURE I}

INTRODUCTION-THE CENTRAL EXPERIENCES

THE problem which I am to invite you to study Descriptogether with me is described in Lord Gifford's Problem. Deed of Foundation by help of very various formulae. But what essentially he saw to be important may be reduced, I think, to three requirements, which indeed express an undying need of the human mind. We are to study, if we respect his wishes (I) the nature of the sole Reality, that within which we live and move and have our being ; (2) the duty and destiny of finite creatures as illuminated by their relations with such a reality; and ( 3 ) our knowledge-and this requirement he puts in the forefront-is to be a knowledge not merely nominal, but true (he means, I think, carrying deep conviction) and felt-or as we might say, it is to involve the communication of a grave experience, and not the mere framework of a theory.

"Not the mere framework of a theory." We The attihave implied in this requirement the double task of tude to philosophy. For certainly, in approaching this high argument, we cannot lay aside the method of serious and systematic thought; the indispensable justification of all procedure that carries our beliefs beyond 
or below the simplest surfaces of life. The framework of a theory we unquestionably must develop. But there is something more; something more, and yet something inseparable; not behind or beyond the theoretical structure, but rather its informing life and spirit. And this something is our attitude to experience ; or more strictly, the mode of experience in which each of us more especially. sees and feels his continuity with reality. And it might very naturally be said that the framework of our theories has its value only as an embodiment of this selection and feeling and point of view. But if we tried to pursue such an idea seriously, we should quickly find it reverse itself; and our attitude in selecting the experience on which man is to rely in interpreting his world would collapse into a mere mood or humour of our mind, if it were not concentrated and organised in a serious philosophical theory. It is the old story of matter and form, of their absolute relativity, and the impossibility of conceiving either apart from the other.

The demands, then, of the gravest methodic thought will tax our best energies in some stages of the pilgrimage which some of us, as I hope, are to undertake together. And therefore it seems well to devote this initial lecture to a rapid anticipatory survey of the sort of attitude in experience and outlook on the world which our exposition will do its best to communicate, as knowledge carrying deep conviction and appealing to our whole being. That was the sense which we ascribed to Lord Gifford's words.

And for clearness' sake I shatl begin by describing this attitude of ours in a great degree through nega- 
tives. It will help us to apprehend what sort of thing we hope to establish, if we lay down clearly from the first what movements and tendencies we shall be obliged on the whole to repel.

I. And first we may say a word on the idea of The truly proportion, centrality, sanity, in the selection of the experience which is to dominate our attitude. We may oppose it to tendencies and inclinations which strike us as pre-eminently over-specialised, centrifugal, capricious. It is commonly held right to avoid the obvious, and in a certain sense we shall preach against it ourselves. But there is an obvious which depends not on immediacy but on centrality and dominance; and the obvious of this kind it is not easy to apprehend nor yet well to ignore. A wood seems an obvious thing, and so does a crowd. But we know that it is not easy to see the wood for the trees, or to apprehend the mind of a crowd or of a society. The former, I take it, is a late acquirement of the painter's art; the latter, many would tell us, was never really understood till the last generation. These instances, the first that come to hand, may serve to indicate the conception of that "obvious" which is familiar and yet neglected. And more important cases will emerge as we proceed.

We begin then with the principle-the truism if you like - that in our attitude to experience, or through experience to our world, we are to put the central things in the centre, to respect the claims of the obvious which is neglected - to take for our standard what man recognises as value when his life is fullest and his soul at its highest stretch. ${ }^{1}$

1 This is, I venture to think, a more tenable form of the demand which Professor Varisco makes (I Massimi Problemi) that the 
But one hears the critic murmur that all these terms of rank and value merely beg the question. What are the central things, and what is the soul's highest stretch? About all that there will be plenty to say when we come to exhibit our attitude in its aspect of logical theory. At present we are only urging by anticipation that there are in life central and dominant experiences, whose importance is obvious and undeniable, but which seldom find due recognition in the formal philosophy of others than the greatest men. And therefore philosophical theory seems frequently, and gravely, to fail in focussing the total conviction which, with courage and an open mind, a man may gather from the world. Theory seems too impatient, too much the victim of antitheses, too liable to break up its object in obedience to crude impressions, instead of using all its strength to ensure that its attitude to life is sane and central-that its experience is strong and profound and complete.

You do not, for example, readily find, represented in philosophical doctrine, so large and free an impression of the world as has recently been gathered by a gifted student of Shakespeare. ${ }^{1}$ Reducing it to our own inferior language, it is something like this. We receive from the world a tremendous impression of evil; there is no question of that. We also receive an overwhelming impression of goodsomething that we call good; that again is unquestionable. And the difficulty begins when you try to disentangle them - the one belongs to the judge of values shall be ex veritate "of the truth" (in the N.T. sense). This sounds to me too much like a division into sheep and goats.

1 A. C. Bradley, Shakespearean Tragedy, p. 24 ff. 
other, and you cannot get them apart. Now instead of patiently interrogating experience, and endeavouring to take account of the largest and bravest attitude of soul, ${ }^{1}$ theory here is apt to rush in, on the basis of first appearances, and either prove that black is white, or that white is black, or that the whole is an invisible patchwork of the two and is really grey.

But this, we urge, does not represent our central impression; it does not confront the more complete and sane and courageous experience. For the phenomena, as we really recognise them, are like those of beauty and ugliness; you cannot divide them between this side and that, and say "Lo here!" or "Lo there!" You have rather to open your eyes to the higher obvious, and look at the greater experiences as they are. You have to apprehend sublimity and splendour actually lighting up the lines of horribleness and squalor. You cannot, perhaps, "solve the problem"; but you can see that the whole thing belongs together in a way which our prima facie judgments wholly fail to confront. So with "good" and "evil" in the Universe. Such experiences as Moral Good, Pleasure, Justice, take you only a certain way. With the best of logic you cannot make a universe out of them; or, more truly, the best of logic refuses to handle these alone. The matter must be of higher quality or it will not give rise to the fuller form. So the higher, yet obvious and dominant, experience carries you at least as far as, for example, strength and endurance, love and sacrifice, the making and the achievement of souls.

1 Ruskin has somewhere called attention to the loss which comes from thinking being "the work as a rule of the cowards" (say, more politely, the sedentary classes), and not that of the soldiers. 
And we shall observe the same principle to hold in the world of cognitive apprehension. We certainly feel error everywhere, and yet again we have a hold of truth. And the great central experience which may be called the arduousness of reality, though we confess it with our lips at every moment, we seldom really face in our philosophical theory. We fall back upon one phase or another of rest and refuge, of repose on a solid nucleus which we call fact, or surrender to a stream of indetermination which we call life, and are blind to the open secret which all life worth living should make as plain to a candid apprehension as a crowd or a forest should be to the bodily eye. For, in the one case as in the other, what is familiar and fundamental appears, for that very reason, to evade precise perception. The great philosophers, it will be found, are just those who have succeeded in discerning the great and simple facts. It is, I am convinced, a serious lack of sympathetic insight which prevents us from understanding that to be right in one's bird's-eye view of centrality and the scheme of values, demands a higher intellectual character and even a more toilsome intellectual achievement than to formulate whole volumes of ingenious ratiocination. True, without logical development there is no philosophy; but no skill in development will compensate for a defective attitude to life. It is not that the "matter" may be bad and the form excellent, or vice versa, and so the one can injure or redeem the other. It is, as we said just now, that the whole, the philosophy, which, like a poem, is matter and form in one, reacts to a sound or defective outlook upon life alike in its spirit and in its structure-call matter or 
form which you will. Bad taste is bad logic, and bad logic is bad taste. Simply to be right, as the greatest men are right, means to have traversed hundreds and thousands of ingenuities, to have rejected them as inadequate, and come back to the centre enriched by their negative results.

2. Turning then for a moment, still in the way The of anticipation and description, to the negative $\begin{gathered}\text { Pilgrim's } \\ \text { Progress of }\end{gathered}$ aspect of the sane and central experience, we take $\begin{gathered}\text { Philo- } \\ \text { sophy. }\end{gathered}$ it as a patent and dominant fact that nowhere, in. asserting our continuity with the real, do we stand in the beginning on safe and solid ground. I mean on ground on which, if we chose, we could remain. It tells us nothing to say that an experience is immediate; for there are countless immediates and there is nothing that cannot be immediate. But if we understand by immediate so far as may be the primary datum, the factual nucleus, the naïve apprehension, then it is the plain and unmistakable lesson of logic and of the world that the immediate cannot stand. You cannot anywhere, whether in life or in logic, find rest and salvation by withdrawing from the intercourse and implications of life; no more in the world of individual property and self-maintenance than in the world of international politics and economics; no more in the world of logical apprehension than in that of moral service and religious devotion. Everywhere to possess reality is an arduous task ; stability and solidity are not in the beginning, but, if anywhere, only in proportion as we enter upon the larger vistas of thingṣ.

All this is what we are calling obvious. But as we shall observe throughout with reference to many 
supreme characters of experience, because it is obvious, it is neglected. The greatest truths, we shall often have to maintain, are assented to but not believed. If this obvious character of all our dominant experience (experience not to be taken as exclusive, but as the profoundest clue to the rest)if this obvious character were not disregarded, how should we come across such arguments with reference to the attainment of philosophical truth, as that the stream cannot rise higher than its source (a type of occurrence which is in fact the essence both of life and of logic), or that in the quest for the Absolute we are abandoning our solid given self? The clamour resounds on all sides that we are dropping the substance for the shadow. And we have perpetually to recur to the obvious and leading facts of our existence, to reassure ourselves that the stubborn truth of things (if these rough contrasts are to be tolerated at all) lies in the opposite sense; and that the shadow and the sub stance stand towards one another not as the critic but as Plato affirms them to stand. We shall find occasion to return to the question of Plato's socalled dualism. At present it is enough to say that this splitting up of Plato's universe into two persistent extremes is a part of the easy-going centrifugal attitude against which our whole thesis will prove to be a protest. For Plato, emphatically and primarily, the world is but one $;^{1}$ and of this one world, the human soul, when most self-centred and self-satisfied, is almost wholly disinherited.

Starting with this attitude and perception, we

1 Mr. Schiller, I think, has taken the same point. I have not the reference. 
see that if our Pilgrim's Progress is adventurous, it is beyond a doubt inevitable. To cling to our initial standing ground - or to strive or pretend to do so, for it is not really possible-is without any question to abide in the City of Destruction. The idea of a solid given - a personality, a fact, an apprehension, which we possess $a b$ initio, and are tempted rashly and perversely to abandon in the quest of the Absolute, is an illusion which has no warrant in vital experience. The road of philosophical speculation is not the possible way for most men, nor the only way for any man; that is true and sound. But in one way and another, in labour, in learning, and in religion, every man has his pilgrimage to make, his self to remould and to acquire, his world and his surroundings to transform. In sin, too, he does it; in what way, we shall try to see later. We are only attempting, in the form of reflection, what every living creature at least is doing, one way or another, between birth and death. And it is in this adventure, and not apart from it, that we find and maintain the personality which we suppose ourselves to possess $a b$ initio.

Platitudes, it may be said, from some old book of hymns or sermons! "We've no abiding city here!" Why yes, $I$ rather think so. But the odd thing is that so much philosophy should be built not merely on the denial of them, but on disregard of the common and recognised human experience which they represent.

3. We will now rapidly survey some typical some illusions, as they appear to me, of what I have instructive called the centrifugal type, a negative relation to 
which will help to define the course of our argument. And after that we will gather into a few propositions the more burning issues of our own contention.

"Il gran rifiuto."

(I) I hope it may set our thoughts in tune for the general aim and method of our argument, if I begin by repudiating what seems to me in principle il gran rifuto, the ultimate abnegation, on the part of philosophy. I select a passage from a writing of Professor William James, whose presence once added lustre even to this University, and whose teaching was a perpetual stimulus and delight to the philosophical world. To be clear and fair, I must point out that in this argument James's moral was ultimately the same as my own. I find 'the great abnegation' in his applying it as a sound criticism upon the normal study of the great philosophers, and as a ground for a new and different philosophy.

Here is the passage. "I wish that I had saved the first couple of pages of a thesis which a student handed me a year or two ago. They illustrated my point so clearly that I am sorry I cannot read them to you now. This young man, who was a graduate from some Western college, began by saying that he had always taken for granted that when you entered a philosophic class-room you had to open relations with a universe entirely distinct from the one you left behind you in the street. The two were supposed, he said, to have so little to do with each other, that you could not possibly occupy your mind with them at the same time. The world of concrete personal experiences to which the street belongs is multitudinous beyond imagination, 
tangled, muddy, painful, and perplexed. The world to which your philosophy-professor introduces you is simple, clean, and noble. The contradictions of real life are absent from it. Its architecture is classic. Principles of reason trace its outlines, logical necessities cement its parts. Purity and dignity are what it most expresses. It is a kind of marble temple shining on a hill. In point of fact it is far less an account of this actual world than a clear addition built upon it, a classic sanctuary in which the rationalist fancy may take refuge from the intolerably confused and gothic character which mere facts present. It is no explanation of our concrete universe, it is another thing altogether, a substitute for it, a remedy, a way of escape," and so on. ${ }^{1}$

I remember to have first read this passage with an interest that grew more breathless as I approached its close, thinking what a magnificent opening Professor James's student had given him for imparting some first hints of the nature of philosophy in the hands of the masters, and the conditions of philosophic study. And I recall my gasp of disappointed amazement when I realised that the opening was to be left unused, or at best exploited in favour of something to be called Pragmatism; that a teacher had actually passed these ideas as sound and just, when taken in reference to the principal existing philosophies. ${ }^{2}$

Now I presume that in this matter your experi-

1 James, Pragmatism, p. 21.

2 It just illustrates the difference between looking at philosophy from without and working at it from within, that after some hundreds of pages of discussion James finds himself, in essence, affirming the view, the acceptance of which by Leibniz he began by treating with contempt. Cf. Pragmatism, p. 296. 
ence is the same as mine. When you first come in contact with those senior fellow-students who are called your professors and lecturers, and you reveal to them, intentionally or unintentionally, your feeling that philosophical systems are foreign to the concerns and difficulties of life, I imagine that they meet you in a very different way from that above suggested. Probably, by one method or another, they try to lead you towards the conception that the gulf which you complain of is caused by the insufficient quantity and quality of the attention which you have hitherto been able to bestow upon the facts of living, compared with the breadth, patience, insight, and sympathy which you are now first called upon to devote to them, and which are new to you, and demand a considerable effort. Naturally, experience when thus approached undergoes transformation; and the language we hold about it is modified. And so we begin to have gleams of insight into the thought and expression of the great men whose breadth, sympathy, and understanding of life are to ours as the ocean to a streamlet. We see how they come to hold a language greatly differing from that which we were used to before we gave very careful attention to the great issues and predominant facts of life. We learn in some degree how any point we take up in the tissue of experience opens out into tremendous problems and indicates unanticipated depths. We begin, as Plato said, to learn the alphabet of the ethical or social and ultimately of the metaphysical world. ${ }^{1}$ Philosophy is the formal embodiment of

1 Ye can discern the face of the sky, but can ye not discern the signs of the times? 
the "penetrative imagination " ${ }^{1}$ it deals with the significance of things; and transforms them, but only by intensified illumination. We shall throughout repudiate this ultimate abnegation which treats the great philosophies as abstractions alien to life. It is il gran rifiuto when life ignores and disowns its own largest and deepest experiences. The phenomenon is a common one, and commoner as the great experiences grow greater.

(2) We shall also meet, with uncompromising "Fact,", resistance, the attempt to take any form of immediateness, understood as excluding mediation, for an and "Self" absolute and reliable datum, whether in the form of dangerous an object of simple apprehension, called by the ates. name of fact, or in the form of an indeterminate creative impulse called by the name of life, or in the form of a subject of experience impervious and isolated, called by the name or self.

Each and all of these three immediates seems to invite the general criticism which we offered above. The solid fact or object of simple perception; the indeterminate living or duration which defies the notional grasp ; the isolated personality, impervious to the mind of others, seem all of them to mark arbitrary refuges or timid withdrawals from the movement of the world. What is dreaded in that movement may be the critical dispersion of our supposed solid $\pi o \hat{v} \sigma \tau \hat{\omega}$ of fact or self, as in the first and third doctrines, or the linkage with a determinate continuity, the spectre of tout est donne, as in the second. In more ways than one there asserts itself the inherent connexion between such refuges and withdrawals and true philosophical 1 Cf. the author's History of Aesthetic, p. 458. 
pessimism. I mean by this not the mere mood in which one mind or another pronounces life not worth living, but the argument by which, connexion is radically severed between real existence and the principle of perfection. ${ }^{1}$ This applies to the first doctrine and the third, which are complementary forms of the same ultimate attitude. The second, embodying rather a principle of indetermination than a determinate discontinuity, carries with it a pessimism or a meliorism as the holder's temper may demand. ${ }^{2}$

Am I then implying that a true philosopher is bound to Optimism, and that the two other attitudes are ex hypothesi condemned? This question, I hope, will answer itself in extenso below. To anticipate in a few words. The decisive consideration surely is that our best and worst are all included in our one universe, and we have no means or occasion for conceiving another or others in which either could be separately present. We can hardly proceed to state cases for comparison in respect of good or evil until we have a fair insight into the actual nature and connexion of what as we primarily apprehend them we call good and evil. To say that we should approve a universe in which there was our "good" without our "evil" may be merely a ridiculously illegitimate hypothesis. But if we have no cases to compare, we have no right to use the comparative or superlative forms of speech. Our real effort must

1 Cf. e.g. Russell's Philosophical Essays, "The Free Man's Worship." The view that the judgment of value is not susceptible of logical defence, together with the doctrine of the imperviousness and isolation of the self, appear to me to belong ultimately to the same position as Mr. Russell's.

2 In James's philosophy I seem to see the makings of both. 
be, I am convinced, towards seeing in what the true best of our universe, taking account of the worst, must consist. It is clear that till we have seen to the bottom of this problem, we cannot be equipped to pass judgment on the universe, for we do not really know what it claims its best to be. If it is urged that we must be entitled to judge by our current ideas of good and bad, or else the universe is a fraud, ${ }^{1}$ I agree that our ideas have some value, and bear upon the point. But I say that in any case we do not know enough to pass judgment ultimately; and I say further that within our actual current ideas there is so much room for discrepancy (owing to the different attitudes of experience on which we have insisted), as to make it evident that there is in them a principle of advance which would at least lead our judgment very far away from our prima facie conceptions.

What demands our attention is to ascertain what we really and self-consistently mean by the best, and the current claim to judge the universe is one of the immediates which we must repudiate.

(3) If, then, adhering to immediacy, we commit Immediacy ourselves to accepting the apparent self as a solid involves starting-point, and demanding for it a distinct fulfilIndividualment in pari materia, we find ourselves on the ground of justice, ethics, teleology. According to the plan of this Introduction we will not yet reason in detail upon these attitudes and postulates; but we may point out that there are modes of experience, "obvious" and "dominant" in our sense of the term, which indicate a modification and transcendence of them. Consider what is called Justice. There is

1 See McTaggart on Mill's saying, Some Dogmas of Religion, p. 2 I 4. 
hardly a morbid romance but founds its pessimism on the wearisome postulate of what it calls justice - some proportion, that is to say, which is claimed as a right, between the given wants and the fortunes of man. The note of this mood and temper is the reiterated "Why" - "Why should A be at a disadvantage when B is not?"-and we feel it to be wholly discordant with the temper of the stronger souls in whom we delight to recognise the ready welcome of differentiation and the insight that even the call for endurance is an opportunity. Justice as thus demanded is a principle of compensation for being what you are, and cannot have a place in a differentiated universe. It would fix and rivet the finite member of a world to his finite and given being, in opposition to his real power, which is, precisely, by means of and through accepting the whole involved in the differentiation, to transcend his apparent limits.

So with Ethics and Teleology. We can see their value and necessity, but we are obliged also to note that they cannot be characters of a whole or world, but only of its finite members. Their nature is summed up in the paradox "The end is progress," and the inconsistency of such a conception forces itself upon us in many forms. A teleology cannot be ultimate; it can express nothing but a necessity for change founded upon a whole which constitutes the situation to be modified, and, in that, the need for modification. There is no meaning in somebody wishing something, ${ }^{1}$ except in view of a definite situation which at once suggests and prima facie denies his wish.

1 James, Pragmatism, pp. 288-9. 
We are convinced by daily life, I think, that the ethical struggle, justice, and teleology are in place, so to speak, only so far as they can be serviceable; as instruments, that is, of the necessary self-assertion of the finite mind. When that point is passed, or that aspect subordinated, there is room only for love and pity, or again for faith and triumph. We feel, as we constantly admit, that our judgment of morality and of failure is not all there is to be said about a man. His value and his reality lie deeper than that. ${ }^{1}$ Good, we feel, needs and includes the ethical struggle, but is much more than it, or the struggle itself would be impossible.

(4) Thus it has always been a fallacy of prima and rules facie judgment to split up the tension of real life out tension ointo pure delight and pure misery-heaven and hell fection, -representing the perfection of experience by the former, and absolute failure by the latter. Such a conception, as we shall see, is forced to a restoration of unity by making the misery of the lost contributory to the happiness of the saved. All views in which pain and struggle are conceived as leading up to a happiness from which they are wholly excluded, partake of this absurdity. When Plato said that neither pleasure nor pain were fit experiences to be ascribed to divine beings-indicating, of course, not a neutral state, but something transcending the two-he said what represents the obvious demand of mind at any tolerably high level. It seems plain to me that we are in conflict with fundamental necessities of the better life, if we

1 Every one, I should think, must have had his moral judgment and his general estimate of values brought into collision by the character of Falstaff. We cannot conceive him in hell any more than he could himself. Every one knows cases of the kind in real life. 
construe the Absolute as heaven, and reckon it as a future of enjoyment crowning the struggle of time. Tension and satisfaction may, as we know, be immensely modified in character, and to conceive them as perfectly fused is beyond our experience; but satisfaction without tension is a thing that reason does not suggest and experience does not indicate. The direction which man at his best has taken in seeking freely for his fullest satisfaction, shows us, in the significance of poetical tragedy, something of the nature which must attach to a satisfactory experience. Of course I do not say that the most perfect tragedy is such an experience. I only say, in conformity with the anticipatory character of the present lecture, that the almost supreme rank occupied by it in the achievements of the human mind, is a perfectly obvious and highly significant fact, which I have never but once seen observed upon in general philosophy. ${ }^{1} \quad$ If we really think the race is progressing to a stage of felicity, in which, without any jot of participation in any tragic experience, it is to draw from it a painless enjoyment, then I think that the doctrine of hell contributing to the pleasures of heaven is not far away.

And the moral of this paragraph and the last together is that starting from commonplace experience we are always tempted to isolate endeavour and fruition, which in all the higher attainments of mind (we may instance morality so far as socially realised, or aesthetic enjoyment) we find to be impossible, and, supposing it possible, ruinous to the experience. You cannot, so to speak, believe in

1 I refer to a passage in Mr. Russell's "Free Man's Worship," (Philosophical Essays), with which I am very strongly in sympathy. 
Optimism or Pessimism alone. If you will have a pure heaven, you must add a pure hell to complete it. If, that is, pain and struggle are not to modify and be modified by fruition, they must fall somewhere by themselves, as a life of Tantalus.

(5) And thus an opinion, supported by thinkers and thrusts for whom I have a profound respect, seems to me the Abso- $_{\text {lut of }}$ untenable, the doctrine, that is, that Philosophy Life. gives hope, not guidance. ${ }^{1}$

So far as this tenet is a warning against doctrinairism, against looking to philosophy for prescriptions of practical detail, it seems to me perfectly just. But those who have studied the distinguished writer who formulates it will be convinced, I think, that there is something more general behind. In the way we have deprecated above, perfection is identified with happiness, as unconditioned by any thing akin to pain,- the motive and colour of the doctrine has some connection with Hedonism-and great stress is laid on the probability of its emergence as a crowning phenomenon of time. And thus-so it seems to me - we are enticed away from any conception of the Absolute as the principle and pervading spirit of our world, and from the conviction that the general direction of our higher experience is a clue to the direction in which perfection has to be sought. To put it plainly, we are promised a "harmony"- that is the "hope" which is given; but on such general grounds and in such general terms that the concrete system of

1 See McTaggart, Studies in Hegelian Cosmology, Sect. 205; and A. E. Taylor's Elements of Metaphysic, 357. Professor Taylor is referring, I think, especially to the question of the future life, while Mr. McTaggart, in the passage referred to, speaks more generally of ideal perfection. 
values, which ought to be immanent as our clue and guidance to the conception of the best, is allowed to drop out. ${ }^{1}$ And this, I think, is due, on the side of concrete experience, to the acceptance of too immediate a fact $a b$ initio in the construing of the ideal-to taking pleasure as a type of felt harmony. With this clue in mind we necessarily split up our experience of life, and omit to employ what is really one half of it as a factor in our ideal. And, therefore, we fail to catch the heart-beat of the Absolute in our actual world, and to be convinced that the things which are best to us are really and in fact akin to what is best in the universe; that their fundamental tendencies are discoverable by the study of our surroundings; and in ultimate reality, though modified in the direction indicated, are not reversed.

Some central points.

4. I will draw towards a conclusion by indicating in a few positive propositions, still by way of description and anticipation, the critical points of the attitude which I shall endeavour to maintain as conformable to our sane and central experiences. And in these, intending to develop them technically later on, I shall strive for plainness even at the cost of exaggeration.

What (I) The principal thing that matters is the mind as level and fulness of thind attained. The destiny such. and separate conservation of particular minds is of inferior importance and merely instrumental to the former. ${ }^{2}$

1 This is not a mere difference of mood and humour. I believe this author's treatment of the Dialectic to be one-sided in this respect. See Review of McTaggart's Commentary on Hegel's Logic; Mind, January I 9 I 1 .

2 Of course experience involves being "lived" by some being. But this is quite different from saying that finite persons are ultimate 
This conviction we shall later attempt to draw out in argument. But I am sure that it is deeply rooted in the every-day mind at its best, though liable to be overriden by conventions which have nothing like the same reality. What a man really cares about-so it seems to me-may be described as making the most of the trust he has received. $\mathrm{He}$ does not value himself as a detached and purely self-identical subject. He values himself as the inheritor of the gifts and surroundings which are focussed in him, and which it is his business to raise to their highest power. ${ }^{1}$ The attitude of a true noble, one in whom noblesse oblige, is a simple example of what mutatis mutandis all men feel. The man is a representative, a trustee for the world, of certain powers and circumstances. And this cannot fail to be so. For suffering and privation are also opportunities. The question for him is how much he can make of them. This is the simple and primary point of view, and also, in the main, the true and fundamental one. It is not the bare personality or the separate destiny that occupies a healthy mind. It is the thing to be done, known, and felt; in a word, the completeness of experience, his contribution to it, and his participation in it.

At every point the web of experience is continuous; he cannot distinguish his part from that of

values. To identify the conservation of values with the permanence or survival of given personalities, as Professor Varisco appears to me to do, is to my mind an extraordinary assumption.

1 Cf. the Poets' Chorus in "Paracelsus":

"Yet we chose thee a birthplace

Where the richness ran to flowers;

Couldst not sing one song for grace,

Not make one blossom man's and ours?" 
others, and the more he realises the continuity the less he cares about the separateness of the contribution to it. ${ }^{1}$ Sometimes it seems to amount to an accident who in particular becomes the mouthpiece and obtains the credit of knowledge and ideas current in certain circles or professions; and it may frequently be felt, both by himself and by others, that the one who does so is neither the main originator nor the one best fitted to be the expounder. ${ }^{2}$ It is impossible to overrate the cooperative element in experience. And its importance has a considerable bearing on what we are apt to call the problem of unfulfilled promise. By unnoticed contributions to the common mind, very much is preserved which seems to have perished, and in some cases perhaps the half has been more than the whole.

The passion of love may be instanced against these ideas. Here, even though we argue that the one who loves rather merges than insists on his own particular being, yet surely the particular being of the loved object is the very core and centre of the emotion. Its destiny, its permanence, even its unchanged immortality, seems to matter more than anything in the universe. Just so; as in all the higher levels of experience, some particular personality becomes important by what it embodies. That is quite obvious; and the fact that passionate love, as the engrossing relation of two personalities,

I "If we could energise a great deal more continuously than most of us can, we might experience physical death literally without being aware of it."-Nettleship's Philosophical Remains, i. 90.

2 The case typified by Arthur Hallam is, I believe, in essentials exceedingly common; that is, that men who are considerable originators, and influence a wide circle, are prevented from producing, and reach the world only as components of other personalities. 
seizes on and kindles into flame all that they contain, is really a document of the value that comes to a particular being when it throws itself wholeheartedly outside itself. The thing has a side of utter selfishness and ownership; but it is when this is burnt away that the greatness of the experience begins. $A$ particular is all-important to each; but this particular is not his own particularity, but another's; and, moreover, it is no longer to him a particular, but takes on the value of a world. It is this that the desire of eternity really signifies, and with this comes a transformation. A great writer has said that hate, like fire, makes any rubbish deadly; and it is no less true that love, like fire, makes the poorest things splendid. It is almost, one might say, the absolute in propria persona.

At any rate, this is one observation which seems central both in life and in theory, that the level or quality of mind, and not the destiny of its centres is the main thing - the principal value.

(2) The same principle, in rather more technical Logic the form, amounts to this, that Logic, or the spirit of spirit of totality, is the clue to reality, value, and. freedom.

The key to this principle is to be found in all that connects the satisfactoriness of experiences with their stability or power of self-maintenance, and both with the nature of creative initiative. Creative initiative is obviously, under the form of change, what stability and self-maintenance are under the form of duration. The desire to liberate the initiative of mind from pre-existing conditions sometimes goes so far that it seems to forget that an inference after all - a typical act of. mind-must have data or premisses to issue from, and that, e.g., 
the creation of a work of art is null and worthless if it does not involve an apprehension or fore-feeling of just that coexistent unity which makes it when completed the very type of a logical whole. The logical spirit, the tendency of parts to self-transcendence and absorption in wholes, is the birth-impulse of initiative, as it is the life-blood of stable existence. And the degree in which this spirit is incarnate in any world or system is one with the value, the satisfactoriness and reality by which such a system must be estimated, as also with the creative effort, by which it must be initiated. ${ }^{1}$

The "good" of a world.

(3) The "good" of the universe must be such as belongs to a world and not to the member of one.

This observation seems fundamental. It is very evident in so comparatively simple a question as that of morality in the particular person and in the state. The member of a world, relative or absolute, is conditioned by his world, and his task presupposes it. His world, itself relatively or absolutely the ultimate condition of things, has an altogether different task. It has to sustain within it all the organs and conditions necessary to constitute a world. The member of a world is conditioned by his surroundings, which set his task; the world is the condition both of the individual and of his task. His good is prescribed by his relation to his task, his dealing with his surroundings. Its "good" cannot conceivably be the same as his. Its "good" must include making his "good" possible; and if it could be "good" through and through, in the sense

1 I attach great importance in this range of thought to what we learn from reflection upon art and poetry, and, I may add, in the discussion of our de facto apprehension of the absolute, to what we learn from the theory of the sublime. 
in which he is expected to be good, his goodness would not be possible. We expect it to be rather the birthplace and theatre, or more-the including totality - of goodness, than itself of the precise nature of what we primarily call good. Its excellency is rather to be great in its possibilities, beyond the reaches of the finite soul, so that this may always find more than it can master; may always find more than scope for its utmost effort and its utmost worship. ${ }^{1}$ We could not, it may be suggested, possibly be satisfied in a universe in which we could be content-which simply ministered to our " goodness," letting us-sin, endure, and aspire slightly, so that we could see clearly it was all calculated for our good. We should then feel ourselves, in our finiteness, the lords and masters, because sole purpose, of the world, which would exist simply to make us feel good. And we should be miserable, and the end would not be attained, for we should have nothing greater than our finite selves to contemplate. We want something above us, something to make us dare and do and hope to be. We are finite, which means incomplete, and not fitted to be absolute ends. ${ }^{2}$

1 The world which we began by speaking of was the State. Will any of this language, it will be asked, apply to it? Is it not a mere contrivance, easily worked and easily seen through? Any one who believes this must be puzzled, I think, by the apparent fecundity of difficulty and evil in socio-political matters. The fact is, it has to deal with a whole nest of lives and their surroundings, and these involve greatnes's and conflicts of all kinds. It has to maintain such a system of life as will permit of the development of many-sided excellence within it.

2 Cf. Browning:

"Oh, dread succession to a dizzy post,

Sad sway of sceptre whose mere touch appals,

Ghastly dethronement, cursed by those the most

On whose repugnant brow the crown next falls." 
Goodness, in other words, we know, cannot be the moral end. If we make it so, it loses its content and collapses into nothingness. ${ }^{1} \quad$ The world that conditions our goodness must not exist merely for our goodness' sake, but must subordinate it to some concrete need or nature. A world's excellence must include its members", and have a relation, or sort of kinship, to it; but must be of the nature of a greatness that goes beyond and sustains it.

The greatness of

(4) The universe is not a place of pleasure, nor souls. even a place compounded of probation and justice; it is, from the highest point of view concerned with finite beings, a place of soul-making.

Our best experience carries us without hesitation thus far. We see for ourselves that mere pleasure, or the mere sense of moral desert and adjustment of consequences to it, take in but little of what has value for the fully capable mind, though both, of course, take in some of it. We may call in evidence history or science, poetry or politics, social life or religion. It is the moulding and the greatness of souls that we really care for.

This observation has to be reconciled with what we said above as to the relative values of the particularity of the particular centres of mind compared with the level of mind as such. But this reconciliation, which must occupy us more fully later on, is not in principle difficult. The destiny or conservation, we said, of particular centres is not what primarily has value, and here we say nothing to conflict with this. What has value is the contribution which the particular centre-a representative of certain elements in the whole-brings to the whole

1 Cf. Green, Prolegomena, Sect. 247. 
in which it is a member. Its particularity, as we shall see, is connected with its special contribution. But the value of the particularity is indirect, and depends on what it helps to realise. ${ }^{1}$

It will be urged that "making" or " moulding" presupposes time and succession, and so we should stand committed to the reality of these. But this will not disturb us. We can have no doubt that there is time in the Absolute. It is a further question whether, and, if at all, in what sense, the Absolute is in time?

(5) Lastly, we experience the Absolute better we have than we experience anything else. This is our the answer to the question, are we finite beings in any throughway or degree to possess or enjoy the Absolute, or does this depend on some such question as whether there is a future life; and is the Absolute related to us as heaven to an orthodox Christian?

The answer is fundamental for our convictions, and is already decided by our attitude to the stability of our starting-point. We all of us experience the Absolute, because the Absolute is in everything. And as it is in everything we do or suffer, we may even say that we experience it more fully than we experience anything else, especially as one profound characteristic runs through the whole. And that is, that the world does not let us alone; it drives us from pillar to post, ${ }^{2}$ and the very chapter of accidents, as we call it, confronts us with an extraordinary mixture of opportunity and suffering, which is itself opportunity.

$1 \mathrm{Cp}$. the whole poem, "It is not growing like a tree-"

2 "Rejoice that man is hurled

From change to change unceasingly

His soul's wings never furled."-BROWNING. 
Of course we do not habitually call this power within which we live "the absolute." And wholly unreflective minds, we may suppose, are hardly aware of any general characteristic in life pointing to a unity, such that it is at once something which is too many for them, and something which gives them wonderful chances. But the fact is there, and is there for them, though it may be only distributed through their perceptions, and never reflected on as a general fact. We all have, in truth, to recognise something absolute both within ${ }^{1}$ and without ourselves; an external power prima facie too strong for us, and yet responding to our destinies and passing into us as an inward power now more and now less than equal to the external surroundings. If we refuse to find absoluteness even in love, or in anything but the minimum of positive fact, and say therefore that our only absolute is death, ${ }^{2}$ yet even that is a power which, primarily hosțile and external, an accident of nature, we can make our own and an expression of our will, by self-sacrifice, or by resignation, or in a sense by suicide. ${ }^{3}$ A being who can determine not to live-the animals below man, it is said, never so determine-has hold of something which is more to him than every possible thing. And in this he gives this something, undefined as it

1 Such a phrase as "absolute certainty" is constantly used by people who would shrink from the recognition of an absolute.

2 "Me non oracula certum Sed mors certa facit

3 "Glad did I live and gladly die, And I laid me down with a will."

In suicide there is not the full union of self and not-self. We do not unite with necessity but borrow its form to clothe our self-will. It is the child's "Then I won't play." I do not say it cannot be right. 
may be, the value of an Absolute, of a not-self which is more himself than his actual self is.

The argument, it may appear, would be simpler and truer if it were the fact that we all, under the discipline of life, ${ }^{1}$ became obviously wiser and better, like pupils in a school with no percentage of failures. As a fact, too many of us seem to deteriorate. But, as we hinted above, "it takes all sorts to make a world ;" and if we could be at ease in Zion, and see every one virtuous and prima facie contented, we could never, I think, be satisfied. It is only by the conjunction of what is quite beyond us with what is deep within us that the open secret of the Absolute confronts us in life, in love, and in death.

5. It is in agreement with the clue given ${ }^{2}$ by experiences like these, which I venture to call Intended course of obvious, central, and sane experiences, that I shall tures. try to set out, in logical connection, during the present session, the foundations and demands of the principle of Individuality, and, during the following one, the straightforward and "higher obvious" view of the worth and destiny of finite individuals.

In the present course, then, we shall be dealing, for the earlier part, with the principle of Individuality considered as the immanent criterion of the real, and also in its relation to inferior forms of the logical universal, such as general law, uniformity of nature, and directive teleology in evolution. In connection with these discussions the bodily side of mind and the rank of finite consciousness as a teleo-

1 "Machinery just meant

To give thy soul its bent,

Try thee and turn thee forth, sufficiently impressed."

2 "With the clue given" only-of course all experiences have a right to recognition in their place. 
logical agency will fall to be considered, and a good deal of logical technique will be unavoidable. And in the latter part we shall speak of the same principle as the key to the character of value in the real, and to the freedom or initiative of its members, as also to its immanent structure, and its mode of inclusion of nature and the finite self.

The results, I give fair warning, will be nothing in any way startling or extraordinary. We shall, on the whole, express and define, I believe, the reasonable faith of resolute and open-minded men. The outside of what I could hope to achieve would be sometimes to insist in words on what they think too obvious to be said, and, by attempting a thorough-going logical connection of what is immanent in all the sides of experience, to establish that a sane and central theory is not full of oddities and caprices, but is a rendering, in coherent thought, of what lies at the heart of actual life and love. 


\section{LECTURE II}

THE CONCRETE UNIVERSAL

WE are in the habit of thinking that we have raised Universal the level of our experience when we have discovered $\begin{aligned} & \text { as a } \\ & \text { general }\end{aligned}$ anything that approaches a general rule. And it is true that prima facie we have done so. We have relied on the principle of community or continuity in experience. That is to say, we have followed some conjunction of properties beyond the case in which we first found them conjoined, and have trusted it to hold good under conditions other than those under which we first came upon it. In doing this we have pursued the tendency on which all knowledge depends-the (tendency) of experience to be "universal" ; that is to say, to carry us beyond any given piece of itself by exhibiting a character which throws light upon further and different contexts, and receives light from them. It is needless to give examples ; every general statement, applying a single predicate to a number of different cases, is an instance in point.

Further, in doing this we have made an appreciable advance towards the ideal of truth; that is, towards a rendering of experience which shall be free from self-contradiction - free, I mean, from different interpretations of the same facts in the 
same relations. Every general rule, in so far as it includes within a single interpretation an area of experience which might have been discordantly apprehended, decreases the possibility of such a discrepancy, and is, therefore, so far as it goes, a movement towards the completion of knowledge as a coherent whole. The instinct or impulse which thus far we appear to take as our guide is apt to express itself in some such formula as "Same causes, same effects," or more generally, "It is the same that produces the same." times passes for the characteristic principle of knowledge and intelligence-a principle depending on repetition of similars ${ }^{2}$ and the recognition of them as they recur. But we have said enough to show that from the very beginning this conception is untrue. Even the baldest generality has its value in the differences of context which it includes and which it illuminates. What the real principle of intelligence is we shall see as we develop this characteristic in a region beyond mere generality.

Defects of general rule.

I. But the abstract generalisation, considered I with reference to truth, has defects which were sufficiently signalised in the very dawn of logical theory by Plato's critical estimate of the exact or

- mathematical sciences. And, following him, almost all considerable thinkers have pointed out that a body of knowledge, if understeod in the sense of a body of highly abstract rules and inferences, must be said prima facie to depart from what is given in experience, and truth, if taken in a similar sense, to

1 Bergson, L'Évolution, p. 49, "Il faut le même pour obtenir le même." Cf. p. I 77, "L'intelligence rejette toute création."

2 Ibid. p. 49,"Notre action ... ne peut se mouvoir que parmi les répétitions." See author's Logic, 2nd ed., Book ii. I 74 ff. 
abandon fact. ${ }^{1} \quad$ It is History, we are even told, by what I take to be a rash interpretation of this familiar doctrine, to which we must look for the type of living experience. Or, in a " new philosophy," we may be referred to an "intuition," the very existence of which in its purity seems a doubtful assumption. These, I repeat, are to my mind rash interpretations. But they point to something which is common ground. For better or worse, the historical tense, the genuinely personal subject, the point of departure which we indicate by such terms as "this" and "mine," are unknown to the processes of science. A general statement is an extract or an abstract. It has even been called hypothetical. Certainly it is not in the fullest sense categorical. Its terms are not, as they stand, affirmed to be actual reality. It tells us thingut reality ; it points out consequences which-must flow from the application to it of specified conditions. It does not pretend to speak of real beings in their whole and fundamental nature. That is to judge categorically in the full sense $;_{\wedge}^{i k}$ to make assertions regarding the nature of the universe as a whole. And this can be done, if at all, by Philosophy alone. For Philosophy is essentially of the concrete and the whole, as science is essentially of the abstract and the part. It may be said, then, with some degree of truth, that science deals with experienced existence at secondhand. It " murders to dissect." The imputation, as we pointed out, is an old one, and is not, of course, in truth, a hostile impeachment, but a

1 Bradley's Principles of Logic, e.g. 92-3. I assume that the highest segment of Plato's divided line is to be interpreted as implying a return to the concrete, from which the second highest has departed. 
simple recognition of the functions of science and of its rank in a logical system. For this reason, if taken as the exclusive basis of a world-theory, science will always be open to the criticism which has recently been launched against mechanical theories of evolution. But also, it is false to argue as if a mechanical theory could contribute nothing to the construction and apprehension of the whole. Mathematical reasoning itself is synthetic, and in the continuity of experience all combinations, however homogeneous their elements, can reveal new properties, stand in relation with new qualities, and throw light upon their nature. The geometrical character of any line is continuous with and essential to the significance which it bears in the most concrete work of art.

The principle of Abstraction has often been criticised as it is embodied in the traditional doctrine of Extension and Intension. It is enough to glance at the tree of Porphyry to see whither such a doctrine must lead. The most general knowledgethat which continues into wider comprehensiveness such a series as Man, Animal, Organism, Material body-must obviously be the least instructive, and must have its climax in complete emptiness.

It is, indeed, the same reason which compels the progressive generalisation to diminish the depth of knowledge, and which forbids the general rule at any stage whatever to deal with the whole of a concrete subject, or, as it was phrased above, to be categorical.

And this underlying reason is to be found in the attempt to cut in two the essential principle of continuity. The endeavour of the simple generalisation 
is to pursue an identity apart from differences. Its method, therefore, is omission. The generality is framed by attending to the common qualities of a number of individuals, and disregarding their differences. This procedure has two inevitable results. i It prohibits the consideration of any world or structure of which the individuals before us are members, and by the same necessity it prohibits the consideration of the entire or concrete nature of any individual by itself. These two consequences are inevitable, because, so long as identity is construed as excluding diversity, no world or structure can be constituted by the identical properties of individuals. Individuals taken per se as members of a class in virtue of identical properties are ex hypothesi parts or members of a whole of repetition, and, so far, of no other kind of whole whatever. And each individual of those so taken can be considered only in respect of the property in virtue of which it is a member of the class. The differences within that property itself, and those which constitute the whole remaining content of the individual nature, are ruled out $a b$ initio by the method. While we are faithful to such a conception there can be no thought of a whole of individuals, and, for the same reason, none of an individual as a whole. The general statement is restricted to affirming the property or properties repeated within each similar member of the class; and their membership of a concrete system, either constituted by their fellows of the class, as in the world of humanity, or by groups of dissimilar units, as in the reciprocally dependent organisms of a locality, is forbidden to appear as a source of further knowledge about them. 
We have, here in fact, the relation of classification by resemblance to grouping by reciprocal determination. The former might be compared to the attempt to explain a human body or a steam-engine by classifying the parts of each in terms of their resemblances to one another. The latter would be typified by the way in which the function of the whole system is accounted for by the co-operation and division of labour due to the different structures and qualities of its constituent members. And it is important to notice that the former mode of consideration, however serviceable for certain purposes, is essentially due to a superficial application of the very same principle which is more fully realised in the latter. The identification, for example, of Plato's Forms with " the objective correlates of classconcepts" would render it absolutely impossible to conceive them as a world of interdependent members, such as is implied in the Form of the Good, and in the conception of a universe of reality.

It must be added, to avoid misunderstanding, that we are not reducing the precise determinations of science, for example, the law of gravitation, to the level of commonplace class-predications resting on superficial observation.

What we are affirming comes to this, that if, by an inadequate theory, the function of the former is interpreted as merely to recognise a common attribute in its recurrent examples, to apprehend "the same producing the same," then such a reduction is erroneously effected, and the operation of scientific principles in leading to novelty whether of truth or of practice is made wholly unintelligible.

2. The endeavour to remove contradiction in 
experience is therefore more successful when it 'World'a explicitly assumes a further shape, such as is indicated of the by the term "a whole of parts," "an organism," "a universal, system," or more generally "a world."

At present we are only desirous to grasp the principle of the distinction between all these forms of experience, on the one hand, and the abstract generality, on the other; and it is not necessary to enter upon the differences between these several conceptions themselves. " The most inclusive of the terms above-mentioned is "world " or "cosmos." A world or cosmos is a system of members, such that every member, being ex hypothesi distinct, nevertheless contributes to the unity of the whole in virtue of the peculiarities which constitute its distinctness. And the important point for us at present is the difference of principle between a world and a class. It takes all sorts to make a world; a class is essentially of one sort only. In a word, the difference is that the ultimate principle of unity or community is fully exemplified in the former, but only superficially in the latter. The ultimate principle, we may say, is sameness in the other $;^{2}$ generality is sameness in spite of the other; universality is sameness by means of the other.

Thus the true embodiment of the logical universal takes the shape of a world whose members are worlds. "Whose members are worlds"-for the same reason which made it inevitable for the mere generality to be defective by the omission of contents which differentiate the class-members from

1 See Taylor, Elements of Metaphysic, p. 96.

2 The principle will be defended when we come to speak of the criterion of truth and reality. 
one another. The universal in the form of a world refers to diversity of content within every member, as the universal in the form of a class neglects it. Such a diversity recognised as a unity, a macrocosm constituted by microcosms, ${ }^{1}$ is the type of the "concrete/universal."

1 It is the opinion of distinguished recent thinkers that in such a macrocosm the numbers of microcosms may be actually endless, and that, within every microcosm the complexity of detail may be endless also (see e.g. Taylor, Elements of Metaphysic, bk. xi., ii. 5 and iv. Io). I cannot understand how this is compatible with the determinate self-containedness of a truly infinite whole, unless we are speaking of appearances, such as space and time, which through their imperfection suggest an endless series. Could the solution of our difference lie here? viz., that a true infinite gives rise to an appearance of endless variety in so far as it is interpreted exclusively through characteristics inadequate to the whole? Cf. Appearance and Reality, p. 290, "In its isolation as a phenomenon Nature is both finite and infinite, and so proclaims itself untrue." It is almost as if you were always losing your place in a book and so reading its pages ad infinitum in different combinations, with some repetition. Cf. Logic, 2nd ed., i. I63. You never get out of the series, because you never get nearer the whole. But the important matter, on which as I understand we are agreed, is that even if the true infinite include endlessness, yet endlessness is not enough to constitute a true infinite.

And, though incompetent to estimate the doctrine of self-representative series I may venture a remark, which seems to me relevant, on the tendency to take it as a type of infinity. It is so taken, as I gather, not because of its endlessness, but because of its self-determination. Well and good; let it be granted that proper parts similar to the whole constitute self-representation. But in truly typical infinite wholes, the self-representation is present in a way curiously analogous to that involved in the series in question, but characteristically different. In a sense, the differentiated organ or spiritual element of a true infinite does contain or repeat the structure of the whole, not, however, by a one-to-one correspondence of terms, but by a differentiated response to organic necessities. A great country does not represent itself by mapping itself on a portion of its surface, but by developing, say, a university at one point, a church at another, a manufacturing town at a third. All these are proper parts repeating the whole structure of the whole, and a good deal could be done to show in detail how this is true. But it would not, of course, be a one-to-one correspondence of terms. A mind, again, does not represent itself by thinking over its thoughts ad infinitum, but by the varied "thought, word, and deed" in each and all of which its nature becomes incarnate. 
The recognition of this logical form as the true type of universality is the key to all sound philosophy. It is possible, indeed, that even in face of such a recognition those philosophers may prove to hold the more suitable language who deny that thought can ever be one with the real. But at any rate, we are bound to follow thought as it obviously develops itself towards a higher vitality and a fuller perfection, in the certainty that if it is itself a vanishing form, it will point us the way to what lies beyond, and when necessary, introduce us to its nature. We may be told that there are other sides of experience to be developed, and we must not assume that by following the development of thought we are on the road to perfection. A warning like this sounds well before we have begun to feel the pulse of experience at all ; but it really rests on the false pre-supposition that we have different minds in different activities of mind. If we view experience bona fide, and follow where its connections lead us, noting the relation of incompleteness to completeness in all the responses of mind, it does not matter from what point we start. It is like going up a hill; you only need to keep ascending, and you must reach the top. You cannot study thought and not be led to will and feeling, nor will or feeling and not be led back to thought.

The concrete universal may be contrasted with the general rule as a centre of radii compared with a superficial area. The test of universality which it imposes is not the number of subjects which share

In both cases what might be serial protrusions are turned back into self-contained organs, and what would, if unsatisfied, set up an endlessness, if satisfied, finds a home to rest in, and maintains its whole "chez soi." 
a common predicate, but rather than this, the number of predicates ${ }^{1}$ that can be attached to a single subject. It is the degree in which a systematic identity subordinates diversity to itself, or, more truly, reveals itself as the spirit of communion and totality, within which identity and difference are distinguishable but inseparable points of view. The account of a judgment whose subject is a proper name, in Mr. Bradley's, ${ }^{2}$ or any similar Logic, is a good introduction to what is meant by a concrete universal. $^{3}$

and is one with the Individual. Why trust the nisus towards a cosmos?

3. We said that the key to all sound philosophy lies in taking the concrete universal, that is, the individual, as the true type of universality. We are often told that the individual cannot be made by a combination of universals. ${ }^{4}$ It is true that it cannot be made by a combination of generalities, but the reason is that it is itself the superior and the only true type of universal.

But, it may be objected, assuming that this is so, that the tendency of experience to carry us from one step to another is universality, and that such a tendency in its fulfilment leads us not to general rules, but to a construction of macrocosm and

1 The expression serves to explain the general nature of the contrast. It is not meant that number is a real test, though it may be a consequence, of richness and completeness of being.

2 Principles of Logic, p. 6r.

3 The universal, as possessed by the mind, is essentially a system or habit of self-adjusting response or reaction, whether automatic or in thought, over a certain range of stimulation. An acquired skill such as that of a cricketer, is a good example. Thus resemblance is quite an inadequate category for it. It deals quite equally with difference. So that I cannot at all accept Mr. Lindsay's dictum in his work on Bergson, p. 228. "The difference (between $A$ and $A^{\prime}$ in induction) must for our purpose be ignored." Adjustment to the difference is the whole point. See author's Logic, 2 nd ed., ii. I 84.

4 E.g. Schiller, Humanism, I 23-6. 
microcosms, why, nevertheless, should we respect this result? Why should we consider that the structure so developed partakes of being and of trueness, as Plato might tell us, and is something more than a castle in Spain?

The argument courted by such an objection must always be the same in essence, but may begin from either end of the process which it analyses.

(I) It may point out, on the one hand, that to doubt is to assert a ground for doubting, and that the tendency of the logical progression, however far from fulfilment, is "to leave no room for doubt"; that is to say, to organise experience in such a way that at whatever point you may try to pick up a positive content and push it against the system, you will be shown that the effort is anticipated, and only takes you back into the system itself. This is to appeal to the principle that truth or reality is the whole. According to this, the reason why you cannot contradict the truth is that it leaves outside it no $\pi \hat{v} \sigma \tau \hat{\omega}$ on which a contradiction could be "grounded." We shall in effect be illustrating this point when we deal below with the power of the concrete universal - its capacity in the way of unifying experience. I may, however, be permitted to adduce an elementary example of the process and principle I have in mind.

How could a competent astronomer meet the doubt expressed by a child, whether in a first or second childhood, who should deny en bloc the revelations of astronomy, and who should say that the Sun and Stars were in fact-here would come his difficulty, but, let us suppose him to urge,-just about what they look like to the naked eye? I take

The whole is truth. 
it that so long as the doubt remained indefinite it would not be possible to deal with it directly. You cannot force such a sceptic to follow a scientific construction. The doubter, even if a child, is already aware that there is some kind of method which professes to get step by step to the result which he distrusts. It is just this method which his indefinite doubt refuses to follow. To him it is all artificial talk, which he cannot see any point in. He refuses to believe that you can go from step to step in the mode which science adopts. His doubt, if arrested at this point, amounts to refusing to commit himself, and defying the astronomer to draw him on beyond the mere momentary spectacle of the heavens. It is the scepticism which, if consistent, would be inert and dumb.

A doubt of this type has no material ground against the system of experience. It has, perhaps, a certain prima facie formal ground, in the immense apparent interval between first appearances and the results of science. But this, again, unless formulated, is no ground at all; and if formulated would stand on the same basis as any material allegation against the system of science.

Now if the doubter makes a positive allegation, whether material or formal, in support of his scepticism, then at once he is lost. If you say, the sun is a lantern, lit up every morning and put out at night, or the stars are holes in a sort of dish cover, through which the light beyond shines through, then, I presume, the competent astronomer has you in his power. You have given a rival interpretation of the appearances. You have picked up a fragment of experience which you are attempting to 
push against the system of sciences, a something which you treat as outside it and as thus destroying its universality. In doing so, however, you acknowledge universality as the test; you are no longer rejecting the system in toto, but are calling upon it to alter itself, and admit your interpretation into its texture. But, so far as it is the whole, the system can reply: "We know all that already; we already possess your interpretation, but in a shape which effects the object implied in every interpretation of appearances, which, in the shape you gave it, it failed to do. You wanted, of course, to connect your vision of the starry heavens with other experiences and ideas so as to express what it was for you in the completest way. But we possess the experiences which you used for that purpose, together with an enormous mass of others. And we can show you that by using them as you did it is impossible to attain the complete expression you desired, because in that way they cannot be united with the full appearances in question, or with the mass of other experience. On the other hand, we can show you a set of connections which will at all events draw out the nature of your experience very much more completely and in far greater union with the rest of experience. We can show you that you were only attempting imperfectly and in confusion what is here, at least comparatively, perfect and complete." The main line of the argument is familiar from Plato downwards. But I have modified it so as to emphasise that side of its implication which consists in the principle that "the truth may be defined as the whole." The whole is the truth, because if you doubt indefinitely you advance nothing against it ; 
if you attempt to push forward a contrary, you agree that "something is," and you can be shown that your something is already contained in the system against which you have advanced it.

Non-contradiction involves a world or whole.

But (2) we may begin at the other end of the process, and analyse its inmost nature under the head of the criterion. I am not introducing this subject for its own logical interest, but merely, in the treatment of the concrete universal, to point out that the appeal to "the whole" is not a detached or arbitrary procedure, but the same thing with the principle otherwise known as the principle of noncontradiction.

The essence of the matter, as I understand it, is simply the determinate development of the character of being. We have the inevitable line of thought definitely traced in Plato-in almost any of the great dialogues, and still more strikingly and fundamentally in the whole evolution of his logical theory taken together. And we have it, if with defective detail, yet substantially on an incontrovertible basis, in Hegel's Dialectic. I will venture to state it in a few plain sentences. What is, is by determinate self-maintenance. There is no meaning in "it is" apart from "it is what it is." It acts, or possesses predicates, and its action or its predicates are "what it is." Now there is a sound sense, as Plato is careful to explain, in which "is" and "is not" can and must be united in the determination of the same content. But in as far as "is" affirms a certain determinate self-maintenance and "is not" affirms a different one, or the character of otherness in general, so far to attach the two as predicates to the same point of being is to allege that in its self- 
maintenance it fails to maintain itself. This is so far to destroy the character of being as an expression for any positive experience. It is to posit and to annul in the same act. In so far then, as an experience presents an appearance of this kind, a combination of "is" and "is not" (or "is other") without any distinction in the subject of affirmations, it falls short of the character of being. We cannot hold that "it is" in the strict sense of the term. It undoes itself; and fails to conserve itself in any actual character. In as far, on the other hand, as the appearance of hostility to self is removed, by transforming the content of experience in question into what is relatively a system, such as to accept. both this and the other as co-operative and no longer conflicting members, the experience " is" in a higher degree; its self-maintenance includes more of reality; and is pro tanto less likely to be confronted with external facts beyond its power to assimilate. This is the process which Plato indicates in Republic. v. Everyday experience, he says in effect, tumbles backwards and forwards between "is" and "is not." To-day a thing is experienced as beautiful, to-morrow, in another light or in another mood, as ugly. This minute we pronounce a thing large; the next minute we have turned to compare it with something else, and we pronounce it small. This is because the beauty we judge by in the first case, and the magnitude we judge by in the second, are fragments and not worlds. If the one judgment were adequately grounded, i.e. included the right conditions and were guarded by the right distinctions, it could not so lightly, and ultimately it could not at all, pass 
over into its contrary. There would still be beauty and ugliness, largeness and smallness, but they would be differents and not contraries. They would not both be predicated, without ground or reservation, of the same subject. When we know what beauty fully means, and have found it in a world of our experience, then, in proportion to the extent and coherence of that world as an inclusive content, it is hard for any change of temper or of surroundings to make us say "it is ugly."

What we have been describing is in other words the self-maintenance or self-assertion of the universal. The universal is just that character of experience which overcomes the "is not" by reducing it to an element harmonious with and corroborative of the "is." It is "the self in the other."

When, therefore, we say that the criterion of truth and of reality is one, and is the character of noncontradiction, this assertion rests on the general nature of experience as outlined above, and more particularly on its nature as universal. And we can see that we are thus experiencing, as it were from the other end, the same principle which in its results revealed itself as the concrete universal. For, as we have just observed, the removal of contradiction involves the character of a "world"; and this character we must ascribe to Plato's áyató $\nu$ and, in ultimate interpretation, to Kant's Noumenon, to every principle in fact which seriously aspires to express the full nature of being.

It is often thought that the criterion should belong to a special class of principles which are distinguished by the peculiarity that they cannot be denied without being affirmed by the denial. Such 
a principle, it may be said, is expressed by the assertion that there is a self-consistent reality; for to say that there is no self-consistent reality (or even that reality need not be self-consistent) implies a degree of insight into the nature of things and the conditions of true assertion regarding it, which in turn involves as its basis the postulate of a reality with a coherent nature of its own-the very principle intended to be denied. An obvious case of the kind, again, is the affirmation that every judgment lays claim to truth; for no disclaimer of the pretension to truth can be framed which has not as a main part of its content the claim to embody a truth-the truth of the disclaimer.

It is true that in the case of principles thus expressed the absurdity of denying the significant law of Identity - the proposition that statements true of reality can be made-reveals itself "within the compass of a lady's ring." But it is a mistake, I suggest, to regard these as logically peculiar cases -case of a priori truth-and therefore to rely wholly on the formal refutation of scepticism which they seem to afford, neglecting the fuller account of noncontradiction, as the principle of the "more" of positive experience and of its self-maintenance, which was drawn out in the last paragraph.

For the impossibility of being denied, without eo ipso being affirmed, which characterises these very simple propositions, only attaches to them in consequence of the extreme emptiness of experience in so far as they appeal to it. For, so far, a proposition implying any possibility at all of a stable experience, even if negative in form, is sufficient to establish all that such principles as these formally 
contend for, which amounts in one shape or another, to no more than the reality of some persistent or objective experience. In a word, if you say anything, in the indicative mood, it commits you to the affirmation of a something; and this is why even the formula "there is nothing," strictly taken, must involve the affirmation of an objective world.

But it is a mistake, so far as I can see, to treat this apparently immediate certainty, which is at bottom equivalent to the abstraction "something is," as superior in logical value to the certainty of any well-established world of concrete experience, although in a purely formal sense the latter may seem to be at a disadvantage, i.e. to be incapable of being formulated as a content of a priori truth. For the apparent disadvantage arises precisely from the fact that here, where we appeal to an advanced phase of the construction of experience, it is prima facie conceivable that any particular elements of the concrete world, however closely knit up with the whole, might be denied in the precise context which they claim, and yet leave standing the world to which they immediately belong. While in the case of the formal principles, to which that of non-contradiction in its abstract shape belongs, if their content could be removed or destroyed by denial, then the whole world would be gone-no content at all would be left to experience. And therefore, because even denial, as we have seen, implies a real something, we say that in denying these principles we inevitably reaffirm them; that is, we affirm a something, which (so deficient in multiplicity is the content of experience to which they appeal) is necessarily one with the affirmation of 
them in their abstract shape. If you say "there is nothing," you assert that there is something ; if you say "there is no truth" you are proclaiming that there is this truth at least; if you say, "contradictory assertions may both be true" - you are asserting the notion of truth which the nexus of your proposition destroys. In other words, when thinking of experience under these general characteristics, e.g. that $\mathrm{A}$ is $\mathrm{A}$, we can deny none of them, because if we deny at all we deny everything; and that is an attempt which even the form of negative assertion suffices to frustrate.

But this distinction, which seems to confer a special guarantee upon principles of the type in question, is in truth merely apparent, and due to our insufficient perception of logical context. For the proof of everything that is proved is ultimately one and the same, namely, that if it is to be denied, nothing can be affirmed. And as it is impossible to deny everything, a proposition so guaranteed must be allowed to stand. Now a certainty thus grounded is really and in the spirit of logic greater in proportion as the whole of experience is fuller and more coherent; for the difficulty of denying everything obviously becomes enhanced as everything becomes a more completely apprehended cosmos with a fuller self-maintenance. But the distinction in favour of the principles whose denial directly affirms them arises in the following way. Though the certainty of experience as a whole grows with its completeness and organisation, yet the power to claim that certainty as guaranteeing particular propositions in any precise and literal form, is diminished by the same cause as that which 
increases the certainty of experience as a whole, that is to say, its diversity and comprehensiveness. For however sound we may hold a special proof to be, it must remain prima facie possible in an advanced stage of experience to deny the precise and literal assertion made by any single and so to speak departmental proposition, and yet to leave standing, apparently untouched, a large proportion of organised experience. The resources in the way of certainty are immensely greater, but become $e 0$ ipso much more difficult to use.

Yet to a great extent this difficulty is illusory; and if we choose as necessary propositions of advanced experience those which indicate vital functions or whole departments of our world rather than those which specify precise and literal fact, we can realise and make available the greater certainty which attaches to a full content of knowledge as compared with any abstract content whatever. We cannot stake our whole belief in reality on the literal and exact formulation even of such principles as the Law of Gravitation, the principle of the Conservation of Energy, the existence of God, still less of special conclusions in the special sciences. But we can and do stake it on the general "trueness and being" of whole provinces of advanced experience, such as religion, or morality, or the world of beauty and of science. And these are a higher and deeper evidence of the being and nature of the real than are the formally undeniable judgments, undeniable because implying only the minimum of experience, to which the abstract shape of the principle of noncontradiction belongs.

The above argument amounts to denying the 
distinction between necessary and contingent truth - truth the denial of which involves a self-contradiction, and truth the denial of which is only a contradiction when seen in its connection with other parts of experience. The test of the inconceivability of the contradictory, ${ }^{1}$ if rightly understood, applies alike to both these classes of truths. I am sure that, for the reasons above stated, Leibniz' extraordinarily vraisemblable defence of the distinction cannot ultimately be maintained. Every true proposition is so in the last resort because its contradictory is not conceivable in harmony with the whole of experience; in other words, is not merely a contradiction of fact but a self-contradiction. This is easily seen, if we fill in its $\mathrm{S}$ and $\mathrm{P}$ as the rest of experience determines them. ${ }^{2}$

And further, when we take this point of view, the fuller ranges of experience with reference to which we say that the truth is the whole, reveal themselves as not separate in kind, but as a further confirmation and manifestation, in its complete growth and maturity, of the truth which in its undifferentiated form presents itself in abstract principles such that their denial involves their affirmation. So-called "contingent" truth might in this sense be held truer and more fundamental

1 The inconceivability of the contrary, in the strict sense, would not establish any truth. Two contrary propositions may both be false.

2 E.g. "Beauty [which we are referring to as an accepted experience] is not a reality." This is in principle of the same type as "there is no truth," though a shade less directly self-contradictory, because you might formally deny the being of beauty and yet leave other reality standing, whereas the second proposition would not leave even itself standing. But you could not substantially deny the reality of beauty and yet leave experience standing, and therefore the denial is substantially self-contradictory. 
than what passes as "necessary," just as secondary qualities may in some sense be held more real and fundamental than primary. The law of contradiction might still hold its formal place if there were no such thing as beauty or organised knowledge or social life or religion, but the guarantee of its necessity, the difficulty of accepting the alternative of believing in nothing, would be very considerably weakened.

Truth or the whole as noncontradiction or satisfaction. What whole?

4. Having now connected the concrete universal with the abstract form of the principle of non-contradiction, and shown that the conception of truth as "the whole" is a realisation and embodiment of the latter, we might pursue the consideration of the concrete universal as the clue to Individuality. \&

But before proceeding with our subject, there is a possible misconception which must be met.

If you take the principle of non-contradiction, or of the whole, as criterion, it may be said, you can get out of it no distinction between truth, goodness, and beauty, and you leave it to be supposed that all satisfaction of the need for harmony is of the same type; and that truth and beauty are simply names for what suits us and makes our experience satisfactory. Truth and beauty would therefore collapse into one under the heading of the good and would be undistinguishable from whatever is found felicitously subservient to practice. This is what a Pragmatist might say. And the first and general answer would be, that the principle of the concrete universal does apply to all types of experience, and that alike in knowledge, in life, and in enjoyment it is the harmoniously concrete which is the higher and the more real. And the meaning of this is, 
that in none of the three aspects can the self as it happens to be serve as a test of reality. In following the law of the universal, it must transmute itself and undergo expansion and correction, obeying the necessity imposed by the real, with which it aims to be, but as given is not, at one. This is enough to dispose of the essential contention of the Pragmatist, the point of which lies in a confusing truth with goodness, and $\beta$ reducing the goodness, so made ultimate standard, to the satisfaction ${ }^{1}$ of the given self.

The essential notion of reality as a spring of adjustment in the self is incompatible with this doctrine, whatever form of experience we contemplate.

But the further answer is that (not only is there in all approach to reality an adjustment of the self, but the adjustment takes different forms according to the function of the self which is in play. The question is simply whether the nature of things can interest us for its own sake, apart from the concrete endeavour to transform our lives and their world. When once the conception of a world which possesses being beyond our own has distinguished itself from the tentative endeavour to supply ourl wants, it seems inevitable that we should be interested in such a world purely from the point of view of what it is, if only because we have the idea of it, which necessarily aspires to complete itself. As to the facts, Mr. Bradley's ${ }^{2}$ criticism of Bain's

1 Whether this is admitted by Pragmatism or not, I will commit myself to saying that all we want either to overthrow the latter, or to make it a truism, is to be allowed to argue upon the nature and conditions of satisfaction.

2 Principles of Logic, p. $18 \mathrm{ff}$. 
doctrine of practice and belief deals sufficiently with them, and has not, to my knowledge, met with an answer. Not all truth is subordinate to practice, or has, as sought for and held, any connection with practice at all. ${ }^{1}$ In a word, in all our functions, "theoretical," "practical," and "contemplative," we seek or accept real reality, and we never entertain a thought of modifying it. If, therefore, a neglect of the distinction were inevitable-if all forms of selfexpression must be ranked together either as "vision" or as "action"-the old point of view which makes $\theta \epsilon \omega \rho i a$ the truest and highest $\pi \rho \hat{a} \xi \iota s$. would be preferable to subordinating truth to "action" in the sense of change. But there is no reason for confounding plain distinctions either in one direction or in the other.

The concrete universal embodies the nisus of thought to individuality.

5. We now return to the concrete universal as a clug to individuality. We are regarding it, in general as the type of complete experience, and from this point of view its characteristics are the same whether we think of it as the object of knowledge, of will, or of enjoyment.

In the first place, then, we have to meet the common contention that our thought is purely discursive, and is therefore unable so much as to approach to the type of self-contained reality. It almost seems at times that in speaking about thought different philosophers have not the same experience in mind. ${ }^{2}$ The tradition of the British school, start-

1 If, that is, "practice" is to be distinguished as one type of the satisfaction of a conation. Truth is, of course, a satisfaction of a conation; one hardly likes to suggest that there has been drawn from this fact a simply and directly fallacious inference. But the example of Hedonism warrants the opinion that even in expert controversy the sine qua non may be confused with the essence.

2 Ward, Naturalism and Agnosticism, ii. 282. Bergson, p. 32 above. 
ing from a theory for which thought is decaying sense, is corroborated by the modern analysis according to which thought is an abstracting and generalising faculty, and science a departure from factual experience. ${ }^{1}$ To some extent, as we saw, this view is justified by the primary character of abstract science; to some extent also it must be admitted that the contents of sense-perception are not transparent to finite thought, and so far it is a linking and transition between contents which are not a unity for it. The double aspect of finite life constitutes here, as everywhere, the difficulty and interest of philosophy. For, on the other hand, it has been urged, and we feel, that $<$ it is thought which constructs and sustains the fabric of experience, and that it is thought-determinations which invest even sense-perception with its value and its meaning. It is only in part, then, that our thought is discursive; it has also an intuitive aspect, in which it remains, within itself, secure in the great structures of its creation. The ultimate tendency of thought, we have seen, is not to generalise, but to constitute a world. ${ }^{2}$ It is true that it presses beyond the given, following the "what" beyond the limits of the "that." But it is also true that in following the "what" it tends $y^{e}$ always to return to a fuller "that." If its impulse is away from the given, it is towards the wholethe world. And as constituting a world it tends to return to the full depth and roundness of experience from which its first step was to depart. In a

1 See R. L. Nettleship in Biography of Green, i. I $8 \mathrm{ff}$; and Logic Lectures, Remains, i. 173; Green in review of John Caird, Works, iii. 142 ; cf. Bradley, Logic, p. 92.

2 This is so even in Induction. The aspect of generalisation even here is quite subordinate. See author's Logic, 2 nd ed., ii. r $74 \mathrm{ff}$. 
$\zeta$ "world," a "concrete universal," we do not lose directness and significance as we depart from primary experience; on the contrary, every detail has gained incalculably in vividness and in meaning, by reason of the intricate interpretation and interconnection, through which thought has developed its possibilities of "being." The watchword of concrete thinking is "Philosophiren ist dephlegmatisiren, vivificiren." "A second of time obeys different laws of proportion according as it is an element in an hour, in a musical phrase, or in an act of forbearance respectively. In Plato's language, it gets more 'determined' at each step; it remains the same itself, but it acquires new significance, and is linked to larger issues." 1

* Following this clue, we shll be inclined ${ }_{n}$ see in thought the principle of concreteness rather than of abstraction, and recognise the highest truth or reality of which thought is capable in the fullest experience, the most self-contained world which finite minds can attain to from any given point. It is fully admitted that no absolutely self-contained experience is accessible to finite intelligences, and that therefore they must always be on one side discursive. On the other hand, so far as a difference between the less and the more true or real is within our horizon at all, it is by this standard - the standard of wholeness or self-containedness, fwhich unites with the principle of non-contradiction in the characteristic of logical stability, ${ }^{2}$ that the difference must be estimated. And, in so far as this estimate can be made, it involves a character in which thought is at home with itself, and is not driven from pillar to

1 Nettleship, Remains, i. 329.

2 See above, p. 46. 
post to make its fortune. All students are familiar with Mr. Bradley's criticism of the "thing" and the "self," the apprehension of beauty, and even the moral and religious consciousness. It is fully in the spirit of Plato, ${ }^{1}$ and original and brilliant as it is in detailed execution, the reception of it by philosophical opinion, as if it introduced a principle new and unheard of in Idealism, has always been to me a source of the greatest amazement. It is plain, even if it were not plainly stated, that the possibility of estimating the comparative remoteness of these experiences from the Absolute implies in them, on the other hand, positive degrees of the character which constitutes reality, and which I have ventured to identify with logical stability. In as far as such types of experience take the form of self-centred worlds we may adopt them as examples of what we mean by the concrete universal, in which the aspiration of all experience to be a whole partially comes to its rights. Only, in as far as they partake of such a character, I hardly see how we can deny to them an aspect in which thought is at home with itself in reality, and assumes the attitude of an intuitive understanding.

We may take as an example a work of art. ${ }^{2}$ This is an object in which we can realise what the Greeks meant by Theoria. In its essence, as a thing of beauty, and neglecting its aspect as a physical object or movement, it is self-contained and a true whole, possessing its significance in itself, and

1 Cf., for example, on the self, the monster simile in Rep. ix., and the condemnation of the phenomenal soul in $x . ;$ and on the finite perception of beauty the well-known place Symposium, 2 I o e.

2 Here I am glad to have Professor Taylor with me, at least in some degree. See Elements of Metaphysic, pp. 32-3. 
not driving our thought beyond it to a detached meaning and explanation. Every point in it carries the burden, or lives with the life, of the whole. Of course its unity and independence are imperfect, ${ }^{1}$ but that makes no difference when we once understand that we are talking about matters of degree within finite experience. The point to be grasped is simply the contrast between the relation of abstract generalisation on the one hand, and of concrete modes of thinking on the other, to completeness of experience. In the latter we see the return to the fulness of experience which thought in the former appeared to abandon. Pursuing the same law or principle-the removal of contradiction-the mind tends to arrive at experience incomparably more living and intense, as also incomparably more logical and rational, than that of every-day perception. The true office of thought, we begin to see, is to build up, to inspire with meaning, to intensify, to "vivify." The object which thought in the true sense has worked upon is not a relic of decaying sense, but is a living world, analogous to a perception of the beautiful, in which every thought-determination adds fresh point and deeper bearing to every element of the whole. We may think of a great business organisation, the economic life of a great city, the moral life of a society, as seen by the casual observer, as subjected to general formulae by the statistical investigator, or as grasped by an active participant, who is also a student, ${ }^{2}$ familiar with all its aspects, and competent to realise the relation of its purposes to their expression. The

1 Appearance, 2nd ed., p. 465.

2 Contrast the assumption that dualism is inevitable. Ward on business and the looker-on, Naturalism and Agnosticism, ii. I33-4. 
more concrete knowledge is the more vital for being methodically precise, and more precise for being more intimately vital, just as the touch of a painter or a musician depends for its vital value on its extraordinary quantitative and qualitative accuracy, which it owes in turn to the dominating sense of the whole. Logical exactitude in the full and true sense is not a deadening but a vitalising quality. Form, interdependence, significance, self-completeness are characters as of thought at its best, so of vitality at its highest. This is the general character by which the concrete universal gives us the clue to the individual. We will further draw it out in three closely-connected relations. Thought, we are insisting, is not a separate faculty of something known as the intelligence. It is the active form of totality, present in all and every experience of a rational being-perhaps, in a degree, in every experience in the universe.

6. When thought is pronounced purely discur- The sive, and so contrasted as secondary and extraneous $\underset{\text { nualism }}{\text { neglignt }}$ with immediate experience and activity, it is being ${ }_{\text {cant be }}^{\text {mund }}$ opposed, I imagine, to the content of sensation, to overcome the living force of will, and to the immediacy and ciple. interest of feeling. On all of these oppositions the conception of the concrete universal can throw some light, though it cannot abolish a distinction of aspects, characteristic of the finite mind, and necessary to the richness of experience. On these matters altogether it seems worth while to remark that, if philosophy is to make any definite advance, it must make an effort to get behind the old idea of the irreducible dualism involved in man's nature as at once spiritual and animal. It is very easy to be 
in a hurry, and say "of course thought cannot see through the differences of the sensuous world, or play a part in feeling or volition other than that of the reflective onlooker; how can we possibly exhibit the distinctions of green and red, of love and hate, of choice and refusal, as operations of the intelligence? Therefore thought is purely discursive, and has to accept its matter from elsewhere, and experience can never be a whole." And it is no less easy to say, "Man in ideal experience must become purely spiritual; and thought must find its completion, if it is to be homogeneous, apart from the world of sense, of feeling or of action." But the task of philosophy is just to have the care and patience necessary to disentangling and estimating the signs and media by which man's animal nature gives utterance to his spiritual being, and without which our ideas of his perfection, imperfect as they are, would be more imperfect still.

/ I will say a word on the nature of thought in general, and then point out its participation in the forms of experience which are held to be most alien to it.

The nature of thinking is not exhausted in the abstract reflective judgment or course of inference. Its essence lies in the passage of a being or content beyond itself, in a word, ideality, adjustment, or the universal. It is one, therefore, with the experience of freedom. "He who talks of freedom, and excludes thought, knows not what he says." ${ }^{1}$ The identity of the two conceptions lies in the transformation of the alien into the kindred, the affirmation of self in and through the other. Where we

1 Hegel's Gesch. d. Philosophie, iii. 477, Eng. Trans. iii. 40 I. 
have this, we have the essence of thought, and it is easy to see that we have it in the higher phases of all finite experience, sentient, emotional, conative, as well as cognitive. The characteristic embodiments of thought within finite life are-knowledge (including sense-perception), love, and work or activity.

i. It is true prima facie that the contents of Sensation sense-perception are not transparent to thought. become As such and by themselves they cannot be defined $;{ }^{1}$ to thought. they cannot be brought as members into an intelligible system. They are not objects in which reason can by logical process recognise its own nature, as it can in life and purpose, and even in mechanical connections. This is prima facie true, but it is not the whole truth, and it just misses the fundamental principle.

The contents of sense-perception, like everything else, reveal a new character in becoming elements of a new whole. Although, like everything else, undefinable in their minimum significance, they acquire in fresh combinations fresh meanings, which must be rooted in what they are. And it would not be justifiable to suppose that the contents of sense, in the actual context in which we apprehend them, are devoid of meaning in which their nature has been drawn out and rendered explicit by contrast and relation. It is certain that they speak to us, that they convey meanings to our complex nature as a whole, though it is true that our thought must fail to interpret adequately in other language what they have to say.

1 But then this is really true of every term. Definition is always in principle further determination. 
The strongest case of this enhanced significance is no doubt in the world of beauty. For the thought which has become expert in this world, such media as sound, colour, form, rhythm, and metre have undoubtedly a logic and a necessity of their own. The universal-the straining towards the whole-is in them as in all experience; and it is idle to deny their constructive and creative nisus the name of thinking, because it does not operate through what we call par excellence logical language and conceptions attached to words. The rhythm that completes a rhythm, the sound that with other sounds satisfies the educated ear, the colour that is demanded by a colour-scheme, are I take it as necessary and as rational as the conclusion of a syllogism. ${ }^{1}$

1 Some reference to this characteristic may include or at least may illustrate the idea that to know the conditions of occurrence of a sensation is one with and supersedes the presentation of the sensuous element itself. There seem to be two directions in which such a suggestion might be interpreted. It might mean a restriction of reality to an intelligible world, after the fashion of Plato's forms as commonly understood, implying that sensation is a nullity and a matter of indifference; or it might imply that

1 Nettleship, Remains, i. 178, "To say that a combination of two tones is musically wrong is to say that 'I cannot, consistently with the law or principles of musical thinking, conceive or hold together those two tones.' To sum up then, each sort of object has its own laws, and each such law is a law of conception." Cf. Whistler's Life, i. I 85. A visitor to Whistler's studio remarked that the upright line in the panelling of the wall was wrong . . . adding "of course, it's a matter of taste." To which Whistler replied . . . "remember, so that you may not make the mistake again, it's not a matter of taste at all, it's a matter of knowledge." I do not say he was precisely right but he was right as implying a necessity of the type of rational necessity. 
sensation can become so transparent to thought, so definitely absorbed in expressiveness, that its contingent and unintelligible character is done away, and it becomes a revelation undistinguishable from, though involving a special perfection in, the meaning which it expresses. Something of this kind we can almost conceive, when we think of the highest moods of aesthetically creative sympathy. And according to the principle on which I shall later have to insist, it is from these fullest experiences that our clues should be sought, if we desire to apprehend how life can most nearly approach perfection. "Colour," it has been said, "is a "spirit upon things by which they become expressive to the spirit." ${ }^{1}$ And we see that in a concrete universal there may be a beginning of a transfiguration of sense which at a higher level would remove the alienation between sense and thought. It is always an illusion, more or less, to think that you can remove the expression, and leave the meaning. It is like thinking that we should lose nothing of a friend's personality if we were never to hear his voice again. If all sensation became to us like the tones of a voice we know, or the touch of a hand we love, we should realise the inseparability of the symbol and the symbolised. ${ }^{2}$

ii. We have also, in claiming any higher status Thought is for thought, to meet the current idea of its relation the life of to feeling. The same antagonism which common

1 Pater, Essays on the Renaissance, 2nd ed., p. 63. The passage is very relevant.

2 Compare the idea, often suggested, that in music we unconsciously hear the numerical relations of the vibrations which underlie the sounds. This is no doubt overstrained; but in the arts which appeal to sight we certainly are affected in this way by underlying proportions which condition the whole effect. 
sense is apt to find between thought and sentient experience, rooted in the same ideas of abstraction and of decaying sense, it also emphatically finds between thought and feeling, whether feeling is taken in the sense of immediate psychical being, of emotion towards an object, or of pleasure and pain.

In all these respects the experience of aesthetic enjoyment may again serve as a type. If there could be a Hedonistic standard of excellence, it would be of an analogous nature to the degree of aesthetic enjoyment. For here the feeling is necessarily and notably one with and proportional to certain determinate attributes of the object. And though we are not prepared to reduce the "higher" pleasure to the "greater" one, and therefore cannot attach ourselves to Hedonism, yet it is true that in the aesthetic object there is something which characterises the feeling responsive to it in a way susceptible of objective valuation, though not necessarily of valuation in terms of pleasurableness. As with sensation, so with emotion or pleasure-pain, it is the concrete universal that draws them out of their blankness and exhibits them as aspects of the difference made to a living world by contents in which it is affirmed or negated ; and thus makes explicit the "more" and "greater" of which they are capable. It seems probable on the whole that Pleasurableness and Emotion vary in value directly and not inversely as the constructive achievement of thought on which they attend. We need only reflect for a moment on the greater works of art to see that this must be so. If, as may be the case, there is a specially concentrated intensity which goes with the blank 
formlessness of the fiercer pleasures and pains-a subject which Plato and Aristotle have thoroughly worked out-it is an intensity, which, however it may be explained, has in it relatively less and not more of "being and of trueness." It negates the expansion of the self, and in some way forces the whole to concentrate itself into what cannot contain it. We feel ourselves smothered in it, and driven into a cul de sac. ${ }^{1}$ In the kinds and degrees of love, as in those of pleasure-pain, we can see the difference made by approaching to the character of thoughtthe character of a harmonious world.

And even if we take feeling as immediate psychical being, the relation remains the same. All thought, no doubt, has a mediate side; but all concrete thought has become immediate no less than mediate. In fact, what the great philosophers meant by thought, the highest possible phase of realisation, is much what most people mean (so far as they grasp the notion of it at all) when they speak of feeling. ${ }^{2}$ For if we admit thought to be in part intuitive, a unity asserted through diversity, there is no longer anything to prevent it from reproducing the character of feeling in the sense of immediate apprehension; an immediate apprehension which is the totality of a mediate discourse. This is the sort of apprehension, which a name, familiar and adored, awakes in us.

iii. To act is to exhibit the same essential nature. Thought It is to go beyond the starting-point, and in going of freence beyond it, to remain at home. ${ }^{3}$ Both sides are activity. essential, and when either is absent, the full con-

1 Nettleship, Remains, i. 336 . I do not say it has no special claim to reality.

2 Nettleship, Biography of Green, p. I I 8.

3 Hegel, Rechts-Philosophie, Sect. 7. 
ception of activity is not realised. It will be pointed out below, that, if, as is alleged, the conception of causal interaction between spatial things originates in our personal sense of activity, it is a singularly unhappy piece of anthropomorphism, which has reacted most deplorably on the conception of its archetype. For causal activity, as we ascribe it to nature, is just what it is impossible for us to experience; and our own experience of activity is just what we cannot without utter confusion ascribe to natural things. No activity is "ours" in which we do not remain at home as well as go abroad; the mere effect of body upon body can never constitute an act of an originative being. To be active, in the sense in which we experience activity, means to be a "free cause" 1 and not a natural cause - that is to say, not to be a term in a succession, perceptible only to an observer, but to be a world which reshapes itself in virtue of its nature and that of its content, and, in doing so, extends its borders, and absorbs and stamps itself upon something that before seemed alien. If we want to interpret our experience of activity we should go to Leibniz and Spinoza, or to the more modern conception of a "free cause." And then we should find that without assimilating conation to cognition (except that cognition is, of course, a conation) we must recognise in all conation, as at least in all other finite experience, the essential character of thought.

It may be observed for the sake of clearness that not all thought is cognition, though all cognition is

1 Green, Prolegomena, sect. 77 ; and Joachim, Ethics of Spinoza, pp. 199-200. 
thought. Cognition is a conation determined by special interests and ideas; they are independent ideas, and not parasitic ; but the form of experience which they determine is not the complete and exclusive form of the unity which experience seeks. Their advantage as candidates for the place of sole end, or criterion of perfection-an advantage the undue assertion of which would constitute intellectualism-rests on the defective formulation of opposing views. Cognition at any rate emphatically exhibits that self-transcendent character of thought which constitutes its freedom and initiative. For these are essentially forms of adjustment and adaptation; they mean that there is an appearance of friction and antagonism which by the right kind of self-assertion can be transformed into responsiveness and co-operation. If the same character were fully recognised, as it might be, by the "activist," to coin an expression, and the voluntarist, in their account of the mainspring of experience, they might soon destroy the tendency to identify thinking with cognition. But if the champions of freedom and spontaneity insist on tearing up the roots of these very qualities, by making them in Spinoza's sense "passive"-that is to say, unconnected with adequacy of ideas to an objective situation; then there is liable to be a reaction towards finding in cognition those essentials of a free and active being which are denied by the advocates of will.

But neither extreme is inevitable; nor has either been adopted by Greek or modern Idealism. Will and activity mean the operation of the nature of thought through the expansion of ideas into fact; but are not confined to, though they include, that 
operation of certain special ideas which constitutes the province of cognition.

The goal 7. Thus by pursuing the conception of the logical of the Universal. universal we have arrived at the idea of something complete and self-contained, in which sensation becomes transparent and feeling becomes deter- minate. - ?

Individuality $=\mathrm{a}$ world selfcomplete.

i. This idea is the idea of the Individual, and Individuality is the ultimate completeness of that character of wholeness and non-contradiction which we first generalised under the name of logical 'stability. It is all one whether we make non-contradiction, wholeness, or Individuality our criterion of the ultimately real. What we mean by it is in each case the same; we mean that which must stand; that which has nothing without to set against it, and which is pure self-maintenance ${ }^{1}$ within.

Individuality, it has been said, has prima facie two extremes. An "atom" ${ }^{2}$ may claim it, on the ground that it is less than can be divided; a world may claim it, on the ground that its positive nature is ruined if anything is added or taken away. In the ultimate sense, the sense indicated above, it is common ground that there can only be one individual, and that, the individual, the Absolute. ${ }^{3}$

1 The purest self-maintenance must, in a sense, involve negation, though not contradiction, see Lect. VI. 3.

2 The atom, as incapable of organised self-maintenance, would really be the extreme opposite of the true individual._Appearance, and ed., p. 364. Cp. Leibniz on atoms versus monads.

3 We say then with Mr. Bradley, following, of course, Plato and Hegel, that the Individual, which as we have seen is the only true form of the universal, is the Real. The curious misconception through which this principle has been rejected by and maintained against Idealism has sprung from the negative or exclusive notion of the Individual. Thus Mr. Schiller's perfect Individual would be 
It is not, however, my primary object here to carry further the theory of the Absolute. My purpose is rather, accepting ultimate Individuality as the character which our fullest experience tends to approach, to draw conclusions as to the nature and position of the human beings to whom in a secondary sense we apply the term Individuals.

ii. The first and most important matter that the Individual argument leads me to insist on is this, that Indivi- is posiduality is essentially a positive conception. There unique, i.e. has his own has been far too great a tendency ${ }^{1}$ to state the quality. essence of Individuality not as the being oneself, but as the not being some one else. And in the Absolute no doubt these two sides must come together; in a perfect arrangement there can be no mere repetition, but in finite experience it is allimportant on which of the two we insist. Uniqueness as guaranteed by a negative relation to other series ${ }^{2}$ is one thing; as constituted by a profound or comprehensive content it is another thing. The one may descend to eccentricity; the other is in itself originality. Originality, within finite conditions, is not in principle excluded by agreement or even by a large measure of repetition. Its essence lies in the richness and completeness of a self, not in the non-existence of any other self approximating to it. The merely exclusive relation is in the first place purely formal, giving no clue to the content of the individuality; and in the next place, if insisted on, it tends to become dangerous. All that is true in it is

one of a multitude, say an angel. Humanism, p. 124, cf. Ritchie, Darwin and Hegel, i. Ioo, with the reference to Seth's Hegelianism and Personality.

1 Royce, i. 456-46o.

2 The guarantee can never be final, Bradley, Mind, lxxiv. I67. 
that individuals must be distinct ; to say that in every sense they are not each other soon becomes untrue: The individual is individual primarily because his own content is stable and self-contained; the ultimate individual has indeed no other individual to be distinguished from.

Individuality prior to purpose.

iii. The uniqueness which is made the mark of individuality is often stated in the form of uniqueness of purpose. We shall return to the subject of purpose when it is necessary to speak of teleology. But it is important to remark at this point that the conception of purpose shares the purely de facto character of negative individuality. A purpose, after all, is nothing but a want, or at most, a wanted object. $^{1} \quad$ It gives no guarantee of depth or value by being a purpose which only one being entertains. It is, moreover, something which cannot be ascribed to a timeless reality; and admitting that a timeless reality is a conception open to dispute, it is still the case that a purpose is nothing more in essence than a partial element of a logical whole which is (whether necessarily or not) drawn out in time. And there is no reason to expect that the part which at any moment remains unfulfilled and so presents itself as a "want"-a contradiction set up by the incompleteness of the world to which it belongs, is a matter of pre-eminent interest or value. In short, as a want in a finite mind a purpose may be "distinctive," but a higher quality of content, as representing a profound necessity of a highly organised world, would be needed to make it individual. It is not the de facto purpose, but the quality and comprehensiveness of the world

1 For the distinction see Green, Prolegomena, sect. 85. 
that sets the purpose, that makes or mars the individuality.

iv. The same set of contrasts appears in the The Indiconnection of individuality with infinity. vidual is infinite but

It has already been attempted ${ }^{1}$ to show that $\begin{gathered}\text { not a } \\ \text { series. }\end{gathered}$ recent investigations on the subject of infinity leave the distinction between self-completeness and endlessness, for philosophical purposes, where it was before. The individual, if our treatment of the problem has any justification, is characterised by self-containedness or self-completeness; and in- 1 cludes endless detail only in the sense in which any endeavour is endless which proceeds in the solution of a problem by a method demonstrably inadequate. To take a simple though all-important example; to know God in spatial extension or in a temporal series would be a task involving endlessness. ${ }^{2}$ And in as far as that which is to be known is a reality, and its nature - the nature of God or of the Absolute - inevitably when approached in a certain way gives rise to the endless procedure, it might even be affirmed that the endlessness was actually real. But this could not mean that the endless series was given. I note, indeed, that the infinite numbers of modern mathematics, are, so far as I can follow the account of them, not to be reached by enumeration. ${ }^{3}$ Their nature is rather that of a class concept involving an extension consisting of "all possible cases," which is practically left indefinite, although it is clear that there must

1 Page 38, footnote.

2 On the question whether infinite progression as such involves a contradiction see Review of McTaggart's Commentary on Hegel's Logic; Mind, January I 9 I I.

3 Russell, Principles of Mathematics, sect. 342 , ff. 
be a number corresponding to it. Attention has long ago been called to this characteristic of class concepts on purely logical ground $;^{1}$ and it would almost seem that here again we have a concept or definition that demands the completeness of a series, rather than a series that is actually complete.

We conclude, then, that the Individual is one in idea with the true infinite, and is the embodiment of the concrete universal, which-is the universal as asserting itself to the full through identity and through difference together. It is complete and coherent - characters whose connection is established by the relation above drawn out between wholeness and non-contradiction. And in the ultimate sense there can be only one Individual.

Is the

Spiritual inward?

The

"inward" not spatial nor mechanical.

8. To form a just estimate of what is involved in the nature of Individuality or the concrete universal, it is necessary to examine the common antithesis of inward and outward.

i. The Individual is one with the spiritual, and the characteristic of the spiritual in its proper nature is inwardness as opposed to externality. But it is important to interpret these terms correctly. The terms are evidently taken from the experience of the mind as aware of its own processes, in contrast with the character of space in which objects appear as outside one another. Méntal process is inward because its component phases are typically inseparable, although diverse. The possession of one carries with it that of the other.

Memory is inward because its diversity is bound up with the being of the mind; you cannot take the one and leave the other. Inwardness is diversity 
without dissociation. Matter is outward, because, as it seems, you can take part of it and leave part, without essentially modifying either. It would be untrue to say that the parts of space in no way presuppose each other; but prima facie the connection is not given within each, and spatial objects refuse to form a self or centre of experience, ${ }^{1}$ though they may be inconceivable without one. Such, in general, is the character of Nature, taken as independent non-psychical existence. It is, as thus hypostasised, the type of being most remote from spirit and from individuality. ${ }^{2}$

With the externality of Nature is bound up the conception of Mechanism. The essence of it is that the world consists of elements, complete in themselves, and yet determined in relation to elements beyond them. If not complete in themselves the elements would be at the mercy of the whole, and their claims to be its self-subsistent components would be gone. If not determined by others, the elements would not manifest even the appearance of entering into and constituting an orderly world. And yet, these two pretensions, the claim to have a nature of their own, or really to be, and the admission that they have their reality in a behaviour determined ab extra by relations, form when taken together, the crudest case of externality. The element behaves according to relations which connect it with the whole, but it has in itself a being -a purely physical or self-external existence-which possesses no communion with the whole. Thus its

1 See Timaeus, $52 \mathrm{c}$. It is plain that for a perfect apprehension there can be in this sense no externality.

2 Appearance, 2nd ed., p. $55^{2}$. 
behaviour is conceived as something betwixt and between; it does not refuse all response to the system in which it stands, but it responds, we might say, ignorantly and narrowly, "speaking when spoken to" but in no way showing a sympathy with its world beyond the definite reactions which answer, each to each, to particular solicitations. According to an old distinction, it acts according to law, and not from the idea of law. It pursues a routine, and takes no account of purpose.

True inwardness is outwardness absorbed.

ii. All this is the received account of the antithesis between the inward or spiritual and the outward or natural, ${ }^{1}$ which culminates in the opposition between spirit and extension; and between purposiveness and mechanism. It is, as I understand, when formulated by philosophy, a partly controversial and partly provisional account. That is to say, in the first place it reiterates from a hostile point of view the ideas of Naturalism, which means, those of uncritical metaphysic founding itself on conceptions current within the natural sciences. And in the next place it recognises that in the different types of our experience there is a certain prima facie justification for such distinctions, without admitting that they can contain ultimate truth.

My reason for drawing out the contrast of inward and outward at the present point, is to repudiate what I take to be a misapplication of it.

Inwardness, when meant to be the equivalent of Individuality or the character of spirit, should be taken as a type of experience superior to externality and including it. But there is a natural

1 Cf. "The outward and visible sign," and "inward and spiritual grace." It is plain that spiritual is here opposed to visible. 
tendency, partly due to the apparent correspondence of the metaphors, partly to the evasiveness which shrinks from all concrete synthesis, to interpret inwardness as the co-ordinate contrary of externality. ${ }^{1}$ The inward thus conceived, drops from the inclusive concrete to the exclusive abstract. The mere inner, Hegel will always tell us, is the mere outer. Individuality, instead of being the fulness of life and content, becomes the bare abstraction of a holy of holies which if it could be entered would prove an empty shrine. Structure, Logic, Determinateness, are banished as implying externality and mechanism.

Technically speaking, the point is that absence of externality seems most cheaply purchased by rejecting all determinations because they seem to be possible starting-points of external relations. And, therefore, the inward or spiritual ceases to be a world and becomes an empty point, as, for instance, in the ego or free will of popular philosophy in contrast with, say, the will of a society or the inspiration of a religious enthusiasm. It is to this misconception that the emptiness of most accounts of the higher experiences ${ }^{2}$ is in a great measure due; and such emptiness in its turn promotes the misconception. It is true, of course, that our accounts of an experience essentially beyond our own can only be abstract and provisional. But it is not true that the contents and objects which form the interest of finite experience can in principle be taken as abolished into vacancy, however they may be transformed. A world cannot consist, so far as I understand, of spiritual centres without circumferences, nor can

1 Taylor, Metaphysic, p. 99.

2. Cf. James, Varieties of Religious Experience. 
they, as inward centres in the popular sense, form circumferences for each other. ${ }^{1}$ Individuality and true spiritual inwardness do not lie at all in that direction. Externality can subsist only as subordinated to inwardness; but inwardness can subsist only in the conquest of externality. The tendency to accept the self-external-nature or matter-as self-existent, must be corrected in the higher experience; as in fact this tendency can never completely maintain itself in any actual consciousness. But to deny its self-existence is one thing, to deny its subsistence as the object or determinate character ${ }^{2}$ necessary to spiritual reality is quite another. The "outer" is the content of the "inner," and granting that these expressions no longer are suitable language for the absolute experience, yet it is a blunder of principle to analyse the outer into a series of inners deprived of all outer. There are two distinct modes of conceiving the advance in spirituality, the one to resolve all externality into series or complexes of psychical centres $;^{3}$ the other to conceive it as raised to an adequate object or character for individuals whom it characterises.

The moral is, then, that as we approach Individ-

1 The spiritual body, to use my own phrase, conceived by $\mathrm{Mr}$. Bradley, Appearance, pp. 340-4 I, would be, I presume, relatively external; a system of differences more or less fixed against each other. I cannot see how there should be a universe without at least some such system.

2 Character as opposed to object, if it is urged that minds at their best are what they know.

3 See below, Lect. $X$. The body seems to be not so much a symbol or repetition of the soul as its basis and complement; i.e. the "truth" of the two would involve a reconstruction of the soul as well as of the body. And thus again the body cannot be taken as consisting of monads which are not the soul; this would deprive the soul of an essential factor; unless indeed we say that the other monads, which enter into the body, also enter into the soul. 
uality we are not to look for diminution of content, of structure, of determinateness. Individuality will show itself as inwardness and spirituality, not by emptiness and abstraction, not even by blank intensity of incommunicable feeling, but, in a word, by the characteristics of "a world." Mechanism and externality will in a sense be superseded, but not by inwardness as their co-ordinate contrary. Part will not be bound to part within the whole purely by quantitative reaction; but, in principle, we should expect the adjustment of quantitative determinations to be infinitely more delicate and more subtly precise - though not insisted on as numerable-as they become concomitants or vehicles of a more intensely focussed significance. In the same way we should expect to find in the higher individuality not more but less of what is commonly called spontaneousness, if that means "indetermination," laxity of connection, and unaccountable new development ; and more of logic, more of expansion towards giving full effect to demands which emerge by systematic necessity from the articulation of the whole; less of the urgency of exclusive feeling, more of the definite emotions attaching to fuller self-expression; less of the mere passion of mystical religion ; more of the amor intellectualis Dei resting on clear spiritual insight. Inwardness will not be the banishment of all that seems outward, but the solution of the outward in the circulation of the total life. ${ }^{1}$

9. The failure to find a satisfactory type of

1 That these are not words without meaning may be realised in some degree by the student of Dante or Wordsworth, and indeed of all art, science, and history. 
Revolting from Mechanism we should go not to History but to Art and $\mathrm{Re}$ ligion.

experience in the abstract or conditional judgments of mechanistic science, may lead us elsewhere than to the concrete universal or cosmos conceived as individual. And so we find the genuine experience, which thought as abstract science fails to grasp, identified with "the historical." " "The actual is wholly historical." It is contrasted both with natural science, and with thought as such, quite in the tone of naive Realism. It alone is concrete experience; richer than thought, which can only be universal and relational (note the confusion of universal and general), giving only science, not existence. It is contingent, admitting contingency into the heart of things as against the necessity of thought-connections. It is the life and the end, while science is the means. I presume that we have here the influence of an ideal of individuality. The intention must be to take as a basis the life of persons, who in some sense pass for individuals, and within whose soul-process in time all finite experience must be included.

Such view, as was said just now, seems little better than Natural Realism. We are to accept as richer than thought a reality consisting in the fragmentary diorama of finite life-processes unrolling themselves in time, seen from the outside, not strictly knowable because a tissue of mere conjunctions; and yet not given, because a mere construction on the basis of the present; and contingent through and through, not having so much as stripped off the form of conjunction which makes true connection impossible.

History is a hybrid form of experience, incapable

1 Ward, Nat. and Agn. ii. 280. 
of any considerable degree of "being or trueness." The doubtful story of successive events cannot amalgamate with the complete interpretation of the social mind, of art, or of religion. These interpretations, when attempted in connection with a narrative of events, fall into separate chapters, isolated from the narrative. The great things, which are necessary in themselves, become within the narrative contingent, or ascribed by most doubtful assumptions of insight, to this actor or that on the historical stage. The study of Christianity is the study of a great world-experience; the assignment to individuals of shares in its development is a problem for scholars, whose conclusions, though of considerable human interest, can never be of supreme importance. Are we, indeed, to see the philosophy of history joining hands with the "psychological valet," who takes upon him to interpret the minds and natures of great men as if he wase God's spy?

And the reason for taking this hybrid form of experience for the type of reality lies in ignoring the concrete universal. This is the defect which leads us to suppose that concreteness and contingency are inseparable, and makes us confound the apparent contingency of details within a cosmos, whose main members are necessary to the whole, ${ }^{2}$ with the contingency at the heart of a spatiotemporal world of incident, which has never been recreated by experience of the fullest type. It is impossible for life at its best to be contingent, and if "freedom" is mentioned, it must be remembered

1 Hegel, Philosophie des Rechts, sect. 124. Cf. Green, Prolegomena, sect. 293.

2 See above, p. 48 ff., on necessity and totality. 
that freedom is the logic of individuality, and as remote as possible from contingency. To say that reality can only be found in the given, and not in its expansion and interpretation through thought, is surely the ancient fallacy of naive Realism. If thought had a point of departure foreign to existence, then it would be idle to speak of either generating the other. But the connection of thought and existence, whatever it may be, is not so simply disposed of as this. We have on our hands the world or worlds of experience in their fullest and most exact realisation, and in them, as we have seen, we find thought inseparable from the recognition of what things are for us at their best. ${ }^{1}$ Social morality, Art, Philosophy, and Religion take us far beyond the spatio-temporal externality of history; these are concrete and necessary living worlds, and in them the finite mind begins to experience something of what individuality must ultimately mean.

The object of the present lecture has been to remove from various points of view the prejudice which sees in the individual not a positive cosmos, with its own logic and organisation, expressive, in spite of its immediate unity, of a determinate being, but an empty and exclusive point, whose spontaneity and purposiveness mean an initiative that draws

1 If it is true that in all predication the subject is Reality, and, further, that there are no ideas which do not qualify this subject, it follows that the truth of the ontological argument is conceded in principle, and the value of the knowledge to be obtained by it is only a question of degree-that is, of the reservation under which any given predicate truly qualifies reality. This seems important, as the right way of putting the problem of truth and reality, though open, of course, to such criticism as Mr. Bradley's in Appearance, 2nd ed., pp. 396-7 ; Schiller, Humanism, p. 251. 
upon no positive source, and focusses in itself no positive striving of the universe. In subsequent lectures we shall further illustrate the former conception with reference to the problems of teleology and interaction. 


\section{LECTURE III}

UNIFORMITY AND GENERAL LAW NOT ANTAGONISTIC TO INDIVIDUALITY

Alleged Mentality in Nature at issue with Uniformity.

I. IT is a widespread idea ${ }^{1}$ that the essence of individuality conflicts with the postulates of the Uniformity of Nature and of universal law. We shall not be able to grasp the true character of the individual, and the bearing of the argument of the previous lecture, till we have disposed of these misconceptions. They arise from the confusion between the abstract and concrete universal ; between the recurrence of similars and the identity of a differentiated system.

It is held that a spiritual philosophy requires mentality in nature, that mentality demands variability, and that high variability is incompatible with the principle of uniformity. The principle of Uniformity is thus misconstrued and a fatal opposition set up between it and the nature of mind; just as, more generally, it is held that Individuality excludes

1 The general position which $\mathrm{I}$ am criticising is to be found in Ward, Naturalism, i. I08; cf. ii. 24 I, 280; Taylor, Elements, 22 I ff.; Royce, World and Individual, ii. I91, I95. Professor Ward does not indeed explicitly argue for pan-psychism (though note p. I08, "the order of an ever-living spirit"), and his sharp contrast between inorganic and organic Nature would be in conflict with such a tendency. Yet I can hardly understand his desire to discredit uniformity throughout the material world in any other sense. 
the fulfilment of general law. Thus we have a fallacy affecting the whole interpretation both of nature and of man. The responsiveness of nature to spirit, their magnificent opposition and reconciliation, is frittered away into a remote resemblance between them, depending on a character-the character of variability-which is exaggerated by a forced hypothesis in the case of nature, and abstracted from its conditions and true significance in the case of what we know as mind.

2. To begin with, the Uniformity of Nature is Uniformity taken for this purpose, not in the sense in which $\begin{gathered}\text { as similar } \\ \text { repetition }\end{gathered}$ it has been held to constitute a logical principle, dist. relevbut in the popular and prima facie sense, disclaimed by logicians, that "the future will resemble the past" - that the procedure of nature is regular, is a mode of repetition, and its elements similar, in a very high though unspecified degree.

It is then argued that actual purposiveness and spontaneity, assumed to be evinced by variation and irregularity, are more widely distributed in nature than Uniformity so construed would admit; while on the other hand, an appearance of such uniformity can be generated even in human conduct, which we know to be spontaneous, by the use of methods analogous to those which give rise to the impression of extreme regularity and resemblance as prevalent in nature. The conclusion is that the spontaneity which we know to prevail in what we recognise as mind, may also prevail in what we are accustomed to think of as external nature, accompanied by a similar variability, which our methods of enquiry disguise.

The Law of Uniformity, then, in the logical 
sense of the term, ${ }^{1}$ in which it means rational system, such that all changes and differences are relevant to each other, is not here expressly in question. On the other hand, unless it is intended by the way to impeach this law-to affirm, that is, inexplicable or irrelevant variation as a proof of spontaneity-there seems to be no contention. To say that there are more differences in nature than some people have thought is to say nothing. To say that there is, in supposed inorganic constants, rational, progressive, and significant variation, would be to say something; but to this, as we shall show, the facts lend no kind of countenance. To say, first, that variability in conduct due to minds establishes indeterminate spontaneity, and that this excludes Uniformity in the logical sense-what I prefer to call " relevancy"-and, further, that such spontaneity is also to be presumed as a fact in what we take for natural elements, and in their behaviour, would, indeed, be to say something. And considering the belief in an antagonism between individuality and general law which accompanies the views we are discussing, it seems probable that we are really in presence of such an attempt to discredit the conception of logical nexus-the conception of relevancy, which is what logicians mean by uniformity-alike in nature and in what we know as mind. This may be disclaimed; but, strictly speaking, it is the only thing that can be meant. ${ }^{2}$ The contention,

1 Mill, Logic, chapter on Ground of Induction; Green, Works, ii. 282, 288-90, "The Conception of the "Unity of the World" ; author's Logic, and ed., ii. I64, I 83.

2 It is clear, I think, that both Ward and Taylor are prepared to maintain that a given cause may vary its operation spontaneously. See below, p. 96, note. 
otherwise interpreted, to the effect that atoms of the same element are not, in fact, all of the same size, is not a philosophical contention at all. The point is worth examining, if only to throw light on the true interest of Social Statistics.

3. The argument rests on a comparison of social Physical statistics with those physical measurements which can only be carried out with reference to enormous measurements compared to social numbers of units en masse. You cannot, it is urged, averages. isolate an atom of oxygen. When you represent its atomic weight by 16 , all you mean is that this figure results from the measurement en masse of an enormous number of atoms, the result being attributed with hypothetical equality of distribution to each single atom; in short, you have got an average figure like the average height or weight of school children of a certain age, or like an actuarial estimate of the prospect of life for individuals under certain conditions. Such average figures, of course, are true of a class or group as a whole for certain purposes, but not of each individual ; and, indeed, their value lies, we might say, in not pretending to represent the individual but in simply serving the purpose for which they are computed-some collective result or comparison.

So, too, it is urged, the atoms of oxygen, for all we know by measurement, may not be rigidly equal at atomic weight 16 , but may oscillate round this amount, as any statistical figures oscillate round the arithmetical mean. In the physical measurement, it is said, we have only the total, from which we infer an average, and we cannot get at the individuals to measure them separately; in social statistics enumeration and separate measurement 
are possible, and, therefore, we are able to criticise the average figure, and the criticism gives rise to the suggestion before us.

In this way, the contention is, we can see that a figure representing some character of a social group is single and may be constant, without indicating any absence of variety among the individuals composing the group. And, therefore, analogy suggests that minute physical elements may after all be various, and endowed with life and spontaneity, seeing that there may be what one might call social constants, as well as physical constants, though no one doubts the variability of the members of the social group.

To me all this argumentation sounds like special pleading. The distribution of mentality in nature seems to be a mere issue of fact. It is the suggestio falsi as to Uniformity and its antagonism to mind that I desire to combat. I will mention one or two points. "Average" i. Am I wholly wrong in thinking it necessary and "Constant" dis- to say, first of all, that we must distinguish an tinguished. average from a constant? You can strike an average from any set of figures; but whether it is or is not a constant depends on a comparison of averages representing groups in some way different. Thus, it is true that if an atomic weight is only a single average, it admits of any degree of variation in the actual atoms; but, for the same reason, if the social statistic is only a single average, it offers no suggestion of constancy in the social phenomena. So far, there is nothing against the suggestion that physical elements vary; but there is nothing for the suggestion that social phenomena can present the appearance of constancy. You can take the average 
of 2, I0, and I0,000 without the slightest implication that the figures averaged show any uniformity.

ii. To establish a constant average, the averages In comof different groups or periods must be compared, garing or else the approximation of the several figures averaged, to their average, must be directly noted the analogy -a method ex hypothesi impossible with minute physical elements.

But here, when we compare physical and true social phenomena, the analogy breaks down. The physical measurements, for all accessible groups of units with the same name (similar atoms, similar wave-lengths, etc.) are ex hypothesi identical ; true social measurements, as opposed to physical ones, for comparable groups under different conditions and in different periods, deviate as a rule progressively and intelligibly. It is not true, on the whole, that they oscillate round constant amounts or tend to come back to them "in the long run." 1 The early statistics, which seem to have created this impression, were in part, I suspect, fallaciously handled, and were also drawn from inadequate periods of time. ${ }^{2}$

1 Contrast Taylor, Elements, p. $22 \mathrm{I}$.

2 Presupposing, of course, that no statistical constancy could be relevant to Buckle's anti-freewill conclusions (cf. Ward, i. I I I), it still remains a question of some interest whether the sort of constancy which impressed him, Quetelet, and even Mill (Logic, ii. 529) really existed or exists. I can see nothing in Quetelet's tables to justify his own saying, that from the figures of one year it is possible to predict those of the next. I have not been able, as I had wished, to find completer material in order to criticise the famous instance of the percentage of unaddressed letters on the whole number posted. But modern statistics of true social phenomena, as I point out in the text, show no signs of fixity, and if any uniformity at all, it is a uniform rate of change of ratio. It is more than a mere matter of curiosity, for I feel sure that, e.g., Venn and Ward and Taylor have been influenced by the audacity of the Quetelet and Buckle 
True social statistics, figures which depend directly or indirectly on human conduct, such as the records of crime and pauperism, and in a great degree those of health, are marked in general by extraordinary sensitiveness, being subject, for different groupings or successive periods, to definite adapted or progressive variations, which show no sign of oscillation round a fixed point, and are readily explicable in connection with changes of moral and material conditions. The records of crime and pauperism for the nineteenth century are ample proof of this. ${ }^{1}$ If these facts are considered

statements, as to the degree of constancy in the long run which they allow to be assumed. See Venn, Empirical Logic, p. 580 ; Taylor, Elements, p. $22 \mathrm{I}$; Ward, loc. cit. There is extraordinary laxity of statement on such matters, e.g. Venn (Logic of Chance, 3rd ed., p. 24 I) speaks and makes Laplace speak of the number of unaddressed letters remaining the same year by year. All other authorities speak of the proportion (ratio). I have not seen the tables. With what number Quetelet expected the next year's figures of suicides to agree, whether the average, or actual figures of the current year, or the ratio to population, I can form no idea.

1 E.g. "Chart of principal Classes of Crime, I 858 to I 898 " (Criminal Statistics, I 898), or any chart of pauperism for the latter half of the nineteenth century. No doubt a progressive decrease must have a limit; but an irreducible minimum, e.g. in pauperism, such as experts conceive of, would not be a mere statistical mean, but would be a new fact, causally explained. To show how slippery is this question of the persistence of social constants I cite two passages from Venn, which the slight difference of the subjects concerned does not seem to me sufficient to reconcile: Empirical Logic, p. 580 (Murder, Thefts, Suicides, Sums expended in charitable or other such purposes, or Insurances effected in the year): "But of such portions of human conduct as of most other portions, it is a simple datum of experience, that in the long run, when we extend our observations over a sufficient space, a great and growing degree of uniformity is generally observable." Cf. Logic of Chance, p. 9 I : "These conditions (health, circumstances, manners and customs of the parents ; the question is of the ratio of sex to sex at birth) partaking of the nature of what we term generally Progress and Civilisation, cannot be expected to show any permanent disposition to hover about an average."

A careful study of Buckle, Quetelet, and the authorities cited by 
the alleged analogy between physical and social constants, beyond the fact that any one group of figures can be represented by an average figure, disappears.

4. And it seems necessary to distinguish between Physical the principle of what may be called, second-class and first-class statistics. Second-class statistics are those which aim at discounting unknown causes by including, as near as may be, their whole cycle. Such is the method we instinctively adopt, if in order to estimate the number of words in every line of our MS., we count them for, say, a dozen lines, and take the average as our guide to the normal number in a line. We hope that the main causes of difference in the number of words per line will have occurred within the single dozen, and that the average on the whole, perhaps of ten thousand lines, will be much the same as that in the dozen which we have counted. We do not trouble ourselves to think what may cause the numbers to vary, but merely hope that we have got a fair sample of all the effects of the unknown causes, and that our average, therefore, is a constant. Of such a nature would be, according to the hypothesis before us, the measurement of atomic weights and of ethereal

them leaves no doubt that what they, like Mill, mean to insist on is relevant variation, i.e. that the figures are constant under constant conditions, and vary with varying ones. But adopting the unfortunate terms uniformity and regularity, they are to some extent hypnotised by them, as appears I think from the case in which $\mathrm{Mr}$. Rawson uses the word "constants," cited in Buckle, i. 3 I. I cannot help repeating the suggestion, rash as it may appear, that an undue influence is exercised in discussions of constancy by the fact that an average figure can be struck for any single period, however prolonged, containing recurrent counts ; which, of course, apart from the comparison of averages for parts of the period, is a mere arithmetical tautology, leading to no inference of any kind. 
vibrations; such is the determination of average durations of life in specified callings or for specified categories of the population. The essence is the absence of all attempt to suggest causes of the observed variations. The method is one which deals with them qua unknown. ${ }^{1}$

But as Sigwart has said, ${ }^{2}$ it is really by their variations that statistics are suggestive; and it is when we come to such comparisons as different death-rates under different sanitary conditions, or different rates of pauperism under different systems of administration, that we approach the province of what might be called first-class statistics. In these we no longer operate with numbers of recurrences of effects, admitting our ignorance of their causes. It is like the difference between a statement of chances giving, say, the chance of an individual dying of smallpox, based on the ratio of cases to population, and the statement based on highly complete causal knowledge giving, say, the chances for the throws of a perfect die. We pass beyond the disjunction of ignorance-under $\mathrm{X}$, so many cases $a$, so many $b$, we have not the least notion why-into the province of the disjunction of knowledge ; $x$ being $a$ gives $a$, being $\beta$ gives $b$, etc., and we know there is nothing persistent in favour

1 It may be said, that the very specification of the category to be dealt with involves the suggestion of a cause ; e.g. duration of life of bachelors, married men, clergy, saw grinders, etc. The fact is that a unity which has an interest, has also an incipient causal presumption. It is true that when comparison begins to work in this way, a transition to first-class statistics is suggested. But primarily, e.g. for actuarial purposes or for simple compendiousness in keeping records, no such suggestion is involved.

2 Eng. Trans. ii. 501. This, I think, must be borne in mind as a mitigation of Taylor's statement that taking an average must always give results which have a mechanical appearance (Elements, p. 331). 
of $a$ more than of $\beta$ and the rest, and vice versa. Variations in ratio of crime and pauperism, variations in the occurrence and fatality of diseases, variations of the general death-rate of a community, and perhaps also of its birth-rate, are capable in different degrees of being correlated with assignable causes, and become more intelligible as they become more divergent, and so in the superficial sense less constant. It is true that statistical conclusions as such remain hypothetical as regards incidence on individuals. We may see that a death-rate must diminish, but we do not know which individuals will be saved, nor, from the death-rate alone, which have been saved. But the unexplained variation is no longer the typical datum, nor the assumption of it the ideal of method. We can go to meet the statistical figure from the other end, with precise analytic explanations of the individual case, given his health, his morals, his economic history. ${ }^{1}$ In dealing with social phenomena, this, the variable and individual element, is the climax of intelligibility. Not constancy, but explicable or relevant variation is the typical character of the measurements involved. Even the roughest methods, properly used, can give no such analogy as is asserted by the argument we are discussing. And the more we perfect the measurements, the less the analogy holds.

5. It was suggested above that the argument in Misconquestion - the argument from non-uniformity to spontaneity in nature-depends on a false conception of the Uniformity of Nature. It aims at ception of Uniformity due to theories of similarity and repeti-

1 Taylor seems to exaggerate the opposite view to this (Elements, and pp. 234-5). 
disproving what we may call the uniformity of Similarity, expressed in the principle that the future will repeat or resemble the past, or, more generally, that one thing of a kind will simply repeat another. But this, as was observed above, is not the meaning of Uniformity as a logical principle or postulate of Science. No doubt the name Uniformity, proposed by Mill, was a misleading appellation for the postulate of rational system and coherence in the world of experience. But Mill, like others after him, clearly explained that the Uniformity of Nature does not mean that the future will resemble the past. This may seem a superfluous discussion of a familiar point. But, in truth, the prejudice which interprets the Uniformity of Nature as the principle of science, in the sense which Mill was careful to reject, ${ }^{1}$ is at the root of the whole recent polemic against the intelligence, and rests on something far deeper than a mere verbal confusion. It springs from a deep-rooted impulse to misconceive and mutilate the whole activity of thought, which is, in essence, a recrudescence of the superstition that its work is purely analytic. Wherever in recent literature, from John Henry Newman to Mr. Kidd, from M. Tarde and Professor Baldwin to M. Bergson and his followers, we find emphasised the solvent and analytic character of intellect, or the antithesis of Imitation and Invention, of Repetition and Creation, there, I am convinced, we have a fundamental error of principle depending on a vicious logical

1 I do not forget that Professor Taylor believes himself faithful to the law of Ground and Consequent (op. cit. p. 230). But I cannot reconcile this attitude with his prolonged advocacy of inexactness in nature. What point can there be in this, if it only means that some variations, relevant and grounded, escape our notice? 
theory. ${ }^{1}$ The hopeless failure of all these theories to deal with the nature of genius, with creation and invention, ${ }^{2}$ shows that we have before us an abstraction of elements - the elements of identity and diversity, which in the attempt to dissociate them become unmeaning and contradictory. Invention and creation are really present in every pulse of thought, in every employment of significant language, and pure repetition is an impossibility for intelligence. ${ }^{3}$

Uniformity, then, as a principle of science, is a uniformity not in the way of resemblance but in the way of identity; not a repetition of resembling elements but the coherence of differences in a whole. It should be called by some such name as Relevancy. An argument which is directed against the former and leaves the latter standing, admits everything that can be demanded by a reasonable mechanistic view of the universe. Nothing is gained against uniformity by making it probable that atoms vary in size, if their variation is not assumed to be in principle irrelevant to their conditions.

The argument set out to show that a psychical or at least a spontaneous character, incompatible with mechanical uniformity, might be presumed in physical objects; and offered to reveal how the appearance of constancy in them was analogous to one which must arise in connection with subjects whom we know to be psychical. But what has appeared on examination of it is that the only true principle of uniformity (Relevancy), so far from being incompatible with a psychical character, is in

1 See author's Logic, 2nd ed., vol. ii. p. $174 \mathrm{ff}$.

2 See Lect. VIII. below.

3 Nettleship on use of language, Remains, i. 128. 
the highest degree applicable to the prerogative case of mind, and that the more nearly as we approach the individual subject. ${ }^{1}$ So that instead of defeating the principle in alleged physical objects, the argument has forced us to assert it in true psychical objects. The important point is to disown the idea that the establishment of great de facto variety either disproves true Uniformity (Relevancy) or proves a psychical nature; and that there is any kind of connection between the disproof of the one and the proof of the other. Such an idea sets us wrong $a b$ initio in our attitude to the characteristics of consciousness, teaching us to connect it with eccentricity and caprice-the negation of coherent systeminstead of with system and rationality. The same fundamental error identifies the spontaneity of life with an unmotived diversity, and intelligence proper with an impotent identity.

It is not indefinite variation but coherent progressiveness and adaptiveness that we take as indications of consciousness. And in this feature, as we have seen, the argument has failed to sustain the alleged approximation of what is called matter to mind. $\smile$

The point is somewhat subtle, and I will restate it against an objection which might be drawn from our own reasoning. Why you complain, it may be replied, of taking breach of uniformity of resemblance as a proof of psychical character, and yet such a breach is the very difference which you allege between inorganic and social statistics to prove that

1 The living organism, so far from being outside the province of intelligence (Bergson, Évolution créatrice) being in the strict sense the only thing we can really understand (Caird, Kant, ii. 530). See, however, note, p. 168, on Bergson's "Intuition." 
the latter do and the former do not suggest conscious spontaneity.

Our answer would be, insisting on what we have said, that what we allege to indicate psychical spontaneity is not mere breach of the uniformity of resemblance, but systematic progressiveness and adaptiveness of response. What we combat is the suggestio falsi-based on confusing rational identity in diversity with the recurrence of resemblancesthat we approach the psychical by coming near to the inexplicable; a suggestion by which the argument for universal mentality draws the popular love of the marvellous to its side. Treating this suggestion, however, as indefensible and probably not meant to be defended, we confine ourselves to explicable variation, which, in any degree of it, is no breach of the uniformity (Relevancy) of Nature. This kind of variation we see no reason to deny, if theory requires it, in physical phenomena hitherto supposed to bé uniformly similar; but we insist on the fact that in regions which we know to be psychical there is not only variation but progressive and adaptive variation correlated with changes of volition. And therefore $a$ we maintain the prima facie difference between material and psychical existence; and $\beta$ we insist that in the mental province the true Uniformity of Nature exhibits itself in the fullest and completest sense. The conception of relaxing uniformity to make room for mind in nature means a failure to face the problem of externality as the antithesis of subjective "mind" $y$. on the one hand ${ }^{1}$ and the problem of free initiative $d x$ or creative logic on the other. ${ }^{2}$

1 See Lect. X.

2 See Lect. IX. 
Individu -

ality

implies

precisely

deter-

minate

response.

6. The same fallacy is apparent in the idea that the conditions of individuality conflict with the postulate of universal law.

It does not much matter in what details this idea asserts itself. It is the same thing throughout; a denial of relevant adjustment, confused with a denial of similar repetition. An efficient cause, we are told, for example, need not be uniform in its action. ${ }^{1}$ This is intended, it would seem, to guard the spontaneity of true causal activity, considered as that of a subject. It can only mean that a cause $A$, without variation of conditions as between $B$ and $C$, can produce out of itself alternatively effects $b$ and $\checkmark \checkmark c$. Such spontaneity, of course, would mean not adjustment, but failure of adjustment, a complete denial of Relevancy. To stimulus B, A might respond with reaction $c$, to stimulus $\mathrm{C}$ with $b$. We are told again, that Individuality is unique and the self impervious. ${ }^{2}$ This is its character, not accidentally, but essentially; its essence is to be sui generis. ${ }^{3} \quad$ It is the playground of contingency. Laws cannot be shown to be absolutely exact; purposive life cannot coexist with rigid routine conformity to general law. ${ }^{4}$ Everywhere the polemic is against the character of rigidity, fixity, repetition, supposed to be inherent in the nature of law, and to be the same thing with adequacy and precision of measurable adjustment. Spontaneity is held to

1 Ward, Naturalism, ii. 24I. Contrast Joseph, Introduction to Logic, p. 374: "Let us ask what is involved in the conception of a cause not acting uniformly; we shall see that it is the same as if we denied the existence of causal connections altogether."

2 Seth, Hegelianism and Personality, pp. $225-8$; cf. Taylor, Elements, p. 282.

3 Ward, Naturalism, ii. I63-66.

4 Taylor, Elements, p. 223. 
be throughout in escaping from general rules, i.e. rules of recurring resemblance. The idea of identity in difference seems never to be applied. For if it were, fineness of adjustment, precision, and relevancy of determinate response, would be recognised as the very incarnation of the universal, and so of life and spontaneity which are one with it. The whole contention, there can be little doubt, reflects the modern tendency to pronounce intelligence not merely in fact but in principle inadequate to life and reality. ${ }^{1}$ It is difficult indeed to see how this tendency can accord with the attempt sometimes conjoined with it, to enthrone the finite consciousness as the director of history and evolution. But the fact is, that we are here on the edge of pluralism and voluntarism, and although the term direction is employed, the guidance by the finite consciousness as the independent controller and reformer of destiny, divorced from an immanent real, is a blind leading of the blind. For Ward no less than for Bergson reality is richer than thought, history is the type of the Absolute, and the true concrete world of philosophy drops away. ${ }^{2}$

At all events what we have to deal with is this. The work of the intelligence is conceived as the formulation of general rules of repetition or resemblance, by which everything ne $v$ is analysed in terms of the old. ${ }^{3}$ And the princ ple of intelligence, thus understood, is naturally corceived to have no

1 As in Bergson passim, e.g. Evolution, p. I75. It is important to note how old this tendency is, dating at least from Schopenhauer, and backed by revived religionism (J. H. Newman).

${ }^{2}$ See, however, as to Bergson A. D. Lindsay's Philosophy of Bergson, ch. v. I adhere to the statement in the text.

3 Bergson, Evolution, p. I 77. 
grasp or purchase on vital and purposive reality. ${ }^{1}$ The conception of teleology, indeed, is exploited to eke out the missing character of rationality. We shall see later how far it justifies the attitude adopted.

$\downarrow$ Our attitude is, on the other hand, that the principle of life and reality is one throughout, and is the principle of individuality, and that this can be traced in all forms of experience, none of which are to be taken as superseding or as discontinuous with each other. Finite intelligence, for example, will not be superseded by but also will not supersede, any other form of finite experience, though it may lead up to a perfect experience other than itself. We must avoid the two complementary errors, of which modern philosophy appears to us to be full, and which have one and the same root. We must not identify intelligence with cognition-the error of alleged Intellectualism, committed mainly if not exclusively by its antagonists -and make it, so interpreted, the guide and rule of life. We must not, on the other hand, influenced by aversion to this error, set up as sovereign any form of spontaneity, activity, subjective teleology, or intuition of life, against the character of intelligence as the active form of totality and nisus towards the whole. We must distinguish the character of thought in its widest and deepest sense as the active form and logical spirit which lives in all modes and contents of experience, from the discursive abstract thinking which is one shape-a typical or schematic outline-of the operations of mind. We must under-

1 The grasp of universals, it is held, marks the failure of insight and interest (Ward, Naturalism, i. I I0, ii. 90). 
stand how all sides and features approach their respective completions concurrently and convergently as the underlying principle of individuality expresses itself more thoroughly through a more determinate grasp of the content of the world. The conscious intelligence is not to be dethroned; it remains above the unconscious, as a revelation of what is there implicit, and as a fuller phase of the remodelling of self by adaptation to the whole. But it is not to be one-sidedly sovereign either as abstract cognition or again as finite mind or will, furnishing direction out of its own isolated contingency. It is neither a subordinate means to evolution, nor an independent rational agent in a world which is mere material for its spontaneity. It is simply the principle of Individuality permeating all experience, but when taken in abstract shape constituting that side of experience which we call discursive thought. We will now follow more in detail the nature of the fallacy which sets Individuality and Spontaneity in contrast to universal law.

i. We may start from Lotze. ${ }^{1}$

False ideas of what

The Absolute is no magician, it does not produce Law involves. Things in appropriate places out of a sheer vacuum, merely because they correspond to the purport of its plan. All particular cases of its operation are based on a system of management according to law, adapted to its operation as a whole. But I must repeat: it is not here as it is with man, who cannot do otherwise; rather this uniformity with general principles is itself a part of what is designed to exist. Hence it is, that each stage in the development of organic life seems to arise step by step out of the reactions which are made necessary for the combined

1 Metaphysic, sect. 233 ; cf. Introduction, Eng. Trans. p. x. 
elements by their persistent nature; nor is there anywhere an exception to the dependence of Life on mechanical causes.

Here we find stated the view which seems prima facie reasonable. But the protest which accompanies it suggests the contrast of law and individuality, which since Lotze's day has developed so as to destroy the doctrine to which in his hands it was subordinate.

The protest, which opposes the idea of law to the idea of an individual system, rests on the fallacy that $\checkmark$ a plurality of undifferentiated points of application is essential to the universality of a law-that the universality of a law, in a word, must be embodied in a class of similars. This fallacy is the same at its root with the negative or exclusive doctrine of individuality. It depends, as has been pointed out, on the confusion of similarity and identity, by which a scientific truth is supposed to be essentially the expression of an attribute in which a great number of instances resemble one another. But the view of sound logic is rather that a scientific truth is the expression of a definite connection of contents within a system-an identity pervading a number of distinct determinations whose connection does not lie in resemblance of the elements to one another, although certain resemblances may and must result from the interconnection. ${ }^{1}$ Thus, for T example, it is possible to regard the law of gravitation as a record of certain resemblances between all particles of matter. But this resemblance is really secondary. The point which constitutes the theory ${ }^{2}$

1 See author's Logic, 2nd ed., ii. I 74 ff. $\quad 2$ Green, Works, ii. 288. 
is the conception of the systematic relation between the distance and the attraction, and the contribution which this conception makes to the further determination of the nature of the physical world. When the nature of the gravitating system is so far revealed, the resemblances following from the partial identity so far established between portions of matter are a corollary. But the basis of the resemblances could not be established, except by analysing them into the precise partial identity which is expressed in the determinate interrelation of parts within the gravitating system. So in the easy example of a machine, say, a steam-engine. The universal in which the members participate is the working of the engine, which primarily depends upon the differing adaptations of the members to their purpose. Certain partial identities, giving rise to resemblances, are involved in these adaptations, as, for example, that all the parts must share a certain degree of strength and toughness and durability. But no machine, no city, no system, could be made out of merely similar members. Even a number of undistinguishable coins, if they are to operate upon each other's value, must be taken as affecting one another by a relation which is not their resemblance, i.e. the relation of cooperating towards the supply of some demand. The distinction is no doubt a truism. But it is an embarrassing fact that forgetfulness of such truisms forms a leading feature of the most modern philosophy. If they were not forgotten, no one could treat a Universal Law or statement of a uniformity of nature as a generality which depends for its truth on the recurrence of similar qualities or events. 
And consequently there could be no reason for suggesting that a universal law is not a necessary element in the conception of a system or individual. The fact is that Plurality and Repetition, which are the medium of generalities as commonly understood, are relatively unimportant subforms of universality. This is a consideration which goes very deep into the modern attitude towards the intelligence. We are constantly being told ${ }^{1}$ that the intelligence can deal with nothing but repetitions. This is simply an echo of the Logic of extension and classification which, greatly as it has been amplified of late, can never, surely, give a genuine account of knowledge.

Every

Individual system is a complex of Laws.

ii. We may take the matter further than this. The relation of the universal law to the individual system is closely typified by that of the Hypothetical to the Categorical Judgment, or of Science to Philosophy. The individual is essentially the province of Categorical judgment, the abstract universal of the Hypothetical ; and we might venture to say that the Categorical judgment is the sphere of Philosophy, the Hypothetical of science. Philosophy deals with affirmations about the universe; Science with the interdependence of details within the universe ${ }^{2}$ - the precise consequents of conditions precisely assigned. Thus every Hypothetical judgment-every relation of antecedent and consequent

1 E.g. Bergson, passim. Ward (Naturalism, ii. 280) points out that in History, where we have less of repetition, we understand better, than, e.g. in exact science. Cf. p. 94 for a similar contrast between Caird and Bergson. In Paulsen, Einleitung, p. 384, to which Ward refers, the polar antithesis of Begreifen and Verstehen is suspect to me. It involves saying that you drop determinateness as you approach true concreteness, which I do not believe.

2 Caird, Kant, ii. 312. 
— is within, and founded upon, a categorically asserted ground or relatipely individual system. Geometrical truth is only true if there is space $;^{1}$ economic truth holds only within the economic world; biological truth belongs to the kingdom of organic life. The abstract truth traces the detailed connections which go to constitute the concrete being; and the nature of the relation implies that every concrete being is a system, the analysis of whose detail may be expressed as abstract truth. We are not saying that any number of Hypotheticals can be equivalent to a categorical truth, or that a series of abstractions taken together can be equivalent to an individual reality; but we are saying that every individual, every living world, as, on the one hand, it has its own system of truths which hold good only within and presupposing it, so, on the other hand, possesses in these truths a system of determinations, each of which, when its background and foundation are made explicit, realises the character of a universal nexus as once true always true. It is always true, because it carries its full conditions with it. A judgment of colour harmony, or of decorative or dramatic fitness, or of appropriate biological response to environment, or of morality, may, or rather must be, the proper background presupposed, as necessary as a geometrical axiom ; and if equally necessary, it possesses, considering the

1 I suppose this would be disputed on the ground that geometrical reasoning is independent of experience. I cannot think that such a view is tenable. It is one thing to distinguish inference from observation of fact; another thing to say that you can think or infer in any matter without immersing the mind in that matter. As for the truth of new kinds of geometry, I suppose that they are affirmed of reality under a precise reservation, and so may be necessary even if their objects are impossible. 
greater fulness of its content, a considerably higher degree of truth. If the background or basis of relation is wanting the judgment is meaningless and cannot be thought.

The universality of such a determination, which derives from the nature of the whole present within it, lies in its embodiment of the spirit of the whole to which it belongs. A potential plurality of similar instances under it-a potential generality or repetition, follows as a corollary in finite experience. But it is a character of imperfection in such experience, and not of perfection. For the ideal of uniqueness, if rightly understood, is in truth one which attaches to a perfect individuality and its members. A misinterpretation of this character of uniqueness is at the root of the view which finds an antagonism between individuality and universal law. So far from uniqueness being antagonistic to universality, the ideal of a universal nexus is to be embodied in the unique. This must be so, if the identity of Indiscernibles is a true principle-a mere repetition is pro tanto fatal to comprehensiveness, ${ }^{1}$ because it tends to collapse into featureless unity, leaving no differences to comprehend. And in fact, the nearer any experience approaches to an unmotived repetition, the more we feel ourselves in the province of error and confusion. Why should any being express a second time what has been adequately expressed before, or how can such a repetition carry knowledge forward? A repetition which is not unmotived but demanded stands on different

1 Taking comprehensiveness, width, inclusiveness, generality, as simple equivalents of universality, indisputable even to common sense. 
ground; the mere fact that it is demanded (as in a decorative repeat) rests on a difference in the situation and makes it in principle unique. The thing is obvious if we think of the ultimate universal as the spirit of a single system, constituted by differences which have for their function to develop and manifest the content of its nature. The nexus of these differences, in the system which is the universal, is a system of laws, each of which is general by holding together the diverse expression of the one life and spirit. It is no less obvious if we think of the completest types of individuality which finite experience furnishes, such as a work of art, or a person, or a highly unified society. In a work of art, a picture, or a poem, every particular effect is unique in the sense that it says something special and distinctive, dependent on the nature of the whole which reveals one of its aspects in that determinate arrangement on which the effect depends. ${ }^{1}$

And we must have read Plato's Philebus and Aristotle's Ethics to very little purpose if we do not understand that, in principle, the fullest universal of character and consciousness will embody itself in the finest and most specialised and unrepeatable responses to environment; and that life, and especially its intensified forms as morality or knowledge, do not consist in observing general rules, but in reacting adequately, with logical, that is, with fine and creative adjustment to the ever-varying complexities of situations. Precision, measurableness, and universal law, these are in the moral act, but they are features of the solution of problems by constructive organisation, and not of obedience to

1 Cf. Essentials of Logic, p. 57. 
abstract rule, and the same thing is relatively true of the adjustments and arrangements of a highly unified society. ${ }^{1}$

Now every such determination-the relation of every colour, point, and line in a Turner picture, of the members of the rhythm in a poem, of intervals of time in an act of patience or courage-all these are more well and truly to be designated universal laws and connections than the truths of number and geometry, or statements of the characters of an organic genus or species. They presuppose indeed a far more special and conerete world or background than the world of space and time in the abstract, or than the world of plants or animals. But they are no less necessary, and much more universal ; for they imply the world of spatio-temporal abstraction, and many other worlds besides, and embody a system of differences much more profoundly connected, and a much fuller and more coherent grade of reality and revelation of the nature of things. ${ }^{2}$

True, a shallower world does not give law to a deeper.

iii. What we really mean in contrasting Individuality with general law is explained by the contrast between different degrees of Individuality, of which

1 The general law, it may be said, is a statement of some common character which can be elicited from the relevant reactions of members in a system. But where the universal is well developed, there will be no similarity in the sense of repetition. There will be a completing of one element by others. Cf. on the whole subject a paper on "Theoria in Aristotle's Ethics," International Journal of Ethics, January I 9 I I, reprinted below in Appendix II.

2 I hold it to be a fundamental error, and a most instructive one, on the part of M. Bergson to think that the human intelligence is especially at home in geometry, and less satisfied and less efficient as its work is remote from cognition of that type. The error is due to measuring the at homeness of intelligence by its apparent purity or independence; but this purity just means that it has hardly begun to discover its full self. Cf. pp. $94 \mathrm{ff}$. 
the lower enter into but do not complete the higher. Thus, as we have seen, it is perfectly true that laws of the world of time or space will not furnish the content of art or personality. But this is simply because they fall short of the requisite universality. They have too little to say of what there is in the world, and their necessity is dependent on a far simpler background than that of the living whole within which the fine adjustments of art or of morality have their inevitable place.

This contrast, which is incontestable, and which applies also in its degree to the chemical and biological worlds as compared with the province of self-conscious and volitional life, is apt to be exploited with a recklessness and ruthlessness which falsifies the theory of individuality, and cuts the membership of the universe apart with a hatchet.

The Laplacean imagination of the ideal calculator is being held up in terrorem ${ }^{1}$ as representing the

1 Ward, Naturalism, i. 4 I ; Bergson, Évolution créatrice, p. 4 I ; Verworn, Allgemeine Physiologie, Eng. Trans. 3 I ff. Dubois Reymond apparently pointed out that "an astronomical knowledge of the brain" could never indicate to us how consciousness arises; a limit which is analogous to the limit suggested below, that without special experience it could never indicate to us what consciousness would accompany each special physical condition. Cp. "Nous devons donc envisager l'état présent de l'univers comme l'effet de son état antérieur et comme la cause de celui qui va suivre. Une intelligence qui, pour un instant donné, connaîtrait toutes les forces dont la nature est animée, et la situation respective des êtres qui la composent, si d'ailleurs elle était assez vaste pour soumettre ces données à l'analyse, embrasserait dans la même formule les mouvements des plus grands corps de l'univers et ceux du plus léger atome; rien ne serait incertain pour elle, et l'avenir comme le passé serait présent à ses yeux. L'esprit humain offre, dans la perfection qu'il a su donner à l'Astronomie, une faible esquisse de cet intelligence. Ses découvertes en Mécanique et en Géométrie, jointes à celle de la pesanteur universelle, l'ont mis à portée de comprendre dans les mêmes expressions analytiques, les 
presumptuous pretensions of the intelligence and furnishing their reductio ad absurdum. Now it cannot be doubted that the ideal in question not merely is, as Laplace observed, at an infinite distance from the possibility of practice, but contains a theoretical defect. But it is very important in what we take this defect to consist, and how far it goes to suggest an inadequacy of intelligence to the real.

In the first place, it is a mistake to assume that such a scheme of calculation is typical of the real work of intelligence in connecting individuality with universal law. And in the second place it is an exaggeration to argue that calculations of the type imagined-founded, that is, on very general characteristics of the spatio-temporal world-have in principle no value at all for the interpretation and even the prediction of what is most individual.

First, then, such a scheme of calculation is not truly typical of intelligence in its dealings with law. Intelligence is fundamentally creative and synthetic, and the more so, the more concrete the world with which it deals. Now though there is literally no such thing as a purely analytic work of intelligence, yet in the treatment of homogeneous quantity the synthetic element is reducible to a minimum. We might perhaps assume the supposed calculation to take a form not exposed to the extreme objection,

états passés et futurs du système du monde. En appliquant la même méthode à quelques autres objets de ses connaissances, il est parvenu à ramener à des lois générales les phénomènes observés, et à prévoir ceux que des circonstances données doivent faire éclore. Tous ces efforts dans la recherche de la vérité tendent à le rapprocher sans cesse de l'intelligence que nous venons de concevoir, mais dont il restera toujours infiniment éloigné."-Laplace, Essai philosophique sur les probabilités, p. 3. 
based on a theoretical defect, that from the movements of a matter conceived as absolutely homogeneous and uniform no difference and therefore nothing could arise. ${ }^{1}$ For the knowledge of data assumed in the hypothesis might furnish a basis for scientific prediction apart from the extreme conception of homogeneity criticised by Leibniz and later writers; and it would still remain a question of theoretical importance how far predictions of life and conduct could be deduced by calculation from any physical data whatever. If the responses of "mind" were to be known beforehand as readily as the phases of youth and age, or of disease, or of the reactions of the lower organisms, that would still be prediction on a relatively mechanical basis. The restitution of a newt's hand is a peculiar feat, but it responds, I take it, absolutely to very simple conditions, and the ordinary course of many diseases is predictable with certainty.

But it is not clear whether Laplace's imaginary calculator, whatever his primary data, is supposed ad hoc to stand to the world of mind as a physicist stone-deaf from birth would stand to the theory of sound; or whether in his knowledge of all forces and of the respective situations of all beings in the world at a single moment there would be included the full experience of mind and its actual objects. In the former case it is obvious that the significance of his results would not be appreciable by himself,

1 See Leibniz on the movement of a uniform wheel (Latta's Leibniz, p. 22I). This appears to give what is the essence of Professor Ward's criticism of mechanistic science. See Naturalism, i. I33, where Ward repeats that argument of the Monadology in illustration of which Latta cites the reference to the wheel from Epistola ad Des Bosses. 
and their interpretation and valuation would be a further and independent operation. But it does not follow from this that the two operations together could give no results of supreme importance. In the latter case, which we may suppose Laplace to have contemplated, the calculator is in principle assumed to have both types of data in his hands, and the substantive question is whether by mere calculation he could, in developing the physical data, develop with them the psychical data and the world of quality, making his knowledge of the universe as complete as the knowledge of a piece of music would be to one who could both predict the vibrations and interpret their musical values.

Now for our immediate purpose the point is this. Whether or no it would be theoretically possible for the calculator to determine the physical basis of every occurrence beforehand, we are not bound to say. But it is certain that, on the extreme assumption that this is conceivable, he would yet be very far from doing the work of the intelligence in the full sense. ${ }^{1}$ In order to pass from moral or social experience given by the hypothesis in his complete view of the world at the moment to the unknown phases of such experience correlative to his physical conclusions, he would have to control and to manipulate in thought wholly different worlds from that of physical nature, worlds aesthetic, moral, political - the regions of life and mind. In any case, give it what assumptions we will, the work of calculation can never be typical of the work of intelligence in grasping reality. We must choose between the types of the deaf physicist, and the

1 Here I am glad to agree with Professor Ward, $i b .44$. 
physicist-musician. In the former case the work is not done ; in the latter a vast additional assumption is employed to make it conceivable.

But secondly, it is false in principle to deny that calculations of the kind imagined might be able to throw light on the operations of mind, whether past, present, or future. We must not forget the continuity of worlds - the building up of the fuller upon the shallower individuality. It would not amount to nothing if a man could do, say, for the analysis of pain and pleasure what the theory of wave propagation has done for the analysis of sound. To say that the comprehension of feeling, or even its experience or actual being, could not or might not be affected by a knowledge of its physical concomitants seems rash if not plainly false. Besides, the world of things in space comprises the organic and human world in simpler ways, which do not amount to nothing. It is something to know, if we do know, that, as a thing in space, an organism cannot be in two places at once, and can only communicate with other organisms under conditions of space and time. In short, it is easy to show that the abstractions of the sciences which deal with things as in space are not everything; but it is a great mistake to suppose that they are nothing, more especially if, in supposing this, one argues at the same time that they are all of actual life which intelligence can comprehend and predict.

It is argued as a matter of general principle that nature is not self-dependent, that it presupposes mind, and that mind cannot be subordinate to or definable by that which apart from it is nothing. I cannot think this an important consideration, apart 
from a definite exhibition of the modus operandi of mind in asserting its superiority. Such an exhibition will be attempted at a later stage of this work. But prima facie the experiences which we sum up as "nature" are none the less what they are because we accept them as coming to us through "mind." Such a general consideration does not alter their content or loosen their connection with the self. To say everything is experienced through mind makes no more difference than to say that everything is the work of God. On the contrary, its prima facie result is to bring them into nearer intimacy, and to tinge all psychical being with something of their character. ${ }^{1}$ In short, all that we know of the worlds of space and time, and of the causally connected appearances which we treat as matter, are already universal connections partially defining the individual real. The real, so far as they define it, may be incomplete and inconsistent, but the whole cannot be cut loose from it. The supreme individuality, and still more any individuality which can be attained in finite experience, is characterised by this fact of appearance in "a nature"; and the further features which seem to us more appropriate to self-determining mind are also universal connections, but within worlds of conduct, which though fuller than what science calls nature, both pre-

1 Note, for instance, the growing idea that psychical states may be extended. I have strong sympathy with much in Professor Alexander's point of view. But it is plain to me that its moral lies in the expansion of psychical and logical characteristics to be characters of "things," in compensation for cutting down the content of "minds." Here I am afraid we should differ. Cf. Professor Varisco's account of external things as elements of consciousness, only, qua things, not included in the unity of any subject ( $I$ Massimi Problemi, p. 30). 
suppose and rest upon it. There can be no reason, prima facie, to deny that what science calls a knowledge of natural law is a partial analysis, and in principle might lead to a high degree of prediction, of what we call individual activity $;^{1}$ and it is false in principle to deny that what we call in the highest sense individual characteristics, are, within the world to which they belong, universal laws. What possible interest or significance could they possess if it were not so-if, say, all Cromwell's actions were not respectively cases under the same universalthe same pervading spirit?

We should instinctively resent prediction of our conduct, it has been well said, based on mere scientific calculation from data existing previous to our birth. We do not resent prediction based on observation and experience of our formed individual character. ${ }^{2}$

The reason is, that the former kind of prediction seems independent of our individuality, while the latter is founded upon it. It is natural to argue, in harmony with this instinct, that the former is impossible, and the latter is possible. The important point, again, is to make a clear distinction between calculation and intelligence. Calculation, in the main, cannot suggest new ideas ; intelligence has this

1 There are, of course, all sorts of things which we can predict out of mere "natural law" about organic beings on our earth; and though for the most part common form, these things, e.g. the need of food, may at any moment leap up into vast moral and historical importance.

2 Bradley, Eth. Studies, p. I8. Cf. Taylor, Elements, p. 220. We dislike not really the foretelling, but the reduction to something which leaves out all we are. In a word, prediction does not matter if it depends on an understanding of what we are, and not on reducing us to what we are not. Cf. "A Study in Bergson," Inter. Journ. of Ethics, October 1910. 
creative insight for its fundamental function. In the nature of things, there seems nothing to hinder the previous calculation of all physical movements and the behaviour of all physical systems such as organic bodies. It must be remembered that this would involve the construction of the whole environment, as it is only in relation to the environment that the development of organic bodies can be understood. Assuming, purely for the curiosity of the speculation, this monstrous possibility, there could be no reason why the accumulation of capacity for complex automatic responses to stimuli-the physical correlate of teleological action-should not be naturally explicable and capable of being scientifically predicted. ${ }^{1}$ But new ideas, the significance of things, according to our previous distinction, would be inaccessible to the calculator as such. ${ }^{2}$ If, however, we were to speak not of pure calculation, but of calculation plus intelligence, then no limitation seems theoretically tenable.

It may be said that you could not predict individual conduct, because the data of individual character could not be complete while any thing remained to be predicted. But in principle intelli-

1 On the correlation of these with psychical process, see Mitchell's Structure of the Mind.

2 If the calculator (speaking always from the point of view of theoretical curiosity) could predict the words - the mere sounds that would be used, but not the ideas, or the movements which make history and not the motives, is this a reductio ad absurdum? It may seem so, but really there is not much in it. The ideas, of course, would come with the cerebral activities which produce the sounds, but the calculator, officially so to speak, would have no cognisance of them, just as the electrician who instals or even who operates a duplex system has no official knowledge of the significance of the messages to be sent, or that are being sent. A battle or a parliamentary debate would be to the calculator like an earthquake or a thunderstorm; or like a treatise to the compositor. Why not? 
gence is one; and new ideas and motives, which could be generated out of new fact, are not inaccessible to forethought in presence of a forecast of the facts. The real answer then would be that, on the extreme speculative hypothesis proposed, calculation plus intelligence might in principle predict the whole of individual character and conduct; but this would only be possible if and because the intelligence in question was able to pre-construct the ideas and habits of the future individual. It cannot be said that we know of no facts at all analogous to this possibility. Intelligence being essentially one, this would be, and is, no detriment to the later individual. It would be as when an earlier thinker or statesman has anticipated the ideas or furnished a solution of the practical problems which are presented independently to a later one. ${ }^{1}$ The latter's individuality, practical and intellectual, is thus in its main lines covered by that of the former; but it is no detriment to his freedom or to his separate actuality. It is merely that finite mind, repeating itself because of its imperfection, has to all appearance needlessly doubled a part. The thing is only too common; it occurs, e.g. in the case of every scientist or philosopher whose work wholly fails to transcend at any point that of his predecessors. No doubt this only applies in practice to the main outline of a man's thought and work, and not, as a rule, to the details of his history; though it is common, of course, for others to know that two people are in love before they know it themselves. But there it is an actual and common and an allimportant fact; and we produce it only as an

${ }^{1}$ See "A Study in Bergson," loc. cit. 
analogy for a very remote speculation. As a fact, however, it is too little noticed, and it has a real bearing on our main issue. In all essentials, the lines of individuals' life-work can be and constantly are either unconsciously anticipated or consciously laid down and predicted by others who come before them, or are close upon them in similar enterprises. ${ }^{1}$ Or, reversing the point of view, surely we may say that to all appearance there are many individuals who in many ways fall within others, and so are surplusage, and "never would be missed," though we must suppose that the apparent repetition has a value which we do not see. Not that to carry out what another mind has predicted is necessarily a defect.

In the above argument, the interest of the question has carried us farther than we were bound to go. Our problem was the relation of Individuality to universal law. And all we were bound to show was the possibility of analysis or explanation, and not the possibility of calculation or prediction. It is enough to insist that an individual system, being a nature or spirit which is universal throughout its differences, necessarily determines between those differences a nexus, which itself is, as embodying a side of the system, universal and necessary. And that it is not repeated in a number of resembling instances is, as we saw, a feature belonging to its universality. Repetition suggests

1 The history of inventions affords many cases. The reinvention of the lever and the screw is a striking instance. The reinvention had been "covered" by the unknown earlier mind. You can predict in short, in as far as you are the same with the individual predicted, and this is not a prohibitive condition, because there can be real identity between different individuals. All mutual intelligence depends upon the fact that individuals cover each other in some degree. 
groundlessness or failure. What truly fills its place as a successful expression of the whole at that place, can fill no other. But its nexus within the whole is intelligible to the mind thinking in terms of the whole, and this is the very type of a necessary law.

And in all the repetitions which every day generalities express, the true type of the universal, however abraded by careless handling, is ultimately to be found. We may fail to observe the differences in or in spite of which a repetition takes place. But it is certain that if they were not there, there could be no repetition; that the two cases or examples, having nothing to hold them apart, could not be two but one. The nature of the universal is traceable even within the bare numerical series, and a fortiori in every constituent of an organic whole.

Every nexus, so far as a universal law, is a necessary determination within and hypothetical upon an Individual whole-whether a world-whole or a member of it, a macrocosm or a microcosm, makes no difference of principle. This is as true of the Law of Contradiction as of the rhythm of the first line of "Lycidas," "and vice versa.

7. I cannot but hold it to be a confusion if sub- To change jective teleology is held to be incompatible with a response the views which have just been advanced. You must be cannot have individuality or spontaneity along with changed. universal law, so the allegation runs, because universal law would require the individual world to repeat its behaviour if the same situation is repeated; and this, if its end or purpose in the two cases is

1 I am assuming that the nexus of this rhythm approves itself to expert thought as necessary in its place. 
different, it will not do, but will respond differently. ${ }^{1}$ The question of teleology will be entered upon more fully in the next lecture, but this much seems clear at once. The end or purpose can be nothing but the nature of the whole, ${ }^{2}$ which is the spirit of the individual world, in as far as its accomplishment is deferred in time, and therefore arouses a sense of want and contradiction because the individual system is sensitive to the delay. It follows that if the purpose is different in two apparently identical cases, the identity is an illusion due to superficial inspection. Within the world which constitutes the individual's being, the contradiction has in some way shifted its place, and this fact cannot possibly mean a new suggestion, an additional idea, tacked on, so to speak, without affecting the organised system, concerning only the future and not the present or the past. $^{3}$ There must have been, in principle, a dislocation of the whole system, a rearrangement of "views," acquiescences, attitudes, and perceptions. The "circumstances"- the elements of the situation which "stand round" the centre of the individual world and take their colour and reciprocal bearing from the adjustment of its content-themselves, as a whole, are liable to have undergone in such a case any degree of transformation, however much their external or fragmentary aspect may remain unchanged. But all this is no contingent

1 Taylor, Elements of Metaphysics, p. 224.

2 Does this way of stating it suppose every purpose to be right ? Only in as far as the Individuality is right, free from defect and deformity. Ultimately, it might be said that to have a purpose is a proof of being somehow wrong. But the wrong may or may not be rightly conceived by the individual.

3 See below on the continuity of purposive adjustment with habitual system. 
or arbitrary new determination; it is the reorganisation of a microcosm-a change of apperception. The truth may well be illustrated by Leibniz's conception of self-developing monads, even though we accept the accession of suggestions from without. For the suggestion from without can only operate by modifying the distribution and connection of the whole; so that ultimately we have, as Leibniz said, a progression of thought and appetition dependent at every stage on the previous phase of thought and appetition. A man who has yielded to temptation once, and who resists the same temptation successfully when it recurs, has not merely exchanged volition $A$ for volition $B$, as one might pick up this pebble instead of that; he has modified his view and sentiment of past, present, and future. His world has dislocated and reshaped itself, so that its main contradiction would now be found in doing what before it was an intolerable contradiction not to do. Purpose, in a word, is secondary; what is primary is the nature of our microcosm; and, of this, purpose is an unfulfilled corollary.

Therefore subjective teleology brings with it nothing to invalidate our conclusion, which is as follows :

Individuality and Spontaneity are not antagonistic to Uniformity of Nature and General Law, if these are rightly understood, but include and necessitate them.

The Uniformity of Nature or principle of Relevancy means that every variation is a member in an intelligible system. It excludes spontaneity only in the sense of behaviour responsive to nothing. Variation is a means of adjustment or response, 
and to establish its existence in a high degree is not inconsistent with, but evidence of, the uniformity of nature in the true sense. The proof of genuine spontaneity is not mere variation, but progressive and adapted variation. Individuality, therefore, meaning not empty eccentricity, but the character of a system as self-contained and coherent, is fully in harmony with the Uniformity of Nature.

Universality lies in the expression of the nature of a system by each and all of its parts suitably to the place or function of each. A system so expressed or organised is a universal, and the nexus between its parts, though none is primarily similar to or a repetition of any other, is a universal nexus or law. It is true that in finite experience, the uniqueness of parts within individuality, or of individuals as parts of the universe, is never perfect. Thus they not only are universals in the true sense, and are built up of universal nexuses, but, in finite experience, necessarily occasion the approximate repetitions-an imperfection-which are expressed in ordinary "general law." Every nexus in finite experience has a potential class or plurality corresponding to it. Individuals are therefore doubly accessible to the intelligence, and, indeed, in many typical instances are its work, though not necessarily the work of cognition nor of discursive thought. Hence there is no occasion to deny that intelligence is in principle capable of anticipating the nature of individuals, their action and cognition; but this is not to say that every form of intelligence, such as calculation per se, is adequate to every type of individual world. The best way to think of the finite individual is to bear in mind the nature of 
a work of art, or of the moral temper as analysed by Aristotle, ${ }^{1}$ or of an organic being as the continual source of adaptation by fine adjustments of extreme determinateness and precision. And subjective teleology, understood as it should be of the shaping and reshaping of a world in the endeavour to find itself and its whole, has nothing to urge against our views. We will speak of it more fully in another lecture.

1 See Appendix II. 


\section{LECTURE IV}

THE TELEOLOGY OF FINITE CONSCIOUSNESS-A SUBFORM OF INDIVIDUALITY

\section{\{HAKMONY}

Individuality is the universal as spirit of a world of which one aspect is Teleology.

I. $W_{E}$ have so far in the main been endeavouring to remove the misapprehension which sees an antagonism between Individuality and the universal. We have attempted to show that it arises from the imperfect penetration of thought, when it accepts the particular in lieu of the individual, and reduces the universal to the general. For us the type at once of the individual and the universal has been the life or spirit of a world, which realises itself in form and determinateness, that is, in fine and adequate adjustment of element to element. For everywhere it is creative Logic, the nature of the whole working in the detail, which constitutes experience and is appreciable in so far as experience has value $;^{1}$ and the more fully we enter into reality the more do we realise the universal nature, the interdependent nexus in which the whole finds expression. All the faults of philosophy, it might be said, lie in failing to apprehend this nature of the individual, and in therefore arbitrarily preferring some one element of experience to the whole. For the whole, of course, cannot be experienced as a whole by us,

1 See Lecture VIII. below. 
and to grasp its constituents and divine its nature is an arduous task; while it is comparatively easy to set the apparent data, uncriticised and unadjusted, over against one another in opposition.

We have now to define our position with reference to one of these sets of data, which is oftep placed in antagonism to the rest. I speak of that popular principle of ethical or theistic Idealism known in general as Teleology. We have further to consider the claims and functions assigned by it - to finite consciousness, seeing that they furnish the type on which ethical and theistic philosophy is apt to model its conception of the supreme mind in relation to the universe.

The object of the present lecture, then, is to examine and estimate the idea of teleology. We have to develop the point that teleology is a conception which loses its distinctive meaning as we deepen its philosophical interpretation $;^{1}$ and that, pari passu, the simplest surface features of finite consciousness, from which its conception is drawn, reveal themselves as an inadequate basis for a theory of reality, perfection, or value.

2. We are familiar in every-day life with the dis- End and tinction of " end and means." It embodies a rough means run discrimination of values, relative to current practice. another. We care for some things for their own sake, for others because they help us to the former. The former, then, serve to explain the valuation or the acquisition of the latter, and themselves need no defence nor explanation. Prima facie, the former come last in time, and the latter, the "means,"

1 Cf. Hegel's view of Teleology, McTaggart's Commentary on Hegel's Logic, sect. 255. 
come before them as conditions precedent of their being attained. "Means" presuppose a degree of impotence. They are ex hypothesi not what we want. We take them because, with the resources open to us, we can get what we want, the "end," in no other way. Thus it is the very essence of an " end" to be partial within a whole, though it may be the completion of a part, and to be selected in contrast to something else, and, prima facie, to events preceding it in time. Aristotle, indeed, whom in this our argument follows, understands by " end" at once the completion of a positive whole which is developing through a process, and the cessation of the process itself. In modern theory the positive whole tends to drop out. The prima facie meaning, based on the current modern usage of "end," has gained the day.

There are indeed facts, in general conformity with Aristotle's view, which might make us pause before treating this temporal and selective character -this essential contrast with a past process and with means-as typical and universal. In many cases of choice it is obvious that consequences have to be discounted on the same footing as means. Our "end," in the sense of that which we aim at, may come first, or in the middle; and the price to be paid for it, the cost of the means, may extend before and after and all round it. We can seldom, in common life, discharge the whole cost before delivery. Thus, at least the temporal distinction between end and means loses its sharpness. Our

1 Cf. Burnet, Aristotle's Ethics, xlvi., with Stout's Groundzork of Psychology, p. 2 I. The modern view makes more of the cessation than of the positive completion. I am referring more especially to the doctrine of vital series. 
view of the end is always qualified by the means, and the means, for computation, include the consequences, or, more largely, the price to be paid. Attainment and conclusion cease to be the same idea; and we become aware that in the whole train of occurrences there is nothing which may not partake of the character of an end ${ }^{1}$ or desirable object.

In ordinary life, we continually experience this blending of end and means - the desired object and its price-and when we approach philosophical reflection it is a fact that starts up into importance. We soon come to recognise that what we have called an end, as if it were a goal and a stoppingplace, is in reality " not a point, but a line," or even a solid; that it tends to expand itself, irregularly, over the whole process of our activity. When, for example, we are dealing with a total system, whether of life or of nature, how are we to discriminate between end and means? We begin with two natural prejudices, the anthropocentric and the temporal, borrowed from our every-day selective practice, and from our primary association of accomplishment and cessation. But neither will stand a moment's reflection. Why should man be the end? And indeed, is there anything to suggest that he is so? Why again assign pre-eminent value to a

\section{To which the whole creation moves?}

1 So in the modern conation theory, the pleasure and the end are found to fall apart (Stout, Analytic Psychology, ii. 273), and the value comes rather to be in the pleasure than in the end=terminus ad quem; i.e. the two characters of value and terminus are dissociated-the one is a concomitant of the whole process, the other is only its close. The same is true of the account of the higher desires which Plato employs; the pleasure is not merely in the satiety of the terminus; it is a character of the whole activity. 
It is obvious that no such ascription of ultimate value to a particular class of creatures nor to a particular moment in time can be justified as an ultimate conception. It rests on the analogy of the choice of a finite being, compelled, because finite, to exercise selection within the universe. It is an attempt to apply the principle of subordination of means to ends to a system within which we can recognise no necessity, and can conceive no clue, for the distinct being of ends or of means. A finite being selects a possible value, and out of the resources which he can find in his world further selects the instruments by help of which he proposes to make it actual. But we cannot conceive that a perfect reality is divided into ends which have value, and means which a limitation of resources compels to be employed to realise them. Such a conception is drawn from the analogy of a finite contriver.

Thus the principle of Teleology when applied to cosmic theory, ${ }^{1}$ loses at once and completely all assistance from the ordinary distinctions of means and ends, and from the presumption of a coincidence between termination and attainment. If it is to retain a meaning, it must abandon the whole analogy of finite contrivance and selection, and must fall back on the characteristics of value which, apart from sequence in time and from selected purposes, attach to the nature of a totality which is perfection. In this transition, the principle of purposiveness, of a nature imperative on every element of a whole,

1 "Parlar di fine, a proposito dell' universo, è adoperar la parola fine in un significato che non è più quello che le conosciamo." Varisco, I Massimi Problemi, p. 2 I 8. 
expands into the principle of Individuality, or positive non-contradiction. In working with it, we substitute the idea of perfection or the whole-a logical or metaphysical, non-temporal, and religious idea-for that of de facto purpose-a psychological, temporal, and ethical idea. We deal with a substantive criterion of value applicable to every detail of a totality, and equally valid if Time is treated as an appearance. The criterion can deal with purposes, but mere de facto purposiveness can neither impeach nor support the-criterion. In short, a purpose as such-a de facto want or desire-only contributes to intelligibility by serving as a reason for its means. For itself, as a mere purpose, it can never exhibit a justification. Every purpose, no doubt, implies a subjective value, but there is no reason why every true value should be a purpose. In extending the idea of teleology to the universe as a whole we are turning from the question whether this fact or that has the appearance of being contrived for a purpose, to the question whether the totality-contrivance or no contrivance, and without any suggestion of dividing it into part which is means and part which is the end-can be apprehended or conceived as satisfactory, i.e. as a supreme value.

The theoretical importance; of the transition is this, that the selective conations of finite minds cannot, in face of such a principle, claim a fundamental position as the source of order and value. And this applies to the mind of a finite god, if such a being is to be treated as conceivable. The finite consciousness is to be considered as creative and as possessing initiative in a sense which we shall 
attempt to explain; but the principles of the universe are thought of as deeper laid than in the choices of finite mind. Minds, as we are aware of them, fall into place rather as an imperfect medium and manifestation of the reality than as an ultimate and sovereign source of it.

The End as Satiety is not Satisfaction.

3. Along with the idea that the true sense of value in the universe is of a teleological type, we find the idea that the true nature of mental process is conative. ${ }^{1}$ And in a certain restricted sense both one and the other doctrine may be sustained, but in the latter case as in the former it is important to note the precise implication.

In the typical conation the important points are the beginning and the close. The beginning is a disturbance, and the close or end is a recovery of equilibrium. As we saw above, in elementary notions of teleology which are drawn in fact from s. the simplest conative experience, the purpose and the close are one, and the end coincides with both. ${ }^{2}$ The recovery of equilibrium means satiety, and this is one with the cessation of the conative process. This is the account of ordinary desire and its satisfaction which Plato on the whole accepted, and it is retained in outline by the modern theory of conation as a "vital series."

But the latent opposition between the two conceptions of the end reveals itself within the pleasuretheory which is continuous from Plato to Aristotle. The "end" for Aristotle's theory was not merely satiety but satisfaction; and satisfactoriness, the

1 Cf. McTaggart on the full meaning of "Cognition" and "Volition," op. cit. sect. 284.

2 Stout, Analytic Psychology, ii. 270 ; Groundwork of Psychology, pp. 2 I, 25 . 
power of giving satisfaction, was a positive characteristic, the completeness of a form, and not simply the cessation of a disturbance. It is a twice-told tale how this idea was worked out in the theory of Plato and Aristotle. For our purpose it is enough to repeat that in Aristotle's usage the term "end" is applied to positive maturity as more than the mere cessation of growth which it involves, and to the continuous or perhaps timeless character of the fullest life and fruition, rather than to the completion of any serial process.

Now at bottom fruition is distinct from conation as above described, as Aristotle is at pains to point out in his criticism of anti-Hedonist arguments ${ }^{1}$; and a satisfaction that can be attained and possessed is something other than satiety. Thus the "end" no longer appears as a terminus ad quem. It has expanded into something which is either a type of activity, independent of and other than conation, or, if it is to be identified with conation, throws a wholly different light, from that by which we described it above, upon its nature and the conditions of its value. ${ }^{2}$ And so we see in recent pleasuretheory, in spite of the primary doctrine that end and cessation coincide, that the desirable element of a conation, its end in the ethical sense, is taken to lie in its character extending over its process and not in its close or termination. ${ }^{3}$ The "End," in the sense of attainment or achievement, expands itself

1 Eth. Nic. x. iv. I.

2 It is clear that for Aristotle $\pi \rho \hat{a} \xi \iota s$ in the full sense and at the highest value - the quintessence of $\pi \rho \hat{\alpha} \xi \iota \varsigma$-is one with the perfect

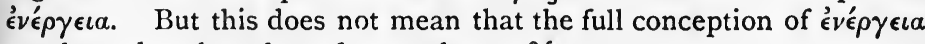
can be reduced to that of every-day $\pi \rho \hat{\alpha} \xi \iota s$.

3 See reference, p. 125 above. 
from the idea of a terminus into that of a satisfactory experience which may be taken as including a conative process of a certain type, or as a new independent and perfected self-affirmation following upon the completion of the changes which form the conation. The distinction made familiar by Kant between sensuous desire and aesthetic interest is typical for this difference, which lies at the root of the expansion above referred to as recognised and emphasised by Aristotle in dealing with Plato's theory of pleasure. In sensuous desire and its satisfaction you have a transition followed by satiety; and that is the typical conation with its "end." In aesthetic enjoyment or any other true fruition, you have a response from an object in which the self is at home, and you have not, in principle and in the main, any transition nor any satiety. ${ }^{1}$ It may be argued that in the higher fruition as in common desire you have really a conative transition, and that the inexhaustible possibilities of the object are in fact what produce the appearance of an achieved and persistent satisfaction. We may agree that this is an element in the case; but still there seems an unmistakable difference of principle. In the process of a finite mind, no doubt, there will always be succession and transition, but in aesthetic enjoyment, for example, it is not the transition towards an unattained terminus that makes the essence of

1 No doubt, as Aristotle points out, in the fullest fruition a man is liable to fatigue. But this seems to be in principle an incident of our limited strength, and not a sign of true satiety with reference to the object of interest. It should be explained that the aesthetic interest or desire which makes us, e.g. go to look at a picture or wish to buy it, does not undo the peculiarity of aesthetic enjoyment in being directed to the pictured semblance of an object, and not to its actual use or possession. 
the activity. ${ }^{1}$ The mind's direction in it is outward, not onward; and one moment of it, as Aristotle urges, is self-complete and as good as the next. It borrows nothing from an approach to a future completeness. Such a fruition may be understood, as is perhaps the natural way of understanding it, to be as it were the protracted terminus of a conation, like eternity coming after time; or may be treated as throwing a light on the true nature and value of conation itself. ${ }^{2}$ In either case, it is something different in principle from the conation whose beginning is disturbance and whose end is satiety.

And the importance of this is that the nature of conation itself has led us back to our old conclusion; and we see again that the true "end" or value does not lie in this special relation to a terminus or finite purpose, but in a character of perfection, which may in finite experience be relatively present throughout. a process, or as a persistent result of it, or at the beginning of it, or in the middle. I repeat, in the simplest case of conation satiety and satisfaction coincide. But if end is to mean a value, satisfaction must be more than satiety. And the idea of conation must be remodelled to meet this necessity, as the modern pleasure-theory, when it lays stress on positive interest within the conation in contrast to mere escape from tension or disturbance, in some degree recognises. ${ }^{3}$

1 Aristotle's counter-attack, alleging that self-complete activity or fruition is really the enjoyable part in all conation whatever, even in the painful pleasures, so that conation would not be in any degree the condition of value or pleasure, may be thought to prove too much, and to correct one mistake by another. The view taken in the text avoids this danger (see Ethics, vii. 12. 2 and 1 4. 7).

2 See above, p. I 29 and following note.

3 Stout, Analytic Psychology, ii. 280: "The analogy of a bent 
It seems to be the case that in finite life conation and fruition coincide in different degrees, from a conation which is principally valued as a release from pain to one which is practically indistinguishable from pure positive enjoyment of self-affirmation, in which if there is essentially conation at all, it is wholly latent. ${ }^{1}$ Between these two extremes there are all sorts of intermediate cases. But the point for us at present is simply the expansion of the idea of end into a connection with fruition and value, and into throwing off all special connection with the ideas of termination as against a process, and superordination as against means.

Teleology supported by Miracle on Monadism.

4. Thus, the point of principle to which I desire to call attention may be stated by contrast with the position adopted by more than one distinguished critic of Naturalism, in maintaining the claims of Teleology against,Mechanism and Epiphenomenalism. As I understand the matter, they rightly contend that the universe, with all its variety and adaptation, cannot really be understood out of quantitative relations between homogeneous units, whether or no such an ideal construction is useful for scientific purposes. It is enough for us to say that, in the first place, the units along with their relations have not the character of self-complete existences-do not fulfil the conditions of self-subsistent being or self-maintenance; and that, in the

spring is not in point." Groundwork of Psychology, p. 24. The effect is that pleasures and pains depend on characters of the progress of a conation, not on its completion.

1 The question is akin to the problem whether feeling involves conation. See Stout, Groundwork, pp. 24, 25, and Bradley, Mind, n.s. xl. p. 449. There is, of course, a wide gap between the simplest effortless enjoyments and the highest persistent satisfaction (say, aesthetic). But the relation of the two to conation seems analogous. 
second place, they obviously wear the features of hypostasised abstractions, which may be of service in describing the world, but cannot conceivably suffice as a theoretical reconstruction of its qualitative and conscious aspects. ${ }^{1}$

But if I correctly follow the critics beyond this point, in proceeding to enforce the claims of teleology within the universe they rest its case exclusively on the capacity of finite consciousness, as such (e.g. apart from its unconscious, or supra-conscious solidarity), for a guidance and selection which constitutes the world as we know it. They deny, as I gather, in principle, that the supreme individuality, whose reality they are concerned to maintain, can manifest itself through a nature which is the complement of mind, and through a social and historical evolution which is more than the work of finite minds. They would not admit that processes, which must appear to the finite consciousness as necessity below it, and as evolution or providence above it, are what equip it with its content, and bestow on it its significance in the world-order.

If I read the tendency aright, the reaction against mechanism bids fair to end in the antithesis of an empty directive unit with a directionless mass of externality, and to enthrone the finite subject, or, worst still, a theistic Demiurge, in his blankness and isolation, as guides and masters of nature and of history. If this is rightly read, I believe that we shall have to recall the votary of mechanism, along with Spinoza, in the interests of the philosophy of history, and the theory of religion. It is intolerable that - Nature, through which alone spirit attains incarna-

1 See Lecture III. 
tion, should be treated as a directionless material; or that art, thought, society, history, in which mind begins to transcend its finiteness, should be ascribed to the directive abilities of units in a plurality, precisely apart from the world-content and the underlying solidarity of spirits, the medium in which all great things are done.

The view in which I find a difficulty seems to be present in two degrees. Either the realm of finite consciousness is taken to be co-extensive with the organic kingdom, that is, with life, and to be responsible for the introduction along with life, of a principle of guidance and construction unknown to inorganic matter, and accounting wholly and essentially for the teleological element in evolution and in history $;^{1}$ or again, the realm of finite consciousness is extended throughout the inorganic world itself, not merely as a possibility of fact, but as a means of accounting for the manifestation of design or harmony in actual nature through reactions which are by others falsely taken to be mechanical. ${ }^{2}$ The distribution of mentality through the inorganic and organic worlds is a mere question of fact; but I am certain that no appeal to it can release us from the necessity of

1 In the sharp opposition between the organic world as on the up grade, and the inorganic as on the down grade, Dr. Ward is very much at one with M. Bergson. On the other hand, as to the nature of the mainspring in the organic world, whether a life-impulse or a teleological consciousness, they seem profoundly at variance. See, however, below on Ward's meaning when he speaks of working the organic machine.

2 For Ward, this view is simply, as I understand, an extension of his individualism. But in asserting the claims of finite mind as known in the organic world he has made its opposition to inorganic nature so pronounced, that I do not see how he can treat the guidance ascribed to finite mind as-immanent in the members of the world as a whole. 
assuming a determinate outward side, which gives content to the mind or will of separate beings; nor can account for definite characteristics of the world from a multiplication of subjective centres alone.

In both cases it appears to me that an error of fundamental principle has been committed. I do not doubt that anything which can ultimately be, must be of the nature of mind or experience, and, therefore, that reality must ultimately be conceived after this manner. But to pass from this ultimate conviction to the idea that finite minds are the sole vehicles and determinants of teleology apart from "a nature,"-a relatively external and mechanical system, by which their content is defined and their individuality manifested, and also apart from a deeper unity through which they co-operate to a harmony transcending their finite purposes-this seems to me as serious an error as that of the mechanistic view itself. And I have attempted to point out that the misconception is deep-rooted in the double meaning of the term teleology.

5. I will insist on this point again. We have seen, Teleology I think, that Teleology is an unlucky term. ${ }^{1}$ In the and Objecsense of "aiming at the unfulfilled" it gives an unreal importance to time, and to the part of any wholeit may be a relatively trivial part-which happens to come last in succession. Of the two implications of the term- "end"-completeness and conclusion -the latter, which is an accessory, usurps precedence over the former which is fundamental. But in truth its significance does not depend on what comes first or last, but what there is in the individual real when it is apprehended in its completeness. Action is 
not truly teleologica(1) because in the time-process some deferred element of some subordinate quasitotality is in it being carried out by means of a finite desire. The "end," in this sense, would not necessarily have teleological ${ }^{2}$ value, and if it had it in some degree, would not necessarily be a leading constituent of it. The true question of value would be independent of temporal relations, and would depend on the structure and significance of the whole in course of completion; that is, on its character of individuality, or nearness to the ultimate whole. The great enemy of all sane idealism is the notion that the ideal belongs to the future. The ideal is what we can see in the light of the whole, and the way in which it shapes the future for us is only an incident-and never the most important incident-of our reading of past, present, and future in their unity. Thus when "end" or "purposiveness" or "teleology" merely indicates the fact that some finite consciousness is urged by some pleasurable impulse or by some unfulfilled idea, there is in this, apart from the content of the idea, nothing specially sacred or significant. ${ }^{3}$ It is vain to look to the bare fact of conscious purpose or impulse for the essence or significance of teleology. Purpose only means, prima facie, that, using

1 Assuming "teleological" to imply something valuable and desirable, in harmony with the universe as most perfectly experienced.

2 Refer to previous footnote.

3 It is all very well to speak, e.g. of pleasure as a guide to fulness of life; but facts of natural selection and of anti-Hedonism (I do not mean in philosophical theory but in the temper and deliberate conduct of mankind) show plainly that the prima facie case is as strong against its guidance as for it. "If your pleasures are right, you survive" is only the correlative of "If they are wrong you perish." 
consciousness in the very widest sense, some creature consciously wants something. But, omitting all the very serious difficulties connected with criticism of the value of the purpose, does the something lose its value when it is attained? Does everything, then, not merely exhibit its value, real or fancied, in being wanted, but derive its value from being wanted? Are fruition or perfection really the death of value?

Are the ideas of positive fulfilment and satisfaction, of a being which is good in itself, and above the alternations of want and satiety, mere chimeras? If this is so, then there is no Absolute, or, if we appeal to finite experience alone, the character of the Absolute wholly fails to suggest itself in or through the experiences of our lives. But, as I have attempted to show, such a conclusion would be flatly in the face both of fact and of theory. No doubt our wants play a part in the ultimate whole, but it is plain that as given they cannot conceivably be a measure of value. We cannot think of an intuitive intelligence itself as creating values out of all relation to a whole with determinate content. It, the "supreme experience," whatever name we may give it, must be one with its world and not a creator out of nothing. ${ }^{1}$

Things are not teleological because they are purposed, but are purposed because they are teleological. ${ }^{2}$ Thus, when we speak of the ultimate real as an individual or as teleological it is hazardous to say that purpose, in the sense of a craving un-

1 See Bergson on the "néant" as the chimera of a possible alternative to all positive worlds (Évolution créatrice, iv.).

2 In the sense explained in footnote on previous page. 
fulfilled in time, can play any part in our conception. Teleology which depends on a feature of the timeprocess is not a teleology which any one but a pragmatist can affirm of ultimate reality; and the lesson thus suggested is only enforced when we come to ask ourselves what is the true test, even for organic evolution, for social progress, or for morals, of the purposiveness of a purpose. Subjective selection is very poor work, except in as far as it becomes more than subjective. Objectiveness of selection, the selection of values which will stand criticism, is the test of true "teleology" or purposiveness.

Convergence of spiritual value and mechanical intelligibility.

6. The problem may be developed by considering the relation of two positions respecting the nature of mechanism whose compatibility has been denied. It has been argued that the position $a$, that nature is instrumental to the development of spiritual values, is incompatible with the position $\beta$, that the spiritual view is that which regards experience as a mechanically intelligible whole. ${ }^{1}$

In considering this question, the first thing is to make our attitude clear, whether right or wrong. For this purpose three points must be explained.

In the first place, according to the ideas developed in the previous chapter, the Uniformity of Nature is here taken as a logical postulate, equivalent to the Law of Identity as interpreted into the Law of Sufficient Reason; ${ }^{2}$ and all attempts to impeach

1 Cf. the author's Psychology of the Moral Self, pp. I17, 126, and Professor Taylor, Mind, lii. 488.

2 Author's Logic, ii. 2 I0-2. If we take the Law of Sufficient Reason as especially implying Teleology, which I understand to have been Leibniz's view, and which is closely analogous to the conception of Taylor's Metaphysics, it really makes no difference of principle. 
it on the score of de facto irregularity in natural phenomena are held irrelevant. To suppose that the Uniformity of Nature is a principle of repetition of similars, and means that the future will resemble the past, and can be impeached by any irregularity which is not taken as miraculous, we considered to be an elementary logical blunder; ${ }^{1}$ While to suppose that such an impeachment is a guarantee of spirituality in the universe is a recurrence to the position of the upholders of miracles in the same imagined interest.

In the second place, we treat it as a parallel error to contrast individuality with law, and to suppose that universal connections are hostile to the former, and only exist in the form of generalities applying to collections of instances related in the way of resemblance. The case of what we vulgarly call an individual, a person designated by a proper name, is a sufficient instance to the contrary. ${ }^{2}$ In the notion that such an individual is not a universal and framed of universals. and that to have a universal you must have a number of resembling points, we have the old fallacy of the substitution of similarity for identity, with the consequent misapprehension of the nature of a universal and as a

Teleology, as we have seen in the previous paragraphs, is simply a temporal sub-form of harmony, just as Sufficient Reason is a subform of Identity in concrete application.

1 The familiar suggestion that granting logical uniformity it is still conceivable that the apparent or de facto inconstancy of nature might be such as to disconcert our theory and practice does not seem relevant here. If realised, it would only mean that different senseperceptions from ours, and perhaps greater intellectual gifts, would be needed to penetrate such a nature, and we should be like savages in regard to it, which is no doubt in some degree the case.

2 Bradley, Principles of Logic, p. 60. 
corollary, the failure to apply a genuine conception of the spiritual.

And in the third place, the idea of mechanism here accepted is one which neither reduces the universe to modifications of homogeneous quantity, nor yet impeaches the "uniformity of nature," and the general quantitative relations underlying natural phenomena. It accepts as the apparent custom of the universe and as a corollary of the interdependence of content and system, that qualities have quantitative connections, and that a high degree of spiritual or emotional expressiveness accompanies a high degree of complexity and intelligible determinateness. $^{2} \quad$ It is one thing to reject a purely abstract calculation as the exclusive scheme of reality; it is another thing to be driven, by a sense of the faulty philosophy of popular science, into the extremes of depreciating the spiritual value of intelligence, and assigning to the bare facts of finite conation an unreal independence in the universe.

In presence of these three explanations the truth and compatibility of the above cited assertions will seem perhaps to be even too obvious. The disputed position was that it is the true spiritual view which regards Nature as mechanically intelligible. The position that Nature is organic to spiritual ends was accepted and need not be defended. It was the consistency of the former with the latter that was in question. What the author desired and still desires to maintain is that either position is inconceivable apart from the other. Individuality, the union of

1 See M. Bergson's criticism of the vortex theory, Les Données, p. I 57 ; and p. 109 above.

2 See Lecture VIII. on the logical basis of the estimate of value. 
comprehensiveness and coherence, the incarnation of non-contradiction, could not be realised in any system which is not transparent according to the Law of Causation or Sufficient Reason. ${ }^{1}$ Where there is (or appears to be) discontinuity, as tested by these characteristics of an intelligible whole, there inevitably is (or appears to be) pro tanto a gap in the embodiment of spiritual purpose and significance. A purpose is not realised, it is not a reality as penetrating and vivifying a mass of content, if it is not affirmed continuously and traceably in a coherent structure. ${ }^{2}$ No purpose or significance can be realised through miracle. Any prejudice to the contrary arises from the logical blunder of fancying the concrete universal - the individual - incompatible with the realisation of "general law"; which is really nothing but a weakened form $^{3}$ of one or other of the universal determinations concerned in the individual structure.

I shall be reminded that causal or mechanical explanation is necessarily incomplete and proceeds ad infinitum. But this is only so if it is taken as

1 I observed above (p. 138 ) on the application of this law to the justification of contingent matter by final causes. If, as we have held, teleology in the sense which connects it with contingency, is secondary and ultimately unreal, the distinction thus founded of course disappears.

2 It is most obvious, and most remarkable, that M. Bergson has never dealt with the conception of a logical universal. His notions of identity and association are those of Mill and Bain. He holds it inconceivable for identity to be realised through difference. The position is absolutely clear in Données, pp. 122, 158. A true notion of Identity would remodel his entire philosophy.

3 Every significant idea is potentially a class - idea ; but to consider it as a class-idea-a predicate capable of plural applications -instead of considering the detail of its content as a member in the universal nature of the system to which it pelongs, is to consider it in a weakened form. To obtain such class-predications, is not, for example, the aim of true scientific induction (Logic, 2nd ed., ii. $174 \mathrm{ff}$.). 
total or absolute, i.e. as involving homogeneity. And even so it is only another side of the same defect of finite experience which makes all teleological explanations arbitrary and eclectic. The former cannot be complete nor the latter rationally justifiable in any experience so far as it is incapable of unifying reality. If both were complete, they would inevitably blend, and the special characters which constitute their differences would become aspects within a unity. This is not an empty imagination. The relation of cause and ground to the whole, on the one hand, ${ }^{1}$ and the tendency of teleology to expand into systematic coherence, ${ }^{2}$ on the other hand, exhibit the beginning of the convergence.

Organic mechanism due to the worldwisdom, not to finite consciousness.

7. A note of the one-sidedness which we are deprecating is to be found in the attempt to analyse mechanism into degenerated finite teleology, on the analogy of secondary automatism; to interpret reflex response throughout the organic world in terms of such acquired facility as that of the skilled pianist. $^{3} \quad$ The contention is that there cannot be a machine embodying an idea, unless it is definitely constructed and also "worked" - supervised and guided-by a finite consciousness with its explicit finite teleology. ${ }^{4}$

In the case of machines constructed by man, there is a certain plausibility in this contention. If

1 Author's Logic, 2nd ed., i. 238.

2 P. I 29 above.

3 Note that if this explanation only appeals to consciousness in the sense of an instinct determined by natural selection, there is really, no basis at all of conscious teleology, beyond the need or pleasure of following an instinct, which implies no guidance by purposive consciousness.

4 Ward, Naturalism and Agnosticism, i. $29 \mathrm{I}$. 
we fix our eyes on their limitations, and not on their positive nature, it is undeniable, of course, that their independence and self-dependence do not carry them far. But this surely is very explicable. It is just because the teleology of finite consciousness, whose construction they are, is itself so very partial and eclectic. The inferior self-dependence of the artificial machine is a mirror of the narrowness of the finite consciousness, and we shall see reason to suggest below that there are problems which civilised man actually solves from day to day, which are, as a whole, beyond the grasp of conscious intelligence, and cannot be dealt with except by a conjunction of consciousnesses only in part determined by their consciousness. Nevertheless, there is nothing in the contact of men with their machines to show, so far as this goes, that the human consciousness is not mechanically constituted; there is certainly no observable point in the construction or control of a machine at which anything but mechanical interconnection takes place between the producer and his product.

And if, instead of picking out the limitations, we look at the possibilities and distinctive nature of a machine, as well as that of any human achievement in material construction, as, say, of a work of fine art, is not its plain lesson that ideas can be embodied in unconscious and external form mechanical in every fibre, and that these cases, which are unmistakable because of their origin in finite consciousness, should give the line to our interpretation of nature where no such consciousness is traceable?

Exactly so, I suppose is the rejoinder, it does give the line to our view of nature, and that view, 
therefore, is that all organic machinery originates in, and is worked by, a finite consciousness But this seems to be drawing a moral which rests on a purely incidental feature, and on the whole is contrary to fact, in place of one which is supported by all the phenomena.

No doubt our machines, for the reason stated above, are one-sided and imperfect machines; and the works of nature excel them in independence, though not in special contrivance. But the works of nature, like the greater achievements of history and practice, are not dependent for their construction and operation on a relevant and explicit consciousness. We know that in man himself it is only a small proportion of the bodily mechanism of which we even say in popular language that it is controlled by consciousness; and whatever consciousness may be present in the world of plant-life or of the lower animals, it is obviously not of a kind that could devise or know how to employ the major part of the complex arrangements of their bodies. A famous argument of Kant applies here in principle. Reason has its purposes, but they are higher purposes than to effect the working of the bodily machine; even in man that is mainly left to reflexes and instinct, and is better done by them. We know that reason is incapable of teaching us to swallow, or to move an arm; and we cannot imagine that the dim feelings, if there are any, which accompany plant-life, taught the orchid to put gum on the base of its pollen-masses, or to adopt stamen-fibres which bend as they are carried through the air. If we ascribe these things to a finite teleological consciousness, we must inevitably be driven on to say as 
much for the forces which, in shaping the Eastern Mediterranean, prepared the essential basis of Graeco-Roman and Christian civilisation, or which made Great Britain an island, and planted marble mountains in Attica.

I am not concerned to maintain that purposes and ideas do or do not as such operate in nature; it seems doubtful what the question can mean. What I am interested in pointing out may be taken to mean almost the reverse, viz. that Nature below conscious intelligence, and Providence, if we like to call it so, above, can achieve, without the help of a relevant ${ }^{1}$ explicit consciousness, results of the same general type as those which are ascribed to the guidance of finite minds. The participation of the inorganic world in history is thoroughly continuous with that of the organic world; and it will hardly be contended that in the former at all events finite consciousness is operative, or that the process is not mechanical in the sense we have given to the word.

The notion that expression of ideas is somehow opposed to mechanism is widespread and tenacious. And it is a fallacy of the same kind as that which takes uniformity to mean that the future will resemble the past.

Thus, for example, in dealing with the utterance of mind through the fine arts, we constantly speak as if "expression" came somehow straight from the soul," while "mechanical finish" was something different in kind. But in truth, of course, both are prima facie alike mechanical, and "expression" must mean, at least in some respects, a more perfect

1 I mean by this a consciousness having before it the full end which is achieved.

2 Cf. Ward, Naturulism, i. Io9. 
mechanical control over the medium than what is termed par excellence mechanical execution. Mind and individuality, so far as finite, find their fullest expression as aspects of very complex and precisely determined mechanical systems. This is the law, I believe wholly without exception, for every higher product of human soul and intelligence and also of cosmic evolution. It follows necessarily from the nature of "being and trueness," as Plato calls them. The greater being must have the more perfect coherence, and the more perfect coherence must have the fuller content. The mechanical appearance-the continuity of transition and determination -must therefore be unbroken, though we may suppose it to depend on the nature of a system in which individuality is manifested through universal law. But it is idle to appeal to finite purposive consciousness as in principle the sole vehicle of teleology within our experience, and the source, through its fossilised habits, of what is construed as a mechanical "nature." The external must be frankly accepted as a factor, actual but not ultimate, in the universe.

Having now, after the argument of section 4, no need to restrict teleology to the realm of finite purpose, we can freely suppose the world-plan to be immanent in the whole, including finite mind and also mechanical nature. Thus the obviously secondary and fragmentary being of the former would constitute a partial revelation of the meaning of things, but by no means its principal vehicle or the sole organ of guidance in evolution or in history. The point here maintained against the critic depends on the continuity of mechanism with the individuality 
of the real, in virtue of that deeper aspect of the latter which is logical rather than teleological. This is why, admitting a certain inadequacy in the mechanical view as commonly understood, we still contend that the true spiritual ideal demands mechanical intelligibility.

8. We may now approach a positive result, and The first take for illustration the case of an organic "plan" product commonly supposed to be below the line working of consciousness, say, a flower. Our view excludes whole. two extremes. On the one hand, it is ridiculous to say that such a product arises by accident; that is, as a by-product of the interaction of elements in whose nature and general laws of combination no such result is immanent, as though we were dealing with the insight of a human contriver, by which the more complex developments and combinations were not anticipated. It is impossible in this way to treat part of the world as primary and part as a secondary superstructure. We must interpret the nature of nature as much by the flower as by the law of gravitation. If we come to that, there are appearances which we cannot on any sound principle refuse to rank with the flower as teleological, in the most direct and simple formations of the inorganic world. The motions of the solar system, the curl of a wave, the curve of a cataract, the abruptness of a precipice, are appearances deeply rooted in the simplest material data, and yet, for all we can see, as well meriting a presumption of teleological value as any object of consciousness except consciousness itself. ${ }^{1}$

1 Ward (Naturalism, i. $276 \mathrm{ff}$.) has insisted on the downhill trend, the "katabolic" character of the physical environment. And he 
On the other hand, we must not say that "purpose is operative" in the flower or the wave, if that is to mean that we ascribe them to an end or idea, somehow superinduced upon the course of their

connects with this its non-teleological, non-constructive character. "The inorganic world has nothing to match dynamite, Liebig's extract, a steam-engine, or a ship-torpedo." But there are some points to bear in mind if we think of drawing a fundamental contrast. I. The "katabolic" processes of inorganic nature are physically continuous with and essential to the "anabolic" processes of life, and if the latter are teleological the former can hardly be otherwise. The whole life-process as storage of energy, e.g. depends on the sun. Much of the work done by purely inorganic forces, e.g. the change of rock into soil, are obvious conditions of the adaptation of the earth to life. It, therefore, can make no difference of principle whether life arose on our earth's surface or not. 2. It is only by an eclectic type of teleological judgment that inorganic nature can be termed in itself non-teleological. A sunset or a mountain or a stormy sea, not to speak of the solar system, though they need no anabolic process, yet, if we think of them as ends, give as much colour for supposing a directed process, a machine that produces them, as Liebig's extract or a ship-torpedo ; and their value, surely, may well be reckoned as not smaller. You reply, "They need no construction, no machine; they flow from the principle of least resistance." But then, we urge, the contrast between teleology and the principle of least resistance falls to the ground. 3. The continuity of the earth's geological structure with social and historical teleology is obvious. They plainly and essentially belong to the same process. "Not so, for life has simply used what it found, and could have used anything it found, and perhaps has used quite different conditions in other planets." This is no answer, in face of the different degrees of success in adaptation which we observe. Life might, for all we know, be successful on different lines from those which prevail here; but our kind of life, at all events, does not deal equally well with all actual conditions, and there is no reason to think that any other kind would be more absolute. Clearly it needs a basis which is at one with it. It does appear to me as if Ward had not made up his mind between an unteleological foundation plus "guidance," and a nature which is self-directing throughout (cf. Nat. ii. 253-54). And I believe the reason lies in the refusal to admit a true externality and the consequent belief that whatever is teleological must be living and subjective (see above, p. I 42); cf. also “' L' evoluzione geologica e la biologica non si possono separare" (Varisco, I Massimi Problemi, Milan, 1910). It is hopeless to separate inorganic from organic in respect of teleology. 
elements by a power comparable to finite consciousness, operating as it were $a b$ extra, and out of a detached spontaneity of its own. If the former notion spelt accident, this spells miracle.

We have seen that teleology is destroyed if no determinate universal relations between the differences of the unity can be truly predicated. As we saw in Lotze, ${ }^{1}$ it is impossible to find a point at which life is not in appearance mechanically conditioned. Thus the individuality manifested, apart from operative consciousness, in a flower, or mountain, or wave, really forces on us a conclusion which goes so far that the case of human consciousness, though appearing so widely different in degree, can hardly carry us further in principle. ${ }^{2}$

Avoiding the two extremes just pointed out, we are driven to affirm that in the structure and being of the flower the common natural elements behave according to what they are, and that the wonderful creation we behold is simply the immanent development of certain factors, which, no doubt, in their isolation seem far enough removed from anything of the kind. We have, indeed, to bear in mind that the environment, the objective selection, of the world, has been active. It is not in a few elements, as laid side by side in the laboratory, but only in the whole interactions of nature, that the plan of the flower has been immanent. All that we are certain of, and of this we are certain under any view of evolution, is that the structure of the plant or

1 Page 99, above.

2 Relation to consciousness, presence in an experience, is no doubt the sine qua non of all values. But this does not forbid a comparison of our experience of external objects, as indicative of teleology, with our experience of our conscious acts. 
animal is a microcosm from which, with adequate knowledge, the nature of its environment could be read off. Whether we attempt to adhere to the strictest doctrine of natural selection, or assume a cause of psychological nature, with or without inheritance of qualities acquired by individuals, the fundamental point remains the same ; it is the world, the environment, which is responsible for the respective differences between the forms of organic evolution. The powers of protoplasm or the initial impulse of life ${ }^{1}$ are a common condition and might be responsible, at the outside, for certain common phenomena in the divergent lines. But on the whole, through one capacity of life or another, it is the world that has given content to the individual commonly so called. The thing is plain in the sphere of intelligence (and? volition, ${ }^{2}$ and with the slight possible reservation indicated above it is no less obvious in the world of organic evolution. I venture to urge that here we are really not relying on any point which can be disputed on metaphysical grounds. Say if you like that the cause is psychological, e.g. that it is subjective selection and not a reaction of matter as such. Still, no sane man will maintain ${ }^{3}$ that in the regions of structural adaptation, except in our conscious efforts to develop the human body, such a psychological cause does conscious teleological work. There is really an equivocation in suggesting that the assumption of

1 Bergson, Evolution créatrice, passim. Cf. Varisco's spontaneity of the monads. All this "life impulse" and "spontaneity" seem to me merely devices to represent a concrete start for the universe. But the universe must be what it is, and they might just as well assume a "nature," as I do.

2 See Lect. IX., below.

3 See p. I 44, above. 
such a cause in these cases helps to account for their teleology. It does not solve problems, nor contrive adaptations. In fact, it would be much truer to assert that subjective selection is negative and natural selection positive than with writers of eminence to affirm the reverse. Subjective selection, we must conceive, offers an infinity of reactions tending to pass into habits; and it is only natural selection that can mould them to a definite line of progress, and elicit from among them a positive structure. To say that natural selection is negative is like saying that the sculptor's art is negative because it works by removal. If "mind," then, is operative in the structural adaptation of the animal and even of the plant, it is not operative as mind. It does not contain the plan, or guide the line of progress. It may be, as compared with the reactions of matter, a more felicitous conception of the agency by which the plan, immanent in the whole, can be appropriated and actualised. But in any case, we are sure of this, that a work as wonderful as the works of finite consciousness is done, say, in a flower, without any intervention of consciousness as a teleological agency; that is, as endowed with a plan or capable of solving a problem. In this case no one would advance the suggestion of the miraculous intervention of a consciousness, which would meet us if we appealed to the embodiment of mind in artificial machines or in works of æsthetic expression. ${ }^{1}$

And, moreover, any such suggestion has, in my

1 In Driesch's Entelechy, which is his name for the power underlying the wonderful facts of alternative development, or repair of injuries, there is, of course, no question of consciousness. 
view, been entirely put out of court by the examination to which we have subjected the correlative conceptions of mechanism and teleology. The idea that when a man constructs a clock, or composes a sonata, you have a purposive intelligence operating by the bare form of design on a system which thus receives something that cannot be communicated by the reaction of mechanical parts on one another, should now appear to be a contradiction in terms. No one would think to-day of accounting for a flower by an explanation of that kind, say, by the purposive interposition of a creative intelligence, and whether or no Nature can aim at ends, it is bare fact that without any contriving consciousness she can present them to our minds.

Thus we have partly seen, and we may now further see, that the foundations of "teleology"really individuality - in the universe are far too deeply laid to be explained by, still more, to be restricted to; the intervention of finite consciousness. Everything goes to show that such consciousness should not be regarded as the source of teleology, but as itself a manifestation, falling within wider manifestations, of the immanent individuality of the real. It is not teleological, for the reason that as a finite subject of desire and volition it is "purposive." It is what.we call purposive because reality is individual and a whole, and manifests this character partly in the short-sighted and eclectic aims of finite intelligence, partly in appearances of a far greater range and scope. The largescale patterns of history and civilisation are not to be found as purposes within any single finite consciousness; the definite continuity and correlation 
of particular intelligent activities, on which the teleological character of human. life as a whole depends-the "ways of Providence"-are a fact, on the whole of the same order as the development of the solar system or the appearance of life upon the surface of the earth. It is impossible to attribute to finite consciousnesses, as agents, the identity at work within finite consciousness as a whole. This identity is exhibited in a development which springs from the linked action of separate and successive finite consciousnesses in view of the environment. ${ }^{1}$ Every step of this development, though in itself intelligent and teleological, is in relation to the whole unconscious ; and the result is still "a nature," though a second and higher nature. This principle is all-important, and holds throughout all levels of being. I am content to stake my whole contention upon it, and if it can be overthrown, or if I have misconceived the relation of anti-naturalist writers to it, I shall be most eager to be set right.

9. I will repeat and emphasise the two parts of Two the contention.

points.

Teleology

The below consciousness.

i. There is teleology below consciousness. The intelligence of man and of animals that can be called intelligent does not, as I see the matter, sustain or conduct their bodily life. To say that all vital responses have been inherited from volitional or quasi-volitional behaviour is, to my mind, doubtful in fact, but in any case, an evasion of the point of principle.

In the first place, if something analogous to volition ${ }^{2}$ moulded the structure of the body in

1 This argument, as was suggested above, is capable of a further application. See below, p. I $59 . \quad 2$ Lotze, Metaphysics, sect. 230. 
earlier phases of evolution, it never moulded them by any conscious wisdom in the mind of that phase ; it followed, almost blindly, the determining of a deeper wisdom, which lay hidden in the general structure of the environment. The denial of teleological significance to natural selection is typical of the contention which I am arguing against.

In the second place, whatever mind may have done in the past for our bodily structures and responses, this cannot come into court when we ask. what part it plays to-day. Man's mind and purposes presuppose, accept, and are founded on, his actual body; the plant-mind, if there is one, presupposes and accepts the plant-form. Say here, as was said of man, that mind is present from the beginning; still it is present in forms so elementary that they must on the whole be moulded rather than mould. The orchid, as I have said above, could have no mind that contrives its fertilisation any more than man has a mind which could teach him to swallow or digest, or could choose the place or century of his birth. Everywhere finite consciousness makes its appearance, so far as this is obvious and unmistakable, at a relatively high level, focusing and revealing the significance of a huge complication of mute history and circumstance behind it and surrounding it.

Teleology above consciousness.

ii. And with the mention of history, and the time and place of a man's birth we come to Teleology above finite consciousness. In history, or in what is greater than history, the linked development of art or ideas and religions, the principle of a teleology beyond though exhibited in finite consciousness is clear and unambiguous. It is not 
finite consciousness that has planned the great phases of civilisation, which are achieved by the linking of finite minds on the essential basis of the geological structure of the globe. Each separate mind reaches but a very little way, and relatively to the whole of a movement must count as unconscious. You may say there is intelligence in every step of the connection; but you cannot claim as a design of finite intelligence what never presented itself in that character to any single mind. The leader of a Greek colony to Ionia in the eighth or ninth century B.C. was certainly paving the way for Christianity; but his relation to it, though in a higher way of working, was essentially that of a coral insect to a coral reef. Neither Christianity nor the coral reef were ever any design of the men or the insects who constructed them; they lay altogether deeper in the roots of things; and this, as I hold, really carries with it the conclusion which in principle must be accepted about evolution. Nothing is properly due to finite mind, as such, which never was a plan before any finite mind.

IO. The contrast, then, of mechanism with tele- what ology is not to be treated as if elucidated at one ology is not to be treated as if elucidated at one Finite Con stroke by the antithesis of purposive consciousness $\begin{gathered}\text { sciousness } \\ \text { applies to }\end{gathered}$ and the reactions of part on part. It is rooted in the very nature of totality, which it regards from two complementary points of view, as an individual whole, and as constituted of inter-reacting members. Of the two points of view, it is impossible for either to be entirely absent. Assuming this impossibility to be possible, a total failure of mechanical intelligibility would reduce the spiritual to the miraculous, 
the negation of all spirituality, as a total failure of teleological intelligibility would reduce individuality to incoherence, and annihilate mechanism. But teleology, being usually thought of par excellence or in abstraction, may more easily be supposed absent than mechanism, which must attend any inter-relation at all. "Understanding without Reason is something, Reason without understanding is nothing." 1

The entire doctrine of theism in the Kantian sense as involving a personal creator and governor of the world, and with it the paramount importance of subjective selection and bare finite consciousness as agents in the universe, in contrast with natural selection and the immanent plan of things, is here called in question, though another and a deeper importance might attach itself, as has been indicated, to finite consciousness from a wholly different point of view. The meeting of extremes in metaphysics is not a thing that should surprise us; and the polemic against the mechanical view of the universe and the epiphenomenal doctrine of intelligence may find these conceptions falling back upon an alliance unexpected alike to themselves and to their antagonist. In these suggestions we are entirely discarding the actual context and contentions of recent epiphenomenalism. But the name "epiphenomenalism" seems to suggest a significance which has not usually been given it. I do not mean to treat consciousness or the self as a byproduct or an accessory; but it is becoming more

1 Hegel's Life, Rosenkranz, p. 546. There is really a teleology in any order, and there must be some order (Bergson, Évolution créatrice, p. 240). But our ideas of teleology are arbitrary and eclectic; and in our sense, therefore, Teleology may be absent. 
and more obvious that, qua the developed finite mind, they must be regarded as appearances which come on the top of a great deal that must go before them. Two opposing contentions seem to demand fusion. To the voluntarist, the believer in a something hardly conscious, underlying explicit intelligence, in which he finds the fundamental reality and the true mainspring of the soul, it must be admitted that a vast underground work is involved in the formation of an intelligent moral being. The conscious self is plainly the last word of an immense evolution which is practically and relatively from unconsciousness to consciousness; and presupposes, necessarily presupposes, so far as we can understand, the co-operation of unconscious nature in moulding the foundation of mind. ${ }^{1}$ I see no logical value whatever in assuming the presence of mind in simpler forms at earlier phases of evolution.

But to admit all this to the advocates of an obscure something called the will-to-live does not destroy, but, if rightly understood, corroborates and enhances, the significance and value of intelligence, and of self-realisation through the realisation of ideas. For it is this that is brought to pass as the climax and the revelation in as far as the underground self emerges into completeness. It is only then that we begin to learn what we are, and to enjoy or possess ourselves, and, by consequence, the world.

The conscious and intelligent self is on the top of, it is made possible by, all the stress and com-

1 " $\mathrm{Ma}$ perchè la monade si svolga in un soggetto $\mathrm{e}$ in un io, è necessario che divenga il centro d'un organismo, che quest' organismo passi per le diverse phasi," etc. (Varisco, op. cit. p. 222). I cannot see how the monad helps. 
plexity of the work that goes before it. If instead of calling it epiphenomenal we call it the climax and sum and substance of evolution, we should be stating the truth which epiphenomenalism caricatures. But it follows, of course, that when the self comes, it does not come empty or without presuppositions. Mind, in a sense, no doubt is the active form of totality, and in that sense is everything; but every particular finite mind has received some filling before it is aware of itself; and it could not be aware of itself if it had not. It begins, so to speak, high up in the world of experience, and is in possession at starting of a content and a machinery which its world has prepared for it. However little a man to-day may believe in materialistic determinism he will be slow to deny that the bodily arrangements and mechanisms are at least the basis of the working of the soul. If we look at the matter rightly, this gives the organised consciousness an enormously greater significance and importance, than if we held it to be, so to speak, a structureless intellectual protoplasm. It is nothing less than an individual spiritual body, a special utterance and revelation of the universe in its highest finite form. It is bare consciousness and the unmoulded power of selection that seem to us in their emptiness impotent abstractions. The concrete self is different, and, as we have said throughout, is a world within a world of worlds.

The similarity between these ideas and the deepest conclusions of religious philosophy cannot fail to attract our attention. That on the whole the finite intelligent being has the duty and position rather of coming to himself and awakening to his 
own nature and his unity with what we call, by an imperfect analogy, a greater mind and will, than of controlling the course of the world, or moulding it as an independent cause, this is a point of view which seems to demand reaffirmation. ${ }^{1}$ At least it is suggestive as against claims which largely spring from making absolute the attitude of individualistic moralism, and has, I think, been divined with a Spinozistic enthusiasm, though not adequately expressed, by some of the scientific leaders whose inadequate mechanical theory is the legitimate prey of recent philosophical criticism.

It will be necessary at a further stage to deal expressly with the question of the finite individual's freedom and initiative. It is enough for the present to suggest that as a self-conscious being he is in principle a member of the universe inter pares; he is something, however trifling, without which it would not be what it is. $\mathrm{He}$ is, indeed, an organ through which, however slightly in degree, the whole maintains itself. And, therefore, it could not justly be maintained that nothing is genuinely done or effected in him and by him. Only the erroneous implication must be avoided as if a finite individual could find as it were a $\pi \circ \hat{v} \sigma \tau \hat{\omega}$ outside the universe and proceed to act upon and reform it. A doctrine which brings together the conception of action, freedom, initiative, achievement, on the one hand, and of the coming to oneself, learning one's place and nature, awakening to one's membership, and rejoicing in that, greater than one's self, which underlies and surrounds one's self, ${ }^{2}$ may give and

1 Cf. McTaggart, Studies in Hegelian Cosmology, sect. I 35.

2 "Haeremus cuncti superis." 
receive assistance in the attempt to conceive the relations between mind and body, or if this is an incorrect expression, the way in which spirit appears as a focus to matter.

To put the case in the extreme. If finite consciousness were nothing, beyond a mind awakening to the significance of that realm or circumference of externality to which it serves as a centre, and a self-identification with the logic and the tension of the absolute in that one vortex or focus of its being, can we say that this would amount to no achievement, and to nothing at all of value? But I am not maintaining this ; it seems as if we might get nearer the matter and make a better case for personality and initiative than that of mere revelation and awakening. Still, dare we say that this alone, the mere recognition of the infinite in ourself, would be nothing worth having, and nothing in which the living finite man-the conscious body as a whole, might be ennobled by achievement? 


\section{LECTURE V}

BODILY BASIS OF MIND AS A WHOLE OF CONTENT

I. WE have seen that teleological wholes are in- Alleged evitably constituted by what may fairly be called mechanical relations, that is to say, a determinate tion of Mechanism. relativity of part to part in the light of the whole. In accordance with this contention we have so far insisted upon the "mechanical" aspect of the material expressions of intelligence. Now we are to argue from the character of material expressions of intelligence to the general possibility of a material counterpart of consciousness, the term counterpart being used in the restricted sense suggested by the relation of " equivalent" quantitative and qualitative series. $^{1}$

But one misunderstanding should first be guarded against. "Granted," it may be said, "that within every teleological whole there is and must be something which we may call mechanism, yet nevertheless we must bear in mind the complete and certain subordination of Mechanism to Teleology. The end determines the means ; the means, the parts or elements, with their determinate reactions, have no initiative; no power of self-organisation; they are

1 Cf. author's Logic, 2nd ed., ii. 74 ff. on " a and $a$ series." 
in no sense to be credited with the end; that can only come from purpose."

Now we have seen that in one sense the "mechanical" point of view is really subordinate. It is-though not logically or truly separable-yet separable on sufferance, separable as accompanying an insight which is imperfect in comparison with the complete apprehension of an individual whole. A child will quickly see how one brick rests upon another; it would be beyond him to understand what thickness a wall must have to carry itself and the roof, or how the lines of the house must run if they are not to jar with one another for the educated eye. These are all "determinate" reactions, and "according to law"; but as the construction of the whole is approached they become more various and harder to hold together, so that, for example, the fact that every brick must be held in place by something else, becomes relatively less and less illuminating as we go on to consider the buttress or the arch.

But if we pass on to say that the purpose of the whole "determines" the mechanical factors, we seem to be transmuting the antithesis of part to whole within something individual into the antithesis of bare particulars to an empty generality. The "purpose of the whole," after all, simply is the whole, put together as it must be put together if it is not to contradict itself and the context of experience. Certainly you could not construct such a whole as a human dwelling-place by attending solely to the laws according to which bricks can be built up into a wall. The essentials of life, apart from which the structure will be self-contradictory, must impose a number of conditions and reservations on 
the choice and application of material ; and in this sense one may say that the material is subordinate, and is selected by the purpose of the structure. Only we have clearly to understand that this point of view is purely relative; that the essentials of life on their side must clothe themselves in determinate form, and submit to selection and modification by the nature of what is called par excellence the material, as actually, though not in general to so great a degree, as the material by them. And by entering into this larger combination, what first appear as the several conditions, the definite isolable factors, show on their side that more is immanent in them than we knew; and in face of the work of a great architect we may exclaim, "I never thought that such things could be done with brick," perhaps, or " with iron."

"But are you not forgetting," it may be urged, "that a heap of bricks left to itself will not so much as build itself into a wall? Surely the man with his pair of hands is the all-important factor, with the appearance of which on the scene teleology begins to operate directly, and ideas impose themselves upon what would otherwise remain mere heaps of material." 1

This does well enough for a rough statement of apparent facts from the point of view of common sense; but it is inadequate for critical theory, and, as is constantly the case, the supreme insight of skilled and sensitive practice will be found to support the attitude of theoretical criticism.

What is it, then, that man with his hands can

1 Cf. Driesch, Gifford Lectures, ii. 193, which I had not seen when I wrote this passage. 
do? He can apply a mechanical force which in virtue of the character ultimately revealed in consciousness ${ }^{1}$ is able to react in view of a great variety of conditions taken together as a whole, and as a whole extended in time. He cannot-I speak now of what is indisputable, of external effects-he çannot produce in the world any change except by his bodily mechanical force in strict co-ordination with the forces and qualities of material things. The idea in his consciousness is powerless except in as far as it is a guide) to combinations and modifications which are latent in determinate Reality, including his own physical abilities. His advantage over "natural" objects is that his range of combination is wider - that it is, indeed, in principle universal, for all that can be experienced can enter into his construction of the world. But yet, in his operations on nature, he is essentially no more than a co-operative mechanical force. He may be the predominant partner, from dealing with a completer whole; but in principle he is just as dependent on the reactions which he can elicit from the other members of the partnership as he is on his own. His very ideas are not created from the-void, but simply represent the immanent capacities of his world as it develops in fact and for consciousness towards a more individual whole; and so far as by defect and confusion they fail to represent this, they become mere empty symbols of ignorance and impotence. After all, then, the man with his hands does not bring with him a new principle or create out of nothing a new totality. He reacts, so to speak, to a- much more concrete whole than his 1 See below, p. 198. 
material copartners, but he can do nothing with them beyond what it is in themselves to do. Teleology, if we know what we mean by it, is a very good name for the principle of his action; but it only means that he is able to take account of more complete totalities than those with which material objects in random grouping (i.e. grouping not specially interesting to man) are likely to be in relation. Every bit of his totality, as of theirs, is determinately necessary in the combination which constitutes it. As an end it is not to be credited, on the side of content, to finite, conscious, and "purposive," interposition. It is the purpose of a section of the world which through consciousness has become explicit; or perhaps, which in making itself explicit has found it necessary to develop consciousness. It may be rejoined that at least the man wants it, while there is no meaning in saying this of the material associates of his work. But this again probably covers a fallacy. "The man wants it," means that under all the conditions of the situation he finds in himself a contradiction if he does not have it; but take away the conditions of the situation and you modify or remove the want, while if the conditions are to remain and to count in the result the want cannot be ascribed to the man-the man cannot be ascribed to the man-in abstraction from them.

The sense of co-operation, thus demanded by theory, is strongly marked in the highest grades of practice, without, it may be noted, having any recourse to pan-psychism. The sculptor tells us that the statute is found lying in the marble. The glassmaker reports that the "metal" (the heated glass) 
is alive in his hands, simply coaxing him to make something beautiful. ${ }^{1}$ The iron-forger, it has been said, is useless until he acquires the feeling of the iron. $^{2}$ These things are more than rhetoric. The matter-the physical medium of art, is one-half its inspiration. Teleology does not come out of the empty mind; it is the focusing of external things together until they reveal their internal life.

Dangers of "Interaction."

2. In approaching the discussion of a "mechanical " counterpart of conscious process, it will be well to begin by explaining the point of view which for us gives interest to the question.

It is strenuously denied that the hypothesis of “ interaction" supports Indeterminism. One would be glad to credit this denial, and it may be admitted that the connection between the two hypotheses is not inevitable. But the confusion which prevails in the whole treatment of teleology strongly suggests that the connection is natural, if not inevitable, and that if it is abandoned the main attractiveness of interaction-in itself a difficult view ${ }^{3}$-is removed. It is possible no doubt to conceive a system of a purely psychical nature such as to fulfil the conditions essential to connected mental process, and differentiated character or energy. And there would seem to be no theoretical objection to the idea of such a system in itself. But if it is bona fide to satisfy an interest which can not be satisfied compatibly with the idea of a mechanical counterpart, then there is a question if it can remain within the conditions of

1 Morris, joint vol. of Lectures on Art, p. 195; Bosanquet, History of Aesthetic, p. 455.

2 Daudet's Jack.

3 See Stout, Manual of Psychology, Introd. Chapter iii. "Body and Mind." 
determinate interconnection, and whether the whole conception of the individual as being something, or possessing a nature of his own, would not have to be surrendered. In short, the idea of the mechanical counterpart is not so valuable for its own sake, as by way of a protest against a certain theoretical tendency, apart from which the exclusion of the mechanical from the conditions of psychical action would lose all its attractiveness.

We have seen the strength of this tendency in the impulse to bring purposive action into sharp antithesis with determinate reaction; to treat purpose and selection as if they were sufficiently explained by pronouncing the word consciousness, and as if the logic of the whole or the assertion of unity against contradiction ceased to be intelligible when we pass from the laws of nature to the aims of conscious action. Now so long as we continue to pay attention to all that side of purposiveness and teleology which finds expression in the material and quantitative counterparts of mind-the socialised surface of the earth, the machine, the work of art, the body, - we have before us something which emphasises the intelligible and coherent side of content and self-expression. ${ }^{1}$ We observe-and it is contrary to our most dangerous prejudices but fully in harmony for example with Plato's deepest views - that the subtlety and precision of correlations which are quantitative though not apprehended through number does not diminish but

1 There is a tendency to say that the unity of a system can lie solely in the purpose, and to treat it as a high conception that the means may be without limitation adaptable to the purpose. It follows from our analysis of teleology that this conception is a contradiction in terms. 
increases as we approach the completest forms of self-utterance accessible to man; and we are led to look for the differentia of the spiritual rather in the most comprehensive organised harmony than in the escape from determinateness and sufficient reason. ${ }^{1}$

Now it seems to be in this very escape from

1 The typical action which, e.g., M. Bergson loves to use as an instance is the raising of one's hand. (Evolution, p. 99 and elsewhere.) And, no doubt, its unity as a felt action is very simple, though if M. Bergson takes it as indivisible in the sense of not possessing diversity because it is comprised in a single feeling, his view seems incorrect. (See Bradley, Mind, lxix. p. 5 I ; Appearance and Reality, pp. $52 \mathrm{I}$, 569.) No doubt, also, as M. Bergson observes, the analysis of such an act into definite multiplicity, as e.g. into spatial positions traversed by the hand, is the application of an external point of view, which does not present itself in carrying out the act. That is to say, the positions traversed are felt as a whole, not one by one. (Mitchell, p. 45.) But what a type of act to choose, compared with what Spinoza or Leibniz, or M. Bergson at his best, would term in the full sense a free activity! ("C'est de l'âme entière, en effet, que la décision libre émane; et l'acte sera d'autant plus libre que la série dynamique à laquelle il se rattache tendra d'avantage à s'identifier avec le moi fundamental." Données, p. I 28.) What are we to say of the action of a statesman or a general, or of any dominant action in which the whole of a life is summed up, when a single piece of conduct issues from the logical focus of a library of books and papers and a life-time of experience? And for us, these are pre-eminently the actions by which man is man. And one strongly suspects that underneath the emphasis laid on spontaneity and immediacy of action as a part of "life," and as contrasted with intelligence, there is a basis of latter-day prejudice and pessimism, by which the value and genuineness of such work as that just referred to is depreciated, and the conscious side of creative art and invention disparaged, by contrast with what is in the narrower sense naive and impulsive and impressionist. We may call attention in M. Bergson as in all other recent theory of this type to the extraordinarily inadequate account of the artist and the inventor. Évolution, pp. 49 and 368. Invention for him, as for all of a certain group of French and American thinkers, is an unaccountable divergence from imitation - a difference split from its identity, which the intelligence cannot grasp. Cf. also Le Rire, p. 175. "L'art est une rupture avec la société et un retour à la simple nature." (See Évolution, p. I78.) No doubt it is natural to suggest that for M. Bergson Intuition is inclusively related to Intelligence, much as, for Hegel, Reason to Understanding. Cp. Lindsay's Bergson, p. $237 \mathrm{ff}$. I see that it ought to be, but I do not think that it is. 
determinateness that the true attractiveness of interaction consists. It is bound to treat mind as a source of energy unaccounted for in the bodily balance-sheet. So long as the system of body and mind together is capable of being regarded as having something to which it is bound to be "equivalent," as possessing, however ideally and in the abstract, an aspect of correlation with a quantity, there is meaning in treating it as of the nature of a totality; as something to which it makes a difference how far it is occupied or possessed by interests and impulses according to their respective intensities and their capacity for unification. But if the very idea of limit or equivalence is destroyed, then, it would appear, we have to deal with an unfathomable fountain of undifferentiated "spiritual energy," and all presumption of the unity of reason-of a tendency in hostile impulses to conflict, and therefore to be reconcilable, is torn up by the roots. "The very idea of equivalence"; for this, it would seem, is all that the constancy of energy amounts to. $^{2}$ All the arguments which point out how very slight and abstract is its import, and how little it affects the nature of processes which are quantitatively equated, ${ }^{3}$ are really in favour of leaving to

1 Cf. Wundt, Logic, ii. 507, cit. in the author's Logic, ii. 75.

2 In Manual, Introd. chap. iii. Professor Stout points out, a little in the tone which I deprecate, that the Law of Conservation of Energy is only asserted of a material system. But surely a psychical system, capable of exchanging energy with a material system, is $a d$ hoc material.

3 In these regions it seems pretty much to equal an assumption that a finite existence has a finite quantity, that is to say, that although different forms of energy may not be measurable by the same physical unit, or some of them not by any physical unit at all, yet on the assumption defended in the text it is possible to say that in principle they correspond to measurable quantities, and will not vary without a reason affecting all the equivalents alike. 
psychical activity this last vanishing link with the world of physical constants. Apart from it, or from some effective substitute in an assumption of rationality of the psychical system, the whole context and tissue of consistent habit and reasonable motive is at the mercy of a volcanic redistribution of energy, suggested by nothing, and bearing no relation to the positive factors operating in the mind.

Now what seems worth pointing out is this. If the popular mind had its way it would doubtless exploit this conception to the full, not merely in the

/ directions where it is perhaps impossible to refute,

2 but in the coarser suggestions which no serious philosophy would countenance. ${ }^{1} \mathrm{We}$ should not merely be told as by the popular doctrine of Free Will that the intensities' with which objects are pursued bear no relation to their rank, connection, and predominance in the mental organism, but that spiritual energy is neither limited by nutrition nor capable of being exhausted by fatigue. There is much in literature and in common speech that indicates a proneness to all three of these views, and if they were to be seriously pushed home the interaction hypothesis would at all events have promoted an important theoretical contention.

But views of this kind seem never to be pushed home. They are restricted within limits which depend on the impossibility of precise measurements, sometimes making use of ideas analogous to that of a power of direction without expenditure of

1 It is noticeable in this connection that Driesch takes alleged spiritualist phenomena as an analogy for the action of his "Entelechy." I believe him to be a thoroughly sound thinker, but the juxtaposition is suggestive. See G.L. ii. 235. 
mechanical energy. ${ }^{1}$ They do not challenge the overwhelming improbability which would attend any thorough-going denial of our current assumptions about the logic of conduct, about nutrition, and exhaustion.

There is an analogous problem about heredity. If, as on some theories would be the case, the soul is supposed to come to the body with its definite endowment of capacities and dispositions, then that view ought to be defended and explained. But the overwhelming weight of probability is surely on the side of the assumption that all definite differentiation belongs to the body, and that all tendencies and capacities are transmitted through bodily arrangements. It is not so much that there is any special difficulty in conceiving a soul endowed with dispositions as that one can see no logical motive for adding these to the bodily arrangements which prima facie seem to form the main element, or a main element, in the differentiation of individuals. To insist on such an addition is in fact to attribute excessive importance to the physical aspect of life. It is because we are afraid of the physical that we try to reduplicate it in the psychical. A true view, recognising that the whole affair is an arrangement of appearances, would not be afraid to follow the plain probabilities as to the nature of the arrangement. But certainly the result would be favourable to supposing that all positive factors of soul life are represented in the physical counterpart.

1 See Appendix I. It is not merely that all such ideas are difficult and indemonstrable hypotheses. Our objection is, moreover, that they bring a fundamentally false bias into psychology and into all higher walks of mind. They disconnect directive power from dominance and organising power. 
And therefore the views in question seem both to be not worth proving and to be, for logic, discredited $a b$ initio. " Not worth proving," in so far as they seem only to survive by restricting themselves to quantities which would involve no serious deviation from our common assumptions. It may be that no one can prove - the present writer certainly could not-that it is impossible to delay death by starvation a second or a minute through a supply of physical energy having a psychical source independent of nutrition. ${ }^{1}$ But it is certain, I suppose, that no philosopher intends to maintain such a possibility up to a point which seriously conflicts with our ordinary assumption that life and all psychosis depends upon the ingestion of food. A thesis which did so conflict, however improbable, would be well worth proving. But a thesis which merely raises a doubt at the margin where quantities are too small for verification, accepting, for all the rest, our normal assumption as a working law, ${ }^{2}$ seems not to stand to win anything important even if per impossibile it were established.

And they are discredited ab initio. It is not playing the game in philosophy to suggest a new principle of explanation, bringing it up at every point to the edge, but not into the region, of possible analysis. But the main line of argument which is adopted in favour of regarding consciousness as a source of energy seems to be of this

1 The contention would have to be that the work of life could thus be bona fide carried on; the phenomena of trance and the like would not be fully relevant.

2 Évolution, p. 275. "Maintenant, d'où vient l'énergie? De l'aliment ingéré, car l'aliment est une espèce d'explosif, qui n'attend que l'étincelle pour se décharger de l'énergie qu'il emmagasine." Cf. ref. to Wundt, p. I69, above. 
nature. It appears to rely on the impossibility of establishing the constancy of energy as an absolutely precise generalisation.

Now this generalisation may not be a principle for which or for its applicability to body and mind one would incur serious logical or ethical sacrifices. In the present context it has perhaps no metaphysical advantage over the idea of a psychical unity exercising mechanical energy ${ }^{1}$. according to some determinate or rational system. The only thing is, that the latter has to be invented, so far as at present appears, entirely out of imagination, and entirely to overthrow our ordinary ideas of causation ; while the former is ready to hand, corresponds in general with our working assumptions as to the conditions of human life, and in principle assigns the control of energy to the predominance of content. There seems to be no reason for departing from it except the bare possibility of inserting at the unknown margin a fragment of a different principle, which in its general tendency belongs to an order of ideas that dare not lift their heads in daylight, and has for its effect, if not for its intention, to dissociate will-power from organisation of content. And therefore-not because of the content of these ideas but because of the attempt to maintain them only in the dark-the suggestion that the soul may be a source of energy without mechanical limit seems to be logically discredited $a b$ initio.

This then is the interest which dictates the remarks of the present chapter on interaction. Interaction, as here understood, means the operation of

1 I believe, if the idea were worked out, such a "psychical" system would show itself to be physical; cp. pp. 2 I 5, 2 I 8 , below. 
body and mind on one another after the analogy of transient causation between material things, And it, therefore, means that bare mind develops mechanical energy outside and independently of the mechanical system of which the body is a part. This once assumed, there seems to be no ground for the limitation of such energy nor for its distribution in accordance with any sufficient reason. ${ }^{1}$ It is not here alleged that to accept a physical counterpart subject to quantitative relations is the only conceivable system of law for consciousness. But it is maintained that some such system there must be, if the mind is to be a mind at all, that any such system will possess the leading characteristics which we find in the physical counterpart, and that it is all important to be clear whether in the theory of interaction more adequate suggestions to this end are being brought forward, or whether the idea of system and sufficient reason is being covertly discarded from the philosophy of mind.

Suggestion is based on idea of qualitative systems quantitatively conditioned.

3. Such a theoretical interest is hostile only to views of interaction which demand mechanicall. operation from naked consciousness. So long as it is admitted that we cannot dissociate physical from psychical states, and that interrelation is most naturally assumed to hold between conditions each of which has both a physical and a psychical side, the fundamental difficulty does not arise. Any such view allows us to remain within the general analogy of qualitative wholes conditioned by more homogeneously ${ }^{2}$ quantitative counterparts.

1 P. 169, above.

2 The qualitative wholes themselves, though less homogeneous, present, it must be remembered, innumerable relations of quantity, gradation, contrast, etc., essential to their effect. 
The view thus suggested would not precisely coincide with either interaction or parallelism. The psychical side would be regarded as an inherent character within the physical process, coming to light under conditions of relative perfection.

Such counterparts are normally of a material nature, as in the familiar cases of the physical bases of sound and colour, and the simplest assumption to which analogy leads us would result in treating the relation of psychical and physical on some such plan as that which does duty in these well-known instances. Enough has been said in the preface in the way of disclaiming all explanation of consciousness. The suggestion before us is not to "explain" consciousness on the analogy of the relation of sound to mechanical motion of an extended medium (which relation itself is a relation of objects of consciousness), but to extend to consciousness in general the conception of de facto equivalence which is illustrated by that particular case. We should thus get a certain orderly arrangement and continuity in the objects of our experience. As has been said above, no character necessary to consciousness appears to be interfered with by retaining the conception of equivalence. For, even if we drop equivalence, we must, in the interest of system, retain finite totality, which then would present itself as a quantitative limit, no less determinate than equivalence, but without the systematic rationale which equivalence affords it. We could not possibly allow that a given finite mind is an unconditioned source of ideas or of energy. Thus, it appears that there must at least be determinateness 
of a psychical system. ${ }^{1}$ And in the last resort this would suffice. But it seems better to retain the connection with physical mechanism, because the evidence carries it so far that to dispense with it after that point becomes a serious break of continuity, and because it supplies us, as we have said, with some suggestion of a rationale for the psychical limitation and differentiation which any sane view must assume.

Mechanical series in mind.

(a) It appears to be admitted that there are parts of psychological doctrine, dealing with the more mechanical aspects of conduct, which "may ultimately be replaced by Physiology." ${ }_{2}$ Wherever an idea or perception sets in motion a series of connections that run an accustomed course to a habitual end, it seems to make no theoretical difference whether the entire reaction is treated as physical or psychical. If the "end" is a muscular movement it is plain that at some point physical connection enters into the series, and there is nothing in its character, even if accompanied by consciousness, to suggest that it has not a physical aspect throughout. Such a series, whether physical or psychical, merits the predicate mechanical. It is released a tergo by a stimulus, and in the typical case runs down to its end like clockwork without readaptation. Whether this typical case is too narrowly described is a question that will need reconsideration. But such, in general, is held to be the character of the associative habits of minds, and especially of those physical or psychical

1 See further, Lect. IX., below.

2 Taylor, Elements, p. 303. Bradley on identical nervous system, involving identical memory, Appearance (2nd ed.), p. 356, and Mind, xlix. 23, on the necessity of dispositions, partly physical, for that realisation of ideas which is will. 
formations which have become known as "dispositions." The conception here suggested is not even obliged to use the whole of the above admissions. It is not necessary to argue that any part of Psychology can be replaced by Physiology. It is enough to note that there can be psychical process which itself bears a mechanicalcharacter, and which without any theoretical sacrifice might at least be associated with a strictly physical and mechanical counterpart.

(b) Every student of psychology must be struck Finite by the recent rapprochement between ideas due to based on Hegel and a sort of glorified resurrection of British a complex psychology. It is no longer, if it ever really was, minate the boast of the idealist to know nothing of the ments. steps of psychical action and evolution. The term "machinery" perpetually recurs in the analysis of volition; and while it would be contemptible to make capital of such a casual expression in favour of a mechanical theory, it is certainly noteworthy that the adult mind is coming more and more to be treated as, at least inter alia, a shopful of machines. ${ }^{1}$ Now such a point of view, for an idealist who knows his business, is not a retrogression from the deepest insight into mind. It is, if rightly handled, the very

1 Here M. Bergson's language is very significant. Our volitional life consists for him in constructing mechanisms, and selecting which to combine and to set going, e.g. Evolution, pp. 273-4. Cf. Bradley, Mind, xlix. e.g. p. 25. It may be said that the view of the text makes the mistake of regarding the work of the cortex as continuous and homogeneous with that of the seats of reflex action. But in modifiable reflexes I suppose it is so in some degree, and, at any rate, what is said in the text is sufficiently borne out by the facts of associative nexus, if we bear in mind that association marries only universals, and that the identity operative in a connection can always develop into fresh detail (Bradley, Logic, p. 303). Any habit may carry one on to new ground; sportsmanship, for instance, to politics. 
legacy of Hegel, if not even of Spinoza. Hegel's "actual soul" is the perfection of a living body highly trained and definitely habituated." We do not know, Spinoza warns us in a wonderful passage, how much the body may be capable of doing. ${ }^{2}$ The question really in principle goes very deep. It is the question of the ultimate nature of teleology, on which something has been said above. Teleology is not the immediate translation into fact of fancies drawn from nowhere. It is the unity of a real individual, for whose parts there is nothing undignified in framing and disciplining themselves to a definite conformity with the whole. When we think of Hegel's conception of the psychical, ${ }^{3}$ how, for him, the planetary, the terrestrial, and the climatic influences draw together and become organic to consciousness in the concrete soul-life of a race and an individual, we must recognise that to be something in particular, to be built up on a definite structure which has learned many detailed lessons of conformity to reality, is in principle what we should expect for the most central and concrete of all finite existences. Thus it would be a false idealism to protest against the use made of laws and "dispositions" in recent analyses of Will, Thought, and Self. And it is interesting that, more particularly, such means are accounted essential for the passing of any idea into external fact. ${ }^{4}$. The mind is at least erected on a foundation of habit and determinate reaction, to which no injustice could be done by connecting it with a physical counterpart, and equating it with a sum of mechanical energy.

1 Phil. des Geistes, sect. 4 I I.

2 Ethics, iii. 2.

3 Phil. des Geistes, sect. $390 \mathrm{ff}$.

4 Bradley, loc. cit. 
4. But a sharp line is apt to be drawn when we vice of come to fresh purposive adjustments ${ }^{1}$ or to selective interest, to that which decides what presentations admitting discontinuity in shall actually be attended to, where we deal with the logical considerations belonging to the psychology of feeling and attention. Here, it is said, we have something which cannot be represented in a physical or mechanical system ; something, therefore, which we must attribute to the purely teleological idea of consciousness per se. Now the term Teleology, it has already been argued, ${ }^{2}$ though not a bad way of describing a certain side of conscious activity, constantly shows itself to be open to grave misunderstanding. Such misunderstanding seems to be present whenever the higher or teleological process, in being contrasted with mechanism, is also contrasted with that necessity and determinateness which mechanism and logic have in common. This contrast we seem to meet with in the dissociation of ethical and historical appreciation from logical insight, ${ }^{3}$ as well as in the conception of points in the world's history where a new principle comes upon the stage, and mechanism is replaced by the action of final causes. ${ }^{4}$

It is a misunderstanding of this nature which is here attacked. The central principle of Idealism seems to be abandoned, if the objects of ethical and historical appreciation are set up as more than an aspect of the whole in its logical individuality. The issue, as it presents itself to me, is whether teleology lies in the mere fact that some one cares for some-

1 Taylor, Metaphysic, p. 3 I I ; cf. App. i.

2 Above, Lecture IV.

4 Ward, Naturalism, i. 276.

3 Taylor, Metaphysic, p. 305. 
thing, or whether the real question is not rather what makes anything worth caring for, and anybody capable of caring for it. ${ }^{1} \quad$ And it appears to me that the reason for which the former or accidental aspect is insisted on, and the latter, the fundamental aspect, is neglected, lies in the spurious interest aroused by the conception of naked consciousness, or the stream of life, creating determinations apart from sufficient mreason. It is here that there comes the parting of the ways with reference to the mechanical counterpart of consciousness. Why cannot fresh purposive adjustment and selective interest, be linked, subject to the reservations already laid down, with a mechanically determined system? The answer plainly is, because they are not thought of as flowing from the nature of any totality, but are conceived as originating de novo, and out of nothing.

Fresh purposive adjustment and selective-interest are the same thing viewed from two sides. It is enough to discuss the former. It is admitted that external action involves psycho-physical systems or "dispositions," which being started by their normal stimulus run down like clockwork to a habitual end. And it is common ground that so far as mental operations of this kind are concerned there is no final impossibility in their being translated into physiological terms. But it is urged that, so to speak, on the top of these, of a mind thus organised and habituated, the nature of purpose forces us to superadd a power of a wholly different order, by which new activities are freely generated in view of

1 See Lect. IV. sect. 5. Contrast "The only real reason I can think of why anything should ever come is that some one wishes it to be here" (James, Pragmatism, p. 289). If the fulfilment of a wish meant satisfaction this might be so. But it does not. 
new experiences, the process remaining for certain phases independent of the physical series, and resuming relations with it at some further point. ${ }^{1}$

This, no doubt, is not the way in which those who insist upon such a view would represent the connection. They would say, to put the principle in a word, that teleology comes first, and that mechanism is fossilised teleology. The bodily counterpart of action, some might add, accompanies it thus far and no farther, viz. as far as automatism, of which secondary automatism would be taken as typical, is used in or substituted for psychical process.

But for the present purpose priority between the two alleged types of process does not matter. The point to which attention is drawn remains unaffected. It may be stated as discontinuity or severance of logical nexus.

Ii. The end, we have urged, is the whole; and if this subject and predicate conflict, then it is the character of being an end in time which must give way. We have it admitted that an adult human mind contains an immense structure of automatic machinery, by which connection is effected with its habitual ends in normal surroundings. I insist on this view, which I believe to be true, and to have more significance than is usually seen. Somehow, on the top of and by the side of this machinery, life is carried forward and new adjustments made. Now life is highly continuous. New adjustments are made on the basis of old. The machinery must

1 Taylor, Metaphysic, p. 311. The quite extraordinary discontinuity introduced into mental life by Bergson's view must strike every student. It becomes in so many words, mechanism plus indeterminate choice. See reference above, p. I 77. 
be somehow co-operating in all determinate thought and action. The environment is a continuum, and life, corresponding to it, is also a continuum. In every change of environment, and in every relevant adjustment, the matter, so to speak, the stuff and medium, is mostly old. The old slides into the new, framing and conditioning it at every turn. ${ }^{1}$ A man is dissatisfied with his tailor or his house or his own character, and wants to make a change. There is no point at which his want is unconditioned by his past practice and surroundings. Things do not suit him, and the particular ways in which they do not suit him slide into the ways in which the new ones are to suit him. He rides on the old identity, guided by negations, to a new diversity. Or say that he begins by chancing upon some new practice, and it harmonises with his past and present better than something in that past and present with which the new conflicts, and which finally it extrudes. It is a very puzzling suggestion that all this determining continuum, which makes the main content of the new as of the old, is to be represented by a psychophysical order discontinuous with the new adjustment and heterogeneous from it. "But the end has generated it; has, so to speak, deposited it; and persists itself, as the growing point, to determine without being determined." But is not this in great part a misapprehension? In depositing this supposed stalactite of mechanical habit, the "end" has surely all along been determining not merely something else but itself. Take the "end"-the selective mind-when it was most nearly free, unsupported by mechanism, disposing of no automatic connections. 1 Cf. Mitchell, Structure, etc., p. 48 o. 
In that phase it was correspondingly empty of content. Probably it had not then even the teleological form of distinct consciousness. Its distinctness most likely depends on the quantity of determinate conditions in relation to which it has embodied in machinery its own nature. ${ }^{1}$ All this, the habitual and determinate reaction of the mind, by which it, as a continuum, responds to its continuous environment-all this falls not outside, but inside the end. The end, no doubt, is something more than any of the automatic habits, and more than all of them together; but it cannot be formulated or be aimed at except by definite reference to them. It is hard to believe that it can stand in need of conditions and a mode of determination wholly discontinuous with those which belong to the greater part of itself. Here again the question of principle is the important thing. If the end, the object, the want, were something emerging out of the depth of a creative consciousness, dissociated from any larger universe, then the demand for discontinuity, both logical and mechanical, would be intelligible. But if the end is the completion, or the supposed and relative completion, of what already stands shaped in a determinate continuum, and if the very want which constitutes it as subjectively teleological means a negative and positive congruity of the formed system to its logical complement, ${ }^{2}$ then the suggestion of

1 M. Bergson, e.g. Evolution, pp. 125, 284, makes a strange use of this idea, but his view supports our contention in some degree.

2 It cannot be too strongly insisted on how small a part of a relatively individual system the desired logical complement at any moment may be-the opening of a door or the turning of one's head. It will be replied the end is not the existence but the possession of the whole, and the change, however slight, is ex hypothesi needed to 
discontinuity seems wholly untenable in principle, whatever view may be taken as to "what the body can do."

On this point a rough statement was admitted ad interim above. ${ }^{1}$ But so far as experience shows, the exclusive assignment of automatism to the physical and teleology to the pure psychical series would break down on the physical side. We have observed on this in treating of plant life, and when we come to secondary automatism there is no room for doubt. Broadly speaking, adjustments of quite the same character that would be made by reflection can be made under automatic habit, with almost any degree of unconsciousness. In other words, it is not true that psycho-physical automatic series are confined to identical trains of movements, unmodifiable after being released a tergo by a stimulus. In the first place, variation according to the stimulus can itself pass into adaptation; and, in the second place, it is clear that adjustment takes place in the whole course of movements, whether we call it variation according to continuously varying stimuli, or adaptation to conditions. The example of skill in games seems quite unambiguous. ${ }^{2}$

We are not, by the line which we have taken, bound to account for fresh purposive adjustments out of purely physico-chemical combinations. All

achieve this. But it is the partial presence of the whole in you, a "partial" which may be all but complete, that conditions the need for completeness.

1 Page I 76.

2 Cf. Stout, Anal. Psych. i. 66, 72, on relative suggestion. A simple illustration is a cricketer playing a ball. He is guided by a "universal" which adjusts his movements to the special course of the ball; but the universal is a habit, all but unconscious, and involving no reflective action of the mind. Cf. p. 40, above. 
that is here attempted is to defend the conceivability of a physical counterpart of consciousness on the general lines of determinateness. This is the point of the analogy $(a)$ of mechanical processes in consciousness, such as admittedly might have a physiological "counterpart, and which yet are absolutely continuous with choice and initiative, $(b)$ of adaptive processes apart from explicit consciousness, which seem homogeneous with such adjustments as consciousness itself in other cases accompanies. , It seems impossible to disregard such a continuity. If it is clear that physical movement per se explains nothing, it is no less clear that in every purposive adjustment there is on our hands the fact of a physical system in reaction, with an immense store of pre-adaptations by all of which the new reaction must presumably be influenced.

It is impossible to rule all this out when we consider the relation of the physical and psychical series.

5. Two further points may be mentioned, "How," Ends are it is asked, "can a physical system possibly repre- embsically sent a 'meaning' or an 'end'?" Understanding that representation and not explanation is in as that of in such
reactions question, the answer seems obvious. Meaning is represented in a material system in as far as a complex reaction, involving the nature of the system as a whole, follows upon a simple stimulus. A penny-in-the-slot machine represents a meaning; and the principle is not confined to the world of human contrivance. When mere contact, such as would have no effect on an ordinary leaf beyond a slight deflection, causes a carnivorous plant to enfold and absorb a substance, it is plain that 
we have what in conscious form (which in instinct is imperfect) would be a meaning of the contact.

So again with a purposive consciousness. "The experience of seeking is the experience of giving ourselves to realising an end, of adopting it, of identifying ourselves with it. Hence for its correlate we may suppose an action of the brain as a whole in support of the particular system realising the end. Such an action of whole on part is well known experimentally in the inhibition and the enhancement of reflex actions." 1

This is only a side of the facts that have already been insisted on. It comes to this. There is no purely fresh purposive adjustment. There is no selective interest cut off with an axe from the continuum of interests. In face of a change of situation there must be a determinate modification of the whole and its parts for consciousness, by which the so-called " new" purpose is generated out of the old, because the universal or spirit of the totality is real. There must also be a determinate modification of the whole nervous system, and its parts, whatever they are. The former is what commands our interest. It must be logical, an effort to maintain and adjust the whole, giving rise by a definite modification to a fresh balance of interests and a fresh purposive conception. But the latter also we have on our hands, and it cannot be disregarded. The mechanical continuum must react, and its reaction cannot but be interwoven with the new logical development, into the stuff and substance of which, as has been explained, it enters at

1 Mitchell, Structure and Growth of the Mind, p. 485. 
every point. ${ }^{1}$ Is there really anything to be gained by suggesting a "guidance," a "déclanchement"which by the very phrases and conception imply an exterior pushing or pulling at certain points, or the release of a trigger at certain isolated momentsfrom outside the system which is so plainly in the main continuous, self-contained, and self-directing ? ${ }^{2}$

6. The object of the present lecture has been The merely to help in paving the way for a genuine con- sciences of ception of the concrete individual. I do not for a $\underset{\text { reinforce }}{\text { mind do }}$ moment pretend that I can overcome the difficulties, each other which have been pronounced insurmountable, of points. uniting the treatment of soul and body in a single explanatory theory.

The difficulties are: first, the imperfect and selfcontradictory nature of such beings as body and soul, when taken apart from each other and from the rest of the world; secondly, the separateness and independence of the physiological and psychological points of view as represented by physiology and psychology respectively; and thirdly, the remoteness from actual experience of the scientific descriptions furnished by the two sciences in question.

I cannot help thinking, however, that when difficulties of this type are advanced as final objections to the philosophical unification of appearances, the pretensions of the special sciences, against which the objection is supposed to be directed, are really being put too high. Granted that a certain falsity attaches to all appearances in isolation, and that the

1 On the continuity of old and new adjustment, see Mitchell, p. 480 .

2 This externality, as of an artist to his material, is strongly expressed in Driesch, Gifford Lectures, ii. 336. 
special sciences which deal with them are defective if compared with a concrete idea of truth; still it seems erroneous to suppose that such isolation and abstraction so much as aims at being the last word of intelligence, and that it is impossible to reconstruct concrete experience with a distinctness borrowed from abstraction. The connection of subjective Idealism with a special form of fallacy, as though the subjectivist position had in itself no scintilla of truth or significance, is an example of this readiness to disorganise kowledge. ${ }^{1}$ I see no reason against an attempt to conceive the restoration of the individual unity which the sciences of body and soul have helped to construct by analysing it. For scientific analysis, it must be remembered, always constructs while it analyses. The thing or object is not realised as a whole before analysis as it is after. ${ }^{2}$ It might be possible to make use of such detail belonging to these sciences, as would help, if only in the most general way, to reconstruct the idea of their common object. It seems, for example, to be needlessly rejecting a sound suggestion, if we neglect to bring together with the complexity of bodily reactions the more recent conceptions of the complex

1 On the limited truth of the connection between Introjectionism and Subjective Idealism, see Norman Smith, Mind, lviii. p. I 49 . I confess that the primary subjectivist argument seems to me to be simpler than Introjectionism, and to apply to one's private experience without consideration of the relation to others. It is simply that we have a logical idea of what self-subsistent objects should be, and that the immediate objects of experience fail, on account of their nonindependence, to satisfy this idea. I may add that it is, I believe, an error in fundamental principle to try and obtain any conclusion from comparison with others' experience which cannot be got from comparison with our own at different times.

2 On the idea that mind is dealt with by Psychology is a wholly symbolic and unreal object, see Alexander, Ar. Proceedings, 1908. 
psychical machinery of the self and the presuppositions which it involves.

7. Of course, even so, I do not hope to effect The world much. But it would be something, in my judgment, of finite to emphasise the idea of a being essentially con- ness is also nected with or even founded upon its environment condition. (past as well as present), to which nevertheless or out of which it brings a principle of unity, in a sense opposed to the struggling partnership of a body and a soul, isolable from the environment and from each other, as traditional popular metaphysic represents them to us.

Instead of a self-subsistent eternal angelic being we should then be led to conceive of the soul asto adapt a phrase of Lotze-a perfection granted by the Absolute according to general laws, upon certain complex accasions and arrangements of externality. After all, we must not shut our eyes to the fact, that, though we cannot see life coming out of inorganic matter, we can, every day and everywhere, see souls, with full human capacities, apparently being brought into existence by the fulfilment of certain very elementary conditions of cell-conjugation and division; and we see that soul is emphatically, though Plato would not have it so, ${ }^{1}$ a thing or power or quality (whatever we like to call it), of which there can be more and less in every conceivable degree, and the more and less vary with the complication of the material system in connection with which it is observed. We are not suggesting that mere temporal or spatial multiplicity (as in the oscillation of light waves) constitutes a claim to the production of consciousness. Such expressions as

1 Phaedo, 93 D, E. 
complexity and complication, which are forward to suggest themselves as non-committal terms, fail to do justice to the point. The interest is rather in the protracted history and wide comprehensiveness of continuous and also co-operative organisation, that lies behind and beneath the appearance of the soul, and still more of the self or ego in its full character. It is not that the mere lapse of time or the intricacy of changes postulated by evolutionary theory can make a transformation explicable, which would be inexplicable if simpler or more rapid. But it is that the determinate incidents of self-maintenance which necessarily come into being in the constitution of a living and still more of a sentient body - the structures, the reflexes, the instincts, the feelings-are shown as at once the instruments by which consciousness and then self are evoked, and the world with which from their first appearance they are identified. Individuality is there for the observer before it is for the subject; or, we may say, determinateness, objective continuity, the character of a definite centre of experience, precede conscious selfhood and furnish its pre-supposition and materials. The finite self, then, qua finite, is the centre or awakening of a determinate world which is its pre-supposition. We may smile at the simplicity of the materialist who could explain consciousness as an effect of material combination; but it seems to remain true on the whole that when the self appears it is "granted by the absolute" as a solution to a definite situation in external arrangements; a solution which could not have been predicted or constructed from the mere observation of physical nature, but which, nevertheless, being 
given, can in some degree understand itself in correlation with its own experience of the physical order. ${ }^{1}$ And we must bear in mind that in the end this being granted by the Absolute upon a certain combination is all that any connection, any form of causation or inherence, can mean. There could therefore be no harm, if we knew what the words meant, in saying that matter or externality is the cause of consciousness. It is, in all probability, as Lotze says, that if we could observe the germinating soul as the microscopist observes the body, its development would appear to the observer to proceed pari passu with the organisation of the body. ${ }^{2}$ And in such a view, whether right or wrong in fact, there is nothing whatever materialistic or unspiritual. In apparent cosmic development, whether inorganic, organic, or logical, the rule is for the stream to rise higher than its source. ${ }^{3}$

We shall find, then, that the absolute must under certain conditions appear as a soul with capacity for forming a self, because the stuff, and pressure for utterance, are there, to which nothing less than a soul can do justice. There will be, as we said at the beginning, no motive whatever to level down the nature of consciousness to that of the psychical or physical foundation; on the other hand there will not be the smallest presumption that the psychical or physical stuff in which the Absolute has deigned

1 It appears to me an absolute error of principle to say that " newly arising elemental agents must be conceived as already preexisting in some way so that life cannot arise upon a constellation of known non-vital agents." (Driesch, Gifford Lectures, ii. 234.)

2 Metaphysic, sect. 246.

3 We have seen that if the inorganic world really follows the line of least resistance, then the line of least resistance is capable of leading up continuously to life and history. 
to become self-consclous is unfit, because itself an externality, to be the instrument of the manifestation of which it has become the occasion; and no motive, therefore, to level up as is attempted by Panpsychism. What could be higher, short of the Absolute itself, than a being which is directly its organ for appropriation and appreciation of some context and province of experience?

It may be urged that a conclusion of this kind is mystical and equivocal. Is the self, we shall be asked, mechanically determined a tergo by the responses and excitements of the nervous system ? Or is it purposive and selective, able to be determined by an idea of an object which is not yet in existence, and which is therefore incapable of producing physical effects upon the present nervous system? The question is not merely, Does a man act freely? but, Does a man act at all ? ${ }^{1}$ We shall attempt to answer these questions precisely and concisely below. But in general principle I answer stubbornly that I cannot see why consciousness, being conceived as the determinate working of a world of content," "though gifted with a peculiar unity, a nisus towards totality, which can only be noted and not explained, should not be the meaning and true inwardness of a physical process which at every point there would be something definitely to determine.

If indeed the self brought with it from another world a new and independent content, there would not be in such a suggestion as the above even the show of rationality which I ascribe to it. But as the self is essentially a world of content engaged in 
certain transformations, and is nothing merely of itself or apart from its world, the conception that this, like other new qualities and responses, is granted as a supervenient perfection upon certain conjunctions of external elements, seems at least a way of formulating the problem with the minimum of temptation to definite error. At any rate, it places in strong relief a set of ideas which seem to me to demand attention: ideas of the dignity and splendour attaching to the position of a conscious being, just because it is a world, however subordinate in the whole scheme of the universe, in which the Absolute begins to reveal its proper nature, through and in union with a certain focus of externalities.

8. I will conclude by trying to bring this problem The point. of body and mind to the clearest possible point, in order to leave no ambiguity as to the principle here advocated.

i. It is hoped that the problem has been made Mind is a more approachable by our attitude to teleology. ing world, The peculiarity of mind, for us, is to be a world of the centre
of an exexperience working itself out towards harmony and ternality. completeness. Such a world, as compared with a something bringing with it a new end or principle, some angel or genius, or some spark of intelligence coming from out-of-doors, ${ }^{1}$ is much more easily correlated with an arrangement ostensibly spatial, like the nervous system.

According to the conception here advocated then, mind is not so much a something, a unit, exercising guidance upon matter, as the fact of selfguidance of that world which appears as matter,

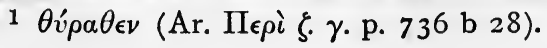


when that reaches a certain level of organisation. Matter is externality, a side of our experience which seems essential to the whole of things, ${ }^{1}$ but not capable of independent reality. Under certain conditions, which are uniform in our experience, a certain type of this externality, also in the main uniform, persists and develops as the vehicle of life and mind. Its responsiveness, which all matter ex hypothesi possesses, takes on a new form, ceases to be spatial appearance, and becomes a centre of response, to which its own antecedent conditions persist as external environment. All that has come to pass is this new kind of apprehensiveness and responsiveness; purposiveness, according to our views, is an incidental consequence of it. Everything, from an elementary substance upwards, reacts in the-whole in which it is a member; life and mind do no less, but nothing more. It is purely our eclecticism that fails to see "purpose" everywhere, e.g. throughout the inorganic world, and consequently, nowhere par excellence. The so-called purpose is really at every point of the whole, though more noted when it is a conscious self that is at some point in self-contradiction, when what we are apt to call a true or subjective purpose-a wish or want-arises. Thus the true representative of purposive consciousness is an organised system; not a mere subject feeling a want.

ii. It is for us really a minor question whether

1 This is, as I understand, the point of divergence between our view and that of the many eminent thinkers (e.g. Professor Stout in Manual, introd. ch. iii.), who advocate pan-psychism. Even if there were, de facto, a psychical something underlying matter, yet it is only as definite externality that it plays a part in our life. We have no use for it as inwardness. Professor Stout seems to have modified his view. See Mind, lxxvii. p. 9. 
life, with all the facts of organic regulation, can be Life is very explained on a physico-chemical basis. For us the much wider point is that it, most certainly can and must be than finite explained, or left unexplained, apart from what is mind, and relatively commonly called mind, that is, from finite centres of consciousness. If we take Driesch's theory of the entelechy as typical for vitalism, we see that the influence of the entelechy is precisely relevant to the state of the material system and to the stimuli acting upon it; and it becomes a verbal question whether in such a case we speak of natural causation or not. The theory with the facts on which it rests plainly shows the impossibility of denying that self-guidance can be immanent in a purely natural system, if we take natural in the sense of " unguided by conscious mind." The attempt to treat the Entelechy as an element operating ab extra upon the material system, when it simply represents the latter in its normal functioning, must be held purely artificial and fictitious. ${ }^{1}$

Thus, then, we have it in principle, plainly from vitalist, and ex hypothesi from anti-vitalist, ${ }^{2}$ that organic regulation is natural and immanent. If matter cannot be said to do it, matter can produce a situation in which it must be done, and done relevantly to stimuli dependent on spatial and material relations. Regulation, then, is a fact prior to and independent of consciousness, and if it is extended when consciousness comes on the scene, as in action determined by experience, that does not necessarily mean that consciousness supplants and supersedes without any continuity the purely organic ground of regulation. It seems more likely that at a certain

${ }^{1}$ Driesch, Gifford Lectures, ii. $336 . \quad{ }^{2}$ E.g. from Verworn. 
point the organism becomes aware of a feature of its own, which becomes at the same crisis more complete, than that its whole character, which, moreover, certainly persists for three-fourths of its processes, ${ }^{1}$ should be cut away about three-quarters up the scale and replaced by something totally different. Consciousness, we repeat, neither creates a high organism nor works it. It is rather the indispensable means of reaping the final and supreme result of the organism's complex adaptations.

Conscious Process is meaning, not effect, of physical process.

iii. In part of the behaviour of human beings, and also no doubt of the higher animals, externality and consciousness become plainly distinct and divergent. Nervous process, we must believe, is movement in space (not that its differences need be purely spatial; they are very probably to a great extent qualitative), while consciousness, even if some of its states and objects are extended, is in the main unspatial; its elements penetrate one another in a way which defies assignment of distance and relative locality. All bodily móvement and brain change is caused, we must believe, if there is to be any science, by bodily conditions. But again, consciousness is the only thing we recognise as the nature and substance of any act which we call our own.

Now we have seen that interaction asks us to make consciousness at once material and not material, and in this way opens up an unlimited vista of inconceivable suggestion, while parallelism is not so much a positive theory as a precaution of method.

1 For all forms of regulation, except restitution, persist, of course, in high organisms, below the level of action due to experience. 
Hence the only possible course, as it seems to me, is simply to accept conscious process as the essence of a certain kind of physical process, and as covered by its physical cost in the body's balancesheet. In all probability, as we have seen, we have to accept an analogous principle of unity in the realms of life below consciousness. This unity and responsiveness of part to whole, as seen in organic "regulation," is a character, it seems, of or necessitated by organic matter; and in the case of unconscious life, it seems impossible that it should be set out by itself as an additional effect, demanding a separate output of energy. There is no separate factor concerned that could be thus set out.

Now consciousness, as we read the relation, is a character of further increased sensitiveness and responsiveness on the same analogy. Take as an example the incoming sensation-the feeling of the prick of a pin. Is this feeling, a sensation with a painful tone, an effect of the physical prick or not? I should reply, "No; not an effect but an interpretation." An effect is a continuation of a process into a further stage. The pin-prick sets up neural change, and ultimately some degree of motor. stimulus. That is an effect. An interpretation is a going into, an appreciating, the nature of a process as it happens. It is an interpretation when we hear certain shocks as music, instead of regarding them, on physical evidence, as transmitted vibrations. Very possibly it may be a rule that there is more effect observable when a physical process finds interpretation; because interpretation has something to do with the degree in which the 
process excites the nervous system. There may be more physical effect when no anaesthetic is used for an operation, than when it is used. But, all the same, an interpretation is not an effect; it is not a new happening; it is an appreciation of what is happening.

Is this mere words and evasion? I cannot think so. It follows from our whole line of thought. The approach to the nature of mind has been for us, always on the basal conception of a centre of a world, an approach to a wider apprehensiveness and responsiveness. We thought of a brick just resting on another brick, of a brick in an arch or in a façade, of an element, one might add, in a crystal. We argued that the growth towards teleology was simply the growth towards individuality of the whole recognised by the centre. Of course there is a gap between external relation and conscious apprehension and response; but, especially considering the intermediate realm of mere' life, it involves, from our point of view, no change of principle. On the hypothesis of interaction you destroy continuity by extracting the principle of unity, and then setting it, empty, to act $a b$ extra; it is a different thing when you keep it within the concrete to which it belongs. All that happens, on our view, is that when you come to matter which has been granted life or consciousness, its capacities of apprehension and response open up a new significance and become the focus of a new kind of whole. Sensation and pain, it is submitted, are what the prick is when the apprehension of it is deepened; they are no additional reaction, but the reaction as apprehended by a certain kind of system. They 
are what the effect on the sentient organism is like when you come to realise it. ${ }^{1}$

So with volition and with speculative thought. The difference of the brain process and the conscious process is given, when we take the one as spatial and the other as not. When this is accepted, the facts are truly given by saying, "We control our acts and ideas; that is, the contents, habits, and reflexes which we are, and which in our nervechange and brain process blend, inhibit, and enhance each other, correspondingly blend and inhibit and enhance each other in the unity-a very partially realised unity, of course- of our non-spatial thought. And in our awareness of this we feel and know what in the nervous process we do-what the world of contents and habits, which is the self, generates by its total response."

Much difficulty has been raised by the assumption that the two systems must be similar, a cell for a thought, a spatial coincidence for identity, ${ }^{2}$ and the like. All we need is that their systematic action should be capable of corresponding, and this in general we can understand. ${ }^{3}$ There is no reason for demanding point to point similarity between the two.

1 The difficulty is here. If I prick my hand, there is presumably all the movement pressure, etc., which there would be if I pricked an indiarubber ball; and then there is the sensation too. Is it not then an effect, and one unaccounted for? I think not. I, my hand, can interpret the complex responses of the organism to the simple shock (p. I 85). A movement needs no more energy because its meaning is seen.

2 This has, no doubt, partly to do with a false theory of identity, which destroys its range and grasp, and makes it analogous to a spatial point. As we are constantly urging, for us the true type of identity is the system of a world.

8 See p. I 85 , above, on meaning and purpose. Cf. Mitchell, Structure and Growth of the Mind, p. $480 \mathrm{ff}$. 
And there is a consideration, important in the theory of knowledge and will, which shows the value of accepting a correspondence between the nervous system and our self-determination. For the self is not wholly an affair of the distinctest consciousness. Its clear course of ideas, as we have constantly insisted, is only a light that breaks out over a huge organisation of adaptations, impulses, reflexes, peripheral sensitiveness of every kind and degree. We get a truer conception of the self, in many important and valuable ways, from thinking of the whole nervous system, and not merely of cortical process, as corresponding to what we are, than by merely following the central course of our clearest purposes and reflections and intensest emotions. Here is one fundamental point, for example, not generally recognised. We have been taught that the will is good or bad apart from failure or success, i.e. if there is an idea passing into realisation, in which a large component is of a type we generally approve, the detailed result, some would say as intended, and nearly all would say as achieved, makes no difference to its value. But this cannot really be so. If an idea cannot secure its own adequate realisation, it is " not ideal enough." It has not enough conformity with the environment ; it does not really contain as much of the secret of coherence or perfection as it professes to contain. I take it that a glance at the nervous system shows us this incontrovertibly. A phase of consciousness, as I gather, corresponds to a set of co-ordinations in which ultimately the whole nervous system is or may be engaged. What we can think depends largely both on our receptiveness and on our active 
dispositions (psychical or physical), and these need not appear as such and distinctly in the focus of our thinking. All the same, our general ideas will be truncated, or rather aborted, if they do not find copious and largely organised active dispositions to fit their content to corresponding detail, and carry it out adequately into the real world. What we can will is reacted upon by what we can do. This is why in the beginning we do not know how to will the good, and have to learn it with pain and labour, by forming habits adequate in detail to its content as the concrete unity of our world.

A man wishes, let us say, as purely as he knows how to wish, to promote religion among his neighbours. But he has no habits or formed dispositions of self-adaptation, self-repression, sympathy, beneficence, penetrative imagination. This defect reacts on his religious ideas themselves. He cannot promote them, because they are imperfect; but also they are imperfect because he has no trained capacities adequate to promoting them. The religious idea is not filled in and made to bridge the gap between abstraction and realisation. The cortical process (should we not be justified in saying?) is in such a case starved and aborted by the failure to find habitual systems and dispositions, whether cortically or subcortically seated, which can meet and amplify and enrich its content with theirs. It has not at its disposal either extended areas of cortical excitement or complex systems of motor activity; and those which it can dispose of, being insufficiently co-ordinated lines of action and expression, are immediately and continually being checked by failure, and consequently 
bring no peripheral reinforcement to the idea. The same would be true, reading suggestion for realisation, of defective theoretical thinking. Now such defects, or their countervailing merits, are in a great degree not factors within consciousness in our explicit volitions and trains of thought. But they affect it and make it other than it would be if the whole nervous organisation were different.

In a word, our whole world is at work in every remodelling of itself $;^{1}$ and if we admit that its habitual and automatic elements help to mould our thinking and our will, we need not scruple to admit that the formed mechanism of the brain is our instrument throughout. Consciousness, as we have maintained throughout, is not an epiphenomenon, if that mean something extraneous and otiose, but it is a supervenient perfection ; it is plainly and unmistakably so. It comes when the individuality of worlds has reached such a pitch of comprehensiveness and their self-direction is faced with such problems of apprehensiveness, that to be an object of experience no longer does justice to their value.

1 Could there be a more suggestive description of the unity of mind than the following account of the nervous system? "(The student) should not forget the constant work that has to be done by the nervous system, and especially how action at every part of the whole is affected by action at any and every part. To work, to carry out its function, is necessary to the health of a neurone; efferent neurones have to maintain the tonus of muscles; in order to do this they require their own stimulation by afferent neurones; and the cortex, besides its conscious functions, regulates the nutrition of the whole body. Experiments in reflex action, and other facts concerning the summation of stimuli, show that the whole system is somehow affected by stimulation at any part. All parts of the nervous system hold each other in mutual tension, and the passage of an impulse, afferent or efferent, is better represented as a disturbance of equilibrium than as a transmission of energy" (Broadbent, Brain, xxvi. 324-5, cited by Mitchell, p. 452). 
Suppose a mountain had a mind-a mind, according to all analogy, lower than that of an oyster-what could it know of its own worth? That would still remain for the artist and the alpine walker to appreciate. It is not meant that the value to be realised evokes by a miracle the means of realising it. But we shall see reason to conclude that the degree of individuality, which, on the one side, is the evolutionary demand that self-direction, hitherto unconscious or associative, shall become explicit and freely logical, is, on the other side, the measure of value.

This, then, is our conclusion in principle. The difference between bodily change and mental action cannot be explained away, but, while accepting it, we have no right to make capital of it in the way of multiplying differences praeter necessitatem. In saying that body is spatial and mind not spatial we have said in effect that body is a causal system and mind a logical one. But body is a causal system long disciplined and subordinated to a unitary selfmaintenance, and it has within it, clearly and obviously, the bases of all the motives and stimuli which enter into mind. I believe we have just to accept the action and expression of a logical system through such a physical one. If it follows that matter is not confined to physico-chemical properties we should accept the conclusion. But it cannot follow that the principle of Uniformity, rightly understood, and of conservation of energy, are inapplicable to it. There is no ground for contending aggressively that rational prediction is inapplicable to its organic forms. We must, indeed, remember that bare calculation will give neither quality nor meaning, and significant prediction would need both. 
But there is nothing in this to cause the foes of intelligence to triumph. In principle all intelligence is one, and its logic is the very essence of creative and inventive process. Therefore a greater intelligence may include a lesser, and in regard to the main problems and purposes of a lifetime, still in the future, not infrequently does so, and if all intelligences did not in this way "cover" one another to some extent, there could be no spiritual world, and no creative activity, implying co-operation, in the universe. To suppose that this unity involves an interference with freedom and initiative is totally to misapprehend the nature of originality.

In a future lecture we will draw out the nature of freedom and initiative as an embodiment of that self-directing logical process, which is the true meaning and the actual working of our minds, through the instrumentality of our organised nervous system.

\section{APPENDIX I. TO LECTURE V}

\section{THE "GUIDANCE" THEORIES}

Cf. Taylor's Metaphysics, p. 289: "Nor again have we any experimental means of proving that those quantities (mass and energy) are more than approximately constant," and references there cited. Add Ward, Naturalism, ii. 59, 82-4, where he explains but rejects the notion of a mechanical system guided by mind with no expenditure, or an inappreciable expenditure, of energy, and so far his view seems just and consistent. But it is clear from p. 84 and from his attitude throughout, that, though for him a mechanical theory is to be rejected in principle, yet in effect what we are to look for is again an inappreciable interference $a b$ extra with the laws of 
motion. It is inert mass plus direction, which, on the whole, he has in mind, although a different.ideal sometimes suggests itself to him. It is this separation of the whole from the guiding element which the view of the text regards as a survival in principle of the notion of matter plus miracle-the attitude of common external teleology. The "plan" is brought to the material; is not in it or elicited from it. The same discontinuity is startlingly apparent in M. Bergson's views, and here, again, unites itself with the inappreciable quantity. I cite a characteristic passage (Évolution créatrice, p. I 25 ): "Supposons, comme nous le faisions entrevoir dans le précédent chapitre, qu'il y ait au fond de la vie un effort pour greffer, sur la nécessité des forces physiques, la plus grande somme possible d'indétermination. Cet effort ne peut aboutir à créer de l'énergie, ou, s'il en crée, la quantite créée n'appartient pas à lordre de grandeur sur lequel ont prise nos sens et nos instruments de mesure, notre expérience et notre science [italics mine]. . . . Lui-même [l'effort] ne possède que ce pouvoir de déclancher. Mais le travail de déclanchement, quoique toujours le même et toujours plus faible que n'importe quelle quantité donnée, sera d'autant plus efficace qu'il fera tomber de plus haut un poids plus lourd, ou, en d'autres termes, que la somme d'énergie potentielle accumulée et disponible sera plus considérable."

So Schiller, Humanism, according to M'Dougall's Social Psychology, p. 234, suggests the idea of a ball balanced in unstable equilibrium on the top of a high divide, disturbed by a minimal force. I have not been able to find the passage referred to.

All these ideas seem to show the radical defect at which my argument is aimed; the choosing unit or element is not a system of the contents dealt with by choice. Mind and its world, choice and action, become utterly discontinuous. For a hint of a better view cf. Bergson, Données, p. I 35 . (The criticism of taking directions of action as things which await our choice.)

Driesch's form of vitalism exhibits all these difficulties in the relation of "mechanical" to "natural" and 
"psychical" operation. By "mechanical" operation he means the production of an extensive manifold by a previously existing extensive manifold, involving a single and external cause correlative to every element in the effect. No such extensive manifold, no arrangement of parts in the three dimensions of space, is capable, in his view, of producing the results which are observed in the "regulation" characteristic of organic life, by which, for example, a typical form may be developed out of the set of elements which normally produce it, though rearranged at random in space, or halved in number. Life, then, is not for him "mechanically" explicable, and he proclaims himself a vitalist.

Per contra the entity, the $x$, which he takes to represent the interests of the normal organic whole, and to which he gives the name of Entelechy, is for him a purely natural element. It is never identical with consciousness, and in its purely organic forms it is not even accompanied by consciousness. It is conceived by him as an intensive manifold, revealed only in its operation. It exercises no energy, but has a power of "regulation" through postponing some to others of the reactions possible within the organism, and setting free those which it has itself suspended or postponed. I cannot offer a scientific criticism of these ideas, but they seem on the surface, though nominally excluding the ascription of physical energy to consciousness, very analogous to those which make mind control body by the exercise of an inappreciable amount of force, which seems to mean, by exercising force and yet not exercising it.

But in the facts which sustain the result, simply taken, we can hardly help finding a "natural" determination referable to the characteristics of certain material combinations, even if the special type of explanatory theory above defined as "mechanical" is rightly excluded. The determination is described as thoroughly univocal ; consciousness is not concerned in it ; it is characteristically relevant and differential (i.e. logically uniform) over an immense area of organic being. The elaborate proofs that it cannot be mechanical are themselves in every case 
proofs of very precise and relevant reactions to the variations of external stimuli. The very meaning of his equipotential system is that it is composed of elements each of which can do whatever its place in the system, however changed by disturbance, may demand in the interests of the normal form. One way or other, it has to be admitted that these powers are exercised not only apart from consciousness but in the closest concomitant variation with matter. If this is true it is unimportant that there is no one living substance (Driesch, ii. 246). Is it not really special pleading, a verbal distinction due ultimately to exaggerating the homogeneousness of physical causation, when such artificial hypotheses are resorted to in order to distinguish responses which cannot but be called natural, in toto and in principle from the qualitative reactions of the material world?

In Driesch's view of the psychical we see the relation yet more clearly. Even in life, without reference to mind, he makes a decided attempt to separate the "entelechy" from the material whole, to treat it as interfering $a b$ extra like an artist with his material, even to think of it as a possible object of systematic classification on a priori grounds, apart from moulding by the environment. The universal is made a particular, operative among the particulars of spatial form, and its immanence in the environment, in the world, is neglected.

When we come, in Driesch's theory, to the Entelechy or Psychoid (as it may then be called) at the level of intelligence, the discontinuities inherent in all the guidance theories become glaringly prominent. It is admitted that the type of hypothesis we are dealing with is that (familiar from Lotze ${ }^{1}$ ) according to which there is a something that plays on the brain as a piano-player on a piano. Or, by a variation of the metaphor, the brain is represented as "a sort of warehouse, a place of storing; . . . it possesses the faculty of storing engrammata. But it can only store engrammata in the sense of given combinations of given elements, and therefore nothing but

1 Metaphysics, sect. 296. There must be a better reference, but I cannot recall it, Driesch, Gifford Lectures, ii. 97. 
the psychical phenomena of simple recognition and of association by contiguity are immediately related to cerebral processes - the faculty of rearranging, nay, even the faculty of association by identity and contrast, has no relationship with any performance of physico-chemical agents whatever." "Ideas," again, "have real cerebral process as their starting point," but judgment has not. Now, if we hold what I take to be plainly true, that all association is impure judgment "marrying only universals," and that ideas are strictly elements in judgment, we are bound to condemn these discontinuities as contrary to fundamental truth in logic and psychology (see Driesch, Gifford Lectures, ii. 97 ff.). Bergson appears to me to make an equally impossible dissociation between contemplative and motor memory, treating the former as corresponding to differences, and being wholly unconnected with brain; the latter as corresponding to identities, and being dependent upon it (Matière, p. I69). The whole theory of the relation between mind and brain, critical no less than traditional, seems to suffer from a want of freedom-from an assumption that if matter is the instrument of mind we must somehow find material structure repeated in the structure of mind.

But in thinking thus, we are really doing just what, as critics of materialism, we intend to avoid. We are limiting our theory of mind to our theory of matter, and then, in order to escape from our limitation, cutting the manifestation of mind in two. Cf. Mitchell, p. 43.

\section{APPENDIX II. TO LECTURE V}

\section{NEURAL AND CONSCIOUS PROCESS}

Can we take the relations of neural process to conscious process a little more into detail, comparing the character of the two with respect to mechanism and logic, and estimate the need and meaning of postulating in the account of consciousness a single immaterial being, or "soul"? 
i. We must, of course, beware of limiting the power of A Logical mind by inference from our notions of neural process. The $\begin{gathered}\text { system can } \\ \text { act through }\end{gathered}$ object of the present remarks is in the other direction. a Causal We have seen that a full view of the nervous system tends system actually to intensify our conception of the concreteness, to it. and of the spiritual value of the concreteness, of the mental life. And now it seems possible to suggest how neural process must fall short of consciousness, and how nevertheless it may be a basis and instrument of mind, without placing any invidious limitation upon the latter.

We have endeavoured throughout, in dealing with body and mind, to substitute the idea of a logical whole, in the widest sense of the term, for that of teleological process in the sense of something mainly concerned with temporal transition from point to point-to replace a line by a system. This conception seemed to give a new value and reality to the unity of body and mind. We can see how it is natural and likely that, to use the most general and modest language, there is always a something in body to correspond to anything that there may be in mind. The notion of a system with all its parts in a state of reciprocal tension takes us some way towards a logical unity.

In thinking, then, of the correspondence between physical and mental movements and elements, we must dismiss, it would seem, some of the cruder difficulties.

To begin with the difference between causation and logical or teleological determination. All causation, as we have seen throughout, is in a fundamental sense logical, and thus, in the larger meaning of the term, teleological. It only falls short of agreement with what we take to be reasonable procedure in so far as special causal processes may only take account of a limited set of factors; and we have no guarantee in any given case that those will be included which are important or interesting to us. But causation embodied in a special machine may follow lines which are even in our sense reasonable, if the machine has been made to represent our interests. There can be, for example, as we all know, a logical machine; and the apparatuses which are used in 
experiment or observation to augment accuracy or correct error, are, as I have pointed out elsewhere, much more concretely and effectively logical than the so-called logical machines. ${ }^{1}$

Now we must remember that the nervous system is a machine, or rather a shopful of machines, built up by adaptive processes - however we may construe their nature-primarily to direct our bodily movements in the interest of the preservation of the species; secondarily and consequentially (secondarily, I mean, from a biological point of view) to represent and to realise our predominant interests and desires. I include among these the disinterested interests, which are the most characteristic, and which emerge from and yet include the others in a way not difficult to understand. ${ }^{2}$ We shall be helped and not hindered by frankly assuming that the brain like many other organs seems as if it had been meant to do one thing, and then had come to be used for something quite different. This, I suppose, is almost a law of the evolution of organs, and is really a useful clue in estimating the brain's relations to the guidance of movement and to activities of a theoretic type.

Hence if our interests and aims are embodied in the nervous system, predominating in its organised structure in proportion as they predominate in our lives-and is it not practically plain that this must be the case?-I can see no possible reason why the output of this physical system should not be logical, allowing for intensity and complexity of excitement as well as for its extent, and for coherence, or presence and absence of reciprocal inhibition ; and why, therefore, it should not act as the engine of will, thought, and feeling. It has been said that it amounts to a miracle ${ }^{3}$ if physical movement and consciousness are simply concomitant. Well; it does, and it does not. In a sense everything is a miracle; all we can do is to

1 Knowledge and Reality, p. 327.

2 See, on the plot of Aristotle's Ethics, "The Perfecting of the Soul," Appendix II. to Lect. X.

3 Stout, Manual, introd. iii. 
require the miracle to be self-consistent and consistent with all else. And, after all, the apparent dualism between matter and consciousness is an arrangement which falls within consciousness; though we hold it only fair play to disregard this general sine qua non when we are studying and comparing the detailed content of experience. But the correspondence of psyche (life-mind) and body from the amoeba up to the nervous system of man is a very extensive, highly differentiated, and thoroughly selfconsistent miracle; and if the nexus is impeached as illusory it may fairly claim the benefit of the saying, "Whom God deceives, he is well deceived." The correspondence would not practically cover a much wider area if we were to succeed in eliciting life from inorganic matter. It would be then much as it is now; some material arrangements, by comparison extraordinarily simple, though in themselves no doubt exceedingly complex, are able to "produce" with inevitable certainty a minimum of soul. And if soul follows matter, corresponding to all its degrees from the amoeba-perhaps from the crystal ${ }^{1}$ - to man's nervous system, this enormous world of detailed and graduated correspondence seems enough to supply the required rational continuity as between two stages of a process fundamentally identical. I refer again to the example of material undulations and musical tones. We bridge this gap without hesitation; yet though not so deep as the other it is quite as distinct.

It seems then that there is no necessary opposition of principle between the nervous system reacting to stimuli always in view of its acquired pre-arrangements, thus giving rise to just those movements which its meaning, our consciousness, demands, and the structure of consciousness as by its inherent logic demanding these movements, or in the same way those other neural changes which continue its own progression. Difficulties of this type are founded on misapprehension.

Mind the mainly non-spatial unity of body in action.

ii. Can we penetrate further into the meaning of the difference between the physical process and the conscious-

1 See Lehmann on Liquid Crystals, Nature, Jan. 7, 1909. 
ness which it subserves? Our very language regarding the two admits an enormous difference between them; and it is a difference, it would seem, that must carry us further. We assume that the neural process must be accepted as a movement in space or at most as a qualitative change of spatial objects of consciousness. Consciousness, on the other hand, is what can have objects, and is not spatial. We have said enough of the prima facie miracle that each should be tied to the other at all. Now the question is what their difference involves.

A hint for discussion might be taken from M. Bergson's conception of the brain as the pointe acérée of the mind.' There is a brain state, he allows, for every psychical state. But the brain-movement includes only the tendency to action (action naissante), which the psychical movement involves. Brain is the point (and edge?) of the knifeblade, which as a whole is the mind. The two are not co-extensive, but the former is in play wherever the latter is effective.

And some such relation seems actually given in the obvious differences. The brain movements, as spatial objects, cannot be a unity in the sense in which consciousness is a unity. We have rejected all idea of representing identity as it is for consciousness by spatial coincidence in the brain. The excitement of an area of brain is prima facie matter in a certain state, with every point distinct from every other. The thought to which it corresponds has its factors distinguishable but not separable. Take our previous instance, meaning and purpose. In these cases there seem to be certain material systems, excitable or excited, so as to awaken, reinforce, or inhibit, each other's excitement. But it is impossible, one would say, that the excitements of physical systems could blend and qualify one another as do factors in a conscious whole. In brain process, the correlate of the sound of a word and of its meaning must be a spatial system; and the correlate of the purpose cannot be coloured and penetrated by

1 Évolution créatrice, p. 285. Mr. M'Dougal's distinction between psycho-neural and psycho-physical parallelism seems to point in the same direction. 
the nature of the cooperant system in space (p. I 86) as the purpose is in mind. And it seems to follow that there is in consciousness a something more, an actual fusion and interpenetration of contents, which could not be conceived as embodied in the physical movement. What corresponds to an individualised conception,"Socrates a mortal man," cannot be at once, like the conception, singular and universal; in a word, within the physical world identity and diversity can only be symbolised and not realised in their own nature. It is as if the brain processes must have in them the materials of the conscious structure, but only in the rough; as if the being of the real system, the interpenetrating reciprocal qualifications, the unitary organisation of contents, can only be symbolised by the spatial process, and, in its real nature, is included in the miracle which we have agreed to admit, and cannot really be given in the physical connections. And yet these physical connections carry out-this is a simple fact- the work which the other structure demands, and may be the basis, the substructure of the true solidarity which belongs to it alone. ${ }^{1}$

The relation might be illustrated by that of our logical inference to the operations of the logical machine. As Mr. Bradley has pointed out, ${ }^{2}$ the machine can hardly be said to draw a conclusion. It conducts certain combinations and carries out certain eliminations, but it is we who take the result as the conclusion of an inference. The universal nexus, the thread of inference, is indeed in a sense real and a fact, ${ }^{3}$ but it hardly is together as a universal except when made one with the conation of a mind. Something of this kind might be the case as between mind and nervous system. Neural process, we might say, gives the physical response or the course of brain change; but only

1 It is important, and in some degree diminishes the magic of the matter, that psychical solidarity is so very imperfect as it is, and that its imperfection largely corresponds, I suppose, to physical nonorganisation. The suggestion is one of a struggle towards unity, in which brain plays an indispensable part.

2 Principles of Logic, p. 357.

3 Alexander, Arist. Proceedings, 1908. 
mind reads these off as elements in its unitary system, that is to say, as in psychological and logical union with each other. The important point is not to confuse the discontinuity between brain change and mind change with a supposed discontinuity between the parts of mind change. (See Appendix I.)

If we take the line just indicated, two difficulties meet us. That which we say does the work has no inkling of the initiation which it carries out. Not merely, it has been said of a kindred view, has no man on this hypothesis ever acted freely, but no man has ever acted at all. ${ }^{1}$ And why should consciousness have been evolved, if it was not a means of directing behaviour superior in practice to unconscious responses, and therefore, a fortiori at any rate, a means of directing behaviour?

On this

view, what acts is not the man? Yes, it is ; his system responds, through his machine.

$a$. If we pay attention, as is surely right, mainly to the main structure of brain and mind, there can be little doubt or difficulty. Here it is quite plain that the nervous system ${ }^{2}$ is the engine of the mind; its leading and predominating systems correspond to the mind's leading and predominating systems; its responses are determined by a whole which, in as far as we are awake to its working, is our mind par excellence; though really to describe our mind completely we ought to include a good deal to which at any given moment we are not awake. $^{3} \quad$ The difficulty arises, like so many difficulties in philosophy, from being desirous not merely to legislate for hard cases, but to make hard cases the sole basis of legislation. We will deny the obvious facts in order to conceive it possible that the mind shall be able to upset its own system; and so we go astray after an idea of guidance $a b$ extra; not the guidance of a self-directing whole, a world which remodels itself; but a guidance which exercises upon its processes interferences of minimal and so inappreciable magnitude. But all this is evasion in the interest of preconceived theory. Take a central

1 Stout, Manual, l.c.

2 I prefer this expression to the brain, because of the considerations stated on p. 202 above.

3 See p. 200 above. 
and unmistakable case of will, when the mind as a whole as near as possible, remodels its life as a whole as near as possible, in a volition extending perhaps over months or years. Here I hold it to be plain that no inappreciable exertion through any kind of steering gear will meet the case. It is not a case of a rudder at all ; the direction is due to the comparative working of the propellers. To conceive it otherwise introduces, without any theoretical gain, an unintelligible breach of continuity. You are supposed to realise an idea not because of its logical character, its power to find alliances, and to disarm opponents in the mental structure, but because of a miraculous finger placed for no conceivable reason (for every conceivable reason is ex hypothesi ruled out of court) on the levers of the mind. But a system which is to be free must mould itself out of its own organisation of content, or its activity cannot be self-directed. For this the nervous system as we understand it is the appropriate engine. What would we have? An arrangement of psychical material acting straight on external things by a mere thought or feeling? It might be answered that is just what we have. We may, if we like, insist that our body is of psychical material-an "image" as M. Bergson says. ${ }^{1} \quad$ The objector's difficulty does not lie there, but in the systematic fixity and partial unconsciousness of the acquired connections. If our psychical system is to have these characters ${ }^{2}$ it becomes partly dissociated, and so material or external. Yet if not, our whole conception of an acquired conformity with and mastery of the environment, of a vast machinery of response, leading up but gradually to a vision of significance, goes by the board. We should no longer see any reason why God and the Absolute should not be as adequately revealed in the amoeba as in civilised man. It is further worth noting that the brain is the less in need of a steering gear outside it, as "entelechy" or "psychoid," because in a remarkable

1 Cf. Varisco, I Massimi Problemi, for whom all bodies are "sensibles," though when not "sensed," outside the unity of any subject.

2 They are, in fact, precisely what, if we take body as psychical, it does have. 
sense it is itself a specialised machine for not merely steering, but determining the direction to be steered, in contrast with merely transmitting impulses to the large scale machine-the body. What I refer to is the fact that the brain receives, modifies, and organises all sorts of impulses which are never allowed to try their isolated effects against each other on the big machine. What reaches the big machine has already competed with and been tried out and organised by myriads of adaptations and arrangements in the interest of the whole organism, connecting it with a countless incoming of stimuli and store of habits. An impulse to stop walking does not, as a rule, conflict in the leg-muscles with the impulse to go on. They come to terms previously in the brain, with all their allies on either side. Thus in its very nature it is prepared to act by logic and not by brute force.

Mind is unity of self-direction, but absolute condition of sense of value.

$\beta$. How should it come to pass that finite consciousness should be evolved, if not as a superior means, and therefore, a fortiori, as certainly at least a means, of directing bodily movement? Here we must recall the fundamental fact of evolution, that organs, whose history looks as if they had been meant exclusively for one function, are constantly being re-adapted so as to do something else. The nervous system, when its history is considered, certainly looks as if it had only been meant to conduct external stimuli to the machinery of physical response. ${ }^{1}$ But when it has to become an instrument for dealing with stimuli from distant objects, with deferred responses, with possibilities, with the behaviour of other systems on the same footing as itself, then the fact of selfdirection, common to all material things, ${ }^{2}$ passes, in view of the storage of experience and capacities, into a sense of centrality and self-value; and the microcosm, thus focused, becomes aware of its own self-direction. It awakens to a

1 This is M. Bergson's strong point, and I suppose has much to do with the modern disparagement of so-called Intellectualism.

2 Or, if this is denied, at least to unconscious organisms. But it seems ridiculous to deny that the reactions which have made the terrestrial globe habitable are self-directed, or to maintain that, say, the participation of Diatoms in the formation of chalk-beds has introduced into them a new principle of direction. 
sense of its own meaning, because now it has a meaning which could not be represented through its being an object for another consciousness.

But why, it may be asked, should such a meaning be confined to high organisms? Why should not a mountain or the globe itself have such a meaning? How much they must have gone through; how much they might tell, if they had memory and could give utterance? All we can say is, that according to all analogy, full consciousness seems reserved for the high organisms par excellence; and its condition, no doubt, is mobility. As we suggested above, if a mountain had consciousness, it would, according to all analogy, be nothing to compare with the consciousness which we have of a mountain, and, therefore, there seems the less reason why it should have consciousness at all. It is mobility which demands the great and varied store of adaptations and experiences, and which, by the demand for a precise and flexible adjustment to the environment, prepares the way for the awareness in which the environment represents itself. The conditions of awareness were very probably first awakened by mobility, but it is contrary to all principles of evolution to infer from this that to control mobility is its final function.

But surely, it will be urged, it is an absurdity to say that the system would work as well if the awareness were unawakened, if pain had no deterrent effect, and if the meaning of books did not govern their composition and effect.

Here we must insist that there is an unwarranted assumption. We do not know that such a system as we possess could be developed beyond a certain level without an awareness being awakened. ${ }^{1}$ Our point has been that the principle of self-direction has been there throughout, and that in a whole of a certain representative capacity it must necessarily awaken to the value of its

1 See above on the effect of an operation with and without anaesthetics. The "more" of physical effect and of feeling go together, and we incline to say this is because we feel more. But it may be because the nervous shock is more widely transmitted. 
world. The system of the finite universe, we might say, is one of vicarious representation. Externality is joined to the absolute through conscious centres. Consciousness is the climax of direction, but the absolute condition of all sense of value.

"Soul" does not help. The unity of finite mind is an ideal, not a fact.

iii. If the mind transcends the neural process in the way suggested above would it not be better to postulate a soul as the substratum, and to call it a single immaterial being ? ${ }^{1}$

It is true that we do not want to make mind an adjective of body. It is, according to the view here advocated, ${ }^{2}$ a fuller unity, more completely differentiated, more thoroughly integrated. On the other hand, an immaterial being, other than and, so to speak, behind or below the uniting consciousness or experience, seems to be unintelligibly framed on the analogy of a material thing. ${ }^{3} \quad$ It takes us back into all the difficulties of the persistent soul-substance, from which Kant's criticism of rational psychology had set us free. All we desire, and all we logically need, is to take mind or soul for what it is - a centre or unity of experience, in connection with a certain material arrangement, which has every appearance of being the condition of its special and distinctive organisation, and of its peculiar adaptation to the environment. If we ask, as an able writer has asked, why should mind have a body ${ }^{4}$ the answer seems to be, as hinted above, ${ }^{5}$ "to store up and adapt the necesșary resources for selfmaintenance as a distinctive world." And as we said, supposing the same task set to psychical characters, they would, in order to achieve it, have to throw off much of their psychical quality. They would have to be stored up in the form of relatively fixed and orderly combinations, embodying the ways in which, for the distinctive

$1 \mathrm{M}$ 'Dougal, Physiological Psychology, p. 168.

2 Cf. Psychology of Moral Self, p. I 24. The passage referred to does not, as has been alleged by critics, maintain psycho-physical parallelism in the received sense. Like the present work, it treats mind as the more complete and the superior system.

3 Cf. Mitchell, p. I $6 \mathrm{ff}$.

4 Strong, Why Mind has a Body.

5 Page 215. 
world in question, an appropriate way of being together had created itself. A being could not consist of mere momentary response and adaptation; it must bring along with it a stuff to give the adaptation content and value. ${ }^{1}$

And it would be a futile dualism to argue that the unity of experience, and its types of interconnection, are to come in from out of doors-from an immaterial being -and organise or crystallise a chaos of content. This is all upside down. The world comes first; it works towards finding a centre, and in this working the types of our thinking and experience arise. So far from the centre being given, in finite experiences it is only an ideal never to be completely realised. A spiritual nucleus, a given unitary being, does not help us at all. After postulating it, either in all living matter or at some arbitrary stage of its development, we should have to explain away by impediments to its self-assertion appearances which it is far simpler to treat as degrees of imperfection in the formation of finite centres of experience. Finite consciousness and the finite self come late, on the top of immense stores of unconscious mechanism and adaptation, which are to all appearance its pre-condition. It is not a datum from the beginning; it is a light and a revelation which comes only when it is prepared for and demanded, and in finite experience very unequally and imperfectly. The standing miracle lies in its difference from brain. The duty of rational theory, with this as with all the miracles of experience, is to interpret its plain character with as little intrusion as possible of gratuitous factors. Mind, so far as it can be in space, is nervous system; nervous system, focussed in the nisus towards unity, which a standing miracle associates with it, is finite mind. You cannot say that the one acts and not the other. There is nothingno part nor point-in the one that is not in the other.

1 Would it be argued that the denial of this precisely gives the definition of a spiritual being, as having no stores or acquisitions relatively inert, but being all always in flaming activity through and through ? But such would not be a finite spiritual being. It would be all always in contact and continuity, and could experience no succession. 
Mind, we have suggested, is the interpretation of nervous system; but a false tradition inclines us to treat the $M$ in terpretation as a gloss, and the letter as the reality. If we discard this false tradition, and also remember that in comparing mind to an interpretation we are comparing it to a part of its own activity, the suggestion takes us perhaps as far as we can get. "Mind" is the meaning of externality, which under certain conditions concentrates in a new focus of meaning, which is a new' finite mind. When we speak of the making of souls, we mean nothing more than the moulding and relative perfecting of minds. 


\section{LECTURE VI}

SELF-CONSCIOUSNESS AS THE CLUE TO THE TYPICAL STRUCTURE OF REALITY

WE have seen that Finite Consciousnesses cannot be/Finite the ultimate directors or constituents of the universe. They and their subjective teleology are appearances at a certain stage; they rest on arrangements below them ; they indicate in every feature fuller forms of the Unitotality above them. Finite consciousness, whether animal or human, did not make its body, and does not set the greater purposes to its world. Something greater and more inclusive than itself both operates through it and reveals itself to it.

I. Is finite consciousness, then, an accident in a The universe of alien nature? Is self-consciousness, ${ }^{1}$ the fullest form of consciousness which we experience, resistant and the responsive born of a defect, and killed by its removal? Or may we look to find in this completest phase of finite experience something which furnishes a clue to the typical structure of reality-something which is not annihilated but rather enhanced by the transi-

1 I mean by self-consciousness the recognition of self in other as experienced in cognition, practice, the aesthetic attitude, and religion. Its essence is not the perception of the whole self as an object by itself as a subject (Appearance, 2 nd ed., p. I I I ), but the recognition in externality of a counterpart, whether discordant or harmonious, with its own principle. 
tion of discord into responsiveness and of the hostile not-self into the other of the self?

The question is, in other words, whether selfhood runs parallel with Individuality, or whether the former experience must cease when the latter is at a maximum? The question is not one necessarily of ultimate importance. There might be experiences in the highest individuality which would rightly supersede the experience of self-hood. But yet, if we can remove a certain misapprehension which stands in the way, we shall have opened the path to a deeper conception of reality, framed at least on the analogy of self-consciousness.

Now in finite experience that to which the universal opposes itself in its unceasing effort to become fully individual, that in overcoming which the self feels itself relatively one and self-complete, is prima facie difference in the form of what is alien or hostile; a resistant not-self in face of which we are ignorant and weak and never, as finite beings, become absolutely triumphant and at home. And it is essential to the basis of our account of Individuality to understand whether this not-self is something which depends on and indicates imperfection, or something which belongs to the essential structure of the real. ${ }^{1}$ Might we, for example, conceive of individuality as perfecting itself as a cosmos and a self-in-otherness, in proportion as the irresponsiveness, or even hostility, which for us is one great mark of the other or the different, is being overcome?

1 A very just illustration of this problem and of the general lines of its solution is to be found in the aesthetic experience of the "sublime" (see A. C. Bradley, Oxford Lectures on Poetry). 
One obvious view rests wholly on the discordance of the not-self, and consequently holds that selfhood is confined to imperfect being, and vanishes in so far as the hostile not-self is overcome. This view perilously resembles, though it is not one with, the view for which all consciousness is a disease and a defect. It is facile, but dangerous, simply to drop the higher characters of experience when we endeavour to conceive the absolute. It is a more trustworthy plan to indicate, if possible, the line of their transmutation. And indeed I notice that the responsive or concordant not-self makes its appearance within the same set of speculations, though disregarded in their result. It seems, then, an error to neglect this significant feature in treating of the ultimate nature to which the individual can aspire. In a word, is discordance the only otherness, and is otherness, therefore, ultimately unreal ? Is it not the case at bottom that discordance itself rests upon the claim and possibility of harmony?

2. I desire, then, to discuss in this chapter the contrafamiliar view which treats what may be called Negativity not as a vanishing defect but as a fundaWhat is a solved contradiction? mental characteristic of the real; to exhibit this view in connection with one or two points in logical theory, and to insist that its value depends on the principle being pressed home in its full force.

I start from what I take to be the nature of full or logical contradiction. The crucial point seems to be that no predicates are intrinsically contrary to one another. ${ }^{1}$ They only become so by the conditions under which they are drawn together. Con-

1 See Bradley, Appearance, 2nd ed., p. 562 ; and cf. author's Companion to Plato's Republic, notes on $436 \mathrm{~B}$ and $479 \mathrm{~A}$. 
tradiction consists in "differents" being ascribed to the same term, while no distinction is alleged within that term such as to make it capable of receiving them.

This is Plato's Law of Contradiction-what does or suffers "opposites"-(the danger of a logical circle is removed if we say "differents," which is enough $^{1}$ ) in the same relation must in itself be two and not one. And this is the root of his distinction between Opinion or Appearance, and Knowledge or Reality. It is a formal contradiction if you say, "This colour is both beautiful and ugly, i.e. not beautiful." It ceases to be a contradiction if you say, "This colour by daylight is beautiful and by candle-light is ugly." Are not, it may be asked, those terms intrinsically contrary which can in no case be affirmed of one another, such as the circle and the square? Why, no. They do not impede one another or the process of thought unless we bring them together in a special form, to which their content is inadequate. ${ }^{2}$ They may quite well be conjoint predicates of the same complex term, and when thus affirmed, and protected by adequate distinction, have nothing in them contrary to one another. It is one of the points that at first tries our patience in Plato, that he seems to find it contradictory that the same thing should look different at different distances. ${ }^{3}$ It is really just a case of what he is constantly explaining, as in the argument above referred to. Obviously, it would be a contra-

1 Bradley, l.c.

2 Cf. Bradley in Mind, lxxii. p. 173.

3 When he introduces the judgment of magnitude, "We see it bigger and smaller," the fact becomes doubtful. But there is enough truth in the statement for his immediate purpose. There is a tendency to the error in question. 
diction if a thing looked the same at different distances; that it looks different at different distances is a plain case under his Law of non-contradiction. There are places for all predicates; and when all predicates are in their places, none of them is contrary to any other. It is the bringing them together, on an inadequate basis of distinction, which is the essence of contradiction and contrariety, and this may happen with any diverse terms whatever. I venture to think that when we find an implication that predicates can be antecedently "contrary" or "opposite," we may infer that contradiction has not been adequately analysed." Contradiction, then, we suggest, is not a dead fact about certain predicates; it is an imperfection in the organisation of systems.

We may describe Contradiction then as a deadlock, caused by the attempt to bring together two or more different terms without adequate adjustment of content for their reception. Contradiction in this sense is rightly pronounced unthinkable, and cannot, therefore, be a characteristic of Truth or of Ultimate Reality. For these, if they are anything, are experiences in which Thought is triumphant and harmonious with itself at least, even if with more besides.

It will be a first step in our argument if we can decide at this point in what sense even such complete and formal contradiction is in some way an actual existent, and a characteristic of Reality. We see at once that it cannot be ultimate; and we are

1 I meet with this difficulty in McTaggart's Studies in Hegelian Dialectic, p. 9. If I am right, the term opposite, applied to predicates, has none but a rhetorical meaning. Cf., however, the same author's Commentary on Hegel's Logic, sect. I I 6, where "opposites" are terms referred to a common basis and reconciled by distinction. 
disposed at the first look to admit that it is merely a blunder of our own making, a subjective error, incapable of belonging to the world of fact. But in saying this, we seem to have unduly idealised our actual world-our given experience so far as we can at all recognise anything as given. We seem to be treating this with the respect only due to ultimate reality. For if there is anything that is given, it is a perpetual unrest of action and cognition; and this testifies to the presence of conflict and discord within every pulse of our experience, that is to say, the presence of contradictions which both in action and speculation make it impossible to repose in any actual moment. It must, I infer, be admitted that every day fact, what is given in normal experience, is self-contradictory as well as actual. If we say that what is self-contradictory cannot be actual fact, then we must deny the actuality of our whole normal world which is the field of our knowledge and action. For it is too plain that every object of knowledge and every situation such as to determine practice, if acquiesced in for a time, is acquiesced in only on sufferance, and really contains incoherences, combinations impossible as they stand, which must as soon as noted drive us onwards. Facts, as we call them, are stable up to a certain point, - will, so to speak, answer certain questions and meet certain needs; but when we transcend their several limits of stability by bringing them into connection with more of the real world, we become aware that none of them are sufficiently stubborn things to stand as finally coherent. The common appearances of our lives-of material things, of conduct, and of institutions, all carry us 
a certain way, and to pronounce them illusory would be a foolish exaggeration. But, to take a single example, if we trust to man's living by bread alone - by bodily comfort-we shall find he cannot, and that though bodily nutrition is actual, we shall fall into contradiction-find that nourishment is not nourishment-if we take it as the.exclusive mode in which human beings are kept alive. We shall find other needs asserted; what we took for our system of "fact" will not give room for them. Our fact has broken down; and all our facts break down in some such way, and at some such point. Thus, if we do not care to adopt the doctrine of Máyawhich arises from a misapprehension on this head -and class the whole known world as illusion, we must admit that what is experienced as actual fact may yet be self-contradictory. ${ }^{1}$ We cannot escape by saying "thus far and no farther"; by saying "we will take the world without asking questions, and thus it shall be perfect fact, and real without contradiction." For such a world will not keep pace with our experience. We shall find that action and argument, " like a wind," take us outside it; and our petrified facts will neither serve our need nor maintain themselves.

The whole difficulty springs from trying to attribute to given fact the features of ultimate Reality. In truth, the actual world is charged with contradiction. Things are given with conjunctions

1 Metaphysical criticism directed to establishing degrees of reality, after the manner of Plato and those who follow him, is of course the completest support of this point of view. It is most striking to note that Hegel desires to treat "Widerspruch" as a category of his Logic, that is, as a necessary predicate of reality at a certain stage, apart from the working contradiction by which every category passes into its successor (McTaggart, Commentary, sect. I I 8-9). 
of predicates which no distinctions are at hand to deal with and explain. In the life of conscious beings, again, contradiction is a felt experience, as actual as pain, dissatisfaction, unrest, which are forms of it or one with it. It consists in an attempted union, which, though given, yet because it fails in the contents necessary for adjustment, a mind or even a life (it would appear) cannot endure. It is actual, as the experience of progress proves, over the whole region of action and cognition, which is equivalent to the region of finite experience.

The spirit of otherness is Negativity.

3. Our next step is to ascertain what form or spirit of "otherness" survives when a logical contradiction is resolved. The point I would draw attention to is that we are here dealing with a survival of what was present in Logical Contradiction. Nothing is changed, except that what was attempted has been achieved. The contents are diverse, as they were; sensuous contents, ideas, emotions, conscious members of a social world. The principle is the same throughout; they rush towards one another through the same impulse, to come together in the whole which animates them; the change is merely that now they and their world have been readjusted, and can carry out their union. How are we to describe the form of their surviving distinctness? We may take such examples as a sensuous harmony of colour or sound, or mind and motive at their best, or two selves united in one emotion, or the satisfaction of desire.

I may illustrate the point by Hegel's view of contradiction. $^{1} \quad$ It is merely an illustration, for I do not wish to raise any historical question. It

1 See above, p. 225. 
is familiar ground that Hegel has been accused of denying or disregarding the logical law which pronounces contradiction to be unthinkable, and that his best interpreters have shown the charge to be false. They have pointed out that the Dialectic, so far from disregarding the law of Contradiction, rests entirely upon it. It is because Contradiction is unthinkable and intolerable that a conjunction of judgments which makes their predicates irreconcilable demands a readjustment of contents and the formation of a new totality.

Now, while I admit that this is contained in Hegel's view of Contradiction, I cannot but think that there is something more behind. Hegel obviously feels himself fundamentally in antagonism to the current formal view of Contradiction as merely unthinkable. No words are too strong for him to express his scorn of such an attitude. "What moves the world is Contradiction; it is ridiculous to say that Contradiction is unthinkable. What is true in this assertion only comes to this, that Contradiction cannot be final, and that by its own action it cancels while it maintains itself (Sich aufhebt). The cancelled and maintained contradiction, however, is not abstract identity, for this is only one side of the antithesis." 1 Here, no doubt, we are in the region of essence, where oppositions are sharp and pointed. But this does not account for the whole of Hegel's attitude, which is fundamental with him: "Whereas people say that Contradiction is not thinkable, the truth is that in pain which a living being feels it is actually a real existence." ${ }^{2}$ (He says the same of motion in space.) Again:

\footnotetext{
1 Encyclop. p. I I9, Zusatz 2. 2 Werke, Bd. v. 249.
} 
"Formal thinking prescribes to itself the rule that Contradiction is not thinkable; but, in fact, the thinking of Contradiction is the essential moment of the Notion." 1 These latter passages are from the discussion of Life and of the Absolute Idea. It is clear that we have here a reference to something more than the mere deadlock between saying and unsaying the same thing. It is agreed that a logical contradiction is a position which cannot be held; but we further note a strong conviction that it contains and implies something, the value and necessity of which accounts for and justifies the inevitability of contradiction itself. Contradiction, as we saw above, is not just a mistake of ours ; it is a check or friction incident to the misfit of experience in its self-systematisation. The question is, what is left, what is found to have been the true movement of union, when the check or friction is removed by readjustment?

This brings us to a suggestion for meeting the problem. "What survives when a contradiction is resolved?" We might venture to reply_- A successful embodiment of "negativity." Hegel often speaks of Negativity as apparently a factor or moment lying deep in the inmost structure of the Real, as the pulse of life and spring of movement of the world. ${ }^{2}$ It is not one with the dead fact of unthinkableness which attaches to logical contradiction. It is rather the spirit of system ${ }^{3}$

1 Werke, Bd. v. 332.

2 For different views on this question see McTaggart, Studies in Hegelian Dialectic, sect. 9 and II 7 ; Prof. McGilvary, Mind, vii. p. 397.

3 See author's Logic, 2nd ed., i. 289, on place of Negation in Knowledge. Cf. Bergson, Évolution créatrice, p. 315, who on this point seems unaware of Plato's profound discussions. 
and self-consciousness-the intimate nature of a being which, while acting and expanding, is yet at home with itself - distinguishable or self-distinguishing, in and throughout the intimate union with its contents in expansion and in action. It is the successful and pure expression of that whole aspect or tendency of anything real, which finds imperfect manifestation, with an accompaniment of friction and hindrance, in what has been described above as Formal or Logical Contradiction.

Negativity, then, it is submitted, is fundamental in all that is real. It is the same characteristic which has been described as the fact that experience is always beyond itself - the character, indeed, which we have described from the beginning as that of the universal, or, in other words, the tendency of every datum to transcend itself as a fragment and complete itself as a whole. It is what has been spoken of under the name of self-consciousness as the nature of a being which is itself and its other in one.

I am suggesting that Negation and Negativity have sometimes been confused with Contradiction. Contradiction, as we have tried to explain it, is an unsuccessful or obstructed Negativity; Negativity a successful or frictionless contradiction. Negation, according to our views which have been maintained elsewhere, is correlative to affirmation. The question about it is, not, how much meaning you can conjure out of a bare denial, but why, in the most highly developed experience, negation bears an equal part. $^{1}$ And the answer is, that negation is funda-

1 Cf. author's Logic, loc. cit. M. Bergson has discussed the question at length (Evolution créatrice, loc. cit.). His answer, though emphasising the factor of interest and sentiment, falls within 
mental in a systematic whole. Its members, in order to be, must also not be. In a sense this is true even of the whole itself, as active in them.

It seems erroneous, therefore, to hold that Negativity vanishes as perfection is approached. The reverse seems to be the case.

Negative and affirmative grow pari passu. When this is not admitted, we suspect a confusion between Contradiction and Negation. It is a point which seems full of significance, and which can hardly be too much insisted on, that otherness and the not-self, the vastness of the universe with which every self has to be reconciled, increases and does not diminish by the same movement by which friction, obstruction, conflict, are reduced and removed. So long as there is no science, and the world baffles and contradicts the mind of the savage at every turn, there can be no such conception of a reality not ourselves over against the self as there is in the days of Newton and Darwin. Whether it is here interpreted to the right effect or not, this matter is one which is, and ought not to be, neglected; viz., that negation plays a larger and not a smaller part as contradiction diminishes. It is contradiction in fact-confusion or conflict checking the orderly expansion of a system, whether a life or a theorywhich hinders significant negation from appearing. A true negativity, say, an organised universe of desire, is a solved contradiction.

This, therefore, it is submitted, is the spirit of difference which survives even where contradiction

the general account given by Plato and others, that negation is the spirit of an interdependent system. This is why often, instead of affirming $a$, it is convenient to deny $b$. 
has been overcome, and where we possess what is most real and most thinkable. Everything contributes to the whole, and the friction or failure of adjustment, which made the contradiction or deadlock, say, in the attempted combination of two or more desires, no doubt represented and enhanced the distinctness of the two sides, which survives in and tends to perfect the completed union. But it appears to me that we are allowing ourselves to lose sight of the full problem if we treat the mere fact of having refused to enter together into a whole - that is, of having been in contradiction, as something which, surviving as such, qualifies the successful union. The qualification, whatever it is, can surely count and work only as it survives within the completed whole, and it is in the factors of this whole itself that we have to find the experience of negativity; which is not, according to the view here insisted on, a note of imperfection, but is a character that is deepest in the most perfectly real experience.

What, then, do we mean by Negativity as a feature of experience? If it only means difference, the distinctness necessary to identification, is not a term connected with the idea of negation too violent and exaggerated to use for it? What is here meant is not precisely difference, but difference as subsumed under the general character of negation, that is to say, diversity or distinctness as regarded from the point of view of an attempted union; the attitude-to take a conscious being, probably the only ultimate case, as at least an illustration-of any spirit that demands a union or satisfaction, to that with which it is impelled to 
unite or in which it aspires to be satisfied. Now no doubt self-completion, (satisfaction, felt solution of contradiction, are possible at many levels of life; and compatible with very easy and effortless experiences. But it is here suggested that in a true typical satisfaction-felt resolution of a contradiction-there is always a certain exaltation which depends essentially on the fact that in satisfaction the self goes out into the other, and, though or because it becomes enriched, is beyond itself. In a word, to put the whole paradox brutally, it is undergoing an experience which logically and in its fundamental structure is one with self-sacrifice. ${ }^{1}$ How can this be construed of anything but a finite being? Obviously not by help of such words as have just been used, presupposing limits and a temporal modification in the self. But there is a point of some interest which may at least serve to bring out the distinction of principle between taking Negation, as, like Contradiction, an incident of finiteness, and taking it as fundamental in Reality.

Hostility

(Contra-

diction) confused with $\mathrm{Re}$ sponsiveness (Negativity).

Vrai-

semblance of the confusion.
4. It has already been implied that the current view of experience, influential even among philosophers, confuses Contradiction and Negativity. The principle that an element of Reality can find completion only in what is not itself, is confused with the imperfection of adjustment in finite beings or contents, which so far hinders such completion from taking place. And thus it comes to be held that Negation, like Contradiction, is a vanishing quantity, and that in a complete experience it would

1 There is self-sacrifice, in form, in so far as the self contradicts itself as a condition of self-expression. But the form may include a contradiction we do not approve of-one which minimises the self on the whole-and then we call it wrong-doing. 
disappear. The point of interest which was just now referred to as emphasising the distinction of principle, is the extreme difficulty of avoiding this confusion. When we endeavour to insist upon the nature of self-consciousness, as self and other in one, by instances and analyses drawn from actual experience, we constantly find ourselves appealing to characteristics which depend upon ignorance and imperfection. The ideal which we have in mind is the self 272 the other, but in actual experience we get little more than the self and the.other. ${ }^{1}$ Now the crux in the distinction of principle arises at this point, because of the appearance as if it were the discrepancy of self and other that for us gives interest to the realisation of self in other. We may take as a characteristic case that apparent responsiveness of external Nature to human moods, the perception of which is at least a great part of the apprehension of the beautiful. The freshness and strength of the feeling which such perceptions bring with them is surely in a great measure dependent on the fact that they come to us as undesigned coincidences. It is for this reason that they seem to bring to us a confirmation of our own sentiments which is rooted somewhere beyond the foundations of our own private being. If there were no novelty, no unfamiliarity, in a word, no friction nor discrepancy intruding upon our apprehension of natural beauty, then, we are inclined to conceive, the return upon ourselves would lose in vigour what it gained in facility, and the magic of the new and inexplicable would be lost in a dull sensation that it is all the same old story.

1 Nettleship, Biography of Green, p. 206. 
Now the case thus stated emphasises the opposite side of the question from that which was stated before. And the interest is that both are undeniably actual. It is true, as we urged, that the sense of the beyond, of a something which stands over against the mind, must be incalculably greater for Newton or for Darwin than for a savage to whom nature is chiefly a mysterious source of unaccountable interferences. But it is also true that a loss " of novelty and strangeness-of friction in making the world our own-seems to very many minds destructive of poetry, and of responsiveness on Nature's part. The two tendencies are deeprooted, and both no doubt must have their justification. Does complete knowledge and familiarity dull the interest of a landscape or a poem, or does it rather, as some would say, cause the response to be even deeper, and the significance to be more profoundly felt? Is novelty necessary to enjoyment, and ought a story to lose its interest when we find we have read it before? ${ }^{1}$ In these simple questions, which our every-day acquaintance with nature, art, and letters, forces upon us, we have an embodiment of the metaphysical issue which is the subject of this chapter. Is Logical Contradiction a necessary condition or accompaniment of a genuine conciliation and satisfaction; or is this, comparatively speaking, an accident of growth, giving place to an exaltation which increases with mastery and the removal of incidental interferences, as the self comes together with a not-self which is completer

1 Cf. the question how far hostility to sense is necessary to the sublime (Professor A. C. Bradley, Oxford Lectures, p. 56). On the whole, and when the experience is at its best, it is not so. 
and more free from discrepancy? There can be no doubt that the latter alternative on the whole represents the truth. It is a bad romance which interests on the first reading only. It is a vulgar appetite for the marvellous which finds superstition more exciting and poetical than science. It is not the obstructive but the truly responsive different, which in the deepest sense attracts and exalts us. ${ }^{1}$ Of course the possibility of the former is rooted in the characteristic which constitutes the latter.

The other tendency we can empirically see to be of a vanishing nature; or else civilisation would, as the pessimist thinks, destroy the charm of the world. But the pessimist is not without his grounds, and novelty and inexplicability must have genuine features of attraction. The two sources of interest have, as we saw, the same root; the possibility of discord is involved in the claim to harmony. In the first place, we can see the necessity that it should be so; if not, if their first aspect was purely deterrent, progress could never begin. Secondly, as we have said already, the response that is cumbered with strangeness and obstruction has the seal of an undesigned coincidence; we feel that the very enemy takes our part. These might be called formal feelings, like the analogous enjoyment of detecting a plot puzzle, or being amazed at unheard-of ingenuities of romance. But when the rind of things is pierced, and the content begins to be won, a deeper set of emotions is stirred; and

1 The two tendencies in the appreciation of beauty which I have taken as examples of interest depending on Logical Contradiction. and on simple Negativity respectively, are curiously parallel to the two views of the conditions of the consciousness of self, which will be discussed below, p. 247. 
we begin to rejoice in the substantive values which expand and affirm our self, and not merely in the surprise that the crust should yield to our instruments at all. There is more to be said than this, of course, about the delights of mystery; but we must be content with a single warning. The attitude of the mystic, which all philosophy must respect, does not depend on mystery in the vulgar sense ; not on the marvellousness, or unaccountableness, or obscurity of ideas. The mystic, above all men, is absorbed in the greatness of a content for its own sake, and in its overwhelming clearness. It is not contradiction, not friction and obstruction, but immediacy as opposed to discursiveness that distinguishes his apprehension of the real.

We may thus understand, perhaps, or approach an understanding, how Logical Contradiction, though apparently a characteristic attending interest and value in the response of the not-self, is so really only as an introduction, and for vanishing reasons. And we can infer that to interpret our interesting sense of the beyond or "other" which furnishes our satisfactions, as due to our ignorance and defect, and as a vanishing quantity in the progress of the mind, is to confuse the incident with the essence; and that, as in the example of natural knowledge, the otherness becomes more definite as the object becomes more adequate to the subject.

It is partly, perhaps, with the view of construing these appearances that many thinkers have embarked on the adventure of treating all the content of life as a translation of the interaction of conscious beings. Here, no doubt, we seem to have a suggestion of an "other" which is able 
to maintain its independence, its otherness, along with any degree of transparency or familiarity. And I mention the speculation chiefly to make clear, if it does not seem clear, what is the particular crux which I have had in mind. We may hold it possible to imagine an intelligent being who has nothing left to learn from a sunset or even from a pain or pleasure ; and, putting that impossible case, we should be unable to comprehend how they can any longer be experiences by union with which his self has anything to gain. But a person, it would be urged, however well you know him, is still an independent source of response, and it may be argued that here, and here only, you find the true other of a self.

I find a difficulty in this speculation which may rest on misapprehension, but which I will indicate in a few words because our view of externality is concerned. What we must have, on any theory, for Reality and especially for Negativity to be manifested in, is the content of life, pain, conflict, sacrifice, satisfaction. Now there is a difficulty, is there not? in getting these contents out of a universe in which nature is a system of persons, except by presupposing, in the outside or other of every thing regarded as a person, what might as well have been presupposed as the outside or other of the persons commonly recognised as such. It is things, is it not? which set the problems of life for persons ; and if you turn all things into persons the differences which make life interesting are gone, except in as far as for practical purposes you turn the persons back again into things, i.e. your food, or your own body, or the place at which you were born. In making the outside adequate to the highest claims, 
you have turned it into an inside, and so, while professing to meet the problem of the outside in the highest degree, you have, it appears to me, really abandoned it altogether. If the instruments and attributes of my life are turned into persons, I surely am reduced to emptiness and deprived of my character, for without external activity my character is nothing. This criticism may be mistaken, but it may pass as affirming that we must perceive as actual the distinctions, which give life its content. There cannot be spirit, it would seem, constituted by 'nothing but pure spiritual centres. ${ }^{1}$ Spirit is a light, a focus, a significance, which can only be by contact with a " nature," ${ }^{2}$ an external world.

Conclu-

sions

5. I will proceed to indicate the consequences of opposed to current opinions. these ideas, well-known consequences, to which I have nothing to add, except just this, to urge that their point is lost if they are not conceived in their whole depth of paradox. I will try to express them through antitheses to current opinions, which will bring out the reasons for which they seem to me important; and these are also the characteristics which define their peculiarity.

Finitehess and eviy not inrsions.

$a$. It is a mistake to treat the finite world, or pain, or evil, as an illusion. To the question whether they are real or are not real, the answer must be, as to all questions of this type, that everything is real, so long as you do not take it for more than it is. On the view here accepted, finiteness, pain, and evil

1 Cf. Caird, Critical Philosophy of Kant, ii. 536 ; Bradley, Mind, li. p. 327 note.

2 How far is such a view cognate with the ideas of M. Bergson? Would he say that la vie would be better, and could be at all, without matter, which appears to be for him in the main the débris or detritus of life, and yet in some way its positive sine qua non? 
are essential features of Reality, and belong to an aspect of it which leaves its marks even on perfection. The view that they are illusions says that if we knew everything and could feel everything we should see and feel that there was no pain or evil at all. The view that contradiction is actual, and, more than that, is an exaggeration of a feature truly fundamental in reality, says that if we knew everything and could feel everything we should see and feel what finiteness, pain, and evil mean, and how they play a part in perfection itself. The way of meeting them-though it is not our business to preach, yet we may permit ourselves to illustrate our view by its effect-the way of meeting them is different in principle for these two theories. [It is absurd and insulting to tell a man in pain or in sin that there is no such thing as pain or sin; it is neither absurd nor insulting to try to let him feel that of each of them something great and precious can be made.] In a certain sense the two views, that which disposes of them as illusion, and that which accepts them as immanent in perfection though not just as they seem, may be forced into approximation. But our present task is to insist on their difference, to urge that all depends on being in earnest with the idea of negativity, and that from such a point of view the idea of illusion is rejected, though that of appearance, as something actual and yet contradictory, is accepted. I do not think that Hegel can be held to treat evil as an illusion, though he has used the word illusion in discussing the matter. ${ }^{1}$ As I understand, the illusion

1 Encyclopädie, sect. 212 ; cf. McTaggart, Studies in Hegelian Dialectic, Chap. v. 
which he speaks of is not the belief that evil or finiteness is actual, but the belief that its actuality prevents the supreme end from being accomplished, whereas in truth it is essential to its accomplishment.

At all events, as against the idea that finiteness, pain, and evil are illusions, the view here indicated would maintain that finite conscious beings actually suffer and do wrong because it is their nature to complete themselves, and the general form of this completion involves as one factor in it the relative loss of self, and in the finite world this is emphasised by various degrees of what we have called Logical Contradiction, that is to say, inadequacy of the elements in which completion is sought. It would follow, and this seems to agree with the best ethical theory, that the ultimate logical structure, if I may so speak, of suffering and of evil is the same as that of satisfaction and of good. That is very noticeable, of course, in Green's theory of morality. It is undoubtedly not easy on this theory to distinguish otherwise than in degree between moral good and evil. And I believe this to be an indication that its main outline, its metaphysical fabric, is sound. ${ }^{1}$ The difference, in principle, is one of the adequacy of the contents in which self-completion is sought, and the consequent degree of their tendency to give rise to discord $^{2}$ and contradiction. But in all important satisfaction there is a thrill, which is analogous to

1 A theory of the bad self, such as we have in Mr. Bradley's Ethical Studies, is needed to work out the distinction of good and bad in conduct.

2 It must be remembered (Bradley, Appearance, 2nd ed., p. 364) that the discord which is not felt may be the most extreme. The hardened sinner is an obvious case. That the inadequate selfcompleteness is sought as true self-completeness is an essential point of the bad self. It is involved in the statement of the text. 
pain, due to the tension of self-completion; and theory seems to demand that, as Plato suggested, a perfect experience ${ }^{1}$ should be, not indifferent or neutral as the careless reader supposes, but such as to include and harmonise in itself the characteristics of pain and pleasure.

$\beta$. The same mode of thought would be hostile/ The perfect to any conception of the divine nature which should involve stability and perfection in such a sense as to must not exclude activity. exclude activity and the general form of self-sacrifice. It is not intended to adhere to the view of those who conceive the divine being as finite, and as possibly one of a number. The intention is rather the reverse, namely, to maintain that finiteness eo ipso arises, if negativity is not given its full significance in the conception of the supreme nature. Dr. E. Caird's criticism of Aristotle's Theoretic Life, ${ }^{2}$ as literally interpreted, puts this point very clearly. It is not an imperfection in the supreme being, but an essential of his completeness, that his nature, summing up that of all Reality, should go out into its other to seek the completion which in this case alone is absolutely found. The "other" in question can only be finite experience; and it is in and because of this, and qualified by it, that the Divine nature maintains its infinity. And, therefore, it may be said that the general form of self-sacrifice-the fundamental logical structure of Reality-is to be found here also, as everywhere. Not, of course, that the infinite being can lose and regain its perfection, but that the burden of the finite is inherently a part or rather an instrument of the self-completion of

1 Philebus, 33 в ; Nettleship's Remains, ii. 3 I I.

2 Evolution of Theology and Greek Philosophy, i. 382 ; ii. 25 ff. 
the infinite. The view is familiar. I only plead that it loses all point if it is not taken in bitter earnest. ${ }^{1}$

I have used remorselessly phrases which imply time- - activity," "going out of oneself," "seeking and finding." The objection to predicating time of the supreme experience lies in the nature of selfcompleteness, and if, on the one hand, succession seems incompatible with this, on the other hand, the idea of instantaneousness or simultaneity, which is a temporal idea, must not here be introduced to embarrass our thoughts. We must surely distinguish the conception of changing or progressing as a whole from the conception of uniting in a selfcomplete being characteristics which for us demand succession. $^{2}$ If we were to be barred from ascribing content to the supreme being, because for us all content is developed in time, the end must be that for us the supreme being will be nothing.

"Surplus of pleasure over pain " not the true point at issue.

$\gamma$. Finally, our point of view is hostile to the form in which questions of optimism and pessimism are usually raised as to the surplus of pleasure over pain in the universe. Even Mr. Bradley has discussed this question with reference to the Absolute. But I cannot help thinking that it is improperly stated. What we as factors of Reality demand, what any factors of Reality as such must demand, is essentially, if I am right, not pleasure but satisfaction, that is, the sense that by help of the negative we have attained ourselves. This, no doubt, implies some pleasure; but the point is, if I am not alto-

I I have had much in mind Nettleship's fragment on the Atonement.

2 I may refer again to one of Nettleship's fragments, that on Immortality. Cf. also Kant's doctrine of the infinite moral progress as seen by God. 
gether wrong, that in satisfaction the pain or difficulty, as a "moment"-i.e. a phase which remains an element-contributes actively to the positive attainment. Whereas, in comparing pleasure and pain as experienced facts of feeling, I presume that they retain their first positions as respectively plus and minus quantities.

This is one point, and another follows from it. The comparison of pleasure and pain in respect of quantity, even if we disregard the difficulties pointed out in anti-Hedonist polemic, betrays an inorganic point of view. The question cannot surely be how many moments of pain you have experienced, and whether you have had enough moments of pleasure, allowing for the intensities on each side, to outweigh them, but whether the experience has done its work, and returned you to yourself a complete or at least a completer being. So, it would seem, the problem should be stated about the universe. Not, if we could reckon up moments of equal pleasure and pain (to simplify the question by reducing it to a matter of counting) which of the two classes would be found to outnumber the other, but rather, is there reason for thinking that pain and finiteness are elements playing a definite part in the whole such that its completeness depends upon containing them? Broadly speaking, I suggest, experience indicates that a soul which has never known pain, like a nation which has never known war, has no depth of being, and is not a personality at all. Of course, this way of looking at the matter does not by itself dispose of the suggestion that the cost even of perfecting a soul may be too high; but the conviction that there essentially must be a certain 
cost corresponds to our best insight in the sphere of every day experience.

All-

important whence we adopt suggestions of satisfaction.

$\delta$. And so, in the end, if such a question as that of pleasure or pain in the Absolute has reality for us at all, it seems all-important whence we take the suggestions from which we are to learn what to look for. We ought surely not to start from commonplace experiences, but rather from those in which self-expression is at the fullest, the rare moments to which Aristotle alludes in the discussion of the Theoretic life. It may be noteworthy that Aristotle consents while Plato refuses to ascribe the feeling of pleasure to the Divine nature; and this may be connected with Aristotle's apparent omission of negativity from his conception of an ideally perfect experience. In his distinction, however, between the enjoyment of self-realisation and the enjoyment of recreation he throws out a hint which we might do well to follow. And for him as for us, apparently, the activities primarily devoted to sheer enjoyment and delight are wrested by the very structure of man's soul to severer forms of self-expression, so that the completest of all the creations in which as yet man has freely and spontaneously sought what at his best he most enjoys is, I presume, for us, as for Aristotle, that of poetical tragedy. This does seem to me to be a paradox worth noting. Can we seriously suppose that a nature which, when it reaches the summit of evolution so far as we have experienced it, is taking such a line as this, will find a perfection in any attainment which is not strongly marked with an analogous temper ? ${ }^{1}$

1 Is it tolerable to contemplate enjoying such imaginations without sharing something of the experiences which suggest them? And if 
I am only using this idea to set the question of optimism in a certain light; that is to say, to state it not as the question whether pain is as it were quantitatively submerged or neutralised by pleasure, but by looking for a completeness in which souls have found themselves, or realised their inherent structure; which completeness, considered as a whole, cannot be quantitatively compared with the factors or elements, such as pain or pleasure, subordinated within it. If we had no negative factor but Contradiction as such, then I suppose completeness could only be in its abolition, i.e. in an Absolute or perfection which bore in it no trace of the character present in finiteness and imperfection. But the distinction between Contradiction, as we defined it, and Negativity, seemed to be suggestive on this head.

6. It is on the whole an attractively simple view The two that the not-self means discord and collision with aspects of the self, and that the self is experienced, and self- self. hood indeed exists, by opposition to such a not-self $;{ }^{1}$ essential to and that consequently, with the cessation of discordance, that is, of what we have called Logical Contradiction, the experiences of selfhood as such must cease and determine, though Individuality

the idea is tolerable, yet could such enjoyment be possible? A truth may be hidden under the notion that the saved are to delight in the vision of the sufferings of hell (Browning, Johannes Agricola), but our ordinary thoughtless hope that others have suffered for the happiness and amusement of those who come after, who are to enter upon the inheritance without a pang, strikes me as essentially one with that mediaeval mood, and as prima facie revolting. Its error is in wholly separating satisfaction from pain. The truth must bring them nearer together. Cf. Introduction, p. 14, on Mr. Bertrand Russell's remarks on Tragedy in his essay entitled, "A Free Man's Worship" (Philosophical Essays).

1 Taylor, Metaphysic, p. 340 ; cp. pp. $6 \mathrm{I}$ and 350. 
proper would all the more survive and prosper. For such a view the responsive not-self would have no existence, and consequently, all differentiations or sub-individualities within the Absolute would be in various degrees imperfect and self-discordant, and the Absolute itself could have no experience of selfhood. They would be mere appearances whose inner imperfection would reveal itself in their discrepancy as against an outer not-self. A conception of this kind, involving the admission that all minor individualities within the Absolute must be imperfect and self-discrepant, would cut many knots. It would release us from the attempt to understand the perfect experience as implying a society of perfect selves, and to explain the relation of our imperfect selves to such supposed perfect differentiations of the Absolute. ${ }^{1}$

But there is an obvious and all-important fact, already mentioned at the beginning of this chapter, which demands that any such ideas should only be accepted with considerable modification. It is quite plain that our conception of self has two ${ }^{2}$ sources in its relation to the not-self, and not one only; and that the sense of unity and reconciliation with the world beyond us is a far larger factor in our awareness of selfhood, and one which increases concomitantly with it, than is the sense of collision with the not-self.

Now if we are going to say that the sense of union with or satisfaction in the not-self-e.g. of

1 The difficulty raised by Mr. McTaggart's view. See Studies in Heglian Cosmology, sect. $22 \mathrm{ff}$.

2 See Taylor, Elements, p. 350 . "The two typical forms of experience from which the concept of self appears to be derived," I can hardly reconcile this with the exclusive prominence given to the negative form, e.g. on p. 340 . 
co-operation with a society-is not an element in furnishing us with our conception of selfhood, then we are driven to this result, that the awareness of selfhood disappears in proportion as the self expands in excellence and success. And in a certain sense such a conclusion is tenable; ${ }^{1}$ and in this sense it might give us a useful indication when we come to consider the attribution of an awareness of self to the Absolute.

But the fundamental point is here. In agreement with the whole doctrine of this chapter, we must take it that the sense of discord and the sense of concord are rooted in one and the same characteristic of experience, the negativity which makes satisfaction possible but which in imperfect conjunctions takes the form of contradiction. If we are willing to dispense with the conception of a system of perfect selves as constituting the Absolute, then we may admit that in some degree contradiction as well as harmony will attach to every finite self, because of its imperfection. Therefore, we may concede that however complete the reconciliation with the notself, however true it is that the self at its best has in its world of externality an immense affirmative expansion, yet the determination of the sense of selfhood by contradiction with the not-self is an element never altogether absent from the finite selfconsciousness, and one that co-operates in giving sharpness to the recognition of self.

The finite self, then, would be essentially such as we know it, imperfect and inconsistent with itself ; though it would have in its nature an element of

1 Cf. "self-consciousness" in the bad sense, the disappearance of which certainly means a strengthening of the self. 
unity and expansion, suggesting a completion which as a finite self we must conceive that it would never attain. As experienced in the absolute experience, when the essence of perfection is to transmute and to triumph over imperfection, it would no longer, so the indication runs, be called a self. ${ }^{1}$ As we have seen and shall see, its substance would lend itself to new arrangements, to the constitution of new worlds in continuity and readjustment with other selves, so that the experience would be no longer describable as constituting a system of selves.

Nevertheless, the positive affirmation of the expanding self in its not-self, which we have seen to be the really essential element of self-consciousness, though not perhaps the limiting factor, gives an indication that cannot be disregarded either for the self in the Absolute, or for the Absolute if we attempt to regard it as a self. We have urged throughout that it is in the highest of our own experiences that we must seek for the clues to the fullest reality. And that we experience our self most completely just when we are least aware of its finite selfness ${ }^{2}$ is a clue which must not be forgotten. Defect and contradiction cannot constitute the really significant essence even of a finite being. It is positive awareness of an area or quality of selfmaintenance that after all the self aspires to, though failure and contradiction may force on it a recognition of its limits-and it is this, the real foundation of selfhood, that is in some way possessed by the self in the Absolute, and by the Absolute so far as analogous to a self.

1 Bradley's Appearance, 2nd ed., p. 529.

2 Cf. again the case of self-consciousness in the bad sense. 
7. Thus we have attempted to show that while contradiction and discrepancy are inevitable in the constitution of the finite self, they are not the ultimate characters which the constitution of a self Has finite $\frac{\text { selfhood }}{\text { a value? }}$ The higher mysticism; presupposes ; and that this ultimate character, quite Absolute. apart from speculations about the Absolute, reveals itself in increasing degrees through those experiences which exhibit the finite self as a self in the fullest sense. We have, however, admitted that much of what we habitually associate with the idea of a self in the "other," is connected with the features of apparent discord and opposition, which give the idea of freshness and independence that seems to reinforce any responsiveness we meet with in nature. And it is not in the absence of negation, but in the growth pari passu and even in the fusion of the negative and positive responses, that we found reason to treat self-consciousness as conditioned, if by a negative, yet not by a contradiction.

A strong light is thrown upon the difference between these two conceptions by a problem which is fundamental for our attitude to the finite self and finite life in general. It is allied to the problem of pessimism, but is really rather the issue between the lower and the higher mysticism. Men have asked, from Greek times downwards at least, whether it is better to be born or not to be born? I do not mean in the commonplace sense of asking whether or no life or the world of lives contains more of pleasure or of pain, as, in my opinion, we roughly and rather unthinkingly distinguish them. On our attitude to this form of the question I have said something above, and shall have more to say 
below. But the point now before us is different and much more serious. It is not a survey of life by a standard taken within it, but an ultimate question as to the place and functions of finite life in the universe; the question insisted on by mysticism in its popular and aggressive forms.

Every student of Plato must often have longed to know what Plato held to be the function and justification of terrestrial life on the whole and in the scheme of the universe. One might state the problem crudely by asking if he ever admitted that any soul was the better for undergoing or having undergone the life on earth. Did our knowledge, our morality, our love of beauty, partially and laboriously won in the conflict of sensations and desires, seem to him to be of any value, for ourselves or for the universe, which would not have equally been real-more real - without them? Did he consciously apply to the whole being of the finite the principle so obvious in his detailed theory, that hindrances and contradictions are opportunities and starting-points? It would be beyond our present subject to attempt an answer to these questions as regards Plato. ${ }^{1}$ But they serve as an introduction to the standpoint of mysticism.

"Earth, these solid stars, this weight of body and limb, Are they not sign and symbol of thy division from Him ?"

These lines, as I understand them, ${ }^{2}$ show an interesting deviation towards natural mysticism in a

1 See Caird, Evolution of Theology in Greek Philosophy, on Timaeus, i. 254 .

2 Tennyson, "The Higher Pantheism." I take the poet to mean that it is finite life which separates the soul from God; I have known it to be held that he meant the hint of separation to lie in the possibility of death, inherent in the body. 
poem which contains along with them a splendid expression of "immanence." 1 And so the mysticism of the East, at any rate in a popular stage which passed into European thought largely through Schopenhauer, answers decisively that it would be better if no one were born. Self, self-consciousness, self-will are held to be disturbances, diseases of the universe, and illusions in the full meaning of the word, that is to say, not merely appearances whose contradictions point to a fuller reality, but phenomena which essentially involve the total contradiction and disappointment of the ideas and desires which constitute them. And this disappointment and contradiction are not held to be in any way instrumental to a realisation of the content of such ideas and desires in any form whatever. A link between such an attitude and the constructive conceptions of Western thought is indeed supplied by the reservation that though not instrumental to any fulfilment of itself, the finite world is connected with the one desirable fulfilment-its own suppression-by a law imposing certain conditions on the attainment of the goal. It cannot be suppressed by violence, e.g. by suicide; the evil lies deep in the will to live, and only the suppression of this will by means which take a form akin to art, morality, and religion, can put a stop to the vicious circle of the wheel of life.

The same paradox is inherent in popular Christianity, and is acutely felt. ${ }^{2}$ And the popular solution

1 "Speak to Him thou for He hears-"

2 E.g. Truelfth Night, Act i. Sc. 5. Fool: "The more fool, madonna, to mourn for your brother's soul being in heaven." 
is not unlike the solution of Schopenhauer's Buddhism. It presses itself on the earliest reflection, and we may state it in the words in which Plato refers to it. "We mortals are here on duty, and must not withdraw till we have our orders." 1 Heaven, we understand, though much better than what we have, would be forfeited by the attempt to grasp at it prematurely. And if our enquiry presses behind the details of the "scheme of salvation" and we ask, "But was the Fall itself a part of the scheme of salvation, and is a world with sin and atonement a better world than one without them ?" it seems as if different views may be taken as to what a typical Christianity should answer. For Christianity, no doubt, sin is the greatest of evilsthe evil; and the victory over it the object of the world. But it would seem that for a Christianity which has the courage of its opinions the idea of the victory involves the idea of the Fall, and the answer would be that the scheme of salvation, involving finiteness and sin, was essential to the nature of God and the perfection of the universe. Speaking at the level of reflective orthodoxy, it would appear hardly possible to admit that anything so deeprooted as the connection of the doctrine of the Trinity with the Incarnation and the Atonement should be considered as an excrescence on the plan of the universe or an arrangement contrived in time to remedy an incidental aberration. Thus we are brought in sight of the philosophical conception, which has frequently been applied to the interpretation of Christian dogma, that finiteness is essential to true infinity, and that the two are 
continuous and interwoven, not exclusive and antagonistic alternatives. ${ }^{1}$

It is from this point of view that we have to adjust our conceptions of the defectiveness of the self and of self-consciousness. We are, broadly speaking, to enter into the idea that finite experience, though itself defective, is neither an accidental disturbance of the Quiet, ${ }^{2}$ nor a regrettable deviation from the Perfect. The absolute or infinite should present itself to us as more of the finite, or the finite at its best, and not as its extinction. More, not in time nor in quantity, but in completeness, in progress along the path of continuity which is indicated by the nature of things. It is at bottom a logical blunder to hold as obvious truth that merely to annul the finite is to affirm the infinite, i.e., that merely not to be in the finite world is logically and per se a presumable gain. In logical phrase, the bare negation has no significance. To be nearer perfection than on earth must mean, if it is to mean anything, not merely to be rid of terrestrial life, but to have realised it and more.

The above treatment of the relation of self and

1 The only important difference between my view and Dr. McTaggart's (Studies in Hegelian Cosmology, sect. $243 \mathrm{ff}$.), is on the question of the attitude of Christianity to virtue and to sin (see especially sect. 255). Technically, to Christianity, I should have thought, virtue per se is nothing; and no man can take part in a Christian liturgy except as, officially, a sinner. It is an overstrained feeling, but not wholly false to the Christian attitude, which makes men sing "Doing is a deadly sin ; Doers shall be damned." I was much struck by a passage in some novel, where a child says to a respectable and worthy old gentleman, "Of course I know that you are a bad, bad man." "Why, my dear?" "Because I heard you say so in church on Sunday."

2 Caliban upon Setebos. The Christian idea of a "state of probation" is at least an attempt to furnish a logical nexus between finiteness and perfection, though the need of probation remains unexplained. 
not-self in self-consciousness is in harmony with these ideas. As in the antithesis of morality and religion, so in the antithesis of self-consciousness and what is more than self, it is our conviction that a positive continuity can be exhibited, and that the defects of the given not merely necessitate transcendence but positively indicate its nature. It is after all not the bare negation by a not-self, but reconciliation with it and expansion through its response, on which self-consciousness in its fulness depends. 'Satisfaction and 'sacrifice,' which for us are opposite examples of the same fundamental structure, ${ }^{1}$ must both contribute of their nature to the complete experience. And such an experience would possess and absorb into its being all that finite selfhood exists to achieve, self-maintenance in self-transcendence.

1 Page 242 above. 


\section{LECTURE VII}

OURSELVES AND THE ABSOLUTE

I. IT seems desirable before going further to make "Man an attempt at stating simply and clearly what beyond appears to us to be the fundamental nature of the "man." inference that carries us beyond ourselves to affirm That it is so is the bedrock an absolute being. It is not merely the logical out- fact of life. line of the argument that needs explanation; it is what this, rightly understood, involves-the whole estimate of the relative value and significance of different provinces of experience, and the question where we are to look for that which will most help us to appreciate the whole. It is here that current opinion seems so seriously defective, and that even first-rate metaphysical speculation hardly shows full appreciation of the resources open to it.

The doctrine of a rational reality transcending the given has been subjected to two main forms of criticism, the one aimed at the rationality of the real, the other at its transcendence of the given. The former may be summed up in three words of Bergson, the phrase which he loves to reiterate, "tout est donné"; the latter was first expressed by Aristotle in his criticism of Plato's form of the good, $<$ and continues to be urged by considerable thinkers to-day. The latter is the subject of the present 
chapter; the former will be discussed at a further point in our argument. It will be time enough to show that freedom and initiative are one with the rationality of the real when we have shown that a 'real' transcending the actual is the very substance and spirit of our experience.

The archetype, then, of one-half the later criticism of absolutist theory may be found in the impatient observation that Aristotle has more than once let fall with reference to the Platonic doctrine of Form, "What on earth can they mean by 'the thing itself,' as e.g. ' man himself,' [or more strictly 'itself'], if, as is the case, the definition of man itself is the same with that of man?"1

What, indeed? If things as given to us, or man as we have experience of him, can have their nature defined, so that the definition shall include selfconsistently all that they are, and nothing beyond it, what more can we possibly want? If that is all, frisch $z u$; let us set down our definitions of man and of nature in terms adequate to our experience and to which our experience is adequate, without internal incoherence and external reference, and be done with troublesome speculation. ${ }^{2}$

But, as we all know, here the difficulty begins. If you set down a description of man as he seems to be, you find that his self-what gives character to the appearance, and is needed to understand it-lies outside what you have portrayed. If you now try to define or describe, coherently and intelligently,

1 Ar. Ethics, i. 6.

2 Of course no one would suggest that this was Aristotle's real attitude. I suppose it is one of the perplexities of Aristotelian interpretation that Aristotle appears so naïve when criticising Plato, while so profound in himself. 
the self of man, or indeed of anything, you find that you have got far beyond what we actually possess in our experience. The moment we enter upon the reflective study of man, we learn that his individuality, his self-identity, lie outside him as he presents himself in time. ${ }^{1}$ His nature, according to Green's phrase which goes to the root of the matter, is in process of being communicated to him.

Now if all this is so, there seems to be a sufficient reason why things themselves, or man itself, ${ }^{2}$ should be contrasted with things and man as prima facie given to our experience. The "self of man" or of things will not be a reduplication of their given being, but will be that way of being in which, in Platonic language, they can really be, i.e. can maintain themselves, can experience or be experienced without contradiction. And if this way of being proves to be very different from the ways which were the first to be suggested and accepted in our interpretations of experience, that is only a case of the universal destiny which is manifest in all growth and education; and even if the character which things bore in our immediate world seems to be absorbed and to disappear in their fuller realisation, this is a characteristic for which there is the strongest every-day analogy in the relation of our commonplace perception and sentiment not to the most

1 See e.g. Nettleship's Biography of Green, pp. 27, I I4, I36. It is the same on any view of the nature of the true self. Cf. Bergson, Evolution, p. 218 : "Nous ne nous tenons jamais tout entiers. Notre sentiment de la durée, je veux dire la coïncidence de notre moi avec lui-même, admet des degrés."

2 This is not, or not merely, a question of approaching the special form of consciousness which we call the consciousness or experience of "self." The self of anything as Plato meant it-the form in which it attains stability and consistency-is a standard with reference to which even the awareness of selfhood has to be judged. 
remote abstractions, but to the full concrete apprehension of what life contains. Ultimately, of course, an absolute must be all-inclusive, and even impotence must find a place in it.

But nevertheless, to any mode of reasoning which rests on accepting as final what we imagine to be first given, whether immediate experience or divided personality, it is a fair rejoinder, and one not nearly enough relied upon, to say, "There is nothing in the world worth having, doing, or being which does not involve a self-transcendence, and an enormous self-transcendence, of the type which you deny." Think of the attitude demanded of one by, say, a masterpiece of art. You say you do not want an Absolute in which you would not recognise yourself. But you scarcely recognise yourself when for a moment Shakespeare or Beethoven has laid his spell upon you. It is a difficult matter to deal with truths, which, as it sometimes appears to the present writer, every one accepts, and no one believes. And perhaps the most efficacious shelter of disbelief is the observation that there is nothing new in them. But there would be enough of novelty were we to believe them in bitter earnest.

Thus it is largely in obedience to commonplace prejudices that interpreters of Plato have agreed to find in him a recognition of two worlds. ${ }^{1}$ The really fundamental point for him I take to have been that there was and could be only a single world, and that

1 If we will have it that it is unhistorical to credit Plato with a monism, then we should understand him better by adhering to his own figure of a triplicism or quadruplism as in the divided line, or more, as in the progression from unity to plurality of, say, the Philebus; we should thus see more clearly that none of the lower phases are solid against the whole, so as to form par excellence $\mathrm{a}_{\text {. }}$ dualism. 
what we commonly presume to be a world is not sne at all, not possessing the features which belong to the self of anything, to a stable and coherent complex.

The prejudice which expresses itself in the popular interpretation of Plato and the popular conception of idealism is really the same which levels to-day the reproach of Agnosticism at the critical effort to establish the nature of a world which could be taken as real. We have the given, it seems to say, and why go further? You can get to nothing concrete or actual; you admit that you cannot possess the experience in which you say your Absolute consists ; why dissolve what you have by hostile criticism when it leads to nothing beyond? So with the votaries of Personality. Metaphysical analysis seems to them to go further and fare worse; to abandon or dissolve the solid facts of individual life and will and the self, and to reach no assignable result which can be put in their place. It seems to them a gratuitous abandonment of the substance for the shadow. ${ }^{1}$

All this is supposed to be rooted in common sense, in every-day thought and feeling, and it is not surprising that it should assert itself strongly. It is really rooted, not in common sense, but in the attitude most opposed to common sense, that of common sense theory. There are two points, however, that should be borne in mind with reference to its latest form.

One of these is the substantive unity in the

1 It does almost seem to me, though I feel strongly how likely I am to be wrong, that even so wise and accomplished a philosopher as Professor Pringle Pattison argues with this naïveté in Man's Place in the Cosmos. 
history of philosophy of that point of view which takes us beyond the given, or what the first interpretation assumes to be the given. There is a tendency to be lost in the details, and to forget that when we reject this way of looking at things we have to meet not merely this or that modern writer, with his special form of dialectic, but the whole position of idealistic philosophy from Plato down to living thinkers, which is in the main perfectly simple and direct. And the other is the deficient disposi-

$1 /$ tion to appeal for corroboration and explanation, to the nature of our best experience itself, and to its progressive difference from what is prima facie given. Metaphysic itself to-day appears to be infected with this diffidence, and to be in consequence too deeply imbued with prejudices resting on prima facie appearance. I will deal with the two points just mentioned in the two following sections.

The spirit of Logic must carry us to the whole.

2. The essential argument of metaphysicsmight be described in general as an argument $a$ contingentia mundi. And the failure to recognise the true nature of this argument and its identity in all Idealist philosophies, depends ultimately on an inadequate conception of logical determination. If, one might almost say, if we have settled it as a matter of principle that a conclusion cannot transcend its premisses either in certainty or in content, then we can never admit the central position of metaphysics. All the commonplace analogies, such as that water cannot rise higher than its source, ${ }^{1}$ or that you cannot get more out of a box than you put into it, are wholly hostile to the nature which metaphysical

1 Pringle Pattison, Man's Place in the Cosmos, p. 207. 
analysis finds in rational procedure. Whether or no it is correct to say that Aristotle held some reasoning to be analytic, it is certain that his definition of the syllogism describes in so many words the synthetic character by which thought builds up its world, "Discourse in which certain things being posited, something else than what is posited necessarily follows on their being true." 1 And we may add, what the theory of induction has made clear, that in the conclusion the premisses become not only more significant, but more certain. It will be objected that this is only the case if the conclusion affirms a fact independently verified, for the explanation of which a particular premiss is demanded to the exclusion of any other. And it would commonly be denied that there is any such relation between a conclusion and its premisses when the premisses or inductive hypothesis have not been shown, by the trial and rejection of a number of others, to be the only ones that are compatible with the required conclusion.

I am convinced that such a view underrates the continuity and fails to apprehend the essence of logical process. ${ }^{2}$ What really happens in any inference whatever is that the data and premisses are brought together in a new whole, and by reason of the new combination their respective limitations, as isolated factors, are pro tanto removed, and a new character is made explicit, which belongs to them in their new combination. Now it is impossible that such a new character should not bring with it a

1 Joseph, Logic, p. 225.

2 See author's Logic, 2 nd ed., ii. I 59, I 7 I, and for a statement of the opposite view add to the reference there given Joseph's Introduction to Logic, pp. 485-6. 
step towards non-contradiction, and new contacts with the general whole of experience; it is impossible that a new meaning read into a proposition, a new application of a purpose, a new sensitive fibre developed in an emotional disposition, should not affect the issue of its truth completeness or stability. ${ }^{1}$

This, then, is the nerve of logical determination, viz. the removal of error or contradiction by means of a positive union in which data or premisses destroy each other's defects, and give rise to a new totality which transcends its factors. This is the essential process of experience throughout, and in all its kinds, and when traced and analysed in propositional form it reveals itself as logic-the creative and originative nexus of mind as such. It may be made explicit, as we have argued above in Lecture II., under the principle which, when abstractly stated, is called the principle of non-contradiction; but, as we have seen, this principle is simply a formulation of the life of the whole, and is not subject to the formal limitations which its abstract appearance may suggest. I will restate this point in a few words.

First, ${ }^{2}$ you cannot escape the application of the principle by what might be called a logical quietism. You cannot say, "If I affirm little or nothing, I am safe from being forced forwards into self-transcendence." For all negation, all exclusion, rest, as we know, on affirmation. You can never satisfy the principle which demands consistency, so long as anything remains outside your system. The negation which puts it outside carries an affirmation 
which must bring it inside. A vacuum or nothingness, or an "I" or an "is" reduced to the merest point, are not self-consistent by force of emptiness, but are nests of contradictions. Each is entangled in a congeries of relations, and yet, claiming no explicit content, it has no power to unify or organise them. ${ }^{1}$ It is an old argument, but it needs to be insisted on in view of the notion that the principle of non-contradiction can be satisfied by mere emptiness, and has no driving-power towards the concrete.

Secondly and more particularly, therefore, as we mentioned in Lecture $\mathrm{I}_{.}{ }^{2}$ the operation of the principle cannot be restricted to the maintenance of the propositions whose denial involves their assertion, as when we say, "There is no truth." That is to say, it cannot be so restricted unless we have learned to discern this characteristic, in its real meaning, in all the great provinces of experience, and more distinctly as they are greater.

We are apt to think that within these provinces - the spheres of our ordinary informal experience and interest-we can deny this and that, without in any way shaking the general framework of our world; and therefore we are apt again to be misled into supposing that here we have to do with a lower order of certainty than that attaching to formal principles with little apparent content. But as I attempted to show above, ${ }^{3}$ this apparent freedom to deny is only possible because in every such negation so very much more is asserted than is touched by the negation's immediate content, so that the negation asserts affirmative truth without itself
1 Bradley's Appearance, p. 364.
2 Page $48 \mathrm{ff}$.
3 L.c. 
being false. For when we make negative observations in the world of historical fact, or of beauty, or of morality, our negation is in every case founded upon the affirmation, as a whole, of the world within which we are making a denial. In every negation, then, and not solely in that of certain formal propositions, an affirmative content is asserted. The difference is, that a negation which can be true asserts immensely more than it denies, while a negation which must be false-the negation of an a priori proposition-affirms only what it denies, and nothing more. In the former case we are pointing out a contrast or distinction within the content of some enormous general affirmation; in the latter we are addressing our negation to the whole affirmation of our world as such. But if in the former case we were to attempt a parallel procedure to that which we appeal to in the latter, we should obtain the same result with substantially better justification. If we were to say, not "that is not well done," but "there is no morality"; or instead of "that is not good art," "there is no aesthetic perception," we should be convicted of self-contradiction in the same manner and degree as if we had said, "There is no truth." 1 As we realised the meaning of our negation, the world of morality and of beauty would spring up and reaffirm themselves as at once the condition and contradiction of our denials. The fuller experience, in spite of the room it leaves for negation in defining the system

1 It might be rejoined that "there is no truth" claims to be truth, while "there is no goodness" only implies or involves the being of goodness. But I think the difference is only one of degree ; the fundamental point is the impossibility of denying what makes the fact of your denial possible. 
of its members, is more truly supported by the principle of non-contradiction than the simple and abstract proposition. It is really because we cannot conceive ourselves denying the complete world of our experiences that we are obliged to hold the simplest a priori truths to be affirmed in their negation. They have to be affirmed because they are the world at its minimum, with only "a single neck." But non-contradiction has really a stronger purchase, the more there is to lose by contradiction. ${ }^{1}$

This, then, the positive and constructive principle of non-contradiction-in other words, the spirit of the whole-is the operative principle of life as of metaphysical thought. We might call it, as I said, in general the argument a contingentia mundi, or inference from the imperfection of data and premisses And it is this, essentially, and overlooking differences of degree, in virtue of which alone we can at all have progressive and continuous experience, whether as inference, or as significant feeling, or as expansion through action. It is this through which my perception of the earth's surface makes one system with my conception of the Antipodes, or the emotion attending the parental instinct passes into the wise tenderness of the civilised parent, and the instinct itself, as we are told, develops into the whole structure of social beneficence. ${ }^{2}$ And it is this, only further pursued, that forces us to the conception of the Absolute. I am aware of no

1 Compare the author's discussion of the relation between " positive" and "negative" freedom. Philosophical Theory of State, pp. 143-6. It is the full and positive conception that is the basis of the empty and formal, not vice versa.

2 M'Dougal, Social Psychology, p. 79. 
point at which an arrest in the process can be justified.

This, then, is the fundamental nature of the inference to the absolute; the passage from the contradictory and unstable in all experience alike to the

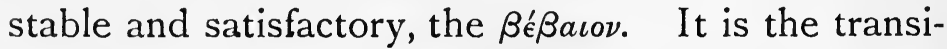
tion which is carefully worked out for every side of life in Plato, and which has formed the framework of serious philosophy ever since. It is misapprehended if we call upon it to put us in (possession)of an ultimate experience which is ex hypothesi incompatible with our limited being. What it will do for us is much more relevant to the transformation of our lives. It exhibits to us in their relative stability and reciprocal suggestions of completeness the provinces of experience which comprise the various values of life; it interprets the correlation of their worth with their reality, and of both with their satisfactoriness to the soul. We put the whole enquiry in a wrong perspective, and lose its truth and its significance, if we make some special form of human destiny the unspoken interest of our arguments; if, one might say, when we refer to the Absolute we are really thinking of Heaven. We should not expect metaphysic to predict terrestrial history; and still less, therefore, that which lies beyond the grave. What it may do, and in the hand of the masters has always done, is, starting from any datum, no matter what, to point out what sort of thing is in actual life-which is in the Absolute now as ever-the higher and more stable; and what is the more defective and the more selfcontradictory; and to indicate the general law or tendency by which the latter is absorbed in the 
former. In this way, it seems true that it "gives us hope," but it does not seem true that it does not give us knowledge and guidance. "Higher, truer, more beautiful, better, and more real, these, on the whole, count in the Universe as they count for us. And existence, on the whole, must correspond with our ideas. For, on the whole, higher means for us a greater amount of that Reality, outside of which all appearance is absolutely nothing." ${ }^{1}$

3. We have seen that, from a logical point of The higher view, the criterion of self-maintenance, degrees of experiences being, or non-contradiction applies not merely to to true infundamental abstract principles but, as Plato applied and to the it, to the several worlds and levels of concrete indedusion experience. It holds good, we have seen, of signi ${ }^{-}{ }^{\text {of ther. }}$ ficant sensation as in beauty, and of feeling in the sense of emotion, or of pleasure and pain, no less than of strictly logical structures, such as science and philosophy, or of the ideas which operate in morality, in social behaviour, or in religion.

Now all these types of experience are phases of individual living, stages in which the "individual" maintains himself in different modes and degrees, and with different achievements in the way of completeness and consistency. And therefore it seems all-important when discussing the nature of the individual to draw into evidence their main characteristics, and to avoid acquiescing in conceptions of ourselves adopted from our first reflections on the apparently separate human being wie er geht und steht. It is obvious that if we take our idea of the individual from what he is at the minimum of his

1 Bradley's Appearance, p. 550 ; cf. p. 560, and above, p. 19. 
conscious being, say in the state of fear or ineffective desire, we shall get a wholly different reading of his nature from that which will suggest itself if we take into account the social aesthetic or religious consciousness and their characteristic or their highest development. And further, identifying degrees of reality with degrees of being or self-maintenance, it seems fair to take, as under one pretext or another is usually assumed in ethical theory, the fuller self for the truer self. And from this simple consideration, which many will call an elementary platitude, very serious results appear to me to follow, which are habitually neglected. The individual, then, does not attain the maximum of individuality in his exclusive self when he feels himself repellent against others. And if personality is taken in the strict sense of the character of being a subject of rights and duties among other similar subjects, then personality itself is only possible in virtue of an individuality which already transcends it. For there can be no system of rights and duties except in virtue of an identity of wills in which rights and duties become a mere machinery of daily life. You cannot coerce the individual and organise his life within a system of "persons" except on the ground of a consciousness on his part which at bottom desires to be coerced and to be organised. So individuality, the principle of reality and the consistent whole, takes us on beyond personality in the strict sense, beyond the consciousness of self which is mediated by an opposing not-self, into the region where we go out of the self and into it by the same movement, in the quasi-religion of social unity, in knowledge, art, and in religion proper. And in all 
these experiences, as the repellent self-consciousness diminishes, and the sense of unity with the world and with man becomes pre-eminent-in all these individuality is strengthened, and the self, though less in opposition to a not-self, is more itself, and is more at home. And when freedom and spontaneity reach their climax in religion the self no longer insists on its exclusive claim, and the whole being goes out together into the service which is perfect freedom. In all this there is nothing that is not familiar, but the result of it for the theory of personality or individuality does not seem to be readily apprehended. It is plain that the height of individuality is to be looked for in experiences which raise to the acutest pitch the sense and fact of identity with man, nature and God. And if we ask for a definition or identification which will give us the individual finite being, per se, so that we can say, this much and no more is he, and at this level we have him and can estimate his separate value, ${ }^{1}$ there is nothing of the kind to be found. If we take him at his best he exhibits quite other features than those which his normal being tempts us most to emphasise, and if we could take him as he really is, it may be again that the best we know of him would be wholly left behind.

At any rate, to repeat the point precisely, two things seem made out. First, the minimum of individuality has not, any more than the minimum meaning of a word, ${ }^{2}$ any claim to be accepted as the normal and determining standard. In such ques-

1 Contrast McTaggart on "Individualism of Value," International Journal of Ethics, July 1908.

2 I refer again to the discussion of freedom, Philosophical Theory of State, l.c. 
tions as that of the communicability and objectivity of feeling, or of the identity between human souls or of the continuity of the maximum experience of the self, there is no justification whatever for making our commonplace sense of impotence, isolation, or self-will the basis of our theories. The formal separateness of "individual" centres of experience is progressively outweighed by their material identity of content and emotions, and if we were to base our theories on what human beings are as they sing together, or fight on the same side, or sacrifice themselves for those dear to them or for a cause, or think with the full power of their intelligence, the difference in our attitude would not be one of idle sentiment alone, but would be a logical and metaphysical difference of immense significance. It would consist in the emphasis laid on identity of content and system in which different selves are one, and in which the usually unrealised continuity of the single self with itself also ultimately lies, as against the differences of organic sensations and limits of immediate experience determined by impotence, which appear to be the grounds of distinction that keep "a mind" apart from others, and, for the same reason, from itself. And, as is suggested by a modern view on which I have commented before, the self, as that which is our unity, the good of life, and that for which we care, would turn out to lie not in a consciousness of the not-self but in a content or quality of being, which, as the view referred to admits, is most completely realised when the antagonistic consciousness of the not-self is at its minimum. This set of notions would give a wholly different lead on the problem of conscious- 
ness of self in the Absolute from that,which is the outcome of taking self-consciousness as a reflective awareness of self, dependent ${ }^{1}$ on an adverse not-self.

And, secondly, this comparison of the higher regions of experience with each other and with those that are less complete enables us in principle to understand the relation of the less to the more inclusive and perfect conditions of mind as a world, and thus to meet one of the fundamental difficulties in the conception of an absolute experience. Such an experience, we say, includes and absorbs the experiences which we possess severally-includes them positively and in a fuller form of each, yet without reproducing them in their separate distinctness. I am inclined to think that the difficulty of in any way conceiving this relation as between any given conditions of mind and any others is the main hindrance to grasping the notion of a continuity between our defective self and a perfection transcending it. No one, it seems, is unreasonable enough to make it a fatal difficulty that we do not profess by metaphysical argument to attain and come into possession of the perfect experience. But there is a natural scepticism as to the conceivability of our alternating and seemingly heterogeneous moods and phases of mind being fused, absorbed, and transcended in any single mode of experience that could really be continuous with all. How can they be contained in it? How and under what conditions can the partial moods, which are

1 Taylor's Elements of Metaphysic, pp. 340, 343, 350. It is loteworthy how the positive view tends in these passages to supplant he negative. 
really in it, subsist apart from it under the conditions of finite being ? ${ }^{1}$

This difficulty can, I believe, in principle be removed from the point of view on which we are now insisting.

We are saying, then, that the clue to the nature of individuality lies in the contrast between the forms of mental life in which self-transcendence is at its minimum with those in which it approaches its maximum. There is a prima facie difficulty due to the difference between true self-transcendence and the alienation from self which lies in the unconsciousness of limitation or impotence. Obviously the latter is almost perfect where the limitation and impotence-the de facto alienation from self-are extreme, ${ }^{2}$ while a great measure of true self-transcendence, as in some types of religious emotion, may be accompanied by an acute and despairing sense of impotence and bondage. But the standard should be the amount of genuine self-identification with the content of reality; the accompanying consciousness of bondage or of freedom is so wholly relative to the range of the self's outlook that it might in some cases be taken as an indication that varies inverselly as the fact.

Passing over this difficulty, then, as only apparent, we can see that in the normal case our less complete attitudes are absorbed and united in those which are more complete, and tend to reappear in their fragmentary character as our impotence is revealed by relative or absolute diminution of mental or bodily

1 An instance in which the fact and interpretation of this absorption is all-important is the advance in Hegel's Logic, from Cognition to the Absolute Idea. See McTaggart, Commentary, sect. 288, and my notice, "Mind," January I 9 I I. $\quad 2$ Bradley's Appearance, 1.c. 
force. As life becomes more finite, in short, our attitudes tend to become alternative and successive rather than fused and solid. It is a simple and necessary consequence of the grades of our impotence, in a world which, though one in principle, is full of diverse aspects, solicitations, and opportunities. The only real difficulty is to see how in principle the aspects and attitudes can be fused or absorbed into one, and not merely blended or conjoined.

In the first place, we must remember that our phases and attitudes never are wholly severed; that man is never in any phase purely feeling, purely practical, purely moral, aesthetic, intellectual, or feligious. There is one kind of unity - it is a familiar topic-before the evolution of differences; there is another, we hope and contend, as they are absorbed and unified in perfection. But also in the intermediate region in which we live, where the differences are very marked and insistent, there is always the unity of feeling in which the self has a certain solidarity with itself, with athers, and with nature. So that there is always a basis of repose, a faith and purpose and appreciation uniting the man with somewhat beyond him; and you do not and cannot get, for example, morality apart from religion-the reliance, that is, on the particular will, judgment, and sense of duty, apart from the social and the cosmic basis of life, which imply man's reliance on a strength and wisdom beyond his own.

Bearing this preliminary point in mind, let us consider the relation of morality, theoretical cognition, the aesthetic attitude, and what we commonly 
call religion, to the more intense and inclusive forms of the religious consciousness.

Religion, like other forms of experience, has many modes and levels, and because of this, a single answer to the question how it is related to science and philosophy can hardly be given. In its primitive form it seems to show but little analogy to the scientific or speculative consciousness $;^{1}$ in its developed and intermediate forms, in the civilisations known to history, it seems, if anything, hostile. So, too, in its relation to art and to morality, there is plenty of ground in many of its stages for pronouncing it hostile, or at best indifferent, both to one and to the other. Still, as we have just seen, actual life can never allow its activities to become whally detached from one another, and the logical connection between them which the nature of consciousness implies never wholly ceases to exhibit itself in the manner of their interdependence. Even the myths of the savage, as we are told to-day, are a first effort at interpretation of the appearance of things, ultimately of the same nature with the hypotheses of science.

Thus it is a question of convenience and degree how we estimate the relation, say, of philosophy and religion par excellence. But undoubtedly we can find experiences in which the two have come together, or rather have not been separated, and are, or have come, together, with very much more besides. If we choose to adopt the name of religion-understanding that it is capable also of many inferior applications-for that frame of thought and

1 According to a certain view of Magic and to the theory of Animism some kinship is traceable. 
levotion which Dante, for example, expresses as his ideal, then we shall be able to illustrate the unity of a highest experience, and the necessity of its dissociation according to the degrees of finiteness and impotence.

In Dante's religion, for example, we have the suggestion of an experience in which $(a)$ as it is religious par excellence the individual finite being feels his will and emotions absorbed and transformed in the perfect will, which is also his will. Yet $(b)$ inseparable from this unity, but distinct within it, there is a side of morality. The supreme will is realised through conflict; and pain and evil, and with them effort and aspiration, are present potentially in the finiteness by which the individual contributes to the divine perfection. And when I say "potentially" I do not mean that they "might be present" but are not. I mean that they $\rightarrow$ are present as a characteristic of the religious experience in question, a depth or tension or seriousness which depends on the holding together of its constituents in a way analogous to the survival of desire in satisfaction. ${ }^{1}$ And this characteristic, if experienced in relative isolation, owing to the obscuring of other aspects of the whole, could reveal itself as the effort, or in extreme cases the despair, which belongs to the moral attitude taken by itself and unqualified.

And further $(c)$ it is an integral part of this religion that the sensible universe is apprehended as a revelation of the Divine order, an apprehension which includes the completest realisation of all that the aesthetic attitude can mean; and $(d)$ what,

1 Cf. the argument of Lecture VI. sect. 3 . 
taken apart, would be the theoretical or speculative intelligence, as all things are seen in God, has also the completest satisfaction, and its need for noncontradiction throughout experience is thoroughly fulfilled.

Now, of course it may be urged that even this highest religious experience is not one which most of us at any rate can actually possess; that merely to describe, as we have done, its constituent factors, in the language of our separate ways of behaviour, is to abandon the conception of its unity; that if its unity were complete, the separation of the experiences would have disappeared; and that if they are traceable as separate, the characteristic imperfection and self-contradiction of each are not done away.

I do not believe that this is a relevant criticism. It belongs to the general type of thought which may be described as logical pessimism, a method fundamentally eristic, which proceeds by the juxtaposition of extreme cases in the absence of the analysis which would exhibit their continuity. It is thus that pain, pleasure, evil, personality are exhibited as hard units, repellent and unyielding against the claims of perfection and totality. But what is here relied on is analysis, sustained by the truth of living experiences. No man is confined even at a single moment within the limits of a single mood or type of behaviour; every man has experience of being aided by greater characters and intelligences or by great emergencies to surpass his habitual self, and to apprehend the effect of an exaltation of his whole being upon the currently distinguished elements of his finite consciousness. In these experiences we only apprehend through life and feeling the truth 
on which the philosopher's analysis insists when, for example, he points out that abstract morality cannot and does not exist per se, but that in logic as in experience its sharp antagonism between ought and "is" implies and possesses a deeper basis, in which what ought to be is one with what is.

And now our point does not seem hard to understand. We assume a finiteness, consisting in various kinds and degrees of impotence, to be the condition of existence for a being capable in principle, say, of the religious experience we have described. It is not hard to see how the logical elements of such a beatific vision should persist or stand out in relative isolation, according to the nature of the impotence, and the type of emergency with which it is confronted. We can see, surely, every day, that the finite mind, whose life is in succession and in choice, will not be able to hold on all at once even to the highest mode of consciousness of which in principle and on occasions it is capable. But this is no hindrance to the fundamental truth that what it does hold on to, what shows, as it were, through the mist, is both of one logical texture and of one emotional tissue with that which relative emphasis and distinction has for the moment, or for part or for the whole of an age or a lifetime, withdrawn from its distinct apprehension. The facts are obvious and familiar, though their importance is apt to be unrecognised. It is plain that when engaged in one thing we cannot be engaged in another, and that what we are doing or suffering at the moment commands our mood and our mental attitude. In moments of moral difficulty we are full of effort, preoccupied with the sense of wrong in the world, 
the sense that the next move is with us, and that good and evil rest upon our shoulders. In moments of detached analytic labour-say, when occupied in experimental research-we necessarily set aside the "relativity" of the "external" world to some kind of knowledge or apprehension, and treat it ad hoc as a self-existent reality which we have to take as given. In moments of religious exaltation of the commoner and narrower type, our minds are withdrawn into a mood of repose and absorption, involving a faith which excludes the temper of research, and the attribution of independence and full reality to the world apprehended through senseperception ; and into an attitude of trust and resignation which, it may be, does less than justice to moral endeavour and responsibility, and yet represents a logical implication apart from which such endeavour and responsibility would be torn up by the roots. All these limitations are defects in the several moods and attitudes themselves, but defects in some degree inevitable to their existence in finite subjects, whose life is carried on by succession and alternation.

The matter is made much easier to grasp when we remember what we insisted on as a preliminary; that we never do realise in actual living the dissociation which we postulate alike for purposes of theoretical analysis and in the rough nomenclature of every-day life. We never are purely intellectual without volition, nor moral apart from being religious, nor aesthetic without practical or theoretical interest. Each of these attitudes, indeed, is in and by itself an instance and example of all the others as well as of itself, although their central characteristics 
are not its central characteristics. This familiar fact is highly significant of the inherent unity of all experiences which our impotence merely disguises, and the problem is to give it its value without making it into a ground of failure to recognise plain distinctions.

Thus the connection of things is obscured and loosened by our finiteness, but it is not done away; and we are able, if we attend, to see how our moods, alternating apparently at random, are in truth the limbs and features of fuller forms of mind, left outstanding in seeming separation through the mist that limits our particular world.

"Well then," the reader may say, "will you plainly tell us what you take the individual finite being to be? We have hitherto supposed him to be a single and permanent spiritual unit, having as his minister a physical body, but with a nature or essence of his own apart from this, perhaps inherited from other souls, perhaps unique and eternal; with a power of initiative which we are in the habit of calling will, activity, spontaneity, a power depending on this essence and not on the suggestions of experience, and possessing to an indefinite extent ability to arrest, modify, and initiate bodily processes. In fact, we have conceived the soul to be like a whole living man, and the body to be like a machine which he directs 'like a boatman in his boat.' Probably, we have thought, he outlives his body. At any rate, the being and destiny of his soul, those of a thing which is itself and nothing else, are distinct and exclusive against those of other souls as much as the bodily life-history of a man on earth is distinct from and exclusive of the 
bodily life-histories of other men. This is at least clear and decisive. If it is not right, what do you put in its place? You seem to volatilise the individual into a sort of logical progression of ideas and emotions, always passing out of itself into, as it were, another theory, as a thought can blend with and be absorbed in another thought within the limits of a single mind. Is this what you mean? Is it not then a man's principal interest and value that he is permanently he and no one else, a selfcomplete being, not composed out of the outward world, but over against it, a rival or superior power, liable to sin and failure, but not essentially incapable of perfection while remaining what he is ; and, as one of the constituent members of the universe, having a weal and woe of his own, which and the like of which, in him and in others distinct from him, determine the perfection and imperfection of the world."

And the answer is, first, negatively, that there are three analogies in the challenge just stated, all of which should be avoided, or at all events transcended, in our conception of the individual.

And in the second place, affirmatively that we want to think of the individual primarily as mind. And we must learn to interpret "mind" positively, in its own right, by what it is and does. The temptation is overwhelming to suggest comparisons and analogies either from external objects or from isolated phenomena within the sphere of mind itself. But though we may help ourselves by these, partly as suggestions, mainly as contrasts, what we really need is to accept the significance of mind on its own mexits and as sui generis, not as a "thing," 
nor yet as a mere power or attribute of a thing (say, of body or of brain), nor again even as a "life," however attractive the analogy may be-but as a "whole" of a special kind, with a structure and concreteness of its own, only to be appreciated by experiencing it where there is a "more" of it, and entering into the characteristic differences between the more of it and-the.less.

i. First, then, we do not want to think of the Three individual merely on the pattern, $a$ of a thing, $\beta$ of $\frac{\text { vicious }}{\text { analogies }}$ a legal personality, $\gamma$ of a self for reflective selfconsciousness.

a. We are aware, no doubt, on reflection that a thing in external nature is not self-subsistent and would be nothing by itself. I do not mean merely for Individual: Thing, 1 Legal Person, Self in III reflective self-conapart from the apprehending mind, but apart from the context and reactions of other things. But the implication by which the analogy of a thing affects our idea of the soul (nobilissimae substantiae), ${ }^{1}$ ego, or self, is that of an identity behind and supporting diversity, but not entering into it or constituted by it. The soul as assumed in the conception of metempsychosis is a sufficient instance; it is a transferable thing, compatible with any body and with any set of experiences. In the face of such a notion, based on an extreme assumption of numerical identity, to speak of the identity of the souls or selves inhabiting at the same time different bodies, or of the diversity of souls within one body, seems wholly unmeaning. It is like speaking of the identity of a chair and a table which stand side by side, or of a chair which becomes a table from time to time as the fancy seizes it. This is, I imagine, 
the feeling with which many people first hear of multiple personalities within a single body.

We feel it hard, on the other hand, to assign concrete and individual value to an ideal or an experience. But some effort in this direction was made inevitable once for all by Kant's criticism of rational psychology, and by Hegel's emphasis on the idea of subject as opposed to substance. ${ }^{1}$ The active form of totality within a certain mass of content, a life of self-transformation on the part of such a mass towards the riddance of contradictions, is the sort of conception we require ; and the analogy of a thing suggests to us nothing more than unaccountable persistent identity heightened to exclusiveness, which just leads us astray.

$\beta$. The term person or personality has all sorts of meanings, and has been made the vehicle of what are meant to be the highest claims on behalf of the individual nature. The individual, it is argued, if he is to have value, if indeed he is to be anything at all, in the strict sense of being, must distinguish and be aware of himself, so that he can be an object to himself, and therefore an interest and a source of aspiration after perfection. No doubt the requirement is sound in principle, and for us, for our moral activity and our social obligations, is true in its accepted form, involving personalities which are exclusive and more or less repellent. The person, as a subject of rights and duties, is essentially the individual in society, as defined by law ; and, as we said above, the legal personality already presupposes

1 The idea of Subject, implying the Subject-object relation, is itself not final but it affords at least a clear line as against the idea of substance. 
a stage of individuality which transcends it. Legal personality represents the social machinery, the mechanism of definite co-operation. But the social spirit which sustains it must be beyond the system which it sustains. You could not secure recognition for a system of obligations unless the minds which accept them were united in a purpose of which the obligations were corollaries. And the social spirit itself is not the final form of individuality even in our experience. Thus, no doubt, the individual must at least be a person, as, at his minimum, he must have the self-identity of a thing. But if personality means rigid systematic limitation as against other persons, and a union with the whole which is only partial and indirect, individuality must be capable of taking a form in which the negative may play a more affirmative part.

$\gamma$. We should not interpret individuality as limited to a self-consciousness reflected from the contrast with a not-self. Our main point in conceiving Individuality is to maintain its freedom; its power or essential nature of self-transformation in obedience to the logic of the whole which operates in it. We do not want to be burdened with the negative approach, and to say that when we are most fully entering into the content which best unites us with the whole and with ourselves, we are ceasing to be individual, because we are beyond the reflective consciousness of self against not-self. Individuality is positive and constructive; and if self-consciousness is negative against the idea of self, individuality must not be limited by being construed in analogy with it. Diversity or affirmative negation will play its part in the system of contents into which indi- 
viduality develops; but that is a different thing from a contradictory negative in the form of a notself resisting the expansion and affirmation of the system of the self.

Mind is sui generis best described as " a world."

ii. Secondly, then, we may use all these analogies, but we must not bind ourselves by them. What we can say affirmatively is that the individual, as we know him, is mind, and a mind. The meaning of his individuality centres on the sense in which he is a mind. For he is this really in two disparate senses, by negation and by affirmation, and the two are not in harmony. His mind is one, because it is united in itself, and also because it is exclusive of others. But the principle through which it is united in itself is not in harmony with its exclusiveness of others, at any rate in the sense in which it does actually exclude them. Its exclusiveness, judged by the principle of its self-identity, is a defect. ${ }^{1} \quad$ The individuality or distinctness which depends purely upon this is external and self-contradictory, connected with the positive unity only by the corollary that unity and power go together, and where power ceases, unity must also find its limit. If a man has more power of comprehension and inclusion so that less is outside him, and that what is outside him is less outside him, his own unity and individuality is so far and for that reason not less but greater. A mind then is a mind, not through a principle hostile to the nature which makes it mind, but through a realisation of that nature, to the imperfection of which realisation the imperfec-

1 Contrast Ward, Naturalism, ii. 167: "Individuality consists precisely in this impossibility," viz. the impossibility of the presentations of each of several subjects becoming accessible to the others. (See Varisco, op. cit. p. 37.) 
tion of its unity is correlative. The conditions of psychical oneness, such as qualitative continuity of feeling and logical connection of ideas and purposes merely carry out on a small scale what is necessary to constitute a unity of mind. But there is no reason to limit this unity to any special complex of feeling and experience, and in fact it is not so limited. The best general description of the nature of mind is to call it a world; and the world which constitutes a mind is not limited according to any hard and fast rule. It has been found suggestive and convenient, for example, to speak as if the principle of individual distinctness were "one mind, one social function." But obviously this is a quite unreal simplification of the facts, unless we reduce its meaning to what is true enough; viz. that it is a serviceable ideal to regard the content of a single mind, however complex, as constituting a single conation. ${ }^{1}$ Consciousnesses are of all degrees of comprehensiveness. They are centred par excellence no doubt in a range of externality which a single body focusses for a single mind each to each; but this immediate centredness is no ultimate limit for their comprehension; and there are many conditions under which it might truly be said that a single mind is constituted by and controls more bodies than one. In a word, then, we are to think of the individual as a world of experience, whose centre is given in the body and in the range of externality that comes by means of it, but whose limits depend on his power. $\mathrm{He}$ is a world that realises, in a limited matter, the logic and spirit of the whole;

1 It would be hard, however, to show that the contents of two or more minds could not together constitute a single conation. 
and, in principle, there is no increase of comprehension, and no transformation of the self, that is inconceivable as happening to him. Whether he even continues to be a self in our limited sense of the term is a matter of degree. Why and how there come to be these separate microcosms which we call finite selves, or (improperly) individuals is a question we cannot answer. But we can see that by its being so, a certain completeness through incompleteness is attained. Every degree, and every distinct centre or origin of individuality or comprehension necessarily constitutes a different vision and interpretation of things, and through all these incompletenesses a totality of differences must emerge which, so far as we can grasp, could not be attained in any other way.

It is suggested, as we noted above, that the unity of the individual lies in a purpose or a conation. And for a being which is finite, whose life is therefore in time, and its world more or less self-contradictory, the element of purpose and conation cannot be absent. But this way of speaking seems connected with what we have before designated as the negative approach. For a purpose or a conation, in general, is nothing more than the operation of a dissatisfaction or a contradiction towards its own removal. But this is a very negative and uncharacteristic conception. According to the nature of the contents which set up the dissatisfaction and are reconciled in the satisfaction you may have a conation of any degree of value from negative to positive. A conation may be a mere escape from discomfort, and end in indifference; or it may partake in a greater or less degree of the nature of a positive develop- 
ment evoked by and evoking a response harmonious to the self. If we are to define the individual by his conation, it should be his conation as relative to some special type of fruition; and it should be understood that the content in which the individuality is based, no less than the completion which its nature demands, characterises and determines the individuality.

What we call "the individual" then is not a fixed essence, but a living world of content, representing a certain range of externality, which in it strives after unity and true individuality or completeness because it has in it the active spirit of non-contradiction, the form of the whole. It is not a series of mental occurrences, nor a power or attribute of the brain. It is, on the contrary, a higher concrete than the body, which enters into it and is its instrument of communication with spatial objects, but in being so is itself only a small part of the spatial theatre as we perceive and conceive it. The structure and conditions of unity of a single mind, under normal conditions and par excellence, are plain and definite. They are nothing mysterious, but just what they are ; a continuity of interest and identity of content and quality maintained in ways which are analysed by psychology. There can be no question, normally, of doubt as to where one self ends and another begins, ${ }^{1}$ and no suggestion that selfhood is a trivial or unreal thing. Nevertheless, we breathe a freer

1 The abnormal phenomena are enough to show that the distinctness and identity of selves are matters de facto, a question of actual qualities and contents; and this is what on a sane theory we should expect, and gives a far higher interest and value to selfhood than if it were a mysterious isolation, imposed by destiny inexplicably and without degrees. 
air when we realise it on the analogy of a concrete thought, held together and kept apart by what it is in itself, and by nothing else in the universe; and when we have banished the conception of a thing whose limits are fixed, and which is characterised and limited by another nature behind and apart from the experiences which grow up within it. 


\section{LECTURE VIII}

INDIVIDUALITY AS THE LOGICAL CRITERION OF VALUE

I. IT is a doctrine in favour to-day, with speculative Doctrine thinkers of high rank, that the judgment of value that you thinkers of high rank, that the judgment of value cannot cannot be logically supported; cannot, as I under- argue on stand the contention, be shown by logical process values. to be right or wrong, and therefore, cannot in practice, except through some misconception, be modified by criticism or argument. "Every idealistic theory of the world has for its ultimate premiss a logically unsupported judgment of value-a judgment which affirms an end of intrinsic worth, and accepts thereby a standard of unconditional obligation." 1 "When a judgment of value is asserted to be ultimately true, it is, of course, useless to seek for a proof or to demand one. It must be either accepted or left alone." ${ }^{2}$ We may go back indeed to Mill, "Questions of ultimate ends are not amenable to direct proof. Whatever is proved to be good must be so by being shown to be a means to something admitted to be good without proof." 3

1 Pringle Pattison, Man's Place in Cosmos, p. vii and p. 225.

2 McTaggart, Int. Journal of Ethics, July, I908, p. 434.

3 Utilitarianism, p. 6, and note the well-known passage a few lines farther down, "There is a larger meaning of the word "proof," etc. With this cf. Sidgwick, Methods of Ethics, 6th ed., pp. 420-r, where he suggests a process of argument directed to produce a modification of an ultimate estimate of value. The definition of a 
This doctrine, understood in its natural sense, seems wholly adverse to the principal doctrines of Plato's philosophy, as also to Aristotle's treatment of the question of the end for man. And it is impossible not to feel a certain surprise that, without any kind of notice or any argument advanced, the leading conceptions of such thinkers should be altogether set aside. The contention in question is indeed capable of being understood in more than one subordinate sense, and not as flatly denying the principle which we claim to share with Plato.

Possible subordinate meanings of it.

Judgment infallible pro tempore.

I proceed first to consider how far in such subordinate interpretations the doctrine retains its point, and then to set out the substantive contention opposed to its full and natural meaning.

i. It is true, in a sense, that every one must treat himself, at any given moment, as infallible. To suspend action or to declare himself in doubt cannot help him; for by either course he positively affirms that the occasion is one which demands it. The necessity is not confined to action, nor is its existence an argument for Pragmatism. A judgment, when made, holds the field; it can only be called in question by a grounded review of it, made by means of another and subsequent judgment. ${ }^{1}$ This is so with all judgment, and therefore with the judgment of value. We are powerless, as a recent representative of extreme Libertarianism has pointed out, to modify even our moral valuation otherwise than by

man's Good in terms which demand a critical readjustment of his actual feeling by hypothetical considerations (p. I I I), and the requirement (p. 406) that the common end should "systematise human activities," seem both of them to open the question of the ultimate good to argument in spite of Sidgwick's tendency to make it a matter of Intuition.

1 Bradley, Mind, April, 1908. 
itself ; it represents what we are, as long as we are so. ${ }^{1}$ Our will, he thinks, we can modify, but not our estimate of value. It is in the possibility of contradiction between these that he finds our freedom and our wrong-doing.

And this fact, as we know by experience, we have to recognise. No argument can make sure of altering a man's mind. For purposes for which a particular person's action or judgment are important, we must argue under his principles and address ourselves to his existing attitude, his accepted scale of values, or else let it alone.

But nothing of all this applies solely to the judgment of value. It is a consequence of the nature of judgment as such; of its dependence upon mental structure. It is the same for theory as for practice, for speculation as for desire. And it does not, of course, exclude in principle the openness of all judgment to discussion and revision; it only reiterates that at any moment we think what we think unless and until we see reason to think otherwise. It insists on what we have throughout maintained, that mind operates as a logical whole.

Probably the recognition of this truth plays a part in the opinion we are discussing. "De gustibus non disputandum " ${ }^{2}$ is a half-truth; and is a principle which, so far as it is tenable at all, extends, as we have just seen, to cognition. It is not easy to remodel the framework of a mind. It is wiser for

1 Mack, Freiheitstheorieen, sect. 177. "Wir können nicht nach Belieben werten, sondern nur so wie gemäss unserer Natur geschehen muss."

2 In fact, nothing is more open to controversy than matters of taste ; there is nothing more constantly the object of it, and nothing in which education and argument are more effective. 
many purposes not to attempt it, but to become all things to all men.

Value relative to Feeling ; but criticised Feeling.

ii. Again, emphasis may be laid on the distinction which we have just held irrelevant, the distinction between cognition, and feeling or desire. To value a thing, it may be said, is to desire it or to find it pleasant, or at least to think of it as possessing the properties which would under certain conditions excite desire or produce pleasure. All this, it may be urged, is a question of feeling, not of reasoning. Judgment may state that a thing pleases, but the pleasure is a fact; and reason, as Hume will tell us, cannot make a new fact. To judge a thing valuable is to recognise a fact, but not to create one. The valuation is antecedent to the judgment.

And here, perhaps, appeal would be made to the fact that the discussion is about ultimate ends or values. Admit for argument's sake, it will be said, that we can by critical examination modify our conception of what things or characters are comprehended in or flow from the ultimate end, still the valuation of something as ultimate comes first, and the further discrimination of what its nature comprehends, rests upon and presupposes that valuation. The fundamental fact is that I care for some sort of thing; then you may argue upon the consequences in which that fact involves me. But you cannot by argument undo my first sense of value, nor could you impart it if I did not possess it. If there was no feeling there could be no value.

I do not doubt this last proposition, but it belongs to a very dangerous class of half-truths." "If no knowledge, then no truth." "If no aesthetic sense,

1 Bradley's Appearance, p. 405. 
then no beauty." But so far we have only sine quibus non, and the simple converses of these judgments (though the converse is not commonly held to be implied in the original), may be quite equally true, and in these cases unquestionably are so. For instance, it is plain that if there were no values there could be no feeling. That is to say, unless in certain experiences our being was respectively less or more, had in it a less or greater reality or perfection, there could be no cause or reason for the immediate sense of heightened or lowered vitality. Thus no inference lies from this connection to the impossibility of arguing relevantly upon the conditions of the higher or lower perfection and on their presence in any instance. ${ }^{1}$ We are not bound to show that argument can de facto modify the feeling of value in a concrete case, though to show this supports the view that argument can have relevancy, but only to explain the relativity of feelings of value to a standard beyond them, e.g. to the mind's degrees of self-completeness or individuality.

But as a matter of fact, experience and argument, which is merely a mode of making experience tell, can modify both the feeling and the judgment of value, just as much and in the same way as they can modify any mood or attitude of mind, cognitive or emotional.

The whole question is really that of the connection between mediate and immediate experiences, and the assertion that no argument is possible about judgments of ultimate ends rests on a confusion, and a mistake. The confusion is between the immediate

1 Bradley, Appearance, p. 406. 
and the ultimate ; and the mistake is in holding the immediate to be above or below critical discussion, an idea already false of the immediate, and moreover transferred by confusion to the ultimate, of which it is much more false.

It is true that before arguing upon questions of value, we must have immediate experience of what is meant by caring for something. We must have the judgment that something can be cared for, before we can develop it by considering what must be cared for more or less; just as we must have the judgment that something is true or real, before we can develop a science of logic or metaphysic. But these necessary minima of experience are in none of the cases ultimate or fundamental; they are merely the starting-points from which experience develops, starting-points of which the typical form is Hegel's place of departure in the idea of mere being. If we were to urge that worth or value is the power to satisfy an idea, and that, therefore, the content of the idea is prior to the conception of worth or value, we should properly be answered that our interest in the content of an idea is itself what is meant by value, and that this only shows that a standard of value is prior to the valuation of particular things. But granting the answer to hold, it is surely plain that the power of an idea to interest or satisfy us is not merely a brute fact, but a matter for logical estimation. $^{1} \quad$ The ultimate or fundamental interest is certainly not the prima facie interest; and in general, the immediate fact of interest, which gives us the idea of valuing or caring about anything, is at the opposite pole of experience from the ultimate or

1 Bradley's Aptearance, p. 406. 
fundamental interest in which we find by consideration that all our power of caring would be adequately occupied.

And it is not true that there is any purely immediate experience. Immediacy is merely a form which any content can take, and which is peculiar to none. It is not true that any form of liking, valuing, or caring is unaffected by the shaping of the whole of life, and by the critical reflection which shows us where fulness lies. And if this is so of immediate experience, it is immensely more so of ultimate experience. There may be some justification for supposing that you cannot be argued into or out of a simple experience of pleasure-though most unquestionably in many cases you can ${ }^{1}$-but to suggest that it cannot be argued and explained in what lies the power of objects or of ideas ultimately to satisfy a mind-in which power lies their value for a mind-seems contrary to everyday experience as well as to the whole bearing of aesthetic, ethic, and metaphysic.

In case the above criticism should-be based on some misunderstanding of the opinion criticised, I will repeat in a positive form what it is here intended to maintain, and what I take as the essential meaning of the view I am defending.

2. It is admitted then (i.) that a man's judgment An idenis his judgment, and binds him till he has altered it criterion by a further judgment ; and (ii.) that before you can in all argue on the ultimate end or worth you must have satisfaction.

1 I repeat, there is nothing in which the mind responds more readily to teaching and criticism than in questions of enjoyment. Neglect of this truth is one of the signal causes of bad education. To learn to like and dislike rightly is the essence of education, as the Greeks maintained. 
experience of what it is to seek an end or to care for something as having worth. But (iii.) it is here maintained that these are merely the relevant cases of the general conditions which attend development of all experience whatever, cognitive no less than emotional or practical, and that they do not interfere with the essential nature of the logical process from the minimum to the maximum of experience. Such a process can always be traced within ${ }^{1}$ the meaning or conditions of pleasure or satisfaction, or of the character which constitutes an end; and the degrees of this meaning or character can be exhibited by logical argument, and can to a great extent be brought home and enforced by reflection, even with practical results. Every one must know that it is sometimes possible to tell a man, "Now you are not really enjoying yourself," and for him to admit that it is so, and to change his conduct in consequence, with satisfactory results.

I repeat that before we can dismiss this conception of an identical criterion in truth, reality, and satisfaction we should have to deal with the whole argument by which Plato leads up to the form of Good-or, what is the same thing, to the conception of a perfection of positive pleasure-and with the substantially similar arguments as advanced by Aristotle. The principle of these arguments in a word is this, that positive pleasure and all satisfaction, as distinct from an intensity of feeling which there is reason to suspect of being illusory, depends on the character of logical stability of the whole inherent in the objects of desire, and that what in this sense is more real, that is, more at one with itself and the 
whole (e.g. free from contradiction) is also the experience in which the mind obtains the more durable and coherent satisfaction, and more completely realises itself. This consideration prescribes the nature of the ultimate good or end, which is the supreme standard of value, and cannot itself be measured by anything else. ${ }^{1}$ The standard is positive non-contradiction, developed through comprehensiveness and consistency.] And by this standard any judgment as to ultimate end or value can be criticised or estimated.

3. But, it may be urged, the facts are plainly Explanaagainst you. You say that degrees of logical stability, tion of conof perfection, of reality, are the standard by which de facto of perfection, of reality, are the standard by which valuations. satisfactoriness, worth, and the character of being Impotence, an ultimate end, are to be measured. Now it is pation, notorious that interest is selective, and that great ends. provinces of the highest and most perfect experience, whether cognitive, practical, or aesthetic, may wholly fail to have value for the majority of minds, or so much as to attract their attention. And if everything was for every mind as indifferent as every experience in its turn is for some mind or other, then value would be word without a meaning. And, therefore, value cannot be measured by metaphysical perfection, but is purely relative to the feeling of particular sentient beings.

This is an argument from de facto impotence, on which our particularity, though not our individuality, depends. But we have seen that the nature of mind contradicts the fact of its impotence, and that it always is more than it is aware of being.

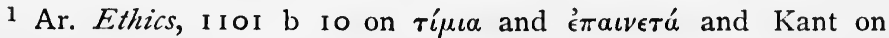
Würde and Preis. 
In the first place, then, as has been pointed out above, the total absence of interest is incompatible with the nature of finite mind. Such mind is involved and entangled in the world of experience, and its degree of being cannot be divorced from its implication in the world of which it is a member. In principle, there must be interest and value where there is a mind a member of a world. The partial and apparent divorce between reality and value cannot be pleaded in support of the conceivability of a complete one.

And in the second place this partial divorce itself means nothing more than that finite minds are what we must call contingent in their degree and direction of development. Their interest, like their knowledge and action, varies and stops short in ways which in detail are unaccountable, but which in general we can see very well to be merely cases of their powerlessness. It is all-important, however, that the positive argument shows no signs of failure, though the negative corroboration can only be exhibited in part. Where we have interest, and so far as we have it, we have implication in reality; where we have more stable and satisfactory interest, we have more implication in reality. It is true that where more implication in reality seems to be offered, we do not always have more interest; it is obvious that our participation in the real must be limited, and the map of its limitations is for us in the main contingently determined.' The general explanation of this is clear; we are preoccupied by certain interests, whose contents are not such as readily to form a logical whole with certain others; just as we may be preoccupied with certain theoretical principles 
which, as we hold them, refuse to coalesce with provinces of knowledge which prima facie lie open to us.

But, it may be rejoined, there is more than this. Not merely different minds pursue different values, but a given mind may apprehend and be familiar with an object or activity of high logical perfection, but yet be relatively or completely indifferent to it, i.e. refuse to assign it value. The answer is practically the same; the object in question is excluded by its nature from forming a whole in its own right with the contents which have preoccupied the mind; but it is pursued and receives attention in virtue of some interest extraneous to it, which is a part of that whole of contents, as a man learns up a repulsive subject for examination, or makes a living by work that he detests.

It has been said ${ }^{1}$ that in principle every man loves every woman; but individuals may plead in excuse non-acquaintance, or special cause of dislike, or a limited capacity of affection which is already preoccupied. There is a truth in the joke; and it applies more seriously to the individual's love of perfection.

It is hard to know how far this discussion needs to be pursued. If we abandon the doctrine "De gustibus non disputandum "-as surely every serious student or critic does abandon it, except in the sense that it is difficult to modify habitual likingsthe view we are disputing seems abandoned along with it.

No one would advance the de facto indifference of my mind or of his own as an argument against

I Oliver Wendell Holmes. 
the value of a scientific discovery or an artistic achievement; and every objective standard of worth which can be suggested must ultimately be reducible to degrees of perfection.

"All

values

relative to

Persons"

compared

with

" nothing

has value

but con-

scious

states of

conscious

beings."

The two propositions may be sharply opposed.

4. It would throw light on the nature of value if we consider in what sense the proposition is to be understood that "all other values are relative to values for, of, or in a person." 1 Translated into the statement that "Nothing has value except the conscious states of conscious beings" it has often revealed a tendency to generate corollaries hostile to the meaning with which Green or Kant affirmed it. $^{2}$ This has certainly happened in so far as it has been pleaded in aid of Hedonism. ${ }^{3}$ And another interesting application of it has been made, from the literal statement of which I have no right to say that thinkers of Green's type are bound to dissent, but which appears to me to point in a very different direction from what is most characteristic in their views.

The doctrine is this : ${ }^{4}$ Nothing has value but the conscious states of conscious beings; and the value of the universe has no unity but that of a sum of these values; more obviously so if the universe as a whole is not a conscious being, but also in a great measure, even if it is. For still, even in that case, the values of the conscious states of finite beings are addible amounts, to be counted in addition to that of the universe as a single conscious being.

1 Green, Prolegomena, sect. 184 .

2 See Kant on Kingdom of Ends, and cf. his distinction between Dignity and Value, with Aristotle's (l.c. supra) between rí $\mu \iota \alpha$ and

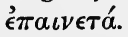

3 Sidgwick, Methods, 6th ed., bk. iii. chap. xiv.

4 McTaggart, International Journal of Ethics, July, I908. 
For those who maintain that the universe as a whole is a single experience, including the finite beings which are finite centres of experience, the discussion is of subordinate importance so far as regards the unity of value. But even for them it is still worth entering upon, both for the subordinate issue as to value, which on that hypothesis it still raises, and because the principle underlying it has an important bearing on the cognate question whether in truth the universe is conscious or not.

To begin with, if we are speaking of all conscious states of all conscious beings, including all that is demanded for their completion, and all possible ways of their being or coming together, it would be true that within this totality we must find all that is of value. And this will, I think, be agreed to by all who accept the doctrine above referred to in Green and Kant. They might say on second thoughts that the word "person," if strictly taken, narrows the proposition unduly. But all would admit it, I believe, if for persons we read conscious beings.

Does this take us at once to the doctrine that the universe has no value but the sum of the values of the conscious states of all conscious beings? Not, I think, in the natural sense of the latter, and in the sense in which I gather it to have been propounded. I take its point to be that the part-values are primary, prior to their sum, which is their sum and nothing more-is determined by them, and is in no sense a whole or standard by which they are determined. The idea that the whole is single and primary, the source and standard of value, and that part-values are to be reckoned as determined by the character of contributoriness to it, is, I gather, 
intended to be rejected. The two statements might be read as having much in common; for, it might be urged, according to both views the parts make up the whole, and the whole is made up of the parts; so what can be the ultimate difference between them? Yet those who think with Green or (I should suppose) with Mr. Bradley would probably accept the first doctrine (see p. 302), but not the second. The second assumes that the states could have value if they existed alone, and if they were in all respects, and were rightly considered as, states external to one another and without implication beyond themselves. The first assigns them value in respect of what they imply, and of their not being, and not being rightly regarded as, states external to one another or to what they imply. The point is a little difficult, though of fundamental importance. If we assign value to any whole as a unit, it may be urged that values relative to this, though derivative from it, must in some sense be assignable to all factors which are in any way involved in the whole; but then any such assignment does not imply any value in the factors taken by themselves. ${ }^{1}$ It is a conception fundamentally distinct from that of factors which have a value as such and per se, so that the value of the whole can be conceived as a sum of values which bona fide and primarily belong to the factors as such. ${ }^{2}$ And this I understand, in its fullest disintegrating implication, to be the meaning in which the statement has been advanced.

The difficulty which this doctrine presents may

1 I am glad here to be supported by Mr. Moore's principle of organic wholes, Principia Ethica, p. $27 \mathrm{ff}$.

$2 \mathrm{Mr}$. Moore, loc. cit., denies this assumption totidem verbis so far as applied to "organic wholes." 
be stated by means of a paradox. "If you treat a state of consciousness of an intelligent finite being as simply a state of consciousness, you treat it as something which it is not. Its essence, as we have so constantly reiterated, lies outside it. Its nature is to be a perfect world; but in any given state this world is incomplete though implied. And the state of consciousness takes its value from the object and the individuality, which must be read into it in order to appreciate it, and which in actual experience are never wholly disjoined from it."

We will pursue this line of thought, and finally note its bearing on the question whether the universe is a conscious being.

i. ${ }^{1}$ There is a familiar argument by which con- States of sciousness is distinguished from the objective relaconscioustions of the conscious being, such as those implied in Truth, Beauty, Virtue, Freedom. You cannot, this argument maintains, really and in the last resort -i.e. if you precisely discriminate what you are lessand doing-justify a preference for a state of consciousness which is true, or virtuous, or has beauty present to it, in so far as your preference is influenced by a care for these characteristics-objective relationswhich you judge to attach to the state of consciousness. Your judgment of such relations, it is urged, is liable to error. Therefore, in formulating a preference for one state of consciousness over another you cannot, or at least you ought not to, take account of anything but the state of consciousness-the condition of the mind at the momentin and by itself; and in thus taking account of it you must exclude all reference to the fact that you

1 Cf. Sidgwick, Methods, III. xiv. 4. 
hold applicable to it certain predicates, such as true, good, free, aesthetically right. These predicates are separable; they depend on objects outside the mental state; they do not lie within the four corners of the mental condition itself.

If I understand rightly, what we have in the view I am discussing is this familiar argument, modified in a single point. The character of the universe, by which in objective relation to the mental state in question it is a ground of the truth or freedom or other characteristic ascribed to that state, is not here ruled out of consideration, but is admitted as a means to the character of the state of consciousness itself, which alone has value.

But this will not suffice. The error of taking a state of consciousness in an intelligent being as in its nature confined to itself seems to be fundamental. You cannot dispose of its object as a mere means to its character. [Its object is a partial apprehension by consciousness of its own nature; it is a world continuous with but extending beyond it; and you cannot value the fragment without an appreciation of the whole. T Truth of a thought does not mean that a mental state is so, and that an object separate from it is also so. This may be the case, and yet the thought may be perfectly false. ${ }^{1}$ Truth of a thought means, surely, that the thought is of a content and context to occupy a harmonious place in the whole spiritual structure of experience. But this character does not lie within the mental state,

1 This is so in the case of a "true" conclusion from "false" premisses. Cf. also The Cloister and the Hearth, chap. xxvi. : "His sincere desire and honest endeavour to perjure himself were baffled by a circumstance he had never foreseen nor indeed thought possible. He had spoken the truth." See author's Logic, 2nd ed., ii. 282. 
though it makes a great difference in the mental state. It belongs to it only as organised within the whole, according to the contrast which was drawn above. $^{1}$

In a word, in valuing truth, beauty, virtue, and the like, we are valuing spiritual worlds, at once objective and subjective, and essentially continuous with greater worlds. Though given to and even in conscious minds, they are not states of conscious minds, nor is it clear, without special examination and proof, that the apparently particular consciousnesses to which they are given are separable existences either as against their own continuance or against other so-called particular beings. We may refuse to call such particulars individuals, and we may refuse to treat the true whole or individual as a sum of individuals.

So much with regard to states of consciousness taken as exclusive of the objective world.

ii. We may carry the argument further by com- you cannot paring the statement which places value in states of value states consciousness as such with that which at first we set beside it, which places value solely in "persons," or, as I should prefer to say, in individuality.

sciousness apart from individuals or the Individual.

When it was maintained that all value was value in or for persons, this was because persons meant a capacity for being ends or worlds. Nothing else, it was thought, existed in its own right, or could be a focus or centre in which a complex of being could come together as fulfilling a plan. But, as has been

1 It appears to me an important concession when the writer says that the self in a conscious state need not know the value of its state. It removes the valuation of the state from immediate feeling or judgment, and leaves it for some further standard-what, if not perfection? 
pointed out with reference to Bentham's valuation of pleasurable states, ${ }^{1}$ and also ${ }^{2}$ very ably, with reference to the analogy between the egoist's self, which he respects, and the moral cosmos, which he rejects, it is quite conceivable that in attaching value to the state of consciousness you may wholly lose the reference to the person, the unity, the idea of end or purpose (i.e. so far as concerns the egoist, he might as well deny his own totality as that of the cosmos). And this is prima facie the essence of any, view which attaches value, not to persons or to individuality, but to states of mind. It is as drawn out above. You may value the states either as entities per se, or as implying a personality which is their whole, or world, or end. But in the latter case you are not valuing them per se; and you could not value them as you do without comprehending the personality to which they belong, or the world of which they are dependent fragments. The argument is the same, or stronger, if we substitute individuality for personality, to avoid the narrower implications which attach to the term person. If all value is in individuality, then we must start from the fullest experience of it we can construct, and the valuation of particular states of consciousness will be secondary to that and derivative from it.

1 Green, Prolegomena, sect. 2 I 4(:) "It is not every person, according to (the Benthamite view), but every pleasure, that is of value in itself.".

2 Sidgwick, Method's, IV. ii. 6th ed., cf. pp. 124 and 381 . It is worth noting that in Studies in Hegelian Dialectic, sect. I 56, Mr. McTaggart sustains the ultimate reality of separate persons against that of particular moments of time. But if these latter are unreal, the states of consciousness which fill them must be also in the same degree unreal. 
The argument is strengthened for those who hold that succession in time is only an appearance. For in this case the particular state of consciousness has ultimately no separate being, ${ }^{1}$ but all the states, as Kant said of the infinite moral progression qua viewed by God, are ultimately comprehended in a similar reality. But that which has ultimately no distinguishable being, cannot ultimately have a distinct valuation.

iii. And the reversal of an argument $^{2}$ above you cannot referred to carries us further still. If a man denies value finite his unity with others, it was asked, why should he apart from

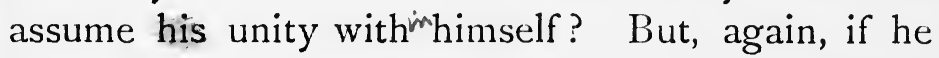
postulates his unity with himself, how can he deny his unity with the further stages of individuality? There seems no reason for drawing a line at which the continuity is to break off, and prima facie the inference is to a unitary perfection lying in the complete individuality of the universe as a conscious being, which is the ultimate value and standard of value. To call it an end seems as dangerous as to call it a person; but to regard it as an individual whole seems no more than is inevitable. This consideration travels outside the subject of unity of value, and refers to unity of experience. But it is impossible to exclude it here, because it is one of the consequences which show what slippery ground we are on when we attempt to treat a state of consciousness as a state of consciousness and no more.

For the same reason, on the hypothesis of a universe conscious as a whole, the separate valuation of its life and of the finite lives that enter into

1 Cf. note 2, previous page.

2 Sidgwick, loc. cit. 
its life seems inconceivable, except in the secondary sense admitted above. The finite consciousness is finite because it stops short and does not come up to its own nature; you cannot give it a value except through and relatively to its own nature, which is the whole. You cannot add the value which it retains, in spite of its shortcoming, to the value which it has in the complete being which it implies. If a thing, seen as you see it, is worth two, but properly seen is worth ten, you cannot add the two to the ten in counting its full value.

True in a sense that universe is not "good" or "bad"; but the whole is always the unit of value.

iv. If, indeed, in the assertion that the universe is not as such good or bad, stress is laid on the peculiarity of these predicates as implying a quasimoral estimate, a divorce between what is and what ought to be, then on this point a measure of agreement is possible. If the universe is taken to be a perfect conscious being, then, judged comparatively to its members, and as giving and being the standard, it is relatively good and the fulfilment of all ideas. But in itself, though perfect, it is not good, because it is not on one side in the contrast of what ought to be with that which is not what it ought to be, but is in process of becoming so. Good and bad are then not appropriate expressions by which to raise a question about it, but if it is raised, the universe must be pronounced good as opposed to bad. It is, however, though in the above sense not strictly good-certainly not morally good in the ordinary sense-yet perfection and the standard of all goodness and value. Strictly, you do not value it $;^{1}$ you value all else by it. Its value is the unit, and all other values must be adjusted so as to 1 Cf. Ar. Ethics, loc. cit. 
amount to it. And this I take to be so far the meaning of those who say that all value is in or for a person, just as it is the meaning of those who take all value to be ultimately one in the perfection of the universe. That all value is of conscious states of conscious beings as such would then be just the opposite of this contention.

v. The treatment of the State ${ }^{1}$ in this discussion Instance is naturally analogous to the treatment of the universe. And we may agree that here is an experience rightly taken as typical of the higher experiences. If the particular-the individual in the current but incorrect sense-is to be the ultimate unit of value here, he will have to be accepted as the State. unitary? The Greek theory, making it one mind in a number of bodies. such throughout. If here we can see that individuality transcends the particular given consciousness, we shall be prepared for a completer transcendence as we pass to fuller experiences. For this reason it seems well to indicate our view of this matter. Is the value of a State in the full sense in the psychical successions forming the several consciousnesses of the conscious beings who compose it, as addible amounts, i.e. starting with a value which each item severally possesses per se?

Our argument is the same as before; in fact, in our previous argument, the State, with other high experiences, would enter into the sequence at the point where, in our view, the values of successive states of consciousness must be referred to their

1 I use the term "State" in the full sense of what it means as a living whole, not the mere legal and political fabric, but the complex of lives and activities, considered as the body of which that is the framework. "Society" I take to mean the same body as the State, but minus the attribute of exercising what is in the last resort absolute physical compulsion. 
"unity in" a person or individual. The State, for us, is a phase of individuality which belongs to the process towards unity at a point far short of its completion. We understand and accept the warning that there can be no value in anything less than a personal consciousness, " in any history of development of mankind as distinct from the persons whose experiences constitute that history, or who are developed in that development."

But granted that nothing has value which is not in some sort a personal consciousness, the question is not settled how much more than its given self at any moment such a consciousness may imply as the unit of value to which it belongs. And first, we might well argue as in effect we argued above, when we said that in a personal consciousness we have already accepted a standard that goes beyond the states of consciousness of a conscious being. By a person, or a being partaking in individuality (even if we include in our idea animals and young children), we presumably mean some sort of a whole; and the states of consciousness as such are not wholes. But further, the real question is whether two or more so-called persons can be members of the same whole or unity for purposes of valuation. Are they to be valued as given, or do they, by forming an integral part of greater wholes, acquire a value completely other than that which they would prima facie possess? I hold it at this point as was indicated above $^{2}$ a concession of enormous importance that the value of any state of consciousness is said not

1 Green, Prolegomena, sect. I84. I make a reservation on behalf of the lower animals, in their degree.

2 Page 307 note. 
necessarily to be known to its subject or to any actual judge. This seems to remove all compulsion to interpret the value as an immediate aspect of a given complex. It is consistent with the view that the significance and implications of the complex, however latent and remote to the ordinary spectator, are the grounds of its value.

Let us view this question in the light of the Greek theory of society, at its best. Its famous paradox runs that the value of a society lies in its happiness as a whole $;^{1}$ not in the happiness of the separate individuals who compose it. That is to say, if you supposed each individual to have the happiness which an observer, looking at him by himself, would be forced to assign as his highest happiness, and if you treated the happiness of the community as the aggregate of happinesses assigned by such a set of judgments, you would altogether miss the nature of the true happiness of the community. "Happiness," I take it, here may fairly be said to equal value, i.e. felt perfection. This you could only obtain by first judging the perfection of a society as a unitary body of experience -because it is in this alone that the individual conscious being is all he can be-and then adjusting to this your estimate of individual perfection.

Of course to value the individuals apart with full understanding would be equal to valuing them as fully unified, and the difference of the points of view would vanish, except that valuing states of consciousness as such could not properly equal valuing unified individuals.

1 Plato, Rep. iv. init. Mr. McTaggart's contention might have arisen as a direct denial of the contention of Plato in this passage. 
The whole view rests on a denial of the position that "individuals" are a mere plurality, such as cannot be unified in their contributions to a common experience. Take, for example, the theory of the position of slaves; which applies in principle to all imperfection and reciprocal supplementation of consciousness in all society whatever. The point amounts to this, that the social life and experience is that of one mind in a number of bodies, whose consciousnesses, formally separate, are materially identical in very different degrees. In value, therefore, they severally take on the character of that to which they are instrumental, in as far as each of them, by thought and loyalty (not merely as a means), transcends its immediate self and is absorbed in the total result. Thus the loyal servant of the statesman or scholar takes a value from the latter's work- he is in and through it a participant in the perfection of the whole, just as the entire society is dignified and sanctified by the knowledge or beneficence or religion which it respects and makes possible; and is also, of course, brutalised and degraded by the sores and evils within it. The principle, I said, is universal. That it does not excuse the special incidents of slavery, is perfectly true; but its importance, first pointed out by Plato and Aristotle in respect of the child and as a partial theory of the slave's position is absolutely fundamental for the whole social experience. The life of any fairly harmonious household is a clear example of what I mean. It is possible for a consciousness to have its end, its explanation and value, in what it shares with another consciousness, and what is incompletely present in itself alone; and, 
ultimately, all finite consciousnesses have it so. Not only the so-called lower are dignified by their respect for a dim apprehension of the achievements of the "higher." The "higher" or so-called leading minds borrow much of their tincture of courage, and dutifulness, and self-denial, from their felt unity with the lower.

God uses us to help each other so,

Lending our minds out.

All this is involved to a careful reader in the classsystem of Plato's Republic; and the foundation of it all is this, that no phase in a particular consciousness is merely a phase of the apparent subject, but it is always and essentially a member of a further whole of experience, which passes through and unites the states of many consciousnesses, but is not exhausted in any, nor in all of them, as states, taken together. ${ }^{1}$ It is true that my state of mind is mine, and yours is yours; but not only do I experience in mine what you experience in yoursthat would be consistent with the total independence of the two minds-but I experience it differently from you, in such a way that there is a systematic relation between the two contents experienced, and neither is intelligible or complete without the other. When you have admitted the unity of the person with himself, it is impossible to stop short of his unity with others, with the world, and with the universe; and the perfection by which he is to be valued is his place in the perfection of these greater wholes. The principle that all value is value of individual experience is thus absolutely maintained; the difference is in

1 Atpearance and Reality, 2nd cd., p. 526. 
what we call individual experience, and the point of departure in valuing it.

In all finite individuals there is self-transcendence, and therefore translocation of the point of reference in valuing; but not all self-transcendence is primarily social. It is therefore untrue to say that $\checkmark$ all good as such is social good, and it is well that $\checkmark$ this common incorrectness should have challenged criticism. It is the paradox of humanity that the best qualities of man himself, and the forms of experience in which he is most perfect, are not at first sight very widely distributed. Art, philosophy, religion, though they bear to society the relation above indicated, are not immediately concerned with the promotion of social relations, and are not specially moulded to the promotion of social ends. The doctrine which we have been opposing is probably a reaction against the exaggerated claims of social good to be the only good, but it seems a mistake to push it so far as to deny that the State is a name for a special form of self-transcendence, in which individuality strongly anticipates the character of its perfection.

Concle- i 5. Thus, then, we admit that in the judgment $\frac{\text { sion. }}{\text { Things can }}$ of value every man is in a sense infallible for him-

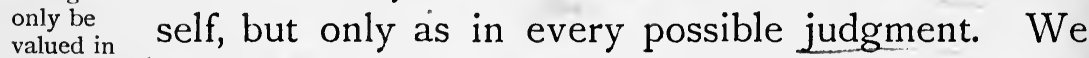

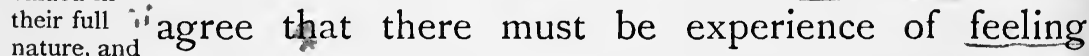
a state of before the judgment of value can be reasoned on; consciousness has within it. and that the unitary value of the universe ought not properly to be called goodness-certainly not with an ethical implication-but should be thought of as the completion of individuality, or as perfection. And we understand that all which is valuable must lie within the whole of conscious experience, 
or the aggregate, or coming together in "some way of conscious states of conscious beings. The question has been whether the judgment of value can be logically supported, and whether the whole which has value lies in the sum of the values of conscious states; understanding that the states are taken as distinct and successive, and their values as âddible quantities. The two questions appeared to be akin; because what is logically supported must involve a continuous principle as opposed to a collection of ultimates; and the answer to both seemed to be that before you can judge of anything, you must see it in its full nature, and that the nature of any conscious state of a conscious being is not to be found within itself, unless, by a reference to the whole, we have specially "taught ourselves to find it there. Therefore we adhere to Plato's conclusion that objects of our likings possess as much of satisfactoriness-which we identify with value-as they possess of reality and truetiess. And that is a logical standard, and $\mathrm{a}^{\text {r }}$ standard involving the whole. 


\section{LECTURE IX}

FREEDOM AND INITIATIVE

Our view inclusiveIndividuality means being a world in oneself and implies a special kind of self-determination.

I. OUR thesis in Lectures III., IV., and V. was what in old-fashioned phrase might be called the dependence of the finite individual upon the external or mechanical world. It was what an enemy might set down as something akin to materialism and to Naturalism. The fundamental conviction which has guided our discussion has been that the truth, or the real, is the whole. And our anxiety has been lest by neglecting any factor, by committing ourselves to any fundamental antithesis, we should ipso facto subordinate mind or spirit to excluded elements, which, so far as excluded, must remain both hostile and superior. Little as it may have seemed so, therefore, our primary object and ideal has been that of freedom. For so far as our mind or spirit attempts to draw upon itself, in the narrower sense-upon an inner self, co-ordinately opposed to the outer world-so far we are convinced it disguises and mistakes its own procedure, and converts the logic of the self into fallacy and superstition. We have been eager, at the risk of being misunderstood, to shake off all bias and prejudice against special forms of appearance, except in so far as, taken in isolation, they claim an unreal predominance. 
It should hardly be necessary to point out that our materialism or externalism is materialism or externalism with a difference. We claim it as the fulness and the genuine purport of concrete idealism, and if it is offered in a shape that implies a reactionary temper, we unhesitatingly reject it. For us, the true pexus throughout is logical and synthetic, not causal in the popular sense in which causation is analytic - a repetition of undifferentiated connexions. "Everything is what it is, and not another thing," so far as this, that the interdependence of different appearances does not simply reduce one of them into another. For example, it is plain that the external world cannot be a self-subsistent entity. But it is one thing to exhibit it as the condition and the complement of spiritual being, and quite another thing to attempt to reduce it to mere inwardness, to subjective or psychical imagery. If it is urged that indeed everything is another thing or more than one other thing in the sense that appearances are transfigured by progressive experience, this, no doubt, is a fundamental truth; but it loses all sense and value if it is taken to suggest that differences can be absorbed without bringing anything of their former self to the transfigured whole.

Thus our type of Individuality has been from the first what we described as the concrete universal, or, more generally, as a world or cosmos. And so far from admitting that this principle makes concessions to Determinism, or to Materialism, or to Naturalism, in a sense hostile to Idealism or to spiritual freedom, our contention is that no other conception offers any loophole whatever by which 
Freedom can be saved, or a creative constructive, and initiative character vindicated for the self.

After restating summarily the essence of the idea in question we will go on to justify our view of its connection with Freedom.

The essence of Individuality, it seemed to us, was to be a world in oneself. That a being, which has this character, must, moreover, be no other world than itself - that the individual, so far as individual, is unique-seemed to be merely a corollary from the ultimate ideal of organisation. Among finite beings the positive character of originality is but little impaired by de facto overlapping or recurrence. It lies in what a man is, not in what he is not.

The essence of individuality, then, is to be a world in oneself. And this holds good in its degree for the most finite "individual." In him, however incompletely, we see what it is to have experience, or, in the most general sense of the term, to be conscious. And we cannot use the term "being" in its full sense of anything but the whole of a consciousness or an experience. Whatever else is (though it may in a derivative and secondary sense possess individuality, like a mountain or tree, assuming them to have no degree of consciousness), is only as a fragment or abstraction within these. We cannot attach any meaning to it except as some portion of the experienced or the experiencing, or both in an undivided moment.

This is, perhaps, common ground to-day, but it has a corollary which needs to be insisted upon. The character of self-completeness, of being a cosmos, carries with it its own mode of self-deter- 
mination and initiative. It is impossible to consider a being as constituted by a unity in diversity of content, and yet to suppose that the nature of the content is to be indifferent, and is not to have its way in the responses and transformation of the whole. It is an old remark, but a true one, that our fears for freedom are due to wanting to learn to swim without going into the water, or, in more serious language, to a lack of faith in the Absolute. We desire to keep our individuality unspotted by the world, unstained by the content of life, and it is the inevitable result that we are driven to envisage it as the slave of circumstance. On the contrary, the conception of consciousness which is here set before us is, in general and in principle, that of a system of content, "come alive" according to certain arrangements by means of which the Absolute allows minor worlds, formally distinct, ${ }^{1}$ and of many degrees of fulness, to constitute its union with externality; which union is itself. The overwhelming impression of such a law of arrangements subserving life, produced by the general survey of the organic world, and especially of the animal intelligence, cannot be set aside. The gradation of animal minds presents an insuperable difficulty to all theories which suggest that finite consciousnesses are correlative each to each with persistent and self-subsistent differentiations of the Absolute. It is far more natural to suppose, what the plain facts seem to teach, that feeling or consciousness come where and in so far as they are demanded. by content to be experienced, their appearance being conditioned by those peculiar phenomena of the

1 We shall recur to this in the second series. 
externalsystem which in innumerable degrees pave the way for the growth of microcosms. In this way something is realised not unlike what is demanded by monadism, viz. that every possible gradation of reality must be occupied; and the Absolute is enriched by experience of all conceivable grades and varieties of content. However this may be, the idea illustrates our point that a finite individual is in essence, a cosmos, which is a portion of the cosmos, bringing relatively to perfection and full experience that which in and through the correlated externality, the Absolute has to manifest and to appropriate.

The relative lateness and artificiality of the ego or self, and the protracted discipline of a living body or succession of bodies which it presupposes, make for the same conclusion. The objections that have been brought against the idea of the "eternal self," though as objections they are, in my view, entirely without weight, yet serve to illustrate the point at issue. In a word, if we once admit the provisional reality of succession in time, there is nothing whatever to be gained by antedating the higher appearances. They come, we must believe, when their conditions are present, and not before. The self is experienced when a persistent mental system has been developed, capable of opposition to a not-self, though it seems strange to say that it can only be felt in as far as such an opposition takes a hostile form. We might say, in a sense, that it is active before it is experienced, in the de facto unity of feeling, within which the unity of consciousness grows up. But all this is a mere distinction of dates of appearance. It is one thing, as Green constantly 
reiterates, to say how we reach the experience of the eternal self; the truth that we possess it is quite another thing. There is no doubt a perplexing and interesting question, why the animal mind, in so many ways continuous with the human mind, should seem bound to arrest its development at a comparatively early stage. It would be much easier to explain a more complete evolution. $A s$ it is, we can only accept the fact, but it cannot be a motive for any treatment of human experience which is not necessary per se to deal with the phenomena. Mind, we repeat, is best regarded as a cosmos, and as working out its behaviour by the logic of a cosmos.

2. A difficulty is raised at once by any such way objection of presenting the facts, which may be considered by make cirthe help of a criticism that has been passed upon Green's account of the self-conscious moral agent. Broadly speaking, it comes to this. Self-consciousness, according to Green, is a character or principle which is the same for all and in all moral agents. ${ }^{1}$ Between such individuals there is no difference but a difference of content; for the self which experiences as well as that which is experienced, is content. Now an assignable difference of content-even of character or of disposition-goes back ultimately to data and environment, including bodily inheritance; it may be called, in fact, a difference of circumstances. This being so, and the principle of self-consciousness being as such common and identical, it is argued that the differences between cumstance the only differentiating influence. We hold the self to be the inwardness of circumstance.

\footnotetext{
1 It seems clear that the same difficulty might be raised about any universal principle, e.g. about Bergson's "Life"; and the solution would be closely analogous to that which will be offered here but subject to the limitation of the principle proposed.
} 
individuals are externally accounted for; the self, in as far as it is distinctive, springs from circumstance and not from its own initiative; in short, what determines the individual to be such as he is comes from without and not from within, from surroundings, in the wide sense explained above, and not from self-consciousness. And therefore, in a word, determinism triumphs; the spiritual principle accounts for nothing distinctive; the body and the circumstances make the man what he is. ${ }^{1}$ The criticism is, in sum, that according to Green's doctrine the difference between one self and another lies simply in circumstances. To this at first sight the rejoinder is obvious. "No, not in circumstances, but in what a man makes of his circumstances. Different minds spring from practically the same circumstances, and make of them wholly different worlds." We shall discuss the problem of character and circumstances more fully in a later Lecture. But it certainly seems as if against a resolute antagonist such an answer would not entirely hold good. ${ }^{2}$ "Of course," he would reply, "things look like that; but the appearance can only be superficial. No doubt the difference of minds is one thing, and the difference of immediate externals another; but the difference of minds, of interests and capacities, is itself, according to the hypothesis, dependent upon circumstances, and cannot be taken as created by the endowment

I Sidgwick, Green, Spencer, Martineau, pp. I9-20.

2 Unless, of course, one were prepared to suggest that each soul comes with a character previous to terrestrial circumstances and independent of it. But such a view seems superfluous and would not save freedom. The antecedent character thus brought down from heaven would itself be a mere circumstance. 
of self-consciousness, seeing that this is the common character of selves."

Such a thorough-going deterministic interpretation ${ }^{1}$ cannot be met by any compromise. It can only be dealt with from a point of view more thorough than its o,wn.

We are hopeful that such a point of view is involved in what has already been advanced. We, following Green, do not wish or need to exclude "circumstances" from the determinant and distinctive features of the self. The self, on the one hand, bears in its quality and content the banner of its place and time. It is what it includes. It is only finite, imperfect, self-contradictory, exclusive, through the impotence which causes it to include so little. On the other hand, its true and ultimate nature lies outside it, in the whole to its dependence on which the defects of its impotence bear witness. And it is actually through the impact of that whole in various forms, in all that we mean by struggle and circumstance, that its own nature is being progressively communicated to it. Therefore it is a mere observation $a b$ extra to remark that all particular given selves bear the identical feature of selfconsciousness, which is in other words a conation towards the unity of a harmonious cosmos, or towards the completed system of an eternal self. The truth of this abstract generality respecting selves as such in no way tends to establish an abstract character for the partly individualised conations in which concrete selves consist. The striving towards unity and coherence is the striving of the

1 Sidgwick, of course, would not have accepted this view; he would hold it to be a reductio ad absurdum of Green's position. 
self as a living system of content; and the fact that this content has its origin "without" is only a corollary of the central truth that every self is a special "within," and deals with some group of elements of that world-life in which all experience is one.

In a word, then, we hold that no ideal of freedom lies in the direction of isolating the self from the world. Freedom lies in the direction towards unity and coherence; and all that becomes one with the self is capable of contributing (even through apparent contradiction and the effort which it stimulates) to this satisfaction of the inherent logical tendency.

Therefore, to the criticism, "Your individual conation takes its line not from a self-conscious entity within it, but from outward circumstance, which is given to the self, and not created by it," we reply, "That, on the whole, though we demur to the last five words, ${ }^{1}$ is, as we understand the matter, what the self is there for and consists in - to convert externality into inwardness, to elicit the conation, the need if we like, or if we like, the teaching, which underlies the circumstances out of which and by means of which it becomes a self. It is the working, the 'logic,' of this relative totality of experience that as we understand the matter, constitutes the freedom of the concrete self; which thus affirms itself as a part of the eternal deed in which the Absolute sustains its living whole of experience."

Objection 3 . So much, then, for the reduction of individufrom pre- determina- ality to difference of conditions. But the critic will tion. return to the charge. Granted that the difference

1 See sect. 3, below. 
of origin between different individuals, together Answered with the fact that this is rooted in the world beyond them, is no impeachment of the essential individuality of each ; still, it will be urged, the fact remains that it all comes from somewhere ; previously existing circumstances, united in a centre which brings is in Art. tion of creative nature of Logic, carrying its no new positive element to combine with them, work out their inevitable resultant in combination with present conditions. It makes no difference, to use the terms of Kant's familiar argument, whether the sequence is physical or psychical; the essential point is predetermination, the power of a past, which is no longer a present, to prescribe what the present is to be. ${ }^{1}$ Thus we seem to have Determinism intensified into fatalism; and the action of an individual, and indeed the history of the world, is described as the rattling off of a chain of results inevitably decreed. "Tout est donné."

It seems needless to insist at length on the answer to this difficulty, as it emerges from a consideration of the relation of noumenon and phenomenon in Kant, or as it forms the essence of Green's doctrine of the eternal self.

Those who are prepared to deny that a world of consciousness carries its past in its present, and that the logical determination of the outcome of such a present world, in the way in which a conclusion comes from premisses, is essentially different from determination by what is past and gone in the way

1 It must be noted that, metaphysically speaking, the mere statement of this conception amounts to a contradiction in terms. How can a past, which is past and no more, determine a present which is present and no more? But we grant that in physical causation the underlying unity, which is certainly presupposed, does not operate as a mind operates. 
of natural causation whether physical or psychical, will not be affected by any restatement of this wellknown argument in its accustomed form. While to those who have in any degree grasped the way of working of a living mind or individual cosmosthe relation of a want to a motive, of a motive to a volition, ${ }^{1}$ of a volition to the structure of the self, it would be wearisome to meet with a reiteration of the familiar account.

But an attempt may be made to present what is ultimately the same argument in a more aggressive and perhaps more universally applicable shape, determined by the recent speculations which tend to exclude logic and intelligence from life, creation, and initiative-even from the "intuition" permitted to philosophy, which ought, surely, to stand on the whole to "intelligence" as Hegel's Reason to his Understanding. It has been said above-and the assertion may have excited surprise-that the whole recent tendency which separates. imitation and invention, repetition and creation, fails most utterly and demonstrably in its treatment of the creative imagination of art. $^{2} \quad$ But the truth is that when you have broken in two the indivisible energy of reason, and assigned one part of it to likeness and the other to difference, ${ }^{3}$ you have rendered both the one and the other utterly and finally impotent and inconceivable. We see this in the general view which condemns the logical intelligence to be at home exclusively in spatial considerations, in solids, in geometry, and to be repelled as by a foreign element

1 See e.g. Green, Prolegomena, bks. ii. and iii. ; Stout, Manual of Psychology, p. 583 ; Mitchell, Structure and Growth of the Mind, pp. 400 and 485 .

2 See p. 168 note.

$3 \mathrm{Ib}$. 
when it comes to deal with life. We remember that a truer philosophy has suggested that so far from finding the organism unintelligible, man's reason can, strictly speaking, understand nothing else. ${ }^{1}$ And we recognise in the account of artistic creation as a pure incarnation of the new and unaccountable the same irrational severance of identity and diversity which has been due, throughout the tradition in question, to working with likeness and unlikeness ${ }^{2}$ instead of with identity and difference. What the theory really means to say is that in artistic creation, in the work of genius and imagination, you have pure difference without identity, pure novelty issuing from no determinate connection, pure irrationality and unaccountableness. The work of art cannot be predicted, given its matter and its author. It is, in a word, beyond the reason and the intelligence, as life, in the speculations, we are referring to, is beyond logic.

This is a less trite form of the controversy about Freedom than that which deals with moral volition as such. But it is thoroughly relevant, and a decision in this court will carry with it the issue in all others.

It is a common and natural notion that the

1 Caird, Kant, ii. pp. 530, 535 ; cf. Bergson's Évolution, pp. 174-5, and on Art, ib., p. 368, "cet imprévisible rien qui est le tout de l'œuvre de l'art."

2 See Lect. I. and Lect. II. 6. The reason why likeness and unlikeness will not do the work of identity and difference, and why their adoption always leads to the fallacy signalised in the text, is simply that likeness, being a repeated effect, cannot be subserved by difference between the terms alleged to be like, whereas identity, being a co-operative universal, is best subserved by difference. Likeness leads up to class relations; identity to organic wholes. See Lect. I. on the relation of the abstract universal, which is often spoken of as a resemblance, to the concrete universal which must be an identity. 
creative imagination of the artist is a faculty of origination de novo. The phrases "creative" or "productive" exercise in themselves a certain magic over our minds; and especially in elementary stages of art, and in early phases of aesthetic training, the imaginative process is apt to be opposed to logical derivation from reality, as the "ought," in imperfect moral theory, is contrasted with the "is."

This tendency is supported, when we come to theorise, by the obvious difference between a work of art and a calculation or an abstract argument. In the former not only can another person not follow the process of production, but the artist himself would be apt to say, though by no means always, or always in the same degree, ${ }^{1}$ that he did not know how it came to him. In the latter case, we are apt to say roughly that the production is common form ; that it is open to any mind which will give the requisite labour and attention, and that the process can be analysed step by step. Of course, if we pressed it home, this statement would soon betray serious limitations; there is genius in science as in art, though, it may be, less definitely specialised and directed by nature. But in any case all this with the fullest weight that can be given it amounts to very little, compared with the thesis to which it is supposed to be relevant.

It only means that in calculation or abstract argument we are dealing with relatively simple and definite matter, which is fixed, combined, and communicated with comparative ease. In it we are only reproducing skeleton elements of the frame-

1 We have to bear in mind such an expression as Rossetti's about "fundamental brainwork." 
work of microcosms, and not the full effect of their concentred contents; and it is not surprising that, within limits which are narrower than we are apt to think, one mind can do in these ways much the same as another. But when we come to any issue in which the whole man is concerned the case is altogether otherwise. It is then only natural and to be expected that you cannot or cannot entirely ${ }^{1}$ substitute one mind for another; and that the issue of one world of content is not to be matched or reproduced by that of other such worlds whose contents $e x$ hypothesi are different.

This is all that the appeal to impossibility of prediction really corroborates. Prediction means doing a thing before it is done $;^{2}$ and of course this is only possible when the conditions are such as can with certainty be determined, and can be assembled in completeness at our pleasure. But in anything which depends on the entire response of the content of a mind, it is ridiculous to suggest such a possibility, except in so far as a mind may on the whole and in the main fall within another and a greater mind, or perhaps be identified with it so that the one may be in some degree substituted for the other. ${ }^{3}$ And in such a case prediction of the main lines of action or thought is possible and frequently actual.

Therefore, the alleged impossibility of prediction or construction of a work of art by other than the author adds nothing in principle to the argument

1 Cf. Lect. III. above, p. II I.

2 Cf. Bergson, Données, p. I68; cf. p. I I 6 supra.

3 This is the basis of the acceptance of testimony or authority. There are some minds we can treat as our own. See Bradley, Presuppositions of Critical History. All spiritual unity depends on this. L.c. supra. 
based upon the obvious contrast between such a work and calculation or abstract demonstration. And this argument goes only to the difference of the matter, and does not in the least suggest that the creative nature of an artistic achievement rests on a fundamentally different principle from that involved in all advance and completion effected by the spirit of logic, which lies in the continuity of the universal. All logical process is the re-shaping of a world of content by its own universal spirit. There is no repetition-not so much as the recurrent application of a word-which is devoid of this creative element $;{ }^{1}$ and in creative production par excellence we have only the same thing at its fullest.

And as we learn to deal with greater shapes of art, and as aesthetic insight and experience increase, the penetrative imagination reveals itself as the higher form of the creative. And we feel that not the invention of novelty, but the logic which lays bare the heart and structure of things, and in doing so purifies and intensifies the feeling which current appearances are too confused and contradictory to evoke, is the true secret of art. No doubt we should fail to predict the incarnation which a painter's or a poet's thought will assume; if we could predict it, we should ourself be he. But this is not because we are too rational, but because we are not rational enough. The "fundamental brainwork" is lacking to us; as is a special capacity for the infinitely delicate logic of expression, by which the passionate thought already in itself too great for us, is embodied in a million ramifications of detail, constituting a tissue of precise determination in which alone the thought in question

1 Cf. author's Logic, and ed., vol. ii. p. $174 \mathrm{ff}$. 
with its passion could find utterance-could become itself. If we say that the process is not rational, because it is largely unconscious, we are committing a serious confusion. The process itself is an intense and exquisitely adjusted and organised consciousness to a great extent obviously and plainly logical. But it is not, of course, another and a different consciousness watching and analysing the first while it proceeds. And in this sense, we are apt to forget, all logical process without exception is unconscious. You cannot make the working function of a syllogism into its major premiss : you cannot predict its conclusion $a b$ extra by a watching and inactive consciousness. The spirit of logic, when at work, deals with what is before the mind, and reshapes it ; but it is not itself a part of what is before the mind. And in this, though remote in degree, it shows its kinship with the creative imagination which at its best and greatest, as we have urged, turns markedly towards the penetrative. If it is "creative," it is so because profound penetration reveals positive treasures beyond the scope of the average mind; not because it deviates into paths of arbitrary fantasy. ${ }^{1}$ In short, then, all logical activity is a world of content reshaping itself by its own spirit and laws in presence of new suggestions; a syllogism is in principle nothing less, and a Parthenon or "Paradise Lost" is in principle nothing more. ${ }^{2}$

1 Here I sympathise with Professor Stout's view of possibility as something discovered within reality.

2 No one, so far as my knowledge goes, has ever raised the question whether the future course of exact science, say, of pure mathematics, is predictable, and if not, why not ? The best answer, as always, is the affirmative, plus conditions. It is predictable, of course, in so far as you are at the point of growth and adequately gifted, but only in so far. Prediction is pre-doing, and passes into doing. 
Now this is the nature and type of originality and initiative which the whole of our argument is directed to vindicate for our conative development, whether practical or intellectual. Our actions and ideas issue from our world as a conclusion from its premisses, or as a poem from its author's spirit. Do we demand any more complete originality and initiative? Is it urged that our ordinary life-progress through moral volition ought to exhibit a creativeness and a novelty of departure to which King Lear or the Sistine Madonna could present not the faintest approximation nor analogy, and which, if per impossibile it could be imputed to them, would tear up by the roots their significance and their human interest? For when we say "continuity," we say ".logic"; and if we deny and remove the latter, we make a cut in the universal, and sever the issuing production from its roots in human nature. It is true that art is not governed by the purpose or interest of producing a total representation of the actual world, but has an autonomous growth and interest of its own. But still the main principle holds good. In that which we hold the freest creation, the unchallenged domain of productive originality, there is nothing which is not one in nature with the remoulding of a cosmos by its own yearning for totality, that synthetic vitality of the logical spirit which Mephistopheles as the genius of modern thought ${ }^{1}$ desiderated, and which the Middle Age at its best had already symbolised by the growth of the leafy spray. ${ }^{2}$

This, then, the creative freedom of art, is what

1 Kuno Fischer's Goethe's Faust, ii. $205 \mathrm{ff}$.

2 Type of the Syllogism; see what Ruskin has called the Strait Gate in the Spanish Chapel at Sta. Maria Novella, in Florence. 
we offer as the type of the characteristic logic or movement of the self. I do not see how an initiative or originality more complete than this can be conceived or desired, or can be consistent with a self that is anything at all. Life-to which we are so often referred as the true continuity or active duration -is nothing in the world but a lower phase of an analogous logic, related to human activity as a hill or cloud to a Turner sketch of it, or as a bird's song to the Iliad. What we are here offered is a share in the eternal deed which constitutes reality; and I am unable to see what more than this our largest wishes can demand.

A self, then, appears to us as the active form of totality, realising itself in a certain mass of experience, as a striving towards unity and coherence. Its self-determination is that of a logical world, ultimately, in the general type, one with the relation of a conclusion to premisses, by which a new and transfigured whole emerges from a mass of data which in one sense contains it, but which in another sense it transcends. The nature which we have claimed for it is more easily identifiable as we appeal to the completest and most triumphant achievements of art and poetry. For the leaps and eccentricities of a purely freakish fancy are from a logical point of view simply possibilities predicated of reality under an exceptional amount of tacit reservation, all of which is formally a breach of logical continuity; while by the creations of the greatest art the possibilities of man and nature are rather intensified and expanded than wiredrawn into decorative ramifications; and the logical continuity is therefore apt to be deeper and more thorough, not more fragile and 
attenuated, than that which passes current in ordinary life. To stigmatise an initiative of this kind as the rattling off of a preformed chain is simply to reject the continuity which makes life interesting. If we want a creativeness more free than this, we shall find no analogy for it in the processes by which anything worth having is produced in the field of knowledge, of practice, or of art. This, then, is our conception of a self, of "what it is to be a self," and "of "what it is to be" free or self-determined.

Difficulties

in the emptiness and timelessness of selfconsciousness. Its emptiness is its omnipotentiality.

4. Two special questions may be considered in illustration of the above point of view, and the most prominent difficulties of grasping it.

$a$. The emptiness of self-consciousness or of the bare subject-object relation, as implied in Green's idealism, has already been referred to, and will be more fully dwelt upon in a later lecture as the secret of the power of the self. But in the present context a few words of explanation seems desirable. The general statement that "self-consciousness or self-objectification is the principle of the self, is plainly an empty and abstract statement. And in this sense the conception which it describes is also an empty conception; that is to say, there is nothing within the four corners of the statement to identify the characteristic there referred to with any special interest or content.

All this is true. It follows inevitably from the character manifested in self-consciousness as the principle of the whole. ${ }^{1}$ It is inconceivable that the principle of the whole should be occupied $a b$ initio

1 Green, Prolegomena, sect. 8I, cites De anima, 429 a 19

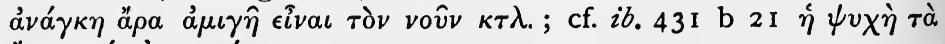

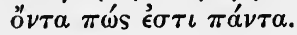


by a determinate partial content. If we ask, is the mind or self-consciousness indifferent, divorced in its nature from any and every content, like pure water which has no taste, ${ }^{1}$ the only proper answer is that its content is the Absolute, even if in attaining the Absolute its own special form has to be surrendered. And again, if we ask, is it no more proper to one partial content than to another, then the answer is, "Certainly it is always more proper to that content which compared with another approaches more nearly to the character of the Absolute." But if we are asking, "Does the bare fact that I am a self-consciousness bind me a priori to a determinate form of life, habit, or character?" the question is plainly absurd. The power of selfconsciousness is to make a self out of circumstances, and to do this, if we were, so to speak, circumstantially determinate antecedently to circumstance, would be an impossibility. We must understand that everything comes from somewhere, and that the meaning of self-consciousness, the active form of totality, is to give everything its character, to be the centre in which everything in its degree tells on the import of the whole. The emptiness of selfconsciousness as such is an inevitable condition of its fulness in actual individuals. Any experiences which fulfil certain very general conditions will suffice to constitute a self-consciousness. And it seems to be imagined that this truth in some way impeaches or impedes the value and significance of self-consciousness. But if self-consciousness is, I do not say the ultimate form of experience, but the

1 A comparison which we should probably hold erroneous, applied by Winckelmann to the character of perfect beauty. 
highest and most significant of its finite shapes, what other law or condition of its being could we have hoped for or anticipated? Such phenomena as are recorded in the "Dissociation of a Personality" only confirm the general conception of a self and the conditions of its stability, ${ }^{1}$ which we ought to have gathered from such thinkers as Plato and Hegel. The keynote is throughout that a true self is something to be made and won, to be held together with pains and labour, not something given to be enjoyed.

Its timelessness is its "durée."

$\beta$. The timelessness or eternity which the same Idealism ascribes to the fundamental self has also been a source of difficulty. But really the matter seems very simple. Time itself, as we all know to-day, is a hybrid experience. Succession does not suffice to constitute it; and in the same way and for the same reason succession does not suffice to constitute a self. All this is familiar ground; and the only point of difference arises in the interpretation of that continuity of content which is admittedly necessary to the experience of duration throughout a succession. The interpretation assumes different shapes according to ultimate metaphysical theory; and those who take the element of succession in time to be ultimately a mere appearance, incapable of maintaining itself in a perfect experience, will hold different language as regards the common facts of duration from those who take succession and continuity to be two inseparable factors of a reality which is fundamentally temporal. The former will

1 This actual word, fundamental in the Platonic theory of mental being, constantly-recurs in this recent study of the life-history of a self, as indicating the high-water mark of its unification of content. 
speak of the self, in proportion as it assumes the nature of a whole present to itself, and further implies a continuity, limited only by de facto impotence, with the whole content of the universe, as approximating to the nature of eternity or nontemporal being, which they hold to be the ultimate nature of the experience which alone is true reality. The latter will treat the experience of system and continuity in the self as merely a side of the real, which can never be shown capable of wholly defeating or including the aspect of successiveness. But when the hybrid or at least the dual nature of time (and, we may add, of space) is thoroughly admitted, the actual facts as to the nature of the finite self are no longer in dispute, and the question, so far as it concerns such a self, becomes one of words. "Durée," the operative concentration of the self's past history at the growing point of the present, is one with the relative timelessness of a finite self. If, then, it is admitted that timelessness is an essential constituent of time-and this much will hardly be denied to-day - then to say of any finite being that it is temporal (has or is "durée") includes, strictly speaking, all that can be demanded for the description of such a self by the theory which takes eternity to be its full and perfect character. For that the finite has an aspect of succession-that qua finite it is not "all there" - this again is what no one could dream of denying. The point at which the theory of the eternal self continues to part company from its critics lies in the emphasis which it will attach to the differential degrees in which the feature of externality and successiveness - of determination by space and time-accompanies the degrees of completeness and 
stability attained to by the self, and its recognition that its true being lies beyond its fullest actual realisation. The distinctive being of the self is inversely as its dependence on externality and successiveness.

Logic is perfect determination. Fatalism is determinist, i.e. imperfect determination.

5. The crucial point, then, which separates determinateness from determinism is the distinction between logic and fatality. By logic we understand, with Plato and Hegel, the supreme law or nature of experience, the impulse towards unity and coherence (the positive spirit of non-contradiction) by which every fragment yearns towards the whole to which it belongs, ${ }^{1}$ and every self to its completion in the Absolute, and of which the Absolute itself is at once an incarnation and a satisfaction. The attempt, which bulks large in recent controversy, to identify this principle with one of its cases, has really no significance beyond that of a relative emphasis which arises in the applications of daily life. It is an obvious though very important truth that the higher moods or attainments are the more concrete and the more inclusive; and that in dropping to less arduous and intense experiences we become restricted to more limited and specialised attitudes. This principle, as we argued above, ${ }^{2}$ is the key to the relation between our commoner experiences and the Absolute; and we have an everyday instance of it when in the succession of our average moods

1 óṕ́ $\gamma \epsilon \tau \alpha$, Phaedo, $75 \mathrm{~B}$, of a fragmentary perception, such as that of a pair of terms which suggest what they fail to realise. I am convinced Plato meant this much more literally than we take it. It is an experience which clamours for completion.

2 See p. $274 \mathrm{ff}$. above. M. Arnold gives us the principle in an everyday shape-

"But tasks in hours of insight will'd

Can be through hours of gloom fulfill'd." 
intellectual work is dissociated from practical selfassertion, and both from love and adoration. But none the less it is the strict and fundamental truth that love is the mainspring of logic, and that practice, if the term has a distinctive sense at all, is a subordinate feature of its movement.

Fatality would be the opposite of this; it would be a movement, a succession, without love or logic, and with moments external to each other, such as we seem to ourselves to detect in the unconscious processes of what we call physical nature. "It takes all sorts to make a world"; and a true theory of appearances will leave room for externality not as a self-subsistent real, but as representing an element of dissociation essential to the order and emphasis of the whole. It is only when we come to treat it as subsistent in its own right, and to erect it into the type by which conscious experience is to be construed, that it assumes the menacing form of fatalism or determinism. ${ }^{1}$ It is really, as compared with logical determinateness, an imperfect, relative, and indeterminate form of connection. It involves the paradox of a universal or continuity, which operates without possessing any being in its own right and form. According to an old comparison, it is like the reaction of an intelligent body in its sleep, or, in more modern language, like the effects of a split-off consciousness as they appear within the self from which it is split off. Now what all this means, for our present point of view, is that externality or physical determination is imperfectly determinate It is sensitive, to use a metaphor, only to certain factors of a situation. It is not the

${ }^{1}$ See McTaggart, Commentary, sect. 185. 
awareness of a whole reshaping itself according to the full significance of the constituent contents. We must learn, if we wish to understand the relation justly, to think of physical causation not as the type of perfect complex determinateness, against which spiritual freedom shows as the responsiveness of a simple self-centred creature, the direct guiding reaction of a purely unitary being; we must rather compare the two as a region of abstract and external contexts and responses between unawakened beings, contrasted with a living and concrete world of appreciation, in which the whole quality of every element is capable in principle ${ }^{1}$ of bearing upon and responding to the whole quality of every other.

Therefore it must be observed, in concluding this consideration of freedom, that determinateness and determinism are in principle opposed. Determinateness must be fullest in the Absolute and in God. And in all experience the plain tendency is for determination and value to go together. The ultimate value is in the whole, and value rises with participation in $i^{2}{ }^{2}$ which means the transfiguration of experience by the bringing to bear of all upon all in the fullest vitality. Such is the ideal of the logic of a self, and to such an ideal the conception of determinism, of a causation which is partial and, so to speak, unawakened, is thoroughly antagonistic.

God, it has been said, could only impart Himself by imparting a self, and we may urge the complementary truth that a self can only be a self in so far as it is the self. The desire to escape the principle

1 Of course it is only in the whole that the appreciation and response are complete.

2 Apparent exceptions to this principle will be dealt with below. 
of self-determination or positive non-contradiction is really, though it may seem otherwise, a desire to shirk responsibility. What the ordinary advocate of freedom at bottom demands as "the power to have acted otherwise," is in the same breath to act and not to act, or, acting, yet not to act. It is to repudiate, not to accept, responsibility, that is, the qualification of the self by its behaviour. $\mathrm{He}$ is offered what he pretends to ask, that his act shall be his and himself; and he runs from his demand the moment he is confronted with its meaning. In every action, and even in the moment of acting, he is to be as if he had not acted and was not acting, uncommitted and undeveloped. "Uncommitted," it may be replied, "before the action, but not after." But this is an evasion. If uncommitted after thousands of actions, and before the thousand and first, he is uncommitted no less after the thousand and first. The point of the doctrine is not that the act does, but that it does not characterise the self. ${ }^{1}$

6. It was admitted just above ${ }^{2}$ that the test of Apparent logical determinateness, as indicating degree of to "deterindividuality or the completeness of a self, may $\underset{=}{m}$ merfeness seem to conflict with the facts. The analogy of the tion of a soundness of a theory, in judging of which we give weight to the distinction between more or less fundamental principles,-principles whose denial involves the denial of more or less complete and coherent ranges of experience, will suffice to remove the difficulty.

It will be best to combine the discussion of this

1 In Mack, Freiheitstheorien, this is plain, e.g. p. 175.

2 Page 342 footnote. 
appearance with the application of the foregoing views to the evil self. For obviously we are likely to be asked, Do you mean to say that the evil self is simply a case of the inevitable logic of the self?

When we approach the problem of the evil self from the point of view of Individuality and completeness, there are at least three typical forms of imperfection which present themselves as demanding 7 consideration. There is the animal self; the naive 'or elementary good self; and the bad self proper, the rebellious or positively negative self. If badness is defect of individuality, a logic imperfectly informed, and so a relative failure to construct a whole (so the problem states itself), why should not the two former types of the self, which prima facie certainly exhibit this incompleteness, be set down as pre-eminent cases of the evil self? How, upon our view, can any distinction between badness and imperfection be upheld?

The animal self comparable to data without a theoryan abstraction.

(i.) The animal self-the bodily needs and desires which man shares with the brute creation-furnishes a ready and obvious example of the imperfect self, and has been exploited in that sense in some degree by the ethical philosophy of Greece, and also by popular morality and religion in all ages. It is needless to refer at length to the fallacies which thus arose. ${ }^{1} \quad$ It is plain, and the Greeks themselves were well aware of it, that the animal content of life must be regarded as the common root of man's purposes, good and bad alike, and not as something

1 The phrase of George Eliot's old lady, "drinking and smoking like the beasts that perish," well sums up the absurdity. Aristotle (Eth. Nic. I I 8 b 8) was aware that the main danger to morality lies in specialised desires and not in the simple wants which we share with the lower animals. Cf. Green, Prolegomena, sect. 265. 
that is to be negatived, unless in the sense of transformation, which takes place in the bad self no less than in the good. The form of imperfection, therefore, that would consist in remaining a brute beast is one that cannot actually exist in a human consciousness, and the forms of vice that are confused with it bear in reality quite a different relation to the individual-self. The animal basis of life is imperfect in the sense in which data are imperfect without a theory, and not in the sense of a theoretical structure capable of narrowness and self-contradiction. It would not amount to so much as an imperfect human self. ${ }^{1}$

(ii.) When we consider the naïve or elementary the naive life of morality ${ }^{2}$ and religion, that, let us say, of a coompared simple, uncultured, but kindly and honourable person of any creed which is not actively savage or to grasp of a fundamental. cruel, we seem to be met by a more serious diffi- principle culty. In the light of the analogy we are pursuing, such a life is, even relatively to the average, very decidedly imperfect, claiming but a low rank of individuality. The mental equipment which suffices for it omits huge provinces of experience, and would be unable to deal with the bulk of the relations which constitute the world 'of an advanced civilisation. If defective individuality is analogous to failure of theoretical grasp, and lies in openness to contradiction and incapacity to unify life, surely, it might be argued, here we have it, and, on our hypo-

1 A question of great interest, but not relevant here, is how far a brute animal can be said to possess a self. How far do we endow them, out of our gathered observations, with the character which for us they certainly display? How far is it anything for themselves?

2 I am here discussing naive morality in respect of that solid and realised content which it involves, abstracting from the theoretical aspect of "moralität" as a mere struggle against evil. 
thesis, we should be driven to the absurdity of admitting, in the plainest sense of the words, that ignorance is vice. For certainly, as compared with such an knocent ignorance, a mind which we should unhesitatingly pronounce wicked and corrupt may have a far wider range of culture, and a relatively full capacity, not only for the theoretical, but even for the practical unification of life. This apparent fact, that a plain, ignorant mind may be good, and one refined and cultured in the highest degree ${ }^{1}$ may be bad, is what would commonly be alleged against us. And what is true in the objection leads up to a most striking verification of our point of view.

The ignorance which Socrates pronounced to be vice was ignorance of the good. The good meant for him the unification of life. Now, the unification of life is a problem which, like other problems, has its fundamental necessities and its outlying corollaries, things which must be known and done to realise it at all, things which may be known and done to realise it more completely. And the essential matter is that the naïve or simple self of everyday morality and religion consists of the principles which are fundamental in the unification of life. The contention that wisdom is goodness transforms itself in the end ${ }^{2}$ into the contention that goodness is wisdom, and with complete justification. Applying the analogy of a theory we have here, in the self at the level of naive morality, an imperfection comparable to the possession of some sound fundamental principle in science, politics, or philosophy, apart from the special knowledge or

1 I state the common opinion, subject to some reservation which the discussion will reveal.

2 Plato, Laws, 689 A-E. 
aptitude demanded by abstruse and remote provinces of research. It would be fair and true to say that what is called morality par excellence is constituted by the main structural outline of the intelligence, a defect in which cannot be wholly compensated as concerning the unification of life by the most complete aptitude and control in specialised provinces of experience.

Thus we see at once why naïve morality and religion, although very highly imperfect forms of individuality, are not in principle ranked as comparable in negative value to forms of the bad self, or as wholly and inevitably surpassed in positive value by the higher developments of civilised mind if possessed in isolation. (That they-the naive attitudes in question-are morally and religiously defective by reason of the limitation which constitutes their naïve character, and that they do fail in a high degree, though not fundamentally, in the unification of life, is a consequence which I not only admit but energetically maintain.) It is because they possess the essential and fundamental conditions of unification, of which scientific or artistic aptitudes, for example, are outlying corollaries and completions, but relatively posterior and dependent. A man is good in as far as his being is unified at all in any sphere of wisdom or activity. And in dealing with a whole so vital as the whole of mind, one cannot say that the perfection of any part is indifferent to that of any other, or, therefore, that morality is entirely unimpaired by aesthetic and scientific incapacity.

Still, in the main, the dependence is the other way; simple morality can more nearly stand alone, 
and its absence shakes the whole foundations of life and mind. Such absence is in respect to life as a whole, what a failure of belief in the first principles of rational system is to the scientific intelligence. ${ }^{1}$

This, then, is the true distinction between -morality, commonly so called, and intellectual or aesthetic excellence, which is goodness in the wider, or (should we rather say?) in the narrower sense. ${ }^{2}$ III It is a distinction of degree between the more and the less fundamental of the ideas which govern life. It is not the current distinction between ideas intellectually held and ideas so held as to be effective in action. Ideas which, as we said of moral ideas, form the main structure of the mind, cannot but be operative-ideas whose content claims such a place, but which do not occupy it because inadequately held, are not truly knowledge. In bare fact, the presence of adequate ideas which are inoperative in moral matters is vastly exaggerated, and it is even doubtful whether, strictly speaking, it can be shown to be real. The point is, that ideas which prove inoperative are such as are not carried out into the connections and associations which would constitute at once their meaning and their power. ${ }^{3}$ It is not true, as a bare fact, that the selfish man knows and

1 One meets with men of enormous learning and cleverness who nevertheless seem fundamentally incapable of dealing fairly with evidence or of understanding the elementary requirements of a sound theory. A mind which is like this right through would be a bad mind - a mind whose powers of unification only served to deepen contradiction.

2 Narrower, because these excellences per se are, after all, provincial moralities, not dealing with the main framework of life as a whole.

3 Cf. further, the analysis of what is involved in such dominance of an idea as cause its realisation. Bradley, in Mind, xliv. pp. 447-8. See pp. 20 I-2 supra. 
realises the value of unselfishness or the superficial man the value of thoroughness. It may be argued backwards and forwards how we strain our imagination of what we lack, and how we "rack the value" of what we have missed, but these feverish aspirations never reach the plain solidity of knowledge.

The intellectual rank and value of morality has here been discussed on the basis of the actual content of the leading moral ideas, and the conclusion would stand fast even if per impossibile it could be shown that the ideas can be fully present without being operative. For if they could exist (as "knowledge") without morality, yet morality could not exist without them, and its nature lies essentially in their content. Whatever we may think of the phrase "wisdom is goodness," it stands fast that goodness is wisdom, and this truth has, as we shall see, ramifications and corollaries of the highest importance.

We have seen, then, that (i.) the animal self is so much below imperfection as not to count at all, even for an imperfect human self; and that (ii.) the self of naïve morality and religion is certainly imperfect, but by reason of possessing the fundamental conditions of unification is a sound foundation, not to be dispensed with or undone, for the fuller determinations demanded by the fuller experience.

But when we come (iii.) to the evil self we have The evil before us something which we recognise at once as different in kind. For here we have essentially the phenomenon, familiar to us in the province of theory, of two quasi-rational systems in active antagonism, knowledge. as claiming to attach different principles and predicates to identical data-here, to the common basis of 
the self. In this case, no doubt, we may and do find a considerable area of positive unification in a system which, nevertheless, we are obliged to recognise as an evil self. It is just as we may find a high degree of organisation and rationality in a theory which, on the whole, we are obliged to reject in favour of one more solid and complete. The evil self is not evil in itself. The most suggestive and extraordinary fact about it is the very high degree in which objects and interests, which in many contexts, or most, we should pronounce good and desirable, may enter into the very tissue and texture of the evil life, ${ }^{1}$ just as beauty enters into the detail of the terrible or hideous in art, or as truth enters into the detail of theories which, on the whole, are false.

The evil self is evil, then, because and in as far as it is antagonistic to the good, for, however highly organised in itself, it is inevitably through this antagonism the adversary of unification of experience, and the vehicle of contradiction in the very heart of the self. Many questions of interest may arise out of this formulation. Is not the evil, then, after all a species of the good-good in the wrong place as dirt is matter in the wrong place? And could not the self be equally divided, so that while the contradiction in it was obvious, we should find it hard to pronounce which self was good and which evil?

But for our present purpose we have seen enough. We have seen how it is that not every imperfect self is pro tanto an evil self; and again, that an evil self may be, regarded in and by itself, of a higher degree of consistency and coherence in

1 Macbeth is a good instance. 
virtue of its positive aim (not of its aim as evil, which is essentially negative or rebellious) than many an imperfect self which is either non-moral or morally good. It is simply the difference between inadequacy and developed contradiction, and thus the facts confirm our conception of maximum individuality or unification of experience as the standard of real and good, and therefore our conception of logic as the law of the striving of the self.

But if this is so, then the evil self is a case of the logical striving of the self after unity, which has brought it into contradiction with a fuller and sounder striving (just as in the region of pure theory we may be a prey to an insoluble antagonism of which both sides are due to the theoretical impulse). Thus a question will naturally arise as to the application of the idea of self-determination to this form of the self. Do we affirm that the essential nisus towards unification and individuality, the conation of the self, can take the shape of a bad self, and this, according to the tenor of our views, as a logical necessity? ${ }^{1}$ And is not this doctrine open to the dangers of fatalism? Is the bad will, where and so far as developed, a logical necessity in the self which develops it, no less than the good will? Certainly it is so. The point and meaning of the bad will is wholly lost unless it is a development of the self in the same sense as the good will; the only difference being that it has seized a false clue such as is essentially incapable of doing the work of unification, which the will as such sets out to do, and is thus brought into more or less explicit antagonism to the purposes of unified life,

1 Cf. Green, Prolegomena, sect. I I I. 
and ultimately to itself. There is no metaphysical difficulty in this view. The assertion of moral evil is involved, as has often been pointed out, in the very nature of morality. Moral evil is not in its whole content something alien and menacing to the world. It is something which has a relative right to be ; it is involved in the fact of finiteness, though its special shapes arise from the logic of individual finite beings. That this should be embodied in the inherent work of selves-it cannot, ex hypothesi, be the whole work of any self-is only part of the contradiction belonging to finite life, where completely harmonious self-affirmation is impossible. Moral evil, we might say, is good hostile to good. ${ }^{1}$ As hostile, it demands amendment and subordination, but it is, in its positive nature, not in the mere antagonism of which by subordination it would be divested, obviously a contribution to the vitality of the whole.

Is this doctrine dangerous, as a suggestion of fatalism; of the will in some agents being predestined to be evil ?

The question applies to good and evil alike. It is whether a necessary action ${ }^{2}$ implies a necessary agent; whether when we say a decision cannot but be such and such, we are saying that the agent "cannot help" making it.

1 Other forms of evil, not specially relevant to the problem of moral good (e.g. pain) will be considered elsewhere. Must the bad self be rebellious against its own good self? May it not be, all of a piece so to speak, rebellious against the socially recognised good? I think, if the case is worked out, it must mean that the good rebelled against is recognised in the character of good, and therefore as a good self against the rebellious self. Would a man, unaware of good, be immoral, or a criminal lunatic?

2 Green, Prolegomena, l.c. 
The primary principle that should govern the whole discussion is this, that the attitude of moral judgment and responsibility for decisions is only one among other attitudes and spheres of experience. More than this, it is, as we shall see, only an aspect of the actual fact and reality, an aspect which would show quite differently in the whole but is isolated (relatively) by our impotence. It must not be set up as absolute or pressed as the whole and inclusive reality of human action. The attitude of moral judgment and decision - the feeling, it now all depends on me, and I, and I only, can determine and am responsible for what is now to take place, is right and true in face of a moral decision to be made, because the several factors or constituents of the will, and the law or spirit of action, are already presupposed in the fact of my being a world which is a self. The question now is how that self will reshape and develop itself. At the moment and in presence of the situation this, its absolute independence, is real and a fact, and is itself an element in determining my behaviour But metaphysical theory, viewing the self in its essential basis of moral solidarity with the natural and social world, and in the special relations with others which forbid its isolation, cannot admit that the independence of the self, though a fact, is more than a partial fact. ${ }^{1}$-Both views are true and represent the reality of the universe in their degree; but it is fatal to confuse them, or, which is the same thing, to set them in antagonism as if they belonged to the same situation and had to meet the same need. It is true that in the moral emergency all depends on the individual

1 See above, Lecture VII. p. 277. 
will which, as explained above, is in the right when it recognises this. But it is true that the individual will is a principle and content having far deeper roots than what we commonly take to be the individual mind, and the task, which is really and rightly its task, is set it by the universe.

The Determinist has relied on this deep-rootedness of the will; but not with complete justification. He rightly urges that prima facie, if moral bona fides is presupposed, our ideas, say, about the nature of volition cannot be drawn in to affect the positive influences and motives which are presupposed as constituting volition. To say in general that your ideas guide your actions ought not to be taken as favouring some ideas (e.g. ideas of fatalism) at the expense of others. But this argument does not come quite fairly from the Determinist. For his metaphysical position is really hostile to the nature of self-determination. He construes the self and motives on the analogy of things which are not a self or motives; and his term "necessary" does not merely express a conviction as to the rationality of the result, but conveys a conception of the nature of the process irreconcilable with the true idea of the moral deliberation by which motives are framed and modified.

With the present theory, it is submitted, this is not the case. It can in no way be held to narrow the scope or transmute the conceptions of moral deliberation or determination. It recognises the self as operative in its own nature, as creative and originative according to its own law the only law of creativeness which prevails in the universe. It recognises a necessary act - an act which must 
be what it is-but not a necessary agent, ${ }^{1}$ because nothing but the agent determines the act, and there is no meaning in applying to him any "must" or "cannot help it" except in the sense that everything is what it is. In other words we may say ${ }^{2}$ that nothing past, nothing external, is operative in the agent's choice. It is all gathered up and made into the agent himself, and its remodelling in him is one with his creative production of a new deed. All it does is to supplement the strictly moral attitude, "It is I, and I only, who have to act; it is I who determine what is to happen, and in determining it I am good or bad," an attitude which cannot exist per se, nor be pushed to the bitter end. It supplements this attitude by the wider recognition of metaphysic (akin to that of religion, apart from which, however unrecognised, morality could not conceivably subsist), ${ }^{3}$ that I through my goodness or badness, which means through my moral judgment and decision, a burden which I cannot possibly be relieved from or put away from me, am yet more or less completely doing the work of the universe, and, as and because I am myself, am acting as a member in a greater self, and am in a large measure continuous with it, and dyed with its colours.

7. The ideal that appears irrepressible in the

1 This view, derived directly from Green, but on the whole the view of the philosophical tradition from Plato downwards, is curiously coincident in its application with Bergson's doctrine, which alleges that every theoretical account of free will is deterministic as resting on a spatial representation of time, neglecting the character of "durée" (Données, p. I68). I agree so far; but as I have argued throughout, he seems to me to truncate the character of "durée."

2 See above on Kant, p. 327.

3 A morality, e.g., which should attempt to disown the " means of grace" in the suggestions and influences of nature and society would be as untrue to moral fact as it would be hostile to religion. 
The ideal treatment of Freedom, Initiative, Individuality, is of Contingency rests on a confusion between the original and the arbitrary. the ideal of Contingency. To establish Contingency in the heart of things is the motto and motive of the moralistic Idealist, ${ }^{1}$ and the scientific thinker, who appeals from mathematics to biology, is disposed to join in the enterprise. ${ }^{2}$ The object of the present lecture, in harmony with the aim of the present work, is to defend a wholly different set of suggestions. The bias towards contingency arises, it would appear, from a misinterpretation of the demand for creative initiative, combined with a failure to appreciate the true nature of logical process. Our effort has been to bring the conception of moral and individual initiative nearer to the idea of logical determination, and so into comparison and connection with the forms of creative activity most indubitably recognised as such and as giving the highest value known in human experience. And it is very noticeable, as has been observed above, that the tendency to confuse creative determination with arbitrariness and contingency displays itself in popular ideas of what is fine and desirable no less in these other spheres than in morality. ${ }^{3}$

1 Ward, Naturalism, ii. 280.

2 Bergson, Evolution, e.g., p. 125 . Conscious life depends for him on the accumulation in the body of an immense store of indetermination. It is obvious that in view of the conceptions which we are working with, the store of indetermination would become the substructure of logical as superseding mechanical determinations.

3 Such are the ideas of art and of originality which were so constantly the object of Goethe's satire, e.g. Werke, iii. I I I.

" From masters I have ever kept apart, To follow others' footsteps seemed disgrace ; Myself have from myself learned all my art."

"Too plainly, it's the case."

("Es ist auch danach") ; or the famous lines on inheritance, Werke, iii. 4 I I, "Gern wär' ich Ueberliefrung los Und ganz original . . ." 
From the present point of view, not only logical theory, but the whole doctrine of the expression of thought and emotion in aesthetic form, of social right and duty, of religious aspiration and attainment, no less than the achievements of science and philosophy, is fatal to the ideal of contingency. It is being master of and mastered by content, with its transfiguration as it reshapes itself towards the whole, that confers logical stability and exalts individuality. 


\section{LECTURE X}

NATURE, THE SELF, AND THE ABSOLUTE

"Nature" I. Is it possible to speak intelligibly of a relation the environment of selves, considered as selfexistent. The line between it and mind not fixed. E.g. Has it Beauty? between Nature and the self? Either term seems inconceivable without the other; and there must be something of arbitrariness in any attempts to draw a line between them.

If indeed we took Nature to mean the homogeneous world of units adapted for calculation as known to mathematical physics, then there would be no difficulty in the distinction, but no interest in the relation. Nature would then be one special abstraction under which our intelligence brings together some general characteristics of the world in space and time, for the purpose of reducing its different appearances to comparable formulae. It would no doubt be an effective form in which to recognise many external conditions that operate upon the self, but it would be far short of what nature means either to the common man or the poet.

On the other hand, if we understand by Nature the universe in space and time interpreted as a living system, the meaning which lies at the root of all art and poetry, we should find it hard to exclude from it the spiritual side of the higher organisms, 
and any further spiritual being which we may suppose their existence to imply. And the distinction, if any remained, between the selfand Nature, would be simply that between part and whole, and so far as a relation between the two was conçerned, could only be taken as leading up to some such view as the following.

For there is a distinction of kind, relevant to our purpose. We want to understand what it is that the environment, the world of things and facts as we experience it, contributes to the being of the self, the subject or centre for which things or facts are objects. Nature in this sense, the spatial, external, objective world, with its full beauty and usefulness, though nearly everything, is not quite everything. It is hard to say where it stops; but plainly we must draw the line somewhere. It cannot be drawn always at the same point between the subject and its environment. For the self, itself, draws its material from Nature, and even as subject, as confronted with its objective surroundings, is making use of that material to give itself the feeling of selfhood. ${ }^{1}$ Nature for everyday sentiment and perception differs only in degree from what it is for the artist and the poet. It is the world in space and time, with all its secondary qualities, and moreover, with all the interpretations and emotions by which in our experience it is taken as qualified. We know that in this sense it could be nothing apart from a self which at least must be sentient. ${ }^{2}$ Nevertheless

1 Psychology of Moral Self, p. 57.

2 I do not see how this proposition can be overthrown. Grant that sensations are objects, grant even per impossibile, that they are physical, I think we must interpret these predicates consistently with depending upon sentience. Professor Alexander, I think, would admit that they are adapted to form part of a world of which mind is a leading constituent. 
it is not created by the self taken apart from the detail of the environment; for so taken the self would be nothing. The self may indeed be said to make its own environment. But this is only by selection; it depends on the given; and even within the given it cannot be arbitrary. It is an affair of interests, motives, preferences, grounds, reasons; at all events, of something; and something does not come from nothing, but from something in particular. The self, which makes the environment, is itself all soaked in environment. You cannot say where self ends and environment begins. Nature, conceived as an environment, can hardly be reckoned as less than the whole detail of thing and fact which enters into the world of the self. How far we treat it as qualified by the interpretations and emotions of the self, is, as we have said, a matter of degree. The influence upon us of our own bodies, of our friends in the world of lower animals, or of external events in which other human beings are concerned, cannot be excluded from it on any consistent principle.

The distinction thus becomes the same in principle with that of circumstance and character. ${ }^{1}$ It is a distinction of points of view. 'A nything in ourselves or our environment is in this sense Nature, which is not considered in the light of the behaviour of a self. Anything belongs to a self, in which details of our world are seen as connected parts within the total reaction of a mind. If we consider the distinction between Nature and fine art, Nature and morality or politics, Nature and industrial or economic activity, we shall find that no other contrast is justified by common usage and experience, or is relevant to the 1 We shall return to this in the second series. 
distinction between Nature and the self. Thus my being born and bred in the Highlands or Lowlands, in town or country, of a strong or a feeble race, are all natural facts; obvious pieces of environment; though my attitude to these facts, or to other things by reason of these facts, belongs to myself, and is the sort of stuff or substance in which myself consists.

Nature, then, as thus considered, is the world in space and time, abstracted from our momentary attitude and considered as self-existent, though at the same time held to be possessed of qualities which presuppose it to be in relation with a cognitive sentient purposive and emotional being. ${ }^{1}$

2. Nature, as thus considered, has obviously an intimate connection with Mind or Self. I use the inseparable term connection as the most non-committal term that

1 This view of Nature seems to me to prescribe the true line to be taken in the recent discussion (see Ar. Proc. for 1909) whether such objects as sensations are psychical or physical. All objects of mind, the answer will be, are psychical. But some are physical as well ; i.e., some enter into a determinate context of reactions, which forms a special part of the psychical world, which we call the physical world and contrast with the psychical. But this is an abstraction, for the physical world can never, in the last resort, put off its psychical character. A tree is beautiful, and green, and tall. All these qualities are, as presentations, necessarily psychical; but the tallness at least, as a character of a thing in space, is certainly physical. And this is probably the true line of demarcation. They are all, as we said, psychical ab initio as presentations. But qua determined by a construction of objects in space they all (including "physical" beauty) become physical also. Then they are relatively opposable to the psychical. But not more than relatively. For, taking as the test of psychical nature the being destroyed if the percipient mind were destroyed, it is plain that in a degree, though only in a degree, presentations remain psychical not only as pure presentations, but even as qualities of spatial objects. The subjective mind, which has perceived and which conceives them, being destroyed, their existence would certainly be pro tanto diminished, though not necessarily annihilated. A physical object must at least be capable of becoming psychical at any moment. If not, it so far has not full existence. 
I can think of. For what nature has to do with mind or self is just the question we are to discuss.

In any case it is undeniable that Nature is in some sense plastic and responsive to finite subjective mind, and, so far may be set down as in some sense "expressive" of mind, or as its embodiment, or as a crystallisation or hieroglyph of it. But this familiar and obvious conception hides within it two quite antagonistic lines of thought, the one starting from i the idea that mind and nature are akin, the other ii from the idea that they are complementary, and prima facie in a kind of opposition.

Starting from kinship we arrive at Monadism or Panpsychism.

i. If our impression of the unity of Nature and Mind leads us to start from the idea of kinship or resemblance, we shall be led to travel the road, so fashionable to-day, which ends in the conception of the Universe as a society of spirits, in which the constituent parts of Nature are members, in grades and divisions unknown to us, but intelligible by analogy. The external world would thus be the body, and its behaviour the language and conduct, of actual spiritual beings, not ourselves. ${ }^{1}$ And whether we preferred the phraseology of will or of meaning, there would be literal and immediate truth in saying that nature possessed a purpose and a significance, akin to our own, and communicable to us according to our measure of sympathy and insight, while barred against us in the main by difference perhaps of modes of utterance, perhaps of the span of consciousness. We should, in short, have accepted the general attitude of Pan-psychism.

1 This so far is a view to which I understand Mr. Bradley to be favourable (Appearance, pp. $27 \mathrm{I}$ and 275). But when it is driven to the extreme of Pan-psychism, I gather that he does not follow, Mind, li. p. 327 note. 
Now it should be noted that if this attitude is carried through, all externality is dissolved away, i.e., all outward appearance becomes resolvable $a d$ infinitum into spirits. For if not, if it is admitted that there is and must be externality as a counterpart of spirit, then there is no reason in principle for denying that parts of Nature in which subjective mind seems a superfluous hypothesis, are just externality or the counterpart of subjective mind elsewhere. If Pan-psychism is necessary, the resolution into spirit must be universal.

I confess that it is a doctrine which has always appeared to me to reveal the poverty of philosophical imagination. It treats the striking and thoroughgoing opposition and inseparability of mind and externality as if it had no more significance than a mere congeries of centres of experience belonging to different classes and degrees. It transforms the complementariness of mind and nature, on which as it would seem, their inseparability depends, by an analysis of one into the other such as wholly to destroy the speciality of function for which the one is needed by the other. ${ }^{1}$ Why insist on reducing to a homogeneous type the contributions of all elements to the whole? What becomes of the material incidents of life-of our food, our clothes, our country, our own bodies? Is it not obvious that our relation to these things is essential to finite being, and that if they are in addition subjective psychical centres their subjective psychical quality is one which so far as realised would destroy their function and character for us ?

The work for which finite mind is necessary and

$$
1 \text { Cf. Mind, l.c. }
$$


valuable may surely be summed up as guidance, including will, and appreciation, including emotion. Below the limits of adjustable conduct and behaviour, in the lower organic world, as in most of the actual working of human and animal bodies, there is no need, as I have pointed out, ${ }^{1}$ of finite mind for will or guidance. The mind which, if any, we presume to be present in a newt or an orchid, must be such as can have no relation in the way of guidance to the processes of organic "restitution" or the contrivance of fertilisation. The highest human intellect could hardly contrive such devices, and there is in them no trace of the peculiarities which attend guidance by consciousness. It would be contrary to all our convictions to presuppose subjective mind to be present in a degree obviously irrelevant to any functions which it does, or apparently could, in such cases perform. Some shrinking from the hostile and attraction to the favourable there may be in the higher of the two cases mentioned, in the lower not even that can well be supposed. A marvellous work of guidance is carried on, but not by finite subjective mind. This relation must be acknowledged and finally accepted.

It is more difficult to limit the value of mind for appreciation. Why should not a plant enjoy its own being, or a mountain or the sea feel its own power and persistence? Of course we are here in a region with but little to sustain conjecture, but it seems worth observing that appreciation is of less interest as its object loses distinctiveness, and that, according to all presumptions of analogy as well as definite evidence, the capacity of consciousness for

1 Lecture IV. above, and its Appendix II. 
distinctive apprehension must diminish as we go down the organic scale. We involuntarily ascribe to the higher animals some appreciation, analogous to ours, of their own grace and splendour. But even here we probably overstate. It is impossible to suppose that their own appearance is known to them, and that their apparent pride and pleasure in existence has any support beyond their immediate feeling of life and vigour. In love and loyalty to offspring and to their group their minds show the highest appreciative quality which we can discern in them, but this value or function of consciousness again, we should suppose, must disappear where there cease to be distinctive family relations, attended by a more or less constancy in a special behaviour towards certain units of the group.

Thus even in the higher animal world, still more in that of the lower organisms, the function of appreciation can hardly be supposed to exist as a raison d'être of subjective mind. It is, on the other hand, emphatically present in the onlooker, the higher among finite spiritual beings, which, in a word, appreciate and understand the lower organic world very far better than that world can be supposed to appreciate and understand itself. Such an argument applies to the inorganic world very much more strongly. Suppose a mountain or a lake to have a dim subjectivity of its own, this consciousness can neither guide itself, nor again appreciate itself as the poet and artist can appreciate it. Whether or no it possesses a subjectivity, its subjectivity does nothing in the finite world. Its function is that of an object to the subjectivity of another, an externality correlative to finite mind, not 
that of a being which is itself a subject or finite mind.

Thus Pan-psychism seems to me a gratuitous hypothesis, depending on a hasty resolution of the responsiveness of Nature to mind by help of the idea of resemblance, and wholly failing to recognise the complementary functions of subjective mind on the one hand and externality on the other as together essential to any complete form of conscious experience.

Starting from

"otherness" we arrive at "source of content."

ii. Suppose that now we start from the opposite point of view. Let us conceive of externality, of a world having systematic determinations in space and time, whatever the secondary and tertiary qualities (e.g., aesthetic qualities) with which as fully experienced it may be endowed, as something complementary to subjective mind, something apart from which mind would not be itself, would not be a self, would not be anything. In this case it would still, in a sense, be true that nature is plastic, is responsive to finite subjective mind, but its external world would not, in principle, be held to be resolvable into elements which are themselves severally subjective centres. It would have a distinctive place and function as externality, in the finite world and in the universe, and that place and function would amount to nothing less than to be the source and storehouse of all positive properties, contents, and distinctions. We should still be able, if we liked, to say that it is a symbol of mind, the expression of will, or of intelligence (which of these we say really makes no difference if we understand what we are talking about, for either is inseparable from what is expressed, and neither is a complete or felicitous description of it), 
and is the very content of our consciousness embodied in a form in which we learn to recognise it.

But all this is a little unfair to the part really played by Nature.

No doubt it does reveal a content which is the content of mind, but that does not mean that mind has abinitio the content in itself, and superfluously, de haut en bas, comes to recognise it in nature. The content of mind is the content of Nature because Nature is the instrument or element of the Absolute by which the mind's own "nature" is communicated to it. On the other hand, the content of Nature is the content of mind, because it is only in the sphere of mind that Nature reveals, to begin with, anything at all, and a fortiori, that she reveals the possibilities of life and spirituality that are shut up within her. As we saw, it is all but impossible to distinguish Nature from mind. To separate them is impossible. If you ask, what in Nature is not mind, you can only answer, the fragmentary or disconnected qua fragmentary or disconnected. If you ask what in mind is not Nature, you can only answer, the spirit of totality, the attitude which makes everything alive in its bearing on the whole. Thus we are careful not to libel Nature by saying that she has no meaning, no will (if we prefer the phrase) of her own, but simply borrows from ours. That would, in our view, be false and perverse. On the contrary, we have them to give her only because we take them, nay, we are and exist by taking them, from her. Mind has nothing of its own but the active form of totality; everything positive it draws from Nature.

The parallel in this respect between mind and 
life is striking, and appears to me to be insufficiently observed. All those discussions which lay weight on the self-sufficingness of life and mind respectively as guides, initiators, contrivers among the forces and data of the environment, ignore the true parallelism and the relation to which it points.

There is no credit or merit due to life or mind, as compared with the natural environment, on the ground of furnishing definite and special lines of variation, peculiar contrivances, adaptations, principles belonging to them and not to nature as contrasted with them. Everything points to the general conclusion that life and mind respectively are the appearance at different stages of an omnipotential ${ }^{1}$ principle, which elicits its whole definite content and development from its surroundings. In the case of life the general term for this evocation of form from the environment, whatever its detailed methods, is natural selection, ${ }^{2}$ and the same term will serve, in a somewhat wider sense, for the evocation of finite mind. ${ }^{3}$ In both cases the strength of the principle lies in what might be called its emptiness. It brings with it no content which could resist or oppose the organisation of all contents. And when we are told of the contrast of life with the supposed mechanical order of inorganic nature, we have to remember that within the realm of life itself, and above its first appearance in some speck of protoplasm, there is a huge world of development whose reactions are no less determinate, no less identical under identical conditions,

1 The term is coined on the analogy of Driesch's "equi-potential systems."

${ }^{2}$ See Lecture IV. above.

3 See second series. 
than those of the mechanical world proper. ${ }^{1}$ So that within the realm of life itself there is just the same essential contrast, though beginning at a higher level, as there is between process commonly held to be mechanical and the world of life as a whole-the contrast between the uniformity of the responses to stimuli, and the adaptation and qualitative variety of the new developments. Thus the latter are not due to miraculous guidance and contrivance on the part of life or mind per se within a homogeneous environment, any more than the earliest beginnings of organic life display powers of initiative and self-adaptation apart from relevant stimuli and occasions in the inorganic world. The real miracle lies in the significance hidden in Nature as a whole, and a counterpart miracle, if we like, in the omni-potentiality of life and mind, which, as the active forms of totality, are able, starting from a minimum of organisation or of subjective being, at apparently random points within the external world, to elicit into organisms, selves, and civilisations, in short, into a second nature, whatever is latent in the first.

External nature, then, in the view here suggested, is not a masked and enfeebled section of the subject-world, but is that from which all finite subjects draw their determinate being and content, as the active form of totality is revealed in partial centres, according to some unknown law by which

1 This is true of all the elementary phenomena of life, such as morphogenesis and restitution. I do not mean to suggest that there are in the universe any reactions which are not identical under identical conditions. I only mean that in the lower organic world such reactions are as normal and as verifiable experimentally as in the physico-chemical world. 
nature, under certain conditions only, becomes the vehicle of life and of subjective mind. Independent being we cannot ascribe to it, nor could we do so, in respect of its character as we are aware of it, even supposing it an appearance of minds analogous to our own. For, so far as the outside is concerned, all the arguments for the impossibility of independence in primary, secondary, and tertiary properties would retain their force. And nothing but the outside has any portion in our world or any contact with us. We want it for the supply of content to our minds; it is idle and superfluous to give it a mind of its own. Our minds are its own mind.

Only, it must be repeated, this is not to deprive it of a being of its own, or to make it merely ancillary to the ends of humanity. ${ }^{1}$ Our view is not that we bring with us ends which Nature is bound to subserve; it is that Nature teaches us what are the ends of the universe (so far as in our given phase and rank we are able to appreciate them) and we are able to learn. It is a vice to make humanity the end ${ }^{2}$ unless all we mean by such phrases is that humanity has power to make its own the ends which the universe through Nature teaches it to appreciate.

3. The system of the universe, it was said in an

1 Note Münsterberg's just protest against this procedure, Eternal Values, p. 276. Contrast Man's Place in the Cosmos, vi. 61.

2 Cf. Laurence Binyon, Painting in the Far East, p. 24: "The high Renaissance pride and glow are apt to leave this bitter taste in the end. Absorption in man as the centre of the world and the hero of existence leads certainly to loss of that sanity and sweetness which an openness to the abiding presence of the non-human living world around us infuses into life. It is not by that absorption that we shall find the full meaning or animating power of our Western faith that in man the divinity is revealed." Cf. above, pp. 25-6. 
earlier lecture, might be described as a representa- Finite tive system. Nature, or externality, lives in the minds the life of conscious beings. This characteristic is $\frac{\text { copula of }}{\text { Natureand }}$ essential and not incidental. We call Nature a the Absystem in space and time; but if, per impossibile, it everyday were purely in space and time, then it could be experience. neither in the one nor in the other. Or, to put the point more simply and truly, space and time themselves are hybrid forms of being. They are externality and succession, presupposing a degree of unity which would annihilate them if it either were completed or were reduced to zero. Nature thus exists only through finite mind. But finite minds again exist only through nature. All finite minds focus and draw their detail from some particular sphere of external nature. They in some degree express, and interpret the significance of external conditions for a focus of mind arising in and constituting a certain concentration of them. Why it is so, in an ultimate sense, we can no more tell, than why the universe is what it is. But we can see that by such an arrangement the value of all that the universe contains may be elicited (supposing all to pass through finite minds) in its strength and purity' on the one hand, and on the other brought into a form which lends itself to a yet fuller unity. Every instinct of what we call the lower creation, every feeling of joy, of energy, of love, even throughout the animal world, is the outcome of some set of external conditions as focussed in life and mind, and is fitted to pass as their crown and climax into that complete experience which is the life of the whole.

It is difficult if we start from such a point of 
view, which nevertheless is almost a datum of fact, to understand the perplexity and hostility aroused by the conception of the Absolute. The truth seems to be that we have formed to ourselves a quite unreally hypostasised notion of the consciousness of finite minds, whether of the animal or of the human type. We seem unable to shake off the superstition which regards them as substances, crystal nuclei, fallen or celestial angels, or both at once. And if we deny these characteristics to the animal mind we probably for that reason get a truer notion of mind from it than from our traditional ideas of the human soul.

The whole ground of discussion would be changed if we realised how every focus of consciousness is an effort, whose success is subject to constant and enormous fluctuations, to seize and make its own the value and significance of a world ${ }^{1}$ beginning from some simple minimum of experience, but capable of extending far beyond, and appreciated only by fits and starts. So far from its being a strange or unwarranted assumption that the experiences of conscious units are transmuted, reinforced, and rearranged, by entrance into a fuller and more extended experience, the thing is plainly fact, which, if we were not blinded by traditional superstition, we should recognise in our daily selves as a matter of course. ${ }^{2}$ We, our subjective selves, are in truth much more to be compared to a rising and falling tide, which is continually covering wider areas as it

1 The idea, traceable, e.g., in James, that thinkers of Green's type take the finite to be merely the object of the Absolute knowledge and not a constituent of the Absolute energy has no foundation. Cf. James' Pluralistic Universe, p. 36 .

2 Cf. Lecture I. p. 27. 
deepens, and dropping back to narrower and shallower ones as it ebbs, than to the isolated pillars with their fixed circumferences, as which we have been taught to think of ourselves.

If we start from such a point of view, for which there is ample suggestion in Plato, ${ }^{1}$ the controversy about Monism assumes a new appearance. Pluralism, which indicates, so to speak, a vertical and not a horizontal division, into pillars and not into strata, falls away as relatively unimportant and superseded, though not wholly false. Multiplicism, the variety of levels of experience, each possessing its peculiar range and area, becomes the obvious truth. Dualism loses its prominence as the one antithesis of Monism, and the question of Monism and the Absolute becomes simply the question how far we are able to maintain a unity within multiplicism while following it out into its higher, which are also necessarily its deeper, ranges. The general formula of the Absolute, I repeat, the transmutation and rearrangement of particular experiences, and also of the contents of particular finite minds, by inclusion in a completer whole of experience, is a matter of everyday verification. The elements of our experience are transmuted by every change of work and of scene, and, in co-operation of several minds, the constituent elements of them all are modified into members of the new and common mind which arises. ${ }^{2}$ It may be objected that this

1 There is no reason for giving a pre-eminent place to "Dualism" in Plato's account of the levels of experience. We might just as well speak of his quadruplism or triplicism, or even multiplicism.

2 For the facts on this head as recognised by modern Genossenschaftsrecht, so far as a corporate will is concerned, see Maitland's Introduction to his translation of Gierke's Political Theories of the Middle Ages. 
latter is a mere abstraction, depending on some one or two common objects with which the several minds come in contact. But in principle this is not so, though the unity may be of any degree of depth or shallowness, and the utterance is much restricted as compared with the felt unity. The tendency of minds is always in forming a working whole to supplement and widen and reinforce each other on various sides and in innumerable details. In the inclusive spirit that is the result every mind contributes to the others something of its own mind and content, so that in proportion as they are thus deepened and widened together, the detail of the minimum consciousness of each, fears pains and perplexities, assumes quite a different value and colouring from that which they possess in the minimum of normal existence. ${ }^{1}$ Our mere varieties of mood during the day produce an effect on us which is obviously analogous to this, owing to the different contents by which we are affected, and we experience every day and all day long the same kind of fluctuation in the value and relative significance of the details of existence. ${ }^{2}$

This then, so far from being an idealistic chimera, is the common law and fact of experience, as verified both every day within what we uncritically take as our single private consciousness, so far as its

1 See, e.g., Trevelyan's account of the Thousand under Garibaldi. But the fact is not merely exceptional. All of us draw courage from our soldiers, industry from our workers, and so on. That is the true meaning of Plato's virtues of the Commonwealth.

2 When James lays it down (Pluralistic Universe, p. 38 ) that "we must always experience the Absolute as if it were a foreign being," I feel on this point I have no common experience with him. See Lecture I. l.c. 
weakness may permit, ${ }^{1}$ and on the larger scale when we compare together such creations as the State, and fine art, and religion, and when we note the mode of our private participation in them. ${ }^{2}$ There is no magic in any precise enumeration of the levels of experience, such as Plato has thrown out on different occasions. You may take, as he has taken, for purposes of illustration, two main levels, or three, or four, or a great number. The point is not in the number chosen, but in the character of the transmutations; and in the fact that they are not merely intellectual, but moral, aesthetic, and religious; that they form, in fact, on the one hand, different worlds with different degrees of reality, though on the other hand they are nothing but one and the same world, more and less fully experienced. ${ }^{3}$

1 I mean that while every mind unquestionably shows a rise and fall of this nature, it is not every mind that reveals plainly the higher phases of experience. But as we shall see, something of these probably comes to all.

2 The question of the nature of participation is no harder in principle, that I can see, in the case of the Absolute than in the case of poetry. The fact is, our conscious life, being a universal, is essentially a participation; though ever varying, as we have said, in degree.

3 I am sure that where we tend to go wrong in interpreting Plato, is by failing to combine the two principles on both of which his heart was set. Those who insist on the transcendent nature of the Forms are so far in the right, that it was Plato's main passion and the nisus of his inspiration to portray the gulf between the worlds in which different minds may actually live and move. At the same time, the whole significance of this contention is lost if it is not held together with the truth maintained by those who deny the transcendence, viz., that the world is above all things single, and the difference of worlds is wholly relative to degrees of impotence. In the passage about "faculties" and their objects, at the end of Rep. v., he is insisting on these two truths in language so forcible that we think he cannot mean what he says. "We do really," he seems to be saying, "live in different worlds according to the differing energy of our minds ; but again, it is only according to the differing energy of our minds that we do live in different worlds." 
The real point is in the transmuting or expanding power of common finite mind.

4. When these facts are given their due weight, all difficulties in the conception of the Absolute are in principle removed. The positive proof in its favour rests logically on the principle of non-contradiction, in respect of its positive bearing as explained in an earlier lecture. ${ }^{1}$ When the nature of the normal process by which a contradiction is removed has once been appreciated and observed to be valid not merely in abstract cognition, but throughout all the regions of our experience, no difficulty of principle remains in affirming a complete unification in which all contradictions are destroyed, though diversity or a negative aspect of course remain. From finding our way among mountains to moulding our daily business with a self-consistent purpose or solving an economic problem, or discerning the reality of beauty through the appearance of ugliness, or the lovable through the apparent failings of character, we find from day to day how contradictory aspects blend into harmony as linking and distinguishing contents come into view.

But, it will be asked, do we not find the opposite? Does not greater knowledge bring greater suffering and the highest effort encounter the most insuperable obstacles? And the answer seems to be, that this is not so in any sense that could invalidate the principle on which we are proceeding. Every finite being has some limits: that does not surprise us, when once we understand what finiteness is. And its properties are ill-balanced; that again does not surprise us. It is not a perfect microcosm or miniature of the universe; so that its knowledge, love, and happiness do not keep step together. That is 
natural for beings which are fragments of a greater being. But all this granted, still, so far as the finite being lives a life at all, it affirms in its whole existence the principle of the Absolute. It transmutes toil into happiness by seeing it as a pledge of devotion, and pain into love by the depth of the tenderness it evokes, and hardship into courage by its revelation of what a man is able to be. That it fails in degree, and in degrees which are not concomitant, is nothing at all against such an analysis of its nature if we have once accepted finiteness. We are not here preaching optimism or " justifying the ways of God." We are doing something much more humble and critical. We are pointing out that transmutation of experience, in accordance with the law of non-contradiction in its positive bearing, is the principle of daily life. And if this is admitted here, there can be no reason for making it a fundamental difficulty when we come to deal with ultimate reality. There is no hiatus in the transition.

It is likely to be said that these appeals to daily fact and commonplace life add nothing to knowledge. But what is to be done? The facts no doubt are familiar; they are indeed commonplaces of literature and practice. But their significance, to my amazement, seems never to be noted, and therefore it is essential to dwell on it. It seems well within the mark to say that a careful analysis of a single day's life of any fairly typical human being would establish triumphantly all that is needed in principle for the affirmation of the Absolute. For this is merely something more of what we are continually experiencing, and the hard and fast limits of range 
and quality often attributed to our self or personality are not to be found anywhere in the real world.

When we come to the great achievements of knowledge, of social and super-social morality, of the sense of beauty, and of religion, the argument that the limits of our normal self cannot be applied as limitations to our ultimate self becomes irresistible. But as, in this sphere, the principal transformations of the minimum self are already victoriously initiated, and in some degree set apart, the evidence of such transformations as normal facts of conscious living is actually less striking than in the course of a common day when we are continually aware of their taking place. If I instance Plato or Shakespeare, the answer comes readily, "But you are not Plato or Shakespeare, far from it." The expansive power of the common mind is really the crux.

The Absolute the high-water mark of a familiar fluctuation. An audacious illustration.

5. Regarded from such a point of view the Absolute is simply the high-water mark of fluctuations in experience, of which, in general, we are daily and normally aware. ${ }^{1}$ The evanescence of the limits of personality, or rather, their absorption in an experience which is deeper as well as wider than our minimum self, as in the supersocial

1 What is meant by the frequently reiterated criticism that the Absolute is non-human, is, as it were, divorced from human life, I am wholly unable to understand. Cf. James, cit. supra. If nothing more is meant than that it is not present in its full nature within any finite experience, this is nothing but a truism regarding any and every feature of the objective world in the commonest sense of the term-the sun, history, love, or poetry. But if it is meant to deny that our experience is more human and valuable, as well as more solid and more verifiable, in proportion as we approach the Absolute, the denial is utterly futile and foolish. We experience nothing perfectly, but we experience the Absolute better than we experience anything else, because it is greater and because everything else we only experience among other things, the Absolute we experience in everything. Cf. Lecture I. 
activities $;^{1}$ and also the transmutation of externality and obstruction into instruments and factors of more complete living, are in their general type familiar facts of every day. The technical point lies in paying due attention, with Plato, to the levels of experience, as determined by the logical criterion, and not allowing ourselves to be obsessed by consideration of its divisions into partially exclusive centres. $^{2}$ Of course, and fortunately, finite excellence is much broken up and subject to division of labour. It is not as if some persons were at the highest level in everything, and the rest nowhere. ${ }^{3}$ If we adequately noted the meaning of the "philosophic" spirit in Plato, we should see that he leaves plenty of room in the highest place for the Treasure of the Humble. ${ }^{4}$ It is his purely diagrammatic representation of the ultimate coherence of all excellences, which is true in principle, that suggests the reverse to superficial readers.

Let us have the audacity to select an actual work of man as a remote analogue of the Absolute, simply

1 Cf. Philosophical Theory of the State, 2nd ed., Introduction. I have there pointed out that such supersocial activities as Art and Religion are at once the quintessence of social life, and beyond its machinery of explicit group-relations. See further Appendix II. below.

2 We shall return to this subject in the second series.

3 What those who call the Absolute non-human (and a fortiori I suppose non-animal) make of the dog that dies for its master, or the sparrow for her young, not to speak of the love of mothers, and the devotion of comrades among the poor, I cannot imagine. It is no answer to say that these are not the whole Absolute in its full transcendent nature. They are transcendent, in the only true sense, and it is in and through them, with other elements, that we faintly learn what experiencing it means.

4 The title of Maeterlinck's well-known work. See on this whole point R. L. Nettleship, Remains, vol. i. p. 385 : "In the heart and on the lips of Plato the love of wisdom is itself that divine foolishness, that strength in weakness, before which the cunning of the world and the pageantry of power fade and are discomfited." 
in order to explain the general structure which we attribute to it in respect of nature and of finite selves.

Let us think of the mind of Dante as uttered in the Divine Comedy, in relation, on the one hand, to the spatial universe; and more particularly to Italy, and also, on the other hand, to the characters, the selves, represented in his poem.

In the first place, externality, the country of Italy, and in a lesser degree the universe, ${ }^{1}$ as an extension in space and time, is there in the experience. . It is not destroyed or abstracted from, but yet appears throughout as something more than extension in space and time-as expression, character, emotion, of a kind, however, in which real externality is involved. It is needless to labour the point. Dante is, under reservation for his peculiar place in history, the voice of Italy, as Shakespeare is of England. Each of them is his country "come alive." In such a passage as "I ruscelletti," " we see how, by the alchemy of genius, external Nature, while still external, has passed into a concrete emotion.

In the next place, the selves who figure in the poem have all rendered up their content to the great experience which was the poet's mind, and are constituent parts of it; while none the less it is necessary for its effectiveness as a poem, that they should be regarded as acting and thinking beings

1 Dante's misconception of the universe from the scientific point of view, partly, I suppose, wilful and allegorical, is irrelevant here. So is the element of pessimism in his theology. The question is merely of the development of fact in his imagination.

2 Inferno, xxx. 64. The observation might be extended to the whole structure of the universe, as Dante has framed it in his imagination. 
for themselves and in the outer world. For purposes of the analogy, it does not matter greatly whether a poem is purely imaginative, or, like Dante's, semi-historical. Always it presumes and presents the selves as real agents in the historical or external field, though it also makes them part of a vision of reality more profound and complete than they themselves, or the onlooker at prosaic or at poetic history, are supposed to recognise. But it is to be emphasised that the selves, however on the one side to be taken as historically or externally actual, yet are not pure separate objects, disconnected from the mind which is the poem, merely mirrored by it, and existing outside and for themselves only. On the contrary, all of these selves are in their degree participants in the moods, volitions, and perceptions which, taken as a whole of experience, are the substance and tissue of the poet's mind in the poem - the conflicting passions of Italy, of the Empire and the Papacy, in a word, of human nature within a certain historical region. In accordance with the view maintained above, ${ }^{1}$ all the minds are contemplated as actually extending in various degrees beyond their minimum point of historical attachment $;^{2}$ and in the levels and ranges of being which they achieve embody all varieties up to the range and level of the poem itself. In Vergil and Beatrice the level of the poem-of the poet's imaginative vision-is even supposed to be transcended, and here, therefore the analogy to the Absolute must fail. But it is good as suggesting the nature of finite participation in reality, through the

1 Lecture III. p. I I 5.

2 This point will be more fully considered in the second series. 
varying grasp and fluctuating power of the selves which constitute it. In principle, we see, the Absolute is only the totality of a hold on reality which permeates in its degree all the conscious creatures of the creation, and uses all its externality.

Finite selves, then, reveal themselves as the copula, ${ }^{1}$ the living tension, by which the full experience affirms itself in and through externality just as through certain selves Dante's mind laid hold of Italy and the world. Every self, as we have seen, is the representative centre of an external world; some nature "comes alive" in it. Every self partakes in some degree of selves and experiences beyond its own centre or minimum, and so expands from its place in nature to a more or less wide and deep participation in the Absolute; within which expansion, as by all inclusion of content, some degree of transmutation is effected in the matter of the selves and experiences which it partially includes.

The Absolute, finally, as remotely suggested by the whole experience which is the living form and substance of the poem-the poem as a thought and mood in its fullest completeness ${ }^{2}$ - is a perfect union of mind and nature, absorbing the world of Nature by and through the world of selves. Every self is a copula, a meeting point of tension and fulfilment, a self-maintenance of the one life through a portion of the external, and of the external as centred in a case of the one life. But, as it is distantly figured in the poem, the complete experience brings to-

1 Cf. Hegel, Wiss. d. Logik, iii. 72.

2 A poem exists in many degrees; cf. A. C. Bradley, Oxford Lectures, p: 28. 
gether all the selves, with nothing omitted, ${ }^{1}$ but transformed and expanded by the place they hold and the illumination they receive in it. Such incidents as those of Paolo and Francesca, of Ugolino, or of Ulysses, are worth many pages of theory, when we come to ask ourselves how there can be meaning in speaking of an actual historical self as transformed and expanded in the reality.

Such phrases as transformed, transmuted, expanded, indeed, though convenient for our procedure, which naturally makes its start from the common facts of our lives, are in one way false and misleading. The true normal, of course, is the real; and it is the self as we know him in Space and Time-whether our own self or that of others-who is a figure deformed and diminished, as we see him, by our impotence to attain the grasp which holds all being in one, and by the individual being narrowed down for us into an appearance, ${ }^{2}$ incomplete and successive, in actual history. As we saw above, ${ }^{3}$ this naturally happens to every aspect of a supreme whole, and must happen to it if a system of finite centres is to be the rule of the universe. Nature must drop down almost ${ }^{4}$ into space and time, selves must drop down into consciousnesses only partly transcending their spatio-

1 Obviously this is a characteristic which cannot be reproduced in a finite example. But it is well to remember that if Shakespeare were to portray one of us, he would tell us a great deal more of ourselves than we, or common history, were aware of.

2 This is quite recognised by common sense in such matters as, e.g., the attempt to pass final moral judgments. Mr. McTaggart has somewhere a fine speculation that the love which clings to the "worthless" has divined a truth beyond our knowledge, and I do not doubt that this idea, which common feeling strongly supports, is sound.

3 Lecture VII. 3.

4 For the reason why one must say "almost," see above, p. 37 I. 
temporal limits; the concrete vision of mind must drop down into a degree of relative separation as Nature and as subjects. But it is all-important for us to note, as we insisted in the passage referred to, that the dissociation of the Absolute (to employ this expression in our own sense), which is met with in daily life, never at all approaches completeness. There is no fusion or union which we can conceive ourselves bound to ascribe to the Absolute in its own form, which has not something to represent it in the world of time and space. Take the case of these abstractions themselves, which we hypostasise really owing to the mere custom of current talk, where their names have such glib currency. We remember that no mere time and space, and no being merely in time or space, are or can be present in our own experience. ${ }^{1}$

This stubborn dissociation of the Absolute, however, the rule and essence of finite life, is an obstacle to the effectiveness of our illustration which only a vigorous sympathy with its intention can even in part overcome. But it is something to recognise where precisely the difficulty lies. In actual existence Dante's poem was a great imaginative creation in a single human mind. ${ }^{2}$ The nature and history with which it dealt were separate and independent facts, outside it, as we should say, and merely more or less reflected in it. But all we can use in our comparison is not the actual independent historical or natural fact, but only the reflection or interpretation of this fact within the imaginative product of

1 See above, p. 37 I.

2 For our purpose we may disregard its reproduction in other minds. 
Dante's mind. And so, of course, we are liable to convey the impression that we are content to represent reality-rocks and streams, men and citiesas the figures of somebody's dream.

But this is to ignore our point. Our meaning depends on placing ourselves within the world of Dante's imagination, and taking its nature and its figures (whether in fact "historical" or purely poetical), as his imagination necessarily took them, for the actual scenery and inhabitants of that "actual" world. And what we are to learn from this effort is, we suggest, something of the true relation between an actual Nature and personalities, as we habitually regard them, on the one hand-for Dante's imagination clearly brings beings like these before itself and us-and the spiritual interpretation which exhibits all these facts, on the other hand, as, without detriment to their actuality ${ }^{1}$ elements in a "vast unitary vision and experience constituting a single spiritual world. It is not merely what we have in Wordsworth, or any spiritual interpretation of life. For we here have actual persons shown as moving freely, and obviously themselves and selfdetermined, while no less obviously, though merely through a deeper insight into their selves, exhibited as elements within an embracing spiritual universe, the universe as present to Dante's imagination. And this spiritual world we feel on the whole-with immense reservations - not to be an arbitrary and artificial comment on the imagined factual history as lying outside it, but to be of the nature of a revelation of the true appearance which such a history might yield under intense illumination,

1 The imagined actuality of the imaginative world. 
without detriment to its factual objectivity for the common eye.

In the ultimate reality-known to us as our everyday world-which we were thus attempting to illustrate, we are confronted, as I said, with a far more stubborn dissociation. Here the element corresponding to the unitary experience embodied in Dante's poem is prima facie wanting. What confronts us in everyday life is a huge obstinate plurality of independent facts. So we are told. In a large measure, as I said at starting, I deny the statement. But let us take it at its worst. In face of this obstinate dissociation, what I have attempted to effect, and what is summarised in the final illustration, is to show, both by systematic logic, and by the interrogation of our higher obvious experience, that our life, within the region of genuine fact, contains uncounted degrees of power and insight, by which, without in any way denying that things are what they are, we can attain to some beginning and can frame some positive conception of what more ${ }^{1}$ they must be, and how if we take them as such a "more," they are at once more themselves, and plainly indicate their dissociation to be a character of partial reality, and their full nature to lie in the universe of a single experience.

This concludes our general theory of the selfinterpretation of the real through the fundamental principle of individuality. Another year, we shall, I hope, be able to pursue in detail the ideas which it leads us to entertain of man's worth and destiny.

1 See author's Logic, 2nd ed, ii. 30 I on the fallacy of withdrawal or abstraction in the search for reality. 


\section{APPENDIX I TO LECTURE $X$}

I SUBJOIN in an Appendix a discussion of some recent and special metaphysical doctrines of the Absolute. In the following book I shall attempt to work out its relation to the individual as it affects our conception of his fortunes and destiny.

I. The eternal character of the Absolute, its inclusion An allof all succession in a non-temporal whole, has lately been affirmed to be explicable by the doctrine of the span of consciousness and the specious present. ${ }^{1}$

Our present is undoubtedly perceived as a solid-a duration-and not as a vanishing point between past and future. Postulate-so I understand the argument-the same character for an all-inclusive experience, and you may regard it as seeing the whole series of events at a blow, just as we may hear a sentence or a musical phrase as a single thing. This is all the secret of eternity, it is suggested, and there is nothing more. The succession of events is before the Divine Mind $^{2}$ as the notes of a single musical phrase may be before our mind; in one sense, all at once, in another sense, as a succession. Its span of consciousness can embrace an infinite succession as a unity.

I will go at once to the fundamental difficulty of principle which I feel in this hypothesis. Among the occurrences which are present as at once to a consciousness with a protracted time-span, the later must either modify the earlier, or not. If they do ${ }^{3}$ it is impossible that the string of events can remain, in actual content, within a longer span of consciousness, what they were, or could be, within a shorter. A man passes, say, four hours

1 Royce, World and Individual, ii. $145 \mathrm{ff}$.

2 I do not gather that any difference between God and the Absolute is treated as relevant here.

3 This seems to me the fact in any portion of succession apprehended as a whole. 
in misery because he fancies that a friend has taken offence at some act of his. At the end of the four hours he becomes aware that he was mistaken, and his distress is dispelled. If the later contents act on the earlier within the same specious present of the longer span. of consciousness, in the same way as they do within the shorter specious present of an ordinary consciousness, the four hours' interval of distress must for such a consciousness cease to exist as such. It cannot help being transformed, and turned, on the whole, to a feeling partaking of gladness. Granting that the supposed omnipresent mind is merely a spectator, still a spectator for whom the end is within one and the same specious present as the beginning cannot regard that beginning as one does who has it without the end. I am far from denying, howeverI am, indeed, anxious to assert - that in the larger reality thus envisaged the sorrow must survive, and, blending with the subsequent joy, give rise to a content different from either. Still, there must be a transformation. ${ }^{1}$ If again within the one specious present the later occurrences do not modify the earlier, if that is to say, as in a common temporal succession, the earlier are not influenced till the later have occurred, then we have no transmutation, but only a fixed panorama of exactly the same occurrences which form a diorama for the man who goes through them. This gives a mere aggregate or congeries. Omniscience is then to see in any lapse of successive events nothing more than a finite being would see so far as he followed that identical lapse. ${ }^{2}$ Surely this will not do. Though nothing is omitted in the perfect mind, everything must be transformed; and the

1 Such a fusion may be read backwards, i.e. taking the complete unity as starting point according to the conception of the dissociation of the Absolute; and thus we should obtain a lifelike idea of the way in which want and fulfilment are dragged apart by appearance in the finite realm.

2 The point is illustrated by Kant's idea that God would see in a unity what for us is the unending moral progression. How as a unity ? The idea is meaningless unless it involves a transformation in kind. 
bare events as we (by superficial abstraction) say that "we" know them, cannot be what take place for the Divine Mind or the Absolute. Applying our former arguments we see that this is inconceivable. For the so-called bare events are not the same for any two human beings, whether agents or observers. How can they possibly be the same for a finite spectator and for the perfect mind? On this showing, a doctor or an expert magistrate, not to speak of a Dante or a Shakespeare, would be far better off than the Absolute experience. For unquestionably to spectators so qualified, occurrences which are dumb and single happenings to the sufferer and to the ordinary looker-on will reveal themselves as steps in a destiny, and as phases of recovery or of decay.

2. A difficult problem, that of loss or forfeiture Perfection through advance towards totality, must just be mentioned here. The complete mind, it will be urged, though it must contain imcannot accept the four hours' misery as final, must be able to appreciate the feeling of the finite mind which for the moment does so.

In this sense it must include the aggregate of incidents it does. as well as their transformation. Every perfection, it would seem, however in principle inclusive, must supersede or thrust out some other appearance or expression, unless, what seems inconceivable and what we have just rejected, there are also reproduced by literal repetition innumerable variations that fall within it. How far, and by what rule, does the truer truth, the more perfect art, the higher religion, the more total and complete reality, supersede and render obsolete and fit to be blotted out the tentative or imperfect or one-sided phase of either? For all of these, though more satisfactory and more complete than their ruder forerunners (taking as a good example the relation of successful to tentative effort) yet are different from them. The picture may in a sense include the sketch; but the sketch has a something that we miss in the picture. Can the divine being, or the Absolute, not apprchend or feel imperfectly, and would such inability be a defect? 
Now how far is this to be pressed? I do not think we escape by saying that though he cannot apprehend imperfectly, he can apprehend my imperfect apprehension. Is every point of view, for instance, from which my eye (and, of course, that of every sentient being) has unthinkingly contemplated every scene it has ever rested on, to be recorded eternally in the tablets of omniscience or at least of omni-experience? Or, putting the question in the difficult form from which we started, can a value, which is held to be superseded by inclusion, as in art or in cognition, ${ }^{1}$ be dropped and pass away without loss to the whole; or if not, must every step and essay and partial failure enter separately and in its own right ${ }^{2}$ into the content of the supreme experience? In principle, the answer can hardly be doubtful. We saw, in the first case under the theory of the extended specious present, what the result must be. There must be inclusion and transmutation. You cannot heap up contents, all relevant to each other, within a single experience, and prevent them from reacting on each other. A hope, and its fulfilment in an unhoped-for form, will not stay apart if the impotence that was the barrier is withdrawn; and in their fusion the whole hope itself must become another thing from what it was,

For the perfect experience, then, the contents and values must be, so to speak, like solids. "Accidental views," imperfect essays, lower forms of beauty and goodness, must be experienced within the totals which must gain depth and weight from all that has led up to them. The quality of the sketch must be found in the picture ; the picture must be differently apprehended because of the sketch which went before it. But occurrences cannot be eternised as a detached and dispersed congeries of facts, as if one were to preserve a Galtonian photograph in the form of all the images which came together to

1 Like the early astronomical theories in comparison with developed modern astronomy.

2 This, of course, is the difficulty. If we allow transmutation and inclusion all becomes easy. 
compose it. In coming to this conclusion, we must be careful not to appeal to the difficulty of supposing the supreme experience to include and retain so many facts. That would be very crude anthropomorphism. Our argument rests on the necessary fusion of experiences relevant to each other. But if we maintain this point of principle we may agree that the dissociation, the realisation of the particular, which gives value to the total, enters largely into the experience of the total.

Transmutation then, must be the rule in the complete experience. Everything must be there, as all the artist's failures, and the fact of failure itself, are there in his success. But they cannot be there as analysed into temporal moments and yet drawn out unchanged into a panorama within a specious present of immeasurable span.

3. It has been urged that the Absolute is will and Absolute purpose. The matter has often been dealt with. ${ }^{1}$ But cannot be I will mention one point following from our earlier argu- purpose ments which seems to me decisive. A purpose, or a will, can never be the whole of a world. A purpose always means that, founding yourself on matter accepted as a these must basis, you recognise a certain alteration as essential in wholes. view of the admitted situation, for the restoration or partial restoration of harmony. Ex nihilo nihil. You cannot gather material for purpose out of no situation. The content you are impelled to produce must be relative to a content which you admit. The same is true of Will, and of Ought. ${ }^{2}$ You cannot say, without basis or preliminary, "I ought to do this." That would indeed be a judgment such as could not be logically supported. It is the defect of all these positions, those which make Purpose, Will, or Ought into ultimate determinants, that they accept a violently unsystematic procedure of valuation after the apparent fashion of Kant's Ethics. "Ought" must always mean the satisfaction of a nature; but you cannot express the satisfaction of a nature ohne weiteres

1 See, e.g., Appearance, p. 483 ff.

2 Cf. Royce, World and Individual, ii. $36 \mathrm{ff}$. 
by saying "ought." You may say, perhaps, ab initio, "I ought to do something"- "I want"- "My nature cries out for a fulfilment" of some kind; though even to do that you must postulate a certain kind of nature in yourself. But certainly what I ought to do must come from an accepted basis of content, a selection of objects to be achieved, suitable to a need or want, itself determined by a contradiction in some existing situation. In a word; every want, will, purpose, or ought, is a partial phenomenon within a totality.

But how, it may be retorted, do you get any basis ${ }^{1}$ except by an ought? Why accept, e.g., the Law of NonContradiction on which we ourselves laid such stress in an earlier Lecture, except by an acknowledgment that you ought to accept it? Now we may construe, if we like, our actual participation in the life of the world as an acknowledgment that we ought to accept something or other. It is an artificial mode of statement; for we have been participants in the world long before a question whether we ought to be so could possibly be raised, and for most people it is never raised at all. But this, it might be answered, is mere history, not justification. When once it is put to us, why accept the principle of positive non-contradiction? Why do we affirm it except that we feel we ought, or will? But the prior answer lies in the nature of our world. It is a world whose implications are of such a type, and within which oneself is so implicated, that even in refusing to accept it, as was explained in an earlier chapter, we already are accepting it. In trying to reject, we are meddling with our world, and owing to its nature, are accepting our implication in it. What we are must determine what we owe.

It is a condition of our willing that we cannot will two contradictories at once; but we cannot find ourselves willing that two contradictories at once shall be unwillable. It would be setting out to make a condition which is presupposed in the making of any condition. That one 
contradictory excludes the other is a basal condition of the world, revealed by the analysis of its structure $;^{1}$ that we accept it in approaching any matter of theory or practice is a consequence of our accepting participation in the world, and this depends upon the datum that our nature is to be a world, and apart from this acceptance, no ought can appeal to us.

Will and Ought, in a word, are the properties of a world that mends discrepancies within itself by a process in time. There can be no will or ought except on the basis of a presupposed reality, within which non-adjustment calls for adjustment. If you so much as acknowledge a fact because you ought, the meaning of that is that you cannot at once reject it and retain the world which you presuppose.

Therefore it seems unintelligible for the Absolute or for any perfect experience to be a will or purpose. It would be a meaningless pursuit of nothing in particular. If the pursuit is to be intelligible, it must be rooted in an actuality that makes it inevitable. To say that the reality as a whole may contain an untold number of finite purposes, and must itself include a satisfaction in which purpose and fulfilment are one, is another thing.

4. It is said that the Absolute may or must contain Numerical a numerical infinity of elements, say, of selves. The Infinity. analogy of a "self-representative" system, such as the doctrine. system of numbers viewed with reference to certain correspondences within it, has been invoked to support this view.

I have referred to this subject in an earlier Lecture, ${ }^{2}$ but will summarise my position here. The doctrine of the self-representative system, at least in its application to the infinity of a conscious whole, is a curious hybrid. It shows the characteristics of both the types of totality ${ }^{3}$

1 It is a postulate, of course, in the sense in which all laws of experience are so, i.e. they work first, and are reflectively established afterwards. This is the rule of all developing mind; it is more than it knows itself to be.

2 Lecture II. p. 38 note.

3 Of course an idealist will not admit that the "false" infinity is a true totality. I therefore use the word under protest. 
which Idealists have been accustomed to call the true and false infinity. It was first introduced, one gathers, as a defence of numerical infinity as an actual given fact. Waiving objection to this doctrine, ${ }^{1}$ we saw that it seemed to promise nothing from our point of view desirable. Numerical recurrences ad infinitum, however arranged in series linked by correspondences, revealed in themselves nothing valuable.

But the infinity of recurrences came to be represented as an infinite fountain of various and valuable content, an unfailing source of diversity in unity. ${ }^{2}$ This is new matter in the doctrine of the numerical infinite, but very old and familiar matter in the doctrine of real infinity. The two gain nothing by their marriage in the selfrepresentative system. As thus united they claim infinity on one ground and value on another. The numerical series has recurrence ad infinitum, and borrows value from a development of content, which, though not wholly absent, is slighter than in any other conceivable type of whole. The system of content has value of its own, but borrows infinity from a system of recurrences fundamentally alien to it.

In truth, surely, the Absolute, like any high experience, is not numerable. ${ }^{3}$ You cannot enumerate the members of a poem or picture, or of a great character. You can find in them numerable parts, but these are not their parts. That is to say, the numerable parts are not

1 Perhaps, however, I had better repeat, for clearness' sake, the objection, that while I very well see how a formula or definition of the kind suggested can involve or necessitate, if it is to be realised in number, a system of infinite series, I cannot see how the infinite series in question can be said to be "given" in it, any more, in principle than the complete evaluation of $\pi$ is given in the idea of $\pi$.

2 Royce, World and Individual, i. 508, 576. I may say, in view of p. 508, that I have nowhere in my Logic spoken of wearisomeness or of want of interest in connection with infinite numbers. My typical case in attacking the false Infinity has always been the attempt to solve a problem by a method irrelevant to its nature. Cp. also Taylor, Metaphysic, I 16, $148 \mathrm{ff}$.

3 See R. L. Nettleship in Review of Archer-Hind's Timaeus (Mind, xiv. I 3 I). 
relevant to the sense in which such wholes are experienced when experienced as they are meant to be or fitted to be. ${ }^{1}$ When a man reads a poem, as a poem is fitted to be read, there is no place in his mind for number. But if the inspiration leaves him, he may count the lines, words, and syllables, and count them, if he likes, over and over again. But, though he may count them for ever, he will never reach the poem by that road, any more than he will get parallels to meet by producing them. ${ }^{2}$ So with the Absolute. If interpreted irrelevantly and dragged down out of its nature, it may be analysable into infinite selves, infinite sensations, infinite pleasures and pains; what does it matter? In the first place this does not show a given quantitative infinity, for an infinity is not given by a fact or formula being given which generates a persistent failure to re-express it in another medium, any more than meeting parallels are given if we say they meet at infinity. And in the second place, if it was a given quantitative infinity, that would not thereby be shown to be the nature of the Absolute, because the Absolute, as we said, is not, qua infinite and self-complete, numerable at all. Its self-representation, like that of any high experience, is of a wholly different order. It stops the recurrent series, and does not prolong them. ${ }^{3}$ That the higher experiences involve an extreme precision and delicacy of adjustment, as we have maintained throughout, is another affair. The old example of the fine adjustment of a moral act to the situation is enough to exhibit the sense in which this is the case. See Appendix II.

1 See Professor A. C. Bradley, Oxford Lecture on Poetry, p. I 4 ff.

2 Cf. author's Logic, and ed.; i. 162.

3 See Lecture II. p. 38 note. 


\section{APPENDIX II TO LECTURE $X$}

\section{THE PERFECTING OF THE SOUL IN ARISTOTLE'S ETHICS}

The minimum act of duty.

I. Every soul of every creature, such is Aristotle's starting point, has a form, or possible perfection, which the universe is striving in it to bring to completion through its life.

In the human soul every stage towards this completion may be called an excellence or virtue; and of these excellences or virtues there are two general divisions. There are first the excellences of man's compound pature, in which feeling and desire are learning submission to the law of reason. These he calls the "ethical" virtues; a term which we, somewhat unfortunately, have taken up and rendered as if equivalent to all that we understand by moral excellence. They derive their name, for him, from their connection with habit; they are qualities or rather attitudes of soul which we acquire in society, and in the main through assimilating the social tradition. Temperance, courage, gentleness, generosity, with many like them, are Aristotle's excellences of man's compound nature, or excellences of habituation, ethical excellences.

The other set of excellences are the excellences of the intellectual part, the so-called intellectual virtues. But I will say at once that we commit a mere misconstruction if we take them to be excellences of intellectual capacity; as we might say, memory, or mathematical talent, or the power of learning languages. The dominant ones at least are nothing of this kind; they are clearly, as we shall see, the excellences of good life and habit, exalted, reinforced and reinterpreted by passing into the region of principle and of great ideas. Intelligence is not an exclusive part, but is the form of the whole.

Now let us begin to sketch the nature of a single act of duty, as Aristotle conceives it, and trace from that 
point the expansion of the moral horizon, till time and place fall away or rather are rounded into a whole and morality passes into religion.

2. The simplest moral duty has for Aristotle a double The exaspect. The motive of the citizen who gives his life for pansion his country, for example is described in a curious two- which it fold language, the significance of which is not difficult to "mean" see. He does the act of duty for its own sake. There is in it something absolute. If it were done for the sake of something beyond, of praise or gain, it would no longer be the act it seemed to be. This we can see at once. But again; this and every act of duty is performed for the sake of the beautiful-for in all virtue this is the motive. And here again we have no doubt what is meant. The duty is done for its own sake, for the sake of what it is. But the conception of what it is is capable of expansion. "For the sake of the beautiful "-a widening horizon is set before us by this description of the moral motive. What is the moral beautiful ? If we fully understood the simplest act of duty, what is it that according to Aristotle we should see there?

Let me illustrate further by the famous doctrine of the mean, the definition of an ethical excellence. An ethical virtue or excellence of man's compound nature is an attitude of will, "being in a relative mean defined by a ratio, and by whatever the man of practical wisdom would define it by."

I will not enter into negative criticism. I shall say at once what I think it signifies, having just pointed out that once more it refers us to something on ahead-to the man of practical wisdom.

We must have observed in any such form of conduct as an act of beneficence, or munificence, how infallibly the churl in spirit betrays himself, to use Aristotle's phrase, in the quantity or degree or time or place or manner or personal relations of his action. Only the true motive gives you the perfect act. The brave man again ; how hard it is to be brave, and gentle, and modest, and calm, and wise. The brave and noble soul, and it alone, will ring true in every side and aspect of its act; 
time, place, manner, degree, behaviour to persons ; all the characters which make up an act whose quality takes form in quantity, and is adapted to the situation with a beautiful adequateness, in every detail just right, neither too little nor yet too much, like the petals of a rose. Such an action is a manifestation of an excellence, a soul rightly tempered and attuned, a disposition or attitude of mind that is the "mean " or adjusted condition relative to or demanded by the situation.

So far, then, the horizon has expanded. The excellent action, done for its own sake, which is for the sake of the beautiful, is now understood to be an act expressive of a state of soul rightly attuned so that in every detail and quantitative particular its utterance hits what is appropriate and adequate.

But there is something more; this temper or attitude does not explain itself, and the phrase which described it, at the same moment beckoned us forward to a further standard. The mean adjustment or ratio which was the characteristic of the excellent attitude of soul was not yet, we saw, thoroughly defined. It is an adjustment to circumstances; but an adjustment in the interests of what ? The answer was given by a reference to something not yet stated. The mean is determined by a further standard; and the standard is the right ratio, and whatever the man of practical wisdom would determine.

The

standard involved in moral duty.

Practical wisdom.

3. This is a reference forward from the first half of the treatise to the second half. Let us recapitulate. Every act of the compound nature of man-his combined reason and desire-which is excellent, or an act of virtue, is done, we saw, at once for its own sake, and for the sake of the beautiful. That is to say, its own nature, being more fully understood, is one with the nature of the beautiful. Wishing to know to what this points us forward, we found that such an act, as an expression of virtue, is something perfectly adequate and adjusted to the situation, right in every particular, in every detail. If the motive or attitude of soul were in any way wrong or imperfect, the act would betray it at once by passing over into exaggeration or deficiency at some one of its 
innumerable aspects and peculiarities. What should be courage, for example, would be vulgar, or ostentatious, or rash, or false, or wanting to itself in resolution or in tranquillity or in gentleness.

The churl in spirit, howe'er he veil

His want in forms for fashion's sake,

Will let his coltish nature break

At seasons through the gilded pale,

For who can always act?

We can understand that a moral perfection which results in a reliably perfect expression may be called beautiful, but still we have not learned in the interest of what central principle our adjustments are to be determined, and we have been referred to something that lies ahead.

The standard, we are told, lies in what is determined by the man of practical wisdom. What is practical wisdom, and where does it obtain its standard?

We said that besides the excellences of man's compound nature, Aristotle ascribes to him what he calls the intellectual excellences; not, we said, such capacities as memory, or scientific acumen, or creative genius, but rather the content of good life, when raised to a level of principle and systematic insight, as opposed to mere habituation and customary self-control.

According to Aristotle, the two intellectual excellences are practical and theoretical wisdom. About theoretical wisdom we will speak later. It is practical wisdom to which we have been referred; and which, in approaching its discussion, Aristotle implies to possess "the standard of the means or adjustments."

Practical wisdom for Aristotle is one with something which is present in all the animal creation and different for every kind of creature. It is the group-instinct, or the group-intelligence, or the consciousness of kind. In humanity it is the statesman's knowledge and perception; the gift and ability of the man who, having trained insight into the distinctively human good or evil of life, based on his own excellence of character in which it is up to a certain point realised, is able to guide the organisa- 
tion, habituation, and education of the group (for the statesman's business is more especially education) in the direction which will lead them to it.

But here once more the horizon expands. The statesman knows what is the end of human life, and has skill and insight to govern society and direct the educational habituation which instils the ethical or current social virtues in the right direction and to the right adjustments and adaptations - the ratios or means in conduct.

'Theoretical wisdom or religion ultimately standard, viz. as the ultimate value or quintessence of life.

4. But still our quest is not ended. What is the end of human life, in view of which the statesman organises both politics and education? The answer is to be found in the relation of practical wisdom to theoretical wisdom. Practical wisdom, we have seen, is different for every organic group, and in a measure may be said to be distributed throughout creation. Theoretical wisdom is always one and the same, and strictly speaking, it is divine ; it studies no production of instruments for the good of mankind; it cannot strictly be said to aim at the special good of mankind; it does not specially concern itself with man, or at all with one group of creatures rather than with another. Its object of study or contemplation is rather what is above and beyond man; there are many things in the universe more divine than man, Aristotle emphatically observes; more especially, it occupies itself with the nature of God. But though it is not an efficient cause of attaining the end of man, the name for which in Aristotle is happiness, it is the formal cause, or at least a part of the formal cause; that is to say, it does not produce human happiness as a cause may produce an effect other than itself; but it is human happiness or the end of man, or at least a considerable constituent of that end.

Now the precise relation of practical to theoretical wisdom according to Aristotle is an interesting point. Practical wisdom, we said, is the wisdom of the statesman, and so far must be assumed to be supreme in society, On the other hand, theoretical wisdom is the higher activity, and is identical, or identical so far as human nature can attain it, with that activity of the soul which is happi- 
ness and the end of human life. Now how can the lower activity of practical wisdom be supreme over the higher, which is theoretical wisdom? Which of the two is really superior and the guide of life? Aristotle puts the contradiction plainly, and his answer is clear. Practical wisdom rules society in the interests of theoretical wisdom. but does not rule over theoretical wisdom itself. Expanding the answer, a follower of Aristotle compares the statesman's art to the house-steward or head of the servants, and theoretical wisdom to the master of the house. The house-steward rules the house with a view to the master's leisure, his $\sigma \chi o \lambda \eta$. The master has his duties of magistrate or thinker or soldier to perform; the household is organised to give him leisure for them. Just such is the statesman's duty, let us say, towards art, or the life of thought or religion.

The relation is expanded by an Aristotelian writer : "So whatever choice or distribution of worldly resources, whether of bodily qualities or of wealth or of friends or of other goods, will be most helpful towards the contemplation of God, that is the best, and that is the most beautiful standard or organisation; and whatever arrangement, whether by defect or by excess, hinders men from glorifying God and enjoying Him, that arrangement is bad." (Stewart, ii., 4, E. E. Ө., 3, I 249, a 2 I-b2 5.) The final standard of the means or adjustments of conduct, then, is the highest life of the soul. The habituation of the young and the moral education of society are to be so guided and framed by the statesman that art and learning and religion shall always hold the highest place, and so far as humanly possible shall have the lead in, and form the inspiration of, his country. The simplest act of duty, we may say, in its twofold scope, points forward to the knowledge of God. The act of duty, we saw, in being for its own sake, is for the sake of the beautiful; and in being for the sake of the beautiful it is a perfecting of the soul by a fine and delicate adjustment and adaptation to the social order; and further, in being an adaptation to the social order, it is finally instrumental to that which inspires and justifies and resumes the mean- 
ing of the social order, namely, to the activity in which the soul finds its perfection in laying hold of the divine. You do not, in the view of Plato and Aristotle, in aspiring to intellectual excellence and to religious contemplation, tread a separate and diverging path from that of the ordinary good citizen. You follow his path but pursue it further, and what the saint or the poet or the thinker may attain at the end is only the quintessence of what all of you have been practising from the beginning.

" Friendship," i.e. communion in the highest experience, the link between groupwelfare and religion.

5. The true relation of theoretical wisdom to moral development receives a remarkable illumination from the theory of friendship, which shows how practical wisdom must in its highest form actually pass into that which is theoretical.

Practical wisdom, we saw, is the human form of the group instinct or consciousness of kind. In Aristotle's view there is, all through creation, a certain feeling of affection corresponding to every form of this consciousness of kind. He illustrates it by the different levels of parental care which attend upon the different levels of intelligence in the animal world. This is so in man as in other species. Every form of human association has its characteristic type of group-sentiment or liking, or "friendship," as he terms it, corresponding to the form of group-intelligence which it implies.

This being so, you have only to consider the case of the highest form of human association to see how the group-intelligence or sense of group-welfare (practical wisdom) must transform itself into theoretical wisdom. For the highest form of human association is that in which human beings have come to care for that in each other which is the best and consequently the most real thing in them, namely, the highest goodness and intelligence. When this is so, the group-consciousness has become the consciousness of a response in the other person to what is highest and best in the self. This response is a heightening of life, by the extension of the awareness of our life to the life of the friend who shares our consciousness of the best things. We feel our life intensified in his. Therefore the consciousness which we share 
with him is ipso facto the consciousness of the highest activity of the soul. Any other common consciousness would be comparatively external and accidental, and would not give us the same community of feeling.

Therefore practical wisdom or the instinct toward group-welfare not only, in directing human society, aims at adjusting it to the presence of the highest activities; but, in so far as men become all they might become, actually passes into other activities.

Thus we have followed the expanding horizon of the great moralist's account of the end of human life, or of the activity of the soul, which is the provisional definition of that end, also called by the name of happiness.

What we have found is that the simplest act of social duty taught by habituation to the growing citizen, say courage or soberness, has in it a motive, or we may say really implies an awakening and a yearning of the soul, which first expresses itself in loyalty to society and in good citizenship, but which can find no final satisfaction till it completes itself in the knowledge and thought of God, in union with whom alone the individual comes to be that which he really is. 



\section{N D E X}

Absolute, 27, 97, 99, 137, 189, 193, 248 ff., VII., 32 r, 337, 340, X., Appendix I.

$A$ contingentia mundi, 262

Agnosticism, 26 I

Alexander, Professor S., I I 2 n., I 88 n., 213,359

Alphabet of the world, 12

Analogies, false, in conception of individual, 282

Anti-vitalism and vitalism, 195

$A$ priori principles, source of their certainty, 46

Aristotle, 124, 129, 1 93, 246, 258, 263, 298, 302 n., 336, 344, X., Appendix II.

Art, in M. Bergson, I 68 n., $329 n$.

Atomic weights, 85

Average, dist. constant, 86

Bain, Alexander, 53, $14 \mathrm{I}$

Beauty, 5, 5I $n$.

Ben Jonson, quoted, $27 n$.

Bergson, Professor Henri, Evolution créatrice, 32, 54 n., 94, $102 n$., I07 n., I 34, I 37, I 50, I68 n., I 72, I 77, 204 ff., 230, 259, 355; Données, 141, I68 n. ; Le Rire, I68 n. ; Matière, 208

Binyon, Laurence, 370

Body and Mind, V.

Bradley, Professor A. C., Shakespearean Tragedy, 4; Oxford Lectures on Poetry, 222, 236, 382,395

Bradley, F. H., in Mind, 69, 132, I $68 n$, I77, 224, 240, 264, 292, 348, 362 ; Appearance and Reality, 38 n., 57, 58, 68, 73, 76, I68 n., 223, 242, 250, 265, 269, 294, 31 5, 362 ; Presuppositions of Critical History, $33 \mathrm{I} n$.; Principles of Logic, 33, 40, 53,
55, 177, 2 3 ; Ethical Studies, I 3 n., 242

Broadbent, quoted from Mitchell, $202 n$.

Browning, quoted, 21, 25, 27, 29; "Caliban," 255

Buckle, H. T., $87 n$., $88 n$.

Burnet, Professor John, I $24 n$.

Caird, E., 94, 102, 240, 243

Calculation and Prediction, IO7 ff.

Causal activity in nature not comparable to free cause, 66

Christianity, on sin and atonement, $253 \mathrm{ff}$.

Criminal statistics $1898,88 n$.

Class, dist. "world," 35-36: see Similarity, Induction

Cloister and the Hearth, quoted, $306 n$.

Cognition and thought, 66 ; not intelligence, $98 \mathrm{ff}$.

Colour, "a spirit upon things," 63

Conation, modern theory of, 128

Consciousness, a single, limits of, 287

Constancy of energy, 169

Content, dist. satisfied, 25

Content, organisation and predominance of, $173 \mathrm{ff}$.

Contingent truth, $5 \mathrm{I}$

Contradiction, dist. negativity, $222 \mathrm{ff}$.

Creative, initiative, 23, IX. ; imagination, 330

Dante, fusion of moods in, 276 ; the world of the Divine Comedy, $38 \mathrm{off}$.

Declanchement, I87

"De gustibus"-false, 293, 30 I

Determinism, opp. to determination, $34 \mathrm{I}, 354$

Discontinuity, in mental life, I $8 \mathbf{I}$

Dissociation of the Absolute, $279 \mathrm{ff}$., 384 
Driesch, Dr. Hans, I 5 I $n$., I 63 , I 70 $n$. , I $87 n$., I9I; his "equipotential, 368 ; entelechy, I95, $207 \mathrm{ff}$.

“ Durée," 339, 355

Dubois Reymond, IO7 $n$.

" End" a value, not a terminus, I 3 I

Entelechy, I 5 I $n$., I 95

Epiphenomenalism, I 32 ff.

"Equivalence," idea of, I69 ff.

Evil, not illusion, 280

"Expression" and "mechanical finish," I 45

Externality, 73; of guidance to organism, I $\$ 7,193$ ff., 220, 289, 380

Fact, I 3

Falstaff, I $7 n$.

Faust, Goethe's, Kuno Fischer on, 334

Feeling and thought, 63

Finite world not illusion, 240

Forfeiture of the imperfect, 389

Forms, in Plato, 375

Freedom and thought, 6o, IX.

Fruition and Conation, I $29 \mathrm{ff}$.

Fusion of moods in Absolute, $274 \mathrm{ff}$. ; read backwards as dissociation, 388

Gierke's Political Theories of the Middle Ages (Maitland), 373

Gifford, Lord, I, 2

Goethe, quoted, $356 n$.

Green, T. H., Prolegomena to Ethics, 26, 66, 79, 302, 308, 312, 323, 336,355 ; Works, 55, 100

Hedonism, 64

Hegel, 44, 60, 65, 79, I56, I78; on contradiction, $228 \mathrm{ff}$.

Heredity, I 7 I

History, contrasted with science and philosophy, 33,78

"Hope, not guidance," criticised, 19

Horizontal division of real truer than vertical, 373

Hostility to sense in sublime, 236

Ideal, its true nature, 136

Identity, dist. similarity, 35 ; law of, I 38 ; in Bergson, I4 I

Il gran rifiuto in philosophy, Io

Illusion, $24 \mathrm{I}$
Illustration of place of quantity in high experience, Aristotle's "mean," $396 \mathrm{ff}$.

Imitation and invention, I $68 n$.

Immediate experience, 70, 295

Immediates, three precarious-fact, life, self, I 3

Inconceivability, test by, $5 \mathrm{I}$

Individual, as the real, 68,77 ; finite individual, 286; province of the categorical, IO2

Individuality and a world, 77 ; supposed discrepant with universal law, 96

Induction does not aim at classgenerality, I4 I

Infinity, numerical and other, $3^{8} n$., 7 I, X., Appendix I.

Intellectualism, 66, 216

"Interaction" and Indeterminism, I 66, I 68- I 69

Interest, inherent in finite mind, 300

Intuition in M. Bergson, I 68 n., 328

Inward and outward, 72

James, Professor Wm., Pluralistic Universe, 372, 374 ; Pragmatism, 10, 180; Varieties of Religious Experience, 75

Joachim, Ethics of Spinoza, 66

Joseph, H. W. B., An Introduction to Logic, 96, 263

Judgment, infallible, reviewed, 292

Justice, 5, I6

Kant, 46, I 44, I 56, 2 I $8,302 n$, 309,388

Laplace, 88 n. ; Essai philosophique sur les probabilites, quoted, IO7 $n$.

Latta, Professor R., I09 $n$.

Leibniz, 66 ; on the movement of a uniform wheel, I09 $n$.

Life, I3, 99, I 50, I 89

Lindsay, A. D., on Bergson, 40, 97, I $68 n$.

Logic, the spirit of totality, 23,340

Logical pessimism, 278

Logical stability, 68, 299

Logical structure of reality, 243

Lotze, 99, I49, I89, I9 I

Love, argument for value of particular being, 22

Lower and higher mysticism, 23 I ff. Lucan, quoted, $28 n$. 
M'Dougal, Social Psychology, 267

M'Gilvary, Professor, 230

M'Taggart, J. E., "Individualisn of Value," 27 I, 291, 302; Hegelian Cosmology, 19, 159, 248; Commentary on Hegel's Logic, $2 \mathrm{I}$, 123, 128, 225, 274; Studies in Hegelian Dialectic, 225, 24I, 308,383

Machines, $142 \mathrm{ff}$., $209 \mathrm{ff}$.

Mack, Freiheitstheorien, 293, 343

Mechanism, 73, I 32, I 38 ff., I 55 ; subordinate to teleology, I $64 \mathrm{ff}$., $206 \mathrm{ff}$.

Mill, J. S., Utilitarianism, 29I ; Logic, $84,88 n$.

Mind, and its filling, 158, V., 220 ; minds we can treat as our own, 33 I

Mitchell, Professor, Structure and Growth of the Mind, I I4 $n$, I 68 n., I 82, I 86

Moore, George, Principia ethica, 304

Moral good, 5

Moral action, only one side of life, 353

Morality, par excellence, dist. other goodness, 348

Münsterberg, Eternal Values, 390

Naturalism, 74

Natural selection, a positive agency, I 5 I

Nature, X., I 35

Necessary action and agent, 352

Negative approach, the, 288

Negativity, $232 \mathrm{ff}$.

Nervous system, illustrates an ethical principle, $200 \mathrm{ff}, 2 \mathrm{I} 6$

Nettleship, R. L., 22, 55, 56, 62, 65, 92, 235, 243 ff., 259, 379, 394

Newman, John Henry, 97

Non-contradiction, law of, 44, $5^{2}$; a positive and constructive principle, 267

Norman Smith, on introjectionism, I 88

Objective relations, opp. to conscious states, 305

Obvious, the, 7

Omnipotential, life and mind, 368

Ontological argument, 8o

Optimism, I 4, 242

Organic regulation, 195
Pain, see pleasure, not illusion, 240, 244

Pan-psychism, 82, 194, 362

Pantheism, in Tennyson, 252

Pater, Walter, on colour, 63

Paulsen, Einleitungindie Philosophie, 102

Personality, 26I

Persons, 284, VIII.

Philosophy, essentially of the concrete, 33 ; categorical, 102

Physical system, I73; how represents a meaning or an "end," I85 ; continuous with psychical, $36 \mathrm{I} n$.

Plato, 8, I 7, 45, 57, 73, 167, 223 ff., 246, 298, 3I 3, 3I 7,340 , 346,373

Pleasure, $5,26,65$, I $25 n$. ; as a guide, $136 n$.; in universe, 244 , 308

Porphyry, tree of, 34

$\pi \rho \hat{\alpha} \xi$ เs and $\epsilon \nu \epsilon \rho \gamma \epsilon \iota \alpha, 129 n$.

Pragmatist, the, 52-53 ; Pragmatism, 292

Prediction of conduct, dist. " reduction," I I $3 n$.; unity of intelligence, I I 5

Pringle Pattison, Professor A. Seth, 96, 26I n., 29I, 370

Probation, 26

Psychical, store of acquisitions, exercising energy, would be physical, I73, 215 ; relation to physical, $36 \mathrm{I} n$.

Psychoid (Driesch), $207 \mathrm{ff}$.

Purpose, cannot be a whole, I62, 361

Quantitative counterparts of qualities, I 74

Quetelet, $87 n$.

Relevancy, better term than uniformity, 93, I I 9

Repetition, wholes of, 35 ; root of generality, opposed to the universal, IO4

Ritchie, Professor David, Darwin and Hegel, $68 n$.

Royce, Prof., 69, 82, 387, 394

Ruskin, John, $5 n$.

Russell, Hon. Bertrand, Philosophical Essays, 14, 18, 247; Principles of Mathematics, $7 \mathrm{I}$ 
Satiety, dist. satisfaction, I 28

Satisfactoriness and satisfaction, 23, 53, I 28 ; and self-sacrifice, 234 ; dist. pleasure, 244, 256

Schiller, F. C. S., Humanism, 40, $68,80,205$

Schopenhauer, 97, 253

Science, hypothetical, I02: see Philosophy

Self, 13 ; animal, 342 ; naïve, 343 ; bad, $349, \mathrm{X}$.

Self - consciousness, no account of differences between selves, 323 ; the two forms of its "other," $235 \mathrm{ff}$.; its full content the Absolute, 337

Self-direction, 2 I 7

Self-representative series and infinity, $38 n ., 393$

Self-representation in a true infinity, $38 n ., 393$

Self-sacrifice, 234, 243, 256

Sensation, character of thought in, 59 ; of a pin-prick, 197; an interpretation, 197 ; psychical or physical? $361 n$.

Sidgwick, Henry, 291, 308, 324

Sigwart, Dr. Christoph, Logic, 90

Sin, reality of, 24I

Similarity, root of general, dist. universal, 35

Soul, does it bring properties with it? I 7 I ; what it is like, I89, 218 , 372

Soul-making, 26

Span of consciousness, 388

Specious present, 388

Spinoza, 66, 1 33,178

Stability, 23

State, the, $25 n$., 3I I, 3I 3

Statistics, first-class and second-class, 89 ; physical and social, $85 \mathrm{ff}$.

"Strait Gate" in Ruskin's Florence, 334

Spiritual, popularly connected with " inward," 74

Spiritualist phenomena, in Driesch, I $70 n$.

Stevenson, Robert Louis, quoted, $28 n$.

Stewart, Professor J. A., 401

Stout, Professor G. F., Manual of Psychology, 166, 169, I92, 2 10; Groundwork of Psychology, I I4, 1 28, I 32 ; Analytic Psychology, 125, 128, 131, 184 n. ; Mind, I 94
Strong, C. A., 218

Subjective Idealism, I 88

Sublime, 222

Sufficient reason, law of, I $_{3} 8$

Supersocial activities, 379

Syllogism, essentially creative, 334

Taylor, Professor A. E., Elements of Metaphysics, 19, 37, 38, 57 n., 75, 82, 87, 91 ff., 96, I I $3 n$., I 18, I 38, I 76, I 79, 204 ff., 247 , 273

Teleology, subjective, and "law," I I 7, IV. ; below and above consciousness, I 53, I 79

Theism, I 56

Thought, its ultimate character, and relation to sense, feeling, will, $60 \mathrm{ff}$; ; to cognition, 66

Timaeus, $73 n$.

Timelessness of the self, cpd. "Durée," 339

Tragedy, significance of, I 8

Transmutation of experiences in Absolute, $373,387-388$

Truth, as "the whole," 43 ; not in mere correspondence, 306

Twelfth Night, quoted, $253 n$.

Ugliness, 5

Ultimate and immediate confused, 295-296

" Unconsciousness," in invention and inference, 333

Uniformity of nature, interpretation discussed, $83 \mathrm{ff}$, , I $38 \mathrm{ff}$.

Universal " world," 37 ; root meaning of, II., $40 n$.; its selfmaintenance, 46 ; the system of an individual, 103; in principle excludes plurality of similars, I04; in the "mean," 397-398, I $20,184 n$.

Varisco, Professor Bernardino, 1 Massimi Problemi, 3 n., I I 2 n., I 26, I $48 n$., I 50, I 57, 2 I 5, 286

Value, I 28 ; in inorganic world, I47, VIII.

Venn, Dr. John, Empirical Logic and Logic of Chance, $87 \mathrm{ff}$. $n$.

Verworn, Allegemeine Physiologie, I07 n., 195

Ward, Professor James, Naturalism and Agnosticism, 54, 58, 78, 82, 
96, 107 n., 109 n., 134, 142; William Morris, 166

on katabolic character of inorganic world, $147 n$., I79, 204 ff., 286,356

Whistler, J. McNeill, on taste and knowledge, 62

" Widerspruch," in Hegel's Logic, 227

World, opp. to class, 35-36 ; universal, 37 ; essential to non-contradiction, 46 ; type of mind and individual, 289 ; essence of individuality, 320 ; two or more, in Plato, 374

Wundt, Logic, 169

THE END 






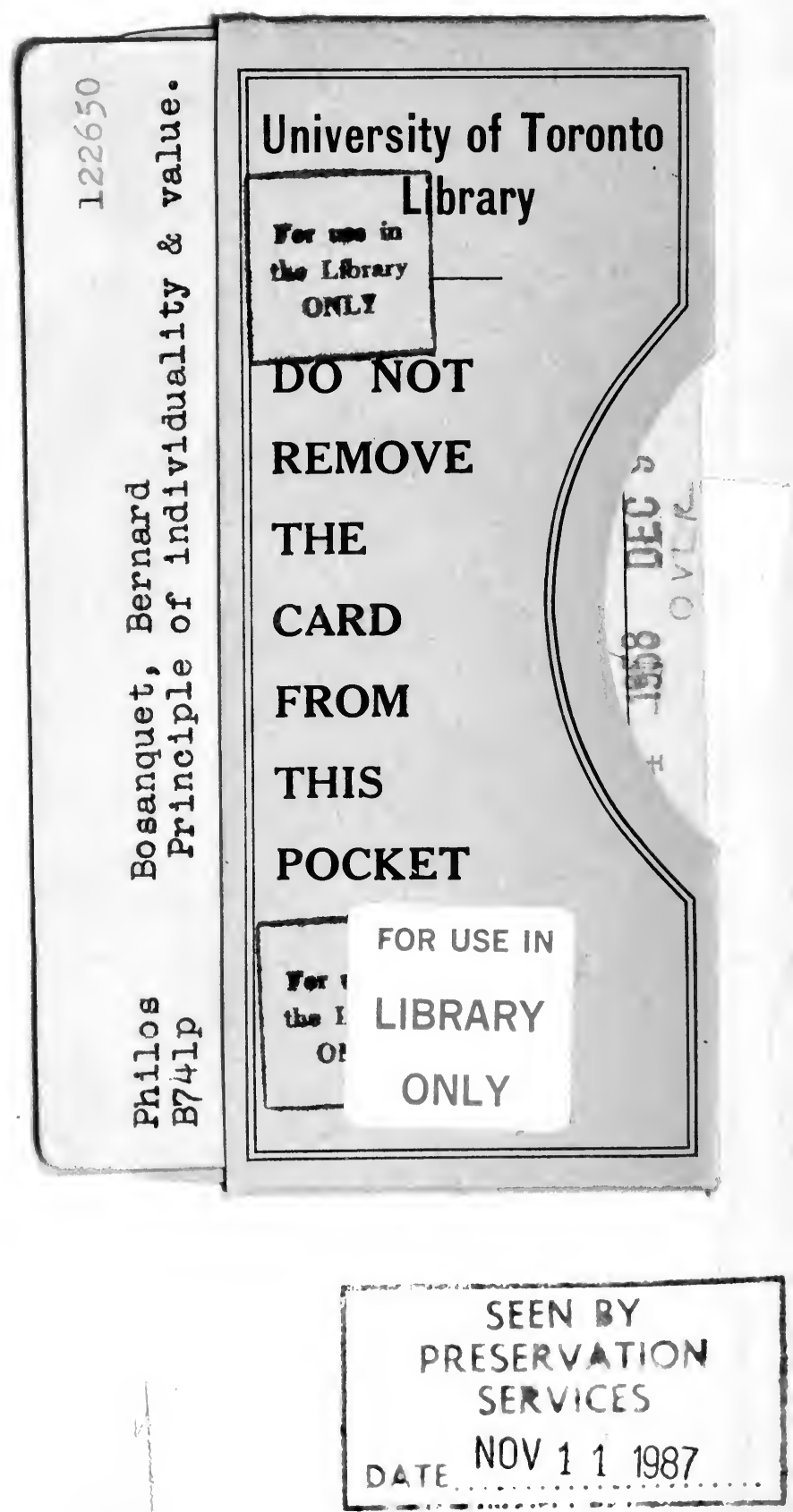


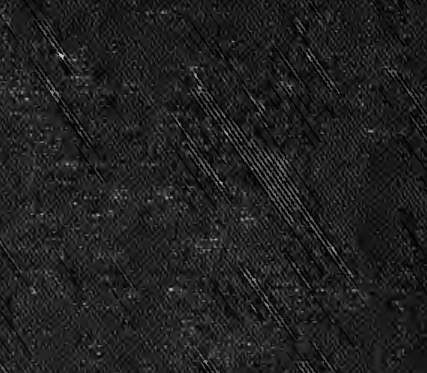

$$
H \mathrm{H}
$$

$$
\text { SWH }
$$$$
\text { HW }
$$

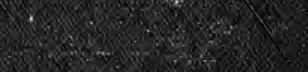<smiles>C1CC2CCC1C2</smiles>

(17.) 4 ine

$$
\text { \& }
$$

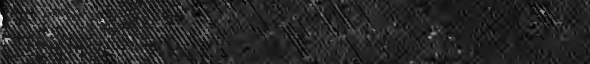

